QK

354.7

- 15 


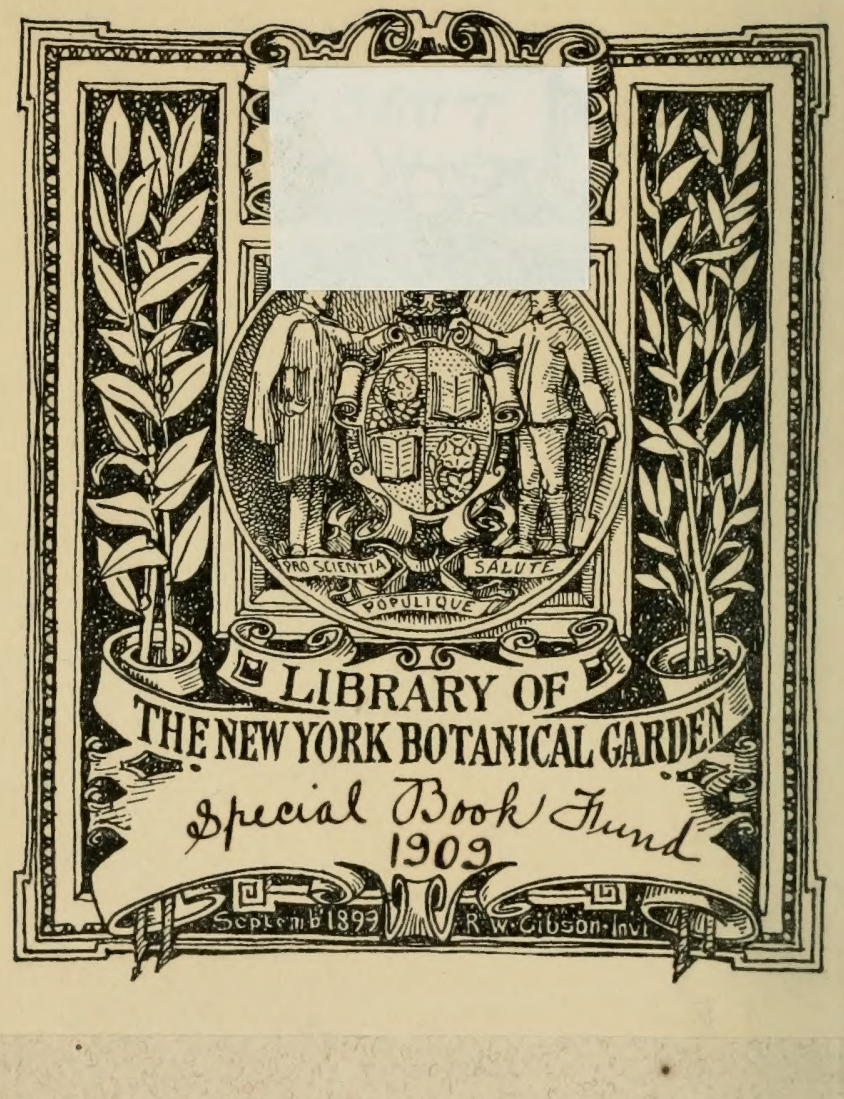









\title{
DE PLANTEN
}

IX $D$ DEX

\section{BOTANISCHEN TUIN}

IBIJ HET

\section{GROOT MILITAIR HOSPITAAL TE WLLTEVREDEN,}

\author{
II U Y Y E
}

\section{INL. BENAMINGEN, GROEIPLAATS EN GEBRUIK,}

NAAR DE BESTE SCHRIJVERS EN INLANDSCIE

OPGAVEN ZAMENGESTELD DOOR

\section{G. J. FIL $\mathbb{T}$,}

Officier van Gezondheid der 2de klasse.

\section{LIBRARY \\ NEW YORK BOTANICAL \\ GARDEN.}

Uitgegeven voor rekening van de Geneeskundigø Vereoniging in N. Indië.

B A T A VIA. - L A N GE \& C O.

1855. 



\section{LIERARY}

NEW YORK

ROTANICAL

V O O R W O O R D.

URKDBN.

De botanische tuin lij het G'root Militcir Hospitan te Weltevreden, warvan meermalen reeds in het Tijdschrift der Natuurkundige Vereeniging voor. Nederlandsch Indië melding is gemaalit, werd in het begin ran het jact 1850 door den heere G. WAssink, diviyerend officier van gezondheid der 1e hilasse (thuns Chef over de Genceslinndige (lienst) aungclegd, op de pleinen gelegen tusschon de verschillende ziokenzalen. IIet hoofdeloel dearlij we's de studie der intundsche geneestirachtige gourassen voor jenuclige genecslunuligen to bevorderen, te voorzien in de behoefte der bij gemelde inrigting gelmikit wordende artsenïgewassen, verfracaijing van het Hospitaal, on tevens de omgeving der zieken vrolijk on aangenamer to maken, zonder op de door een groot acantal zielien bewoonde zalon de zoo noodige luchtstrooming in het minst te verhinderen.

Gedurende dit tijdvak is het getal der in dezen tuin adnueplente gewassen langzamerhand grooter geurorden; in December 1851 bechroeg hun aantal 331, in February 1854, 504, tervijl or heden reeds 5558 plentensoorten aumwerig zijn. Voor het grootste gedeelle zijn het inlanclsche, doch men treft or ooli vele Europesche on vooral 
Amerizaansche artscnijgewassen on sierplanten in an.

IIet het opzigt over dezen tuin van Januarij 1851 tot Mei 1855 belast, werden mij vooral door mijne jongere collegi's ditiverf inlichtingen gevrcagd omtrent het nut dezer planten, hare gencesTrachtige aanvending en beschrijving.

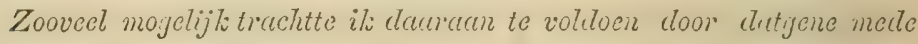
te deeten, wat il gedurende mijn liort verblijf in deze gevesten heb Funnen opsporen, of wel itw verwees hen natr verschillende schrijuers. De werken over Indische planten on hunne geneeshrachten handelende zijn echter niet in ieclers handen, somtijds zeldzaam te betiomen of zeer lostbacr en het is om die reden alat ili besloot het hiernavolgende zamen te stellen.

Om tot die zamenstelling te geraken, teekencle ils omtrent elke plant detyene op, wat recls door Bostius, Vax Rireede, Bur-

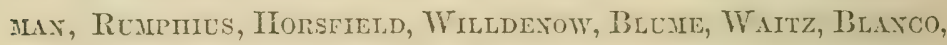

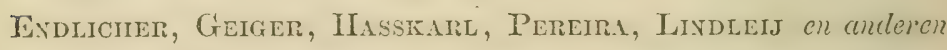
is opgeycuen, on vergelectidezo opgaven zoo onderling ats met van inlanders betiomene inlichtingen. Tun hetycen dere luttsion mij medededden en its als nieurv voor de wetenschap) beschouvde, teekende il. alleen dat op, wat verscheidene hunner mij voor vacur opgaven, nimmer wat slechts één hunner mij vertelde.

Door de vriendelighe hulp van de heeren BLeEKer en Bauer, ucurvoor it: die hecren openlijti mijnen opreyten denti betuig, werelen mij de hicrboven genocmele bockurerlen, veor zoo verre ze nict in mijn bezit waren, welwillend ten gebmilie afgestaan.

Behalve de botanische nacm heb il bij ellie plant opgegeven de bekende inlcondsche benamingen, de grociplunts en lect huishoudelijl. of genecskrachtidg gebruili: zalicn, het lijgcloor betregente zijn zoo 
veel mogetijh weggcluten. Van bijna ellie plant hob it. iets vermeld gevonden; bij weinigen slechts ontbrectit de inlandsche bencming on opgave van het gebruili; aleze laatste zijn meestal Europesche of Amerikaansche siercactplanton.

Wat de inlandsche benamingen betreft, zoo hob it getracht alle van deze eilanden reeds betiende synonymon achter clie plant to plaatsen, en vooral de van Java nog niet betiente namen to verzamelen. Vack toch heeft in elle of in vele residention ene on clezelfde plant verschillende benamingen, cn werkclijk heb it mim cen

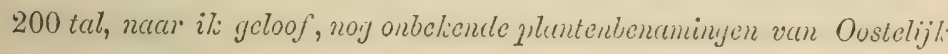
Java, Sumatra on Menado opgegeven.

Deze, zoo mede de reeds bekende, schreef its zoo vecl mogelijk volgens de gewone vitspruat der Inlanders.

Achter de verschillende planten komen eonige verliortingen voor, wolke de plaatsen aanduidon, waar de plant dezen nacm voorl; deze verkortingen zijn als volgt:

Amb. Amboina.

Bat. Batavia.

Bd. Banda.

Bi. Bima.

B.. Boegineesch.

Br. Bocroe.

Boy. Bonoa.

Bit. Boeton.

Cel. Celebes.

Cr. Ceram.

Ch. Chinesseh.

IIt. Iritoe.
Huom. Huamohel.

J. Javaansch.

Lt. Leijtimor.

Lli. Lochoe.

II. Maleisch:

Mand. Mandheling.

Mak. Makasser.

MIen. Menado.

MIol. Molukkos.

OJ. Oostelijk Java.

Rtt: Rotti:

S. Sundaneesch: 
Sw. Sawoe.

'T. 'Ternate.

Tmb. Tambolko.
Td. Tidore.

'Tm. Timor.

U1. Uliassers.

Batavia,

Mei 1855 .

G.J. F I E I 


\section{CORMOPHIJTA ACROBRIJA.}

POLYPODIACEAE RBr.

No. 1. Botaniscine NaAmr. - Acrostichum alcicorne. Sw.

Intandsche bexaling. - Pakoe oentjal en Pakoe minjangan S. \& MI.

Gromiplants. - Veelvuldig op hooge boomen.

2 Вот. Nr. - Acrostichum nummularifolium BI.

IXI. BE.. Doedoeitan MI. Pitisan J.

Gr. PL. - Klimt op Java en elders veelal tegen boomen op.

Genr. - IIet sap der blakeren drinken eenige Inlanders tegen loest; met de bloemen van Djarak (Ricinus communis L.) affgekookt, bezigen zij dit kruid tegen buikjijnen; torwijl sommigen het teggen gonorrhoeae anwenden in aftreksel, vermengel met adas (Anisum vulgare L.), poelassarie (Alijxia stellati R. \& S.) on de wortel der papaija (Carica papaija L.)

3 Boт Nu. - Polijpodium crassinervium Bl.

INL. BEv. - Pakoe katakka of kadaka. MI.

Gr. PL. - Java, zoekt vochtige, beschaduwde plaatsen.

GEBr. - Sommige Javanen dienen aan ksoorislijderz cen afkonk seí elezer bladeren toc.

4 Вот. Nır. Polijpodium L. Spec. 1.

INIt. BEN. Pakoe.

Gr. PL. - Java, op vochtige plaatsen.

Genri. - Men bezigt de bladsteckn hier on dinar tot ctijlen roou schapen- en geitenstallen.

5 Вот. Nз. - Adiantum L. Spec, 1.

Inl. ben. Pakoe.

Gr. ru. - Java, op vochtige plaatsen.

6 Вот. Nur - Pteris L. Spec. 1.

INI. BEX, - Pakne en Pakoe loorang s'; Rakka J. 
Gr. rL. - Java, in schaduwrijke oorden.

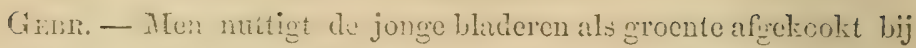
de rijst. Op Java wrijf men het ligehaam van lsoortslijders in met een aflooksel dezer bladeren.

7. Вот. Nэг - Aspidium Sw. Spec. 1.

INL. I3Ex, - Pakoe lën S.

Gr. PL. - als voren.

Gesr. - Men cet de jonge Haderen als grocnte bij de rijst.

Ilet fin toor insuijling nit den wortel verkiegen diteat men op Java bij koortsen inwendig toe.

8. Bot. Nur. - Aspidium Sw. Spec. 1.

INt. BEY., Gr. pL. en GEBr. als rorell.

9. Вот. Nз. - Cibotium glaucescens Kaulf.

Tre. sm. - P'engarwar djambi M. Pakoe tijang S. Akkar kockoctjinģan Mr.

Gr. PL. - O. en W. kust van Sumatra en ook op Java in rochtige beschaduwde oorden.

Gerr. - Het goudgeele haar, dat boven op den stam of liever Joofdwortel anwezis is, wordt vitwendig lij verbloerlingen enz.

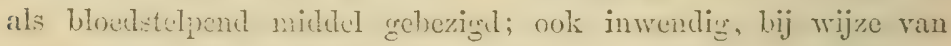
extract, toegaliend bewij:t het govele diensten bij inwendige blocdingen, zoo als bij menstruaalvloed cnz. Niet alleen op Java maar ook in Nedcrland zijn deze geneeskrachten erkend (zic Heije, wenhen en maningen enz, $1,2,3,1,20$ (i) terwijl nn wijlon

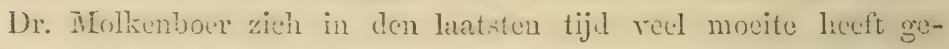
geven in lut doen tan naspringen naur de genceslirachtige en chemische eigenschappen van het pluis.

- 10. Вот. Nлг - Alsophila lurida EndI.

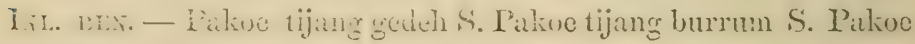
kidang Mr.

Gr. PL. $-\mathrm{O}_{1}$, Java in rochtige bergstreken.

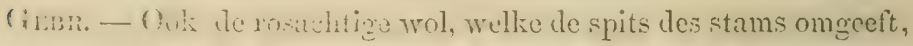

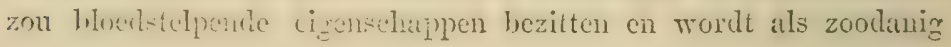
op Java gebezigd.

11. Вот. Nr. - Alsophila glauca Endl.

LY.. BEX. - Pulkoo tijang boddas. S. 
Gir. PL. - Op Javin in berogstreken.

\section{SCHIZAEACEAE MIrt.}

12. Вот. Nur. - Lijgodium circinatum Stw.

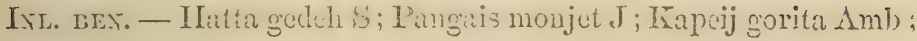
Rabcij on Ribeij Lh.

Grire - Eene sliugerphent, wolke bijia oreral in dezen arehipel voorkomt.

Ginfo - Iimplins zent van deze plant: "men bezigt de stengels tot liet zannenstellen of binten ran liofertjes en roor ander bindwerk. De Balinezen eten de jonge niet ontrolde bladeren als gruente. De bladeren fijugewreren met zout en Cureuma legt men op gekneusde en gebrande ledematen:" Volgens IIasskarl, zonden de Javanen de bladeren nitwendi", gebruiken om op wonden te leggen, veroorzaalit dloor den beet van visschen (Tkan leles). Volgens door mij ingewomnono berigten wordt cen aflkooksel der bladeren gedronken bij die andoening der pistrerlztuigen, welke rerkregen worklt door het misbruik der vruelit Djengkol (Inga bigemina Witl.) Ook zouten de stengels een goed touw opleveren.

\section{LIJCOPODIACEAE DC.}

13. Boт. Nr. - Lijcopodium javanicum Sw.

TVL. BEN. - Raneh MI. \& S. Koempari MI:

Gr. Pu. - Op Java in bergstreken op vochtige plaatsen.

Gebr. - Men maaki anhicre ecu alkookscl ran het jonge kutud vermengd met de woricl fan Curenma viritillura Rxh). (Konneng

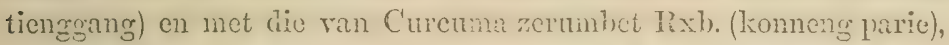
en geeft dit to drinken aan kramproilven dalulijk na lumne bevalling:

Uitwendig bezigt mein do fijngerverene bladeren bij schurft.

\section{CIJCADEACEAE Findl.}

11. Bот. Nir. - Cijeas rovoluta Thnb. 


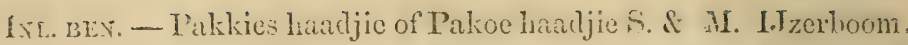

Gir. PL. - China, Japan, de Moluk che cilanden, op Jiva veclal in tuinen.

Gisi. - Tolgens 'Thunbern, worden de ruthen door de Japannezen gegeten, is het merg des stams bovenmate roedend en wordt in Japan zoo hoog geschat, dat het op lijfstraffe verboden is dezen boom uittevoeren. Geiger haalt aan, dat men in China uit het binnenste des stams eene soort van Sago bereidt.

15. Вот. Nu. - Cijcas circinalis L.

INL. LEx. - Pakkies haadjie en Pakoe haadjic S. \& M. Pakoe batak S. Sajor klappa on Sajor radja MI. Lagogo en Patocka Cel. Utta niwel of Utta nuër Amb. Ijocijaroe of Marljong octoc en Pitojo T.

Gr. PL. - Afrika, Oost Indien, ook op Java en Madura langs de stranden.

Genr. - Deze schoone boom, van welle Teijsmann de aanmerkelijke warmteontwikkeling in te pas geopende blociwijze reeds rermeld heeft, en welke somtijils des avonds $11^{\circ} \mathrm{C}$. sterkex zoude zijn dan die der buitenlucht, heeft niet alleen als roedsel maar ook als geneesmidtel ecnige warte. Uit de dikwijls zecr hooge stam wordt eene soort ran Sago bereicl. Tele cilanders, vooral o1) Sumatra on in de Molukken, nuttigen de jonge bladeren en het bovenste der steng afgeknokt als cene smakelijke groente, Blaneo lraalt aan, dat $n p$ de I'hiliplijnsche eilanden de rruchten worden gegeten, doch dat zij niet smakclijk zijn. V'olgens Endlicher zijn de jonge stengels eetbanr, met het uit dezelve gedrukt sap vermeent men kolijkpijnen tegen te gnan, branding der maag te bedaren en blocdbraking to genezen. De vruchtdragende toppen worden in Milabar fijngeslagen of gestampt en bij wijze van pap op de londenstrcck gelegd, thar zị nierpijnon zouten leenigen en onwillekeurige zaadvbed tegengaan. Men ect de ruchten met suiker gekonfijt; raauw genuttigd veroorzaken zij rerstoppingen. Uit de jongere met water afgeknokte rruchten worlt cen geneesmildel bereid, dat als braakrerwekkend. hijzonder matgzuirerend workt. Do zaden der Australische soorIen worken als stexke brankmidtolen don te bewnners der Flindors eilanden aangewend 
Voor zoo verre ik heb kunnen na gaan, is bij de Jivanen dit alles onbekend, en liemnen slechts weinigen het roedemil vermo gend der jonge bladeren.

\title{
CORMOPHIJ'TA AMPHIBLIJA
}

\author{
GRAMINEAE Jss.
}

16. Bor. Na. - Zea Mraijs L.

IYL. BEN. - Djagong S. \& MI.

Gr. PL. - Zuid Amerika; zij wordt op Jiva en omliggende cilanden reelvuldig in tuinen aangekweekt.

Gens. - Omtrent het 'Turksche koorn is reeds zeer veel in handbocken geschreven; ik wil alleen hier nog vermelden, dat de Javanen zoowel de rijpe als de onrijpe vruchten nuttigen, hetzij boven het vuur geroost, hetzij gekookt, hetzij in verschillendo soorten van gebak; ook wordt door hen uit dezelve cene soort van suiker bereid.

17. Вот. Nir. - Coix lacrijma L.

IVL. BEx. - Hanjehreh en IIandjeulieh S; Salch M. \& Amb;

Djalie en Djalie batoe J; Sinkoer batoe Mand.

Gr. PL.-Japan, Oost Indien, op Java in het wild on ook veel in tuinen.

GEbr. - Bij gebrek aan andere granen kan het zaad dezer grassoort gegeten worden, nadat te voren de harde schil gedurende twee dagen er afgeweekt is. $O p$ de Philippijnsche cilanden verzamelen volgens Blanco de Krreolen het zaad, om er een meel van te maken, hetwelk een geschikt voedsel is voor zwakke en van ziekte herstellende personen.

Op Java bezigt men de harle blaauwe zaden tot het vervaardigen ran bidsnoeren (tasbeh) en van guirlandes bij iulandselıe 
feesten. II sun stconachtig omhulsel wordt reronderstcld roborccrend en diuretisch te werken (Lindleij), en werd vroeger bij Phthisis en Hijdrops toegediend (Endlicher).

18. Вот NII. Panicum palmaefolium Kroen.

Iri. Bex. - Samchuin badak S ; Dawon loslocan karbo J; Kicsick Mrand.

Gr. PL. - Java en Sumatra, veelal in tuinen.

Gerrs. - De jonge spruiton worten tloor de inlunders gekookt en bij de rijst gegeten, en ook aan kraamvioutwen spoedig na hunne bevalling to eten gegeven.

19. Вот. Nu. - Pennisetum macrochaetén Jeq.

IVL. BEx. - Koenjiet S; Paddie djawa II; 'Tjoewawoet J.

Gre. PL. - Oostindische Archipgl, wordt op Java dikwijls aangeplant.

Genr. - Iret zand is eon gewild roedsel ran tortelduiven en andere kleine vogels, en ook de Javanen nuttigen het dikwijls als cene brei gelsookt; zij bereiden er loor gisting eene alcoholische drank nit, welke op Java Baclek en te Batavia Brum genaamd wordt, en hen dikwijls sterk bedwelmt.

20. Вот. Nu. - Arundinaria glaucescens Rich.

IYL. BEN. - Bamboe tjina MI.

Gr. PL. - Japan, China, op Java en tuinen.

Genr. - Dit dune riet worlt gubruilit roor wandelstokjes en pijpenroeren.

21. Bот. Nir. - Bambusa vulgaris Wld.

Irs. BEN. - Bamboe atter S. \& MI; Awie atter S; Awie tammas $\mathrm{S}$; Bamboe djawa J;

Gr. PL. - Java.

Grer. - Deze rictsoort worcit slechts roor heiningen, enz. gebezigd, daar ze spocdig doon inscliten rertecrd wordt. Ilet water dat zich tusschon liare eclodingen rerzamolt, worit dikwijls lij buikandoeningen gedronken ter hocveclheid ram 2 it 4 oncen.

22. Bот. Nr. - Bambrsa Blumeaua Śchlt. of Schijzostachitum durie Rupr.

INT. BEN, - Bamboo doerio MI; Awi hancr tjoctjock S; Bamboo irnton J. 
Gri. pL. - Java, Sumatra enz, veclal als borstwcering ronclom de kampongs.

Gerr. - Nadat deze soort eenigen tijd in het water gelegen heeft, wordt zij veclsullig tot huisbout, enz. gebruikt, ook worden de jonge uitspruitsels (rebong) gekookt gegeten.

23. Вот. Nir. - Bambusa mitis Poir.

IrL. BEx. - Bamboe hater geulies S; Avi hater geulies S;

Bamboe ampel Bat; Tihing ampol Bali; Domul Amb;

Domor Lt; 'Tabatico nani 'I; Boeloe Seri en bocloe keij Bd.

Gr. PL. - Door den geheelen archipel.

Gebr. - Vooral van deze soort worden veclvuldign do jonge spruitoil afgekookt on geroozt gegeten en zijin zij in lnet zuur ingelegel eene lekkere tocspijze (atjar) ook op Europesche tafels. IIet oude riet wordt slechts tot het dragen van goederen (piliol-an) en voor heiningen gebezigd.

24. Вот. Nur. - Bambusa Selireb. Spec. 1.

IVT. IEX. - Awi hater konneng S; Bamboe koeuing II; I3amboe gading $\mathrm{J}$.

- Gr. pL. - Op Java veelvaldig als sieraadplant in tuinen.

Grerr. -Ook van deze soort is de rebong zeer gुozoclat en dient het riet tot dezelfile doeleinden als de vorige soort. De rlocistof welke zich bij het versche riet steeds tussehen de geledingen bevindt, wordt ter hooveelheid van 2 ì :3 oncen dikwijls bij geelzucht gedronken.

25. Вот. Nis. —Siccharum officinarum I. та1. communis R. \& \$.

Irt. BE. - Teboe en 'Tiwoe S. \& MI; 'Tewoe Amb. \& Bd; Oega 'T; Kamsia Ch.

Gr. PL. - Langs den Euphraat; wordt op Jiva vecl aangebourd.

Gerr. - Ranuw en in stukjes gesneden kaauwt de inlander liet suikerriet als cene lekkernij; men bezigt het medo tot het bereiden van sommigo spijzon; ook de jonge spurtiten worden geroost of gekookt dikwijls bij rijst gegeten. 'Zic omtrent suikerriet en suiker overigens de bestaande handboeken.

26. Вот. Nм. - Imperata Kocnigii Palis.

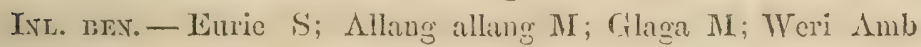
kocssoe 'T. 
Cir. PL. - U - Jiva, sumatra enz. tot op eene hoogte ran 3-1000 voeten; N. Holland; Japan.

Gerr. - De jonge scheuten worden door het rundvee galarne geegeten. IIet gedrnogde gras dient tot liet dekken ran huizen. De wortels worden met de bladeren van Phijllanthus nuriri $L$. mamaniran) als thee afgetrokken on gechronken bij urethroblennorrhoeae; Hasskarl geeft aan, bij bloedwateren.

27. Вот. Nı. - Anthisthiria arundinacea Rxb.

Iru. Bex. - Kassoh S; Manja burum S.

GR. PL. - Java.

GEBr. - Zij levert voor paarden en rundree cen good roedsel op; de jonge spruiten bezigt de inlander dikwijls als groente bij de rijst.

28. Bor. Nr. - Andropogon muricatus Ritz. (Anatherum muricatum Palis).

IVL. BEX. - Akkar wangie II; Loros setoe Jav.

Gr. PL. - Wordt op Jara reelvuldig in tuinen aangekweekt, zou ook op Isle de France en Bourbon.

GEbr. - In Indie worden de welriekende wortels veel gebruikt om tusschen de kleckleren te leggen, zoo om hunne geur als ook ter afwering ran seluadelijke insekten. Van deze wortels worden onk ma1jes gerlochten, welke, rooral als zij nat gemaakt worden, sterk rieken; rerder bereidi men er eenen zweetdrijrenden drank en cene actheriselie olie nit, wellse rolgens Roijle Ol. Calami of Grasclie van Namen zoude zijn. De wortels zouden ook tegen Cholera gebruikt worden, en zij kwamen roor eenige jaren onder den nam van Radix Iwarancusae in don landel voor. Endticher noent den wortel aromatisch-scherp, prikkelend en zweetdrijvend.

29. Box. Nu. - Antropogon ('Trachijpogon) Schocnanthus L. INr. BEN. - Serch II: Ilissa $\Lambda \mathrm{mb}$. Goemaro koessoe 'T.

Gris. PL. - Oost Indion, wordt crok op) Java ('nz. reel in tuinen aangekwcekt.

GEBr. - Uit elit aangenaam rickente gras, ook wol Citroen- of limoengras genoemd, bereidt men ecne vlugtige olie (minjakh sereh) en cone zalf. Een afkonksel ran hetzelve wordt door de IIindnesche artsen als zwect- en pisdrjivend midtel geroemd ou 
worlt op Mianillit tegen rheumatische pijuen anngerrend (Gicigar). Volgens Endlicher wordt het gras door indisehe volkeren als een prikkelend, krampstillend, maag versterkend, pis- en zwectdrijpund middel aangeprezen. Blanco geeft aan, dat men op de Philipinijnsche cilinden een afliooksel der wortels tocdient bij zickten der pisafscheidende werktuigen. Op Jara bezigt men dit gras dikwijls in de huishouding ter bereiding ran saucen, groenten enz. welke bij de rijst genuttigd worden, omdat het aan deze eenen aangenamen geur mededeelt. Iij wijze van kerrij of wel als aftreksel, vermongd met sauchun (Panicum palmaefolium Koen), koenjit (Cureuma longa L), kamirie (Aleurites moluceana WVh.) en tjabeh djawa (Piper longum L). wordt het aan pas bevallene kraamvrouwen dikwijls bij do rijst tocgediend. Eindelijk hatalt Rumphius reeds ann, dat de Amboinsehe Sagnweer, welke over zee vervoerd moet worden, rermengd wordt met deze plint, met gember, muskaatnoten en eijeren.

\section{CIJPERACEAE Dc.}

30. Вот. Nı. - Scleria Berg. Spec. 1. en

31. Вот. Nu. - Cijperus L. Spec. 1.

INL. BEN. - Ielat.

Gr. PL. - Java.

GEsR. - Ifiervan is mij niets bekend geworden, wanrechijnlijk strekken zij liet rundree tot roedsel.

\section{COMIMELIJNACEAE BH.}

32. Вот. Nır. - Commelijna paludosa Bl.

InL. rex. - Patock gaijak of P. gigak S; Tjelegor J; Teponang J. en Djewor J.

Gr. PL. - Op Java gaarne in schaduwrijke rochtige oorden.

GEbr. - Ilet jonge kruid van deze en andere Commelijnasoorten wordt door de inlanders gekookt en bij de rijst gegeten.

33. Вот. Nu. - Tradescantia terminalis Bl.

IYL. BEY. - Djoekoet gehwor S.

Gr. PL. - Java, Molucco's. 
CiEsr. - Wordt als sicrnatplant dikwijls in tuinen anngetroffen.

\section{ALISNIACEAT RBr.}

31. Вот. Ny. - Sagittaria lirundinacea Bl.

INL. DEv. - Etjeeng S; Bea-bea M.

Gr. PL. - Veelvuldig in moerassige streken.

GEBr. - De jongo bladen en bladsteclen, worden door vele inlanders met graagte als groente bij de rijst gemeten.

\section{FLAGELLARIEAE Endl.}

3ร. Вот. Ny. - Flagellaria indica $\mathrm{L}$.

IYL. Lyey. - Oar S; Oar naga S; Oar tambang S; Rottan Oe1an II; Lnemboei $J$; Willo en Wala II; Waro, Wara en Aijwara Lt; Urioma 'T.

Gr. PL. - Tropisch Azic, Nienw Ifolland, do geheele O. J Archipel.

Gebr. - Van deze plant noemt Lindleij de bladeren zamentrokkend en wondhedent. Rumphinz gieft aan dat de stenguls als bindtouw geberigh en de foknentede blateren op rersehe wonden worden golegil. Afet het kruid zomle het howflhnar gowasschen worden om het uitvallen to beletten. Op Java is van dit alles weinig of nicts bekend, doch worken de blateren dror sommigen als groente (lalip) gegeten.

36. 'Вот. Nur. - Methonica superba Lam.

IXD. זEY. - Djamblang S.

Gr. PL. - In onbebouwde oorden op Java.

Gerr. - De tweehooflige bolwortel zoude zeer giftig zijn. 37. Вот. Nir. - Polyanthes tuberosa L.

INL. EEx. - Kembang sedep malam en $\mathrm{k}$ : soendal malam $\mathbf{M}$; Troena malam $\mathrm{AT}$.

Grs. rr. - Mexien. Op Jisa in bijna alle tuinen als sierplent.

Gribr. - Van deze bolplant, welke alleen om hare geurige witte blocmen door de schoone sekse op Javi nict alleen, maar 
ook elders zeer gezocht is, vermeldt Lindleij, dat zij na zonsondergang haar meeste geur verspreidt, en men heeft waargenomen, dat zij bij zocle avonden na donder, wanneer de dampkringsluclit sterk met electricitoit is beliden, vonken, flikkeringen, ja zolls heldere vlammetjes afiverpt, in zoo groote hoeveelheid, dat de bloemen als verbleekt (verwelkt) sehijnen. IBlanco zegt, "ran de sterko geur dezer bloemen vallen hijsterici in flakuw, als dood ter neder."

38. Вот. Nм. - I 'исеа flaccida Haw.

39. Bor. Nir. Jucea gloriosa Andr.

Gr. rr. - Amerika. Beide op Java als sierplanten in sommige tuinen.

Gerr. - Vau sommige Yueca soorten werkt de vleczige doosvrucht ontlasting bevorderend en wordt de wortel bij wijze van zeep gebezigd.

40. Вот. Nu. - Aloë vulgaris De.

IrI. BE. - Lida boeaija MI.

Gr. PL. - Afrika, vooral aan de kaap de Goedo Hoop, ook in West Indie; op Java in tuinen.

Gerr. - Deze plant levert de bekende Aloë. De inlanders bereiden net het sap der bladeren ecne surnt ran drank, tjimtjouw genaamd; ook maken zij, nadat de bladeren met lkalkwater cenigen tijal zijn nitgetrokken, met dezulve cene sonrt van gubak. De gutncuscle bladuren legren zij bij hevige looffluijn ter ver-

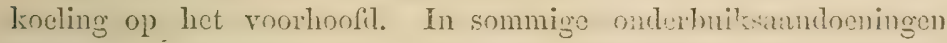
drinken zij cen aftreksel chir bluderen tot bevorduring vain den stoulgang.

41. Вот. Nur. - Asparagus officinalis $\mathrm{L}$.

Gr. PL. - Europa in zandige gronden; Japan; op Java in conige looger gelegene tuinen.

GEsr. - De wortel, welke vroeger in de Apotheken verkrijghaar was en onder de 5 radices aperientes werd gerekend, zoomede haar eigenaarlig bestandtecl, A praragine genoemd, en het zaad bezitten pisclijurende, braakwerwukkende, zelfs giftige cigenselıappen (zie uitvocriger do bestaande handboeken).

42. Вот. Nir. - Dracaena ferrea L. variet. rubens Hsskl.

IYL. LEx. - Andong meirah S; Hanjocwang burrum S. 
Gr. PL. - Java \& Sumatra in tuinen en in let wild.

GErr. - De jonge bladeren worden gelookt bij de rijst gegeten.

\section{DIOSCOREAE RBr.}

44. Bot. Nar. - Dioscorea alata L.

IVL. bEN. - Hoci lielien S; Hoei poetoen S; Oubie lielien MI Oubie tangan MI; Oebie kepas MI; Oebie aijam M; Oubie lakki lakki Mr; Lami MIak; Heri assapin Amb; Heri manoe $\Lambda \mathrm{mb}$; Iferi malona $\Lambda \mathrm{mb}$; Oehie en Iferi $\Lambda m b$; Ieli Ilit; Loetoe Bd; Ima T.

Gr. PL. - In bijna alle tropische gewesten; zij wordt ook in dezen Archipel zeer algemeen aangekweekt:

Gebr. - Van de Yamsplant worden de wortelknollen even als elder's bij wijze van aardappelen gegeten. Van sommige Dioseorea soorten worden door Aziatische volkeren de bladeren aangeprezen tegen slangenbeten, van andere worden zij, gekookt met Corianderzaad, bij tusschenpoozende koortsen toegediend.

45. Вот. Nir. - Dioscorea lirsuta 131.

INL. BEv. - Aroij gatong S; IIoci gatlong S; Ocbie gaclong $\mathbf{M}$. J. \& Bali; Oebie oetan MI Sikappa Bali; Seappe Mak; Bitocle MIen; Ondo Bt; Iaijoero Lt; Ulibita en Uhulibita Lh; IIaijoelo HIt.

Gr. pu. - Door den geheelen O. J. Archipel; op Java reel al in tuinen.

Gebr. - Even als van de vorige soort wordt ook van deze de soms reusachtige groote wortel gegeten, doch stechs na alvorens afgekookt te ziju, daar zij raauw gegeten vergiftige eigenschappen (dia bekin mabokh orang) bezit. Reeds Rumphius haalt aan dat dezelve benaauwdheid, duizeligheid, micrenkruipen, verlamming, braking en vermeerderde stoelyang veroorzaken, waartegen klapperwater wordt gedronken. Uitwendig wordt de wortel bij tand en kiespijn aangewend. Ook ol de Philippijnsche cilanden wordt de knol gekookt gegeten en aldarr het sap voor giftig gehouden. 


\section{'TACCEAT Lindl.}

46. Boт. Nu. - Tacea pinnatifida Frstr.

Irt. BEY. - Takka laut M; Kolopale Bt; Nepoe T.

Gr. PL. - Op Java, doch meer in de MLolukkos.

Gebr. - Uit de wortel dezer 'Tacea wordt een fijn meel rexkregen, hetwelk als sago gebruikt en gegeten wordt.

\section{IRIDEAE RBr.}

47. Вот. Nu. - Sisijrinchium latifolium Sw.

IYL. BEN, - Sauchun lulus S; Loeloean sapie J.

Gr. PL. - Europa, op Java in tuinen aangeplant.

GEsr. - Volgens Lindleij worden eenige Sisijrinchiumsoorten anngewend als diuretica, purgantia en emetica, doch zouden zij soms cene op zeezickte gelijkende braking met geheele inzinking der krachten kunnen veroorzaken. Op Java worden de bladeren rermengd met 'Tatter (Solanum verbascifolium L.), Semboeng (Pluchea balsamifera Less), Kasimboekan (Eclipta L. sp.) Bamboe apoes (Bambusa apus Schlt) enz. met water fijngewreven aan kraamvrouwen toemediend.

48. Вот. Nar. - Pardanthus chinense Kor.

I.rL. BEx.-Akkar tjamakka S; Gegeh bengan S; Kelipas MI; kepelkepet-an J; Ketip MIen; Salim Datok MIand.

Gr. PL. - Op Java en naburige cilanden in zandige en onbcbourde streken.

Gesr. - Endlicher vermellt dat de volkeren van den vasten wal ran Indie deze plant om liare oplossende en openende eigenschappen aanwenden. In Mandheling kaauwen pas bevallene kraamvrouwen de wortel bij hunne sirih.

\section{AMLARIJLIDEAE RBr.}

49. Bor. Nı. - Crinum zeijlanicum Ker.

I.YL. BEY. - Bakoeng S \& M.

Gr. PL. - Wordt op Java reclvuldig in tuinen gevonden als sieraadplant.

GEBr. - Endlicher geeft aan dat de wortel ran cenige Cri numsoorten in Azie en Amcrilsa bij wijze ran cataplasma op 
gezwollenc declen angewond worit. Volgens inlandsche opyaven wordt de wortel van deze soort bij hevige hoofdpijn en delirium ten gerolge van lioorts uitweudig gebruilit, na alvorens met water fijngewreven te zijn; ook zoude hij een gocd blaartrekkend middel zijn.

50. Вот. Nı. - Crinum asiaticum L.

LVt. BEN. - Bakoeng S, Mr, Bali \& MIakasser.

Gr. PL. - Door bijna den geheelen Archipel, vooral an de stranden, rivieroevers en moerassige streken.

GEnr. - Recds Ramphius liaalt an dat deze wortelknol donr zijne scherpe braakrerwekkende cigenschapion ecn goed tegengiit was hij giftige pijhwonden, welke pijlen in vroegere onIogen op Aakisser en andere plaatsen veelal in den oorlog deor de inboorlingen werden rebezigd, weshatre tan ook de soldaten deze wortel steeds bij zich droegen en bij rexwonding zooveel van dit mildel moesten kaauwen en inslikiken, als zij in eens in den mond konden nemen, waarna spoedig braking volgde en do huiduitwaseming bevorderd werd; ook bij de beet ran insekten cin, visschen werd hij ingenomen. Volgens hem wordt hij fijn gewreven of in schijgen gelegel op de huidzickten der inlanders, Blah en Bouboel genoemd. Ook Iforsfichl roemt zijne lwacht als traakmidtel, decel er vele proeven mede en berealt liem de tergenwoordice geneesheeren ter verdere profineming aan; ik geloof echter hij als emetieum geheel in veruetelhcil geraakt is. Op Java bezigt mon deze soort uitwendig even als de vorige, doch mecr bepaald bij kleine kinderen (oerot oerot sadja).

51. Bor. Nar. - Crinum lorifolium-longifolium Schlt. variet, flore rubro-striato.

\section{IYL. BEY. - Bakoeng S. \& MI.}

Gr. PL. - Europa. Op Java als sicraadplant in vele tuinen.

Gerr. - Ook op deze soort is het van de vorenstaando soorten opgesomde warschijnlijk toepassclijk.

52. Вот. Nмr - Pancratium zeijlanicum L.

Iry. Bev. - Brambang Oetan MI. \& Jav; Kasse sclan Bali; Batsjang kiang Ch.

Gir. in.. - Ureral in dezen aredingl op lage mocrasige gronden. 
Gerr. - Op Malabar zonte men de wortel berigen tot liet dooden van londen; en op Jiva het sap, door persing nit de bladeren verkregen, bij doofheid in de ooren druprelen, en de hilderen zelve in sommige zilven mengen. Niemand hedt mij echter hicromtrent iets bepaalds kunnen mededeclen.

53. Вот. Nar. - Haemanthus puniceum Jeq.

IvL. BEX. - Babawangan trisna S; Ompô-Ompô MLand.

Gr. PL. - Op Java veelvuldig in tuinen.

Geir. - Sieraadplant.

54. Bот. Nir. - Agave Rumphii Hsskl.

Iru. BEx. - Nannas sabrang II; Nannas wolanda J.

Gr. rL. - Luid Amerika, op Java veelal in en rondom tuinen.

Gebr. - Uit de bladvezelen bereiden de inlanders allier en elders naaigaren en touw; zij zijn echter grover dan die van Ananassa sativa Lindl. Van Agave americana L. vermeldt Blanco dat men de fijngewrevene bladeren op kanker aanwendt.

55. Вот. Nзг - Fourcroija tuberosa Haw.

Gir. PL. - Zuid Amerika, op Java en elders in viele tuinen, als sicraadplant uit Luropa overgebragt.

\section{BRORIELIACEAE Lindl.}

\section{6. Вот. Nu. - Ananassa sativa Lindl.}

Irr. mey. - Namnas MI, J, Amb. \& T.; Mlanas Bali; Pangran Mak; Oeri bengala Hí; Kajoe nassa Bud.

Gr. PL. - Oost- en West Indie, alhier meestal in en rondom tuinen.

Gerro - Zon huishoulelijk als gencesknchtig is deze plant ran groote waarde. Vooral op Java worden nit de bladrezelen garen en klecdjes geweren, welke somtijls zoo fijn en wit als zijde en vrij sterk zijp. De rijpe vruchten zijn zeer gezocht, zij worden raauw, gekookt en met suiker ingelegd gegeton, doch is het stecls goed $\mathrm{zo}$, ranuw etende ecrst met water af te wasschen, ten cinde cen gedeelte van hun scherp zuur weg te nemen; matig gebruikt zijin zij onschardelijk, zij kumnen 
evenwel ligtelijk tot buikziekten, als kolijken, diurrhoen on dijsenterie aanleiding geven; evenwel bezigen de inlanders ze somtijds bij katarrhale diarrhoe. Veel gebruik makt men ook van de onrijpe vruchten; nict een inlander is onbekend met hunne pisdrijvende eigenschappen, en vrij algemeen worden ze dan ook door hen tegen Gonorrhoeae angewend; zij eten ze als dan gewoonlijk in schijvon gesnecten met suiker, nadat men dit mengsel alvorens eenigen tijel in de opene lucht of 's nachts in de daauw heeft afgetrokken. Ouk Rumphius, Horsfield, Endlicher, Waitz en anderen staven deze eigenschap, de laatste zelfs door zelfyroeven. Ook als authelminthicum schijnt de ourijpe vrucht goede diensten te kunnen bewijzen. Endlicher nict alleen rermoldt dit van de Antillen, maar ook Rumphius dat in de MLolukko's en Blanco dat op de Philippijnsche cilanden het sap der nog niet gehecl rijpe vruchten des morgens aan kleine kinderen wordt tocgediend tegen ingewandswormen. Eindelijk wordt op deze cilanden de omrijpe vrucht menigvuldig misluruikt als een sterk emmenagogum en abortivum. Alle door mij ingewonnene berigten staren deze hoedanigheden der rijpe en onrijpe ananas: terwijl men mij nog heeft verzekerd, dat kraamvrouwen de jonge bladeren met eenige andere kruiden afgetrokken drinken, ten einde de afscheiding der lochiae te bevorderen.

\section{ORCHIDEAE RBr.}

57. Вот. Nм. - Dendrobium Șw. Spec. 1.

IyL. EEY. - Anggrek S. \& MI.

Gr. PL. - Als parasiet op hoog geboomte van Java's bosschen. 5ร. Bот. Nıг, - Cijmbidium Sw. Spec. 1.

INL. BEx. - Anggrek S. \& MI.

Gr. PL. - Op Java op hoog geboomte.

59. Bот. Ny. - Acrides arachnites Lindl.

INL. BE.Y. - Anggrek S. \& MI.

Gr. pr. - In bosschen aan den roet ran het Salakh en Sáriboe gebergte.

60. Bor. Nar. - Rhijnchostijlis retusa $13 \mathrm{l}$.

TYI, BEX. - Angegrek oentjal S. 
Gri. pL. - Vooral bij Buitenzors en Bantam op hoog greboomte. Alle deze Oichilene worden om liunne fraajje, zonderling gerormde bloemon veelvuldig in tuinen aangekweekt.

61. Вот. NıI. - Vanilla planifolia Andr.

Gr. PL. - Zuid Amerika en vooral ook Mexico. Op Java wordt zij tegenwoordig velvuldig in tuinen aangyetrollen. 'Zij is in 1810 door Dr Pierot het ecrst naar Java overgebragt en levert aan hen, die met de wijze van voortteeling bekend zijn, vrij groote en geurige vruchten.

Gesr. - De vruchten dezer plant zijn de in alle handboeken beschrevene en vecl geluruikt workende siliquae Vanillae. Den Javanen schijnt hun gebruik nog onbekend te zijn.

\section{ZINGIBERACEAE C. Rich.}

62. Вот. Nм. - Zingiber oficinale $\mathrm{I}$.

LYL. מEN. - Djahej of Djahi S. M. J. \& Mali; Halija of Alea II; Lea Cel; Sehij en Siwe Amb; Sohij Ld; Gora 'Id; Goraka en Woraka $\mathrm{T}$; Kion en Tjong $\mathrm{Ch}$.

Gr. PL. - De kust van Guinea, van daar naar Oost en West Indie overgebragt; op Java meestal in tuinen.

Grark. - De algemeen bekende Gemberwortel wordt door den inlander ook ingelegd gegeten en raauw bij vele spijzen en bij in- en uitwendige geneesmidlelen gemengrl. Irij keut aan hem dezelfde geneeskrachten toe als de Europeanen.

63. Вот. Na. - Zingiber casumumar Rxb.

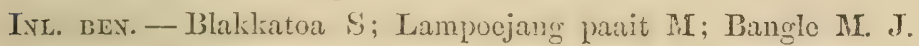
\& Bali; Oenin pakkeij en Makkeij Amb.

Gr. PL. - Op bijna alle deze eilanden in tuinen en in het wild.

Gebr. - Deze wortel was vroeger onder den naam van Rad: Casumunar in de apotheken serkrijghar. IIij wordt in deze streken veelvuldig door kramvrouwen zoo uit als inwendig gebezigd ter bsvorituring der kraanzuivering; zij gobruiken hen bij wijze van djame, vernenged met situchun (23anieum palmaefolium Koen), konneng tamman (Curemina loyga $r, \beta$ minor Irsskl), scheh (Audroporou Schocuanthus I.), singocyoe (Clerodendrum 
serratum Sprog), dawon tjangkoedoe (Morinda citrifolia L). enz. Volgens Rumphius dient men dit mengsel ook toe bij kolijkpijnen en gecelzucht.

64. Вот. Nм. - Zingiber gramineum Bl.

Ix̌. BEx. - Banglaai S; Lampoejang wangie MI; Banglej J; Soentie J; Alea paddi MF; Sehij of Siwe lale Amb; Bocsso IIt; Sehijirara Lt; Woraka 'T.

Gr. PL. - Menigvuldig in dezen archipel op grasvelden.

GEsr. - Veelvuldig wordt deze wortel door iulanders angewend, zoo uit een geneeskundig als lijgeloovig oogpunt. Zij mengen hem in bijna alle humne gencesmiddelen, doch vooral in die tegen allijnamische koortsen, diarrhoea, flatulentia, zelfs tegen dijsenterie; zij verbinden er somtijds wourlen en zweren mede; kraamvrouwen drinken valk een aftreksel van dezen; cindelijk stampen zij ze en wrijven daarmede het gehecle ligchaam in ter voorkoming van ziekten, (of lierer om duivels nit lietzolve verwijderd te louden). Zij planten bij cenen mislukten oogst deze plant rondom hunne tuinen, in de meening dat daardoor de kwade geesten bevreeśd wegloopen.

65. Вот. Nyr. - Curcuma longa L.

Ixt. bxx. - Konneng gedeh S; Koening besanr MI; Koening en ILoenjit M, J, en Mak; Tomon gering S'; Oenik Mand; Oe$\operatorname{nin} \mathrm{Amb}$; Koenil Bd; Goratschi $\mathrm{T}$; Uin kion Ch.

Gr. PL. - China, Hindostan. de O. J. Archijel, op Java in het wild en in tuinen,

Gemr. - De bekende Curcumawortel mengen de inlanders veelvuldig in hunne spijzen, vooral in hunne kerxij's, zoo om deze te kleuren als om er eenen prikkelenden smatk ann mele te declen; verder in vele humner djamoes, zoo als in dic hij No. ris olgegeren. Bij tromw- en andere feesten schilderen zij er hum ligchatm mede geel. IIj is een geliefloosd middel bij geclzucht, ook bij obstruetion in liet poortaderstelsel en bij stecnzickten van nieren on blaas. Volgens Blanco bezigt men den wortel in China als niesmiddel en in spijzen. $O_{p}$ de Philiplijnscle cilanden leagt men den fijngewrevenen wortel op den voct, wanncer icmand in eenen doorn getrapt heeft, ten cinde dezen er uit te trekken.

66. Зот. Ny. - Curcuma longa L. F. minor IIsskl. 
LỸ. แЕพ. - Konneng tamman S.

Gr. PL. - Zie boven.

Gerr. - Fijngewaeven bezigi men dezen dikwijl:s uitwendig bij pijnen in de onderste leduitaten door ziekten of vermocidheid te weeg gebragt. Zie ook het mengsel onder No, 63 vermeld.

67. Вот. Ny. - Curèma zerumbet Rxb.

IxL. BEx. - Konneng boddas S; Komeng paric S ; Koening poetih MF; Tommo MI. J. \& Bali; Temoe tis J; Tommon Mak; Karbanga ' $I$ '.

Gr. PL. - Zie boven.

Gesr. - Deze plant lovert de zoogenaumde Rad. Zedoariae, ook dezen bezigen de iv'anders uitricudig bij en gevoel van pijn of vermoeidheid in de onderste ledematen, en wrijpen zij zich met het fijngekneusle kruid het ligchaam in na polzzickten.

68. Вот. Nu. - Kaumpferia galanga L.

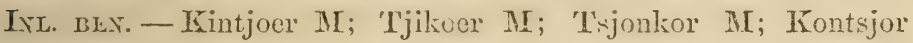
II; Koentja J; So-oelo Ht; So-ner Lt; 'rokoer IBd; Sokko on Patakkar 'T; Batakka Men; Assior Mrand.

Gr. PL. - Oost Indie; op Java in het wild en in tuinon.

GEBR. - Ook deze wortel wordt door de inlanders veelvuldig bij hunne spijzen gemengd, uitwendig bij beenpijnen aangewend even als No. 66 en 67, en bezigen kraamvrotiwen ze gelijk No. 63; eindelijk is bij een goode huidyrikkel bij versehil lende ontstekingen van inwendige organen. Rumpluius vermeldt nog dat het sap des wortels bij orrenvloed in de coren wordt gechruppeld en ook vruchtdrijvende krachten zou bezitten.

69. Вот. Nar. - Kaempferia pandurata Rxb.

IVI. BEN. - Koentjie M; Temo koentjie Mr; Lampoetie 'T.

Gr. PL. - Zie boven.

Gern. - Deze wortel, welke ook eene geele kleurstof bczit, mengen de inlanders in sommige humer spijzen. Bij windzucht wrijven zij zich den buik in met de fijngewrevene wortels on katuwen deze somtijds met pinang bij dronge locst en spruw.

70. Вот. Nur. - Amomum cardumomum L.

IvL. Eev. Koppol of Kappol S; Kapoclaga M.

Gr. 1'L. - Javar en Sumatrín in het wild in bereachtige strelion on in tuinen. 
Gezr. - Volgens Geiger zoude deze plant de zoogonoemde somina carkamomi rotunda leveren. IIare zaden worden alhier geweten; het kruid on de wortel worden met water fijngewreven en ditarnede de beenen ingewreven bij vermoeidhuid, rheumatische en andere pijnen.

71. Bot. Nx. - Amomum gracile Bl.

INi. Bex. - Ella S, M; Parahoeloe leutiek S.

Gri. PL. - Java in bergstreken.

GEsr. - Uitwendig bij beenpijnen gelijk de vorige soort.

72. Вот. Nir. - Amomum aculeatum Rxb.

IXI. BEY. - Prahoelo of Parahoeloe gedeh' S.

Gr. PL. - Java op vochtige plaatsen.

73. Вот. Nir. - Amomum maximum Rxb.

IvL. BEv. - Hanggassan gedeh S; Katilan Bat.; Wrassa of Worssa J.

Gri. PL. - Java.

GEisr. - Volgens Lindlcij zouden hare zaden de Grana Parradisii zijn. De jonge bladeren en vuuchten worden op Jiva gegeten; de wortel door kraamvrouwen angewend als No. 63.

7t. Вот. Ny. - Hedijchion flavescens Car.

IYI. BEY. - Gandasohlie S.

Gr. PL. - Java in het wild en vrij algemeen als sicraadplant in tuinen.

75. Вот. Nu. - Alpinia galanga Sw.

INL. BEX. Ladji bener S'; Ladja betoel MI; Lankwas M; Laus I; Lawassa of Lakwas of Lawas Amb; Galiassa 'I.

Gr. PL. - Java, Sumatra, China, Cochinchina. Op Java veelvuldig in de tuinen en rondom de huizen.

GeвR. - Van dezen wortel, welke de Rad. Galangae der apotheken is, merkt Rumphius aan, hij maagversterkend en krampstillund werkt; dat hij met axijn fijngewreven en bij wijze ran eataplasma uitwendig gebeziggd blaartrekkend is en niczen rerwekt; dat de bloemen soms l'auw of in azijn ingeleghl worden gregeten. Op) Java bezight mon thans den wortel vectvuldig ter bereidling der sauzen, wellke bij de rijst worden gebezigd, ten einde deze seherper en smakelijker te maken. Met water fijngewreven smeert de inlander danmede de ondersto ledematen 
in, wannecr hij thor ziekte of vermocidheid pijnen gevoelt.

76. Вот. Nur. Costus speciosa Sm.

IXL. BE. - Patching S, M \& J; Kajoe dawár en 'Toeboe toeboc Mr; Tehos lopoe Amb; Muri muri \& Tebe pussa Lh; Uya uga 'T; Toansing Men; Tawar tawar Mand,

Gr. PL. - Oost Indie, op deze eilanden op vochtige gronden.

Gebn. - Omtrent het gebruik dezer plant loopen de opgaven zeer uiteen. Findlicher geeft aan, dat de wortel om zijnen sterk bitteren smaak donr de indische volkeren tot de tonische midlelen wordt gebragt, geheel verschillend van de andere Zingiberaceac. Rumphius zegt: deze plant is van verkoelende kracht on zweetdrijgend. De jonge spruiten leveren eene goede gromte (sajor); zij zijn goed bij ontstokene oogen, vooral bij die dlon. pokken ontstaan; het hoofd daanmedo gewasschen doen zij het haar groeijen. Het hout met water fijngetvroven en gedronken is een goed zweetdrijvend middel bij koortsen. De inlandsche opgaven mij medegedeeld zijn de rolgende: de vruchten worden gegeten; het fijngekneusde kruid bezigt men nitwendigk bij slangenbeten; het sap onder uit de stengen verkregen dient men toe bij dijsenterie; kraamvrouwen bezigen do wortel gelijk No. 63 .

\section{CANNACEAE Agrhd.}

77. Boт. Nir. - Maranta indica L.

INT. BEX. - Patat sago S; Araroet M.

Cir. pt. - Jamaika, Oost Inclie, op deze cilanden dikwijls aangekweekt.

GEirr. - Op Java worden de wortelstokken gekookt gegeton, zij leveren het bekende zetmeel, Arrowroot genaamd, op.

78. Вот. Nм. - Canna coccinea Ait.

fNr. BEx. - Sabbeh burrum S; 'Tasbeh MI; Poespanida of J'osponidro $\mathrm{J}$; Kembang gedang $J$; Miloe miloe $J$ : Laikiet nimblu, Men; Sesobeh Mand.

Gr. PL. - Oost Indie, op Java en elders in het wild en in tuinen. 79. Boт. Ni. - Canna flavescens Lk. 
INL. BEx. - Sabbeh konneng S, zie overigens hiervoren.

Gri. PL. - als voren.

Gebr. - Op Java schijnen deze beide planten noch huishoudelijk noch geneeskundig aangeweut te wouden; men plant ze aldaar slechts als sieraadplant om lumne roode en geele bloemen, en bezigt de harde zwarte zaadkorrels soms ter verratardiging van bidsnoeren of in plaats van havel tot het vangen vau kleine rogeltjes. Ontront de Caunasoorten in het algemeen geeft Endlicher aan: "men gelooft lat de wortels van cenigen zacht zweet- en pistrijvend werken; de zaden ran andere prijst men ook als plantsvervangers der kofij, zij geven eene purper kleur af, zijn echter minder krachtig." Lindleij vermeldt: de vleezige corms van sommige Canna's worden in Peru gegeten, en eeno soort van arrowroot, genaamd Tous les mois, wordt in -West Indie uit cene soort vervaardigd, welke men veronderstelt dat de C: achiras is.

\section{IIUSACEAE Agrdls.}

80. BoT. NuI. - Musa paradisiaca L.

Irt. bex, - Ijou S; Pisang MI; Kedang J; Bijo Bali; Oenting Mrak; Koela \& Oerij Anb \& Bd; Kojo 'T: Tema Cr'; 'T'schijo Ch.

Gr. PL. - Cejilon, Oost Indie \& eilanden, meestal in tuinen.

Gebr. - Deze plant, waarvan in dezen arehipel stellig een reertigtal varictuiten roorkomen, wordt tot verschillende docleinden sebezigd.

De bladeren en de steng, vooral het binnenste, worden door sommige beesten gaturae gegeten, ook zouden de jonge nitspruitsels volgens Lindleij als eene leklkere grounte kumen gemuttigd worden. De stam, welke zich zecr gemakkelijk in enkele schillen laat afstroopen, bezigt men verseh en gedroogd tot het impakken van verschillende voorwerpen, als planten, tabak, enz. In hospitalen zijn deze schillen bijzonder dienstig tot hut van de slatpplaatsen der zielien deen afyloeijen vam water, specksel en andere onreinheden, b. v. bij de amwending der irrigatictosstel, salivatie als anderzins. De stam zonde ook tot bereiding van 
potasch kumnen gebruikt worden. Ook de bladeren zijn diensti; tot het inpalkken ran versehillende voorwerpen, vooral nadit zij eenigen tijel boven bet vuur zijn gehouden, daar zij alsclan minder scheuren: verder tot borden of tot deksels boven spijzen; in hospitalen bezigt men ook deze veelvuldig tot het doen wegvloeijen van vlocistufliun, of wel, mits zij dikwijls verversclit worden, voor oogschermen. Do nog in de stam beslotene, onontwikkelde jonge blateren, wolke van een fluweelachtig aanvoelen en zeer fijn weefsel zijn, kumnen darurtoc doelmatig opgerolel, zecr groed bij wijze van bougies bij strictura urethrae of fistulac gebruikt worden. Uit de vezelrijke bladsteelen bereiden sommige volkeren garen en kleedjes, en volgens Blanco dient de stam tot bereiding van manillatouw. De Javanen drinkon dikwijls het vocht, dat bij insnijling en atschilfering uit de steng vloeit, ter hoeveelheid van 8 tot 12 en meer oncen daags, bij dijsenterie of levige diarrhoe, en wel dan wanneer andere middelen fillen. De blvemknoppen, bloemen en onrijpe vruchten worden raauw, gekookt en greroost gegeten. De rijpe vrucht is een zeer gezond roedscl, die raauw, gekuolst en gekonfijt genuttigd wordt, al:; diacteticum bij vele ziekten kan alangeprezen worden en door de inlanders geroost of gebrand bij diarrhoe wordt anngewend.

81. Box. N.I. - Heliconia Grtn. spec. 1 (an Bihai L?)

IvL. BEx. - Tjou leuwung S; Pisang kolleh en P: oetan M. Gr. PL. - Op Java en Sumatra in het wild en in tuinen.

GEsr. - Ook deze bladeren bezigt men veelal tot het inpakken van tabak, enz: verder tot bereiding van potasch, als laxerend micldel roor paarden en tot rexkoelend bodeksel bij sommige ziekten en zweeren (Blceker).

\section{AlROIDEAE JsS.}

82. Boт. Nir. - Arum bicolor Vent.

Gr. pL. - Op Java in vele tuinen, vooral van Euxopcanen.

GEer. - Als sieraadplant, van elders ingevocrd.

83. Вот. Nı. - Colocasia vera Rmph. (Variet. 2).

IvL. מey. - Tallus S; 'Tallas MI. \& J; Kladie M. Bali \& Mals; Aladie Mals; Inam on Ina $\Lambda \mathrm{mb}$; Kedos $\mathrm{Bel}$; $\mathrm{Ou}_{\mathrm{Ch}} \mathrm{C}$ 
Gir. PL. - Erijpte, China, Oost Indie; wordt op deze eilanden veelvuldig nangelweekt.

GEer. - De jonge bladeren doch meer de wortelknollen worden door de inlanders gegeten, echter steuls afrgekonkt of geroosterd, daar zij anders de keel te recl prikketen; zij helblon alstan cenen lukkeren, duch eenigzins kleverigen smakk, zijn een zeer gewild vocdscl, vooral bij misluklking der rijstongst; op Sumatra zijn vele kampongs, wier inwoncrs zich uitsluitend met dit voedsel behelpen.

81. Bor. Ni. - Colocasia odorata Bron. var. $\Lambda$. viridis IIsskl.

IrL. BE. - Bira boddas S; en

84a. Вот. Nu. - Colocasia odorata Brgn. variet. B rubra Hsskl.

INu. LEx. - Bira burrum $S$; Senteh hitam $J$ :

Gr. PL. - Oost Indie.

GEBr. - De inlanders wrijven dezen wortel met water fijn, en wenden hem als huidpriklkel an bij zielsten van inwendig geleggene organon. De meeste Culucasiasuorton bezitten in alle hunne deelen scherpe beginselen, zij veroorzalien op de huid aangewend niet alleen prikkeling, maar verwekken soms blareu en puisten, even alis croton-olie, brakkwijnsteen, enz, van daar dat mon ze daar aanwendt, waar wij spaansche vliegpleister, zalf van Autenrieth, enz, zouden bezigen. De wortels met zout dijngewreven en op de wond gelegd, bezitten cone zokere vermandheid bij slangenbeten, zosmede bij kwathardige zweren en herpes.

85. Вот. Nм. - Colocasia macrorrhiza Schtt.

IYL. BEy. - Kareoh S; Kadjar kadjar MI.

Gr. PL. - Wordt door den geheelen O. J. Archipel veel aangeplant.

Grsir. - Ook de wortelknollen van deze soort worden veelvuldig gegeten, zij zijn echter krassend, niet lekker valn smaik; op de üuidzec-cilanden vooral vindt men er uitgestrekte velden mede beplant. Iline wortels en bladeren worden na geroosterd te zijn met water fijngewreren en uitwendig bij pijnen in de ledematen rondom de gewrichten atangewend. Volgens IIasskarl zoude het sap uit de bladstelen bij hoest dienstig zijn. 
86. Boт. Nr. - Culladium giganteum Bl.

INI. BEN. - Tiroe boddas $\$$.

Gr. PL. - Java.

Gebr. - Ook deze wortel bezit zeer scherpe eigenschappen en wordt bij inwendig lijden veelvuldig als hidprikkel aangewend; van het sap der bladstelen verneldt IIasskarl het gebruik tegen loest.

87. Bот. Nir. - Aglaonema simplex Bl.

INL. EEx. - 'Tjaricang S; 'Tjariewoe S.

Gr. P'L. - Op Java in bosehrijke bergstreken met steenaclitigen grond.

Gebr. - Tabak in deze bladeren ingepakt wordende, zoude eenen betoren smak bekomen. De bladeren en bladsteelen afgekorolst met katjang hidjoe (Phascolus radiatus L.) worden dikwijls aan kraamvrouwen bij de rijst te eten gegeven.

88. Bот. Nir. - Homalonema rubrum Hsskl.

IvL. BEx. - Tjarieang buxrum S; Senteh woelong J; Nampoo J; Silong doewa Mand; Beteh meirah Men.

Gr. PL. - O. J. Archipel.

Geßri, - Bladeren en steng worden door de Javanen met water fijngewreven en bij lioorts (sakit moeriah) op de lendenstreck gelegd. De stam met cenige andere kruiden vermengd en afigeknokt, drinken de reeds bujanden en hoofiten dikwijls als aphrodisiacum.

89. Вот. Nr. - Raplidophora lacera Hsskl.

IxL. вex. - Tjaloebangtang S; Tjalocmampang M; Lolloh keboh S; Lolloh moending S.

Gr. PL. - In Westelijk Java.

Genri. - De bladeren fijngesneden en met gras vermengrd ggeft men als een buikzuivercud middel atir pairden to eten, door het gebruik hiervan zouden deze vet en glanzend worden.

90. Вот. Nм. - Scindapsus officinalis Schtt.

IVL. BEN. - Lolloh monjet S.

Gr. PL. - Bengalen, Java.

GErri. - De Bengalezen kennen aan deze plant wormdrijvende krachten toe en verkoopen de bloemscheden onder den naam van Guj-pippuli. De Javanen schijnen deze plant nict to gebruilion. 
91. Boт. Nyr. - Pothos scandens L.

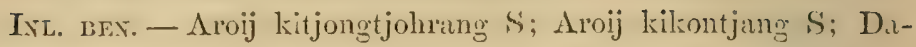
won doedoek M; Tapanawa ketjil Amb.

GR. PL. - O. J. Archipel.

GEbr. - Deze plant wordt in IIindostan als cen geneesmiddel bij rotkoortsen aangeprezen. Volgens Iasskarl worden de ranken getoezigd tot vlechtwerk en soms tot zwartverwen, en worelen de sappen gedronken en in de lendenen ingewreven bij lendenpijn. Volgens mondelinge opyaven der inlinders wrijven zij de blatleren met adas (Anisum vulgaris L.) en poelassarie (Alijxiil stellata R. \& S.) vermengd met water fijn en. drinken dit bij opgezetheid der buik.

92. Вот. Ny. - Lasia heterophijlla Schtt.

IVL. BEX. - Sampie MI.

Gr. PL. - Java.

Gerir. - Deze plant wordt door kraamvrouwen gुebezigd eren als No. 6t. Bij been- en gewrichtspijuen wrijlt de inlanrler haar met water fijn en legt dit om de pijnlijke deelen. Bij het buiklijien, don hen sakit proet anggêt genaand, drinken zij cen afkooksel van wortel en kruid.

93. Вот. Nзг - Acorus terrestris Rmph.

IxL. BE. - Jariengo en Djeriengoe MI; Kajoe swangi Bd; Aijwahä̈e Lh; 'Tsjaupo Ch.

Gr. Pt. - Door dezen geheelen archipal in moerassen.

Gebr. - De wortel dezer plant kan zeer goed onze Radix Acori calami vervangen en wordt dan ook veelvuldig door europesche geneeshecren voorgesehreven. Ook de inlinders bezigen hem dikwjjls bij de ziel:ten waartegen zij Zingiber gramineum en de vorige plant aanwenden, zoo in als nitwendig.

\section{PANDANEAE RBr.}

94. Boт. Ny. - Pandanus furcatus Rxb.

IYL. BEx. - 'Ijankocang S'.

Gr. PL. - Oost Indie.

Gesr. - De jonge spruiten, boven het vuur gebrand cn met suiker vermengd, drinkt men bij hoest. Volgens Hilsskitl wor- 
den de spitsen der takken mot de nog onontwikkelde bladeren met water afigekookt, zonder er zout bij te voegen, en dit gegeten bij vergiftiging; van de bladeren worden matten of geldzakken gemaakt. Omtrent de Pandanussoorten in het algemeen geuft Endlicher aan:" de vruchten zijn ectbaar, sommige ecnigzins aromatisch, onrijp zijnde houdt men dezelve roor stondendrijvend. Ilet kiemwit is amandelachtig. Het matig zamentrekkende sipp der bladeren wordt bij diarrhoe en dijsenterie toeguliend. De bloemkolven zijn zeer welriekend, de jongere met melk afgeknokt bohooren tot de liefdeopwokkende dranken der Indische volkeren. Verschillend is het huishondelijk gebruik der bloemliolven en bladeren."

95. Bот. Nxr. - Pandanus inermis. Rwdt.

Ivi. isex, - De plant heet Pandan MI. \& J, de bloemen Pocdak S. \& M.

Gr. PL. - Java.

Gebr. - Van de bladeren maak men fijn vlechtwerk, als sigarenkokers, enz: de welriekende Hoemen bezigt men als sieritd en om hunne lekkere geur.

96. Bo'r. Nur. - Pandanus latifolius Rmph.

INL. BEX. - Pandan rampeh gedeh S; Pandan wangic \& P: bebaauw MI; Keker noni Amb.

GR. PL. - Arabie, Oost Indie on op bijna alle deze eilanden.

GEir. - De bladeren, welke versch zijnde weinig reuk verspreiden, worden fijn gesneden zeer sterk riekend, en zoodinnig met bloemen vermengd tusschen de klecteren gelegrl of in het har gedragen. Rumplius geeft ook aan, men dezelve bij de rijst zoude kooken, om deze eenen aangenamen geur medo te deelen, en dat men uit dezelve cene olie vervaardigt. Geiger vermeldt dat de onrijpe vruchten dezer plant, welke vroeger I'. odoratissimus genoemd werd, als emmenagogum zoude kunnen dienen.

97. Bот. Nyr - Pandanus samak Hsskl.

INL. nex. - P'andan samak s; P'undan tikar MI Pundan orang on $\mathrm{P}$. rie $\mathrm{J}$.

Gr. pL. - Op Java langs de strauden.

Gisir. - Van de bluderen vlecht men, nadat zij aan stukken 
gesneden, gekookt en gedrongrl zijn, eene grove snort van matton. De wortel, na toebereid te zijn met adas (Semina Anisi vulgaris L.) en poclassarie (Lign. Alijxiae stellatae R. \& S'), dient men toe bij waterzucht.

98. Bот. Nı. - Pandanus utilis IVld.

IVt. BEN. - Pandan meirah MI.

Gr. PI. - Bourbon, Madagascar, op Java in tuinen orergebragt.

Gerr. - De bladeren kunnen door verweeking tot ecn zeer bruikbaar vlas verwerkt worden, waaruit men kleedingstukken lsan vervaardigen: de vruchten maken met die der Artocarpus incisa $\mathrm{L}$. het hoofdroedsel der Zuidzeceilanders uit.

\section{PALMAE $\mathrm{L}$.}

99. Bor. Ny. - Pinanga Rmph. Spec. 1.

100. Boт. Ny. - Areca catechu $\mathrm{L}$.

Int. BEx. - Djambej soesoe S; Pinang MI; Rapo Mak; IIoa of Hua Amb; Pua Bd; Hena en Pare 'T.

Gr. PL. - 'Tropisch Azie, Sịam, Malakka, in den O. J. Archipel veelal anngekweekt.

Gerr. - Do blad - en bloemschedun dienen tot het inpakken van voorwerpen, welke voor regen moeten beveiligkl workin. De noten worden fijngesneden en met tabak, sirihbladen en killk gुokaauwd, de zoogenaamde betelpruintjes; het roode specksel hierdoor bekomen wordt door den inlander onder hot prevulen ran spreuken veclvuldig gebezigd op verwonde of pijnlijke declen, zoo als bij verwondingen, hootlpijn, buikpijn, wormen, windzucht, enz: deze besmcering noemen zij Sembons of Sumbor. Volgens ecnigen zouden oude, zeur xijpe vuthten fijngewreven en gegeten een sterk aphrodisiacum zijn, terwijl liumphius nog aanhaalt dat de Chinezen dikwijls met rutuht een ankookscl der bolsters van pinangnoten bezigen bij chronische diarrhoe en dijsenterie; daar dit al'kooksel sterk looistofhoulend is kim het dikwijls goede diensten bewijzen. $O_{p}$ deze cilinden schijnt nit de noten geene Catechu bereid te worden, daar deze op Sumatra, Riouw enz. in orergroote hocveclleid nit de Un- 
caria gambir Rxb. daar gesteld worlt. Vele schrijvers gelooven celiter nog dat dit artikel uit de P'inangnoten wordt verkregen en Pereira geeft hieromtrent onder anderen het navolgende aan: "op Ceijlon worden uit dezelve twee soorten vau Catechu bereid; " de eene soort zwart en zeer onzuiver, genaamd Kassu; de andere "geclachtirg bruin, aardachtig op de doorbraak en vrij van bijge" mengde zelfstandigheden, genaamd Cowrij.

"Behalve deze zijn nog andere soorten in den handel, als $1^{\circ}$. "ran Singapore, eene soort genaamd Gambir van de Uncaria "gambir Rxb. 2॰ van Bihar on N. Indie eene soort waarschijn"lijk afkomstig van Acacia Cutechu: $3^{\circ}$. Pegucatechu, aflkomsticr "van Butea frondosa Guib, benevens eenige andere van minder "bekenten oorsprong.

"Do Catechu wordt vooral gebezigd als zamentrekkend middel "ch wel $1^{\circ}$. bij aandoeningen van mond-en keelholte; $2^{\circ}$. als "maargversterkend middel bij dijspepsie; $3^{\circ}$. als zamentrekkend "middel voor het darmkanaal bij verouderde diarrhoe en dijsen"terie; $4^{\circ}$. bij atonische bloedvloeijingen; $5^{\circ}$. bij loodkolijk; $6^{\circ}$. "bij slijmvloeijingen en $7^{\circ}$. plaatselijk op zweren."

101. Вот. Nм. - Sagguerus saccharifer Bl.

IvL. BEx, - Kawoeng S; Gomoetoe M; Aren J; Lahang J; Jahaka Bali; Naun Bi; Jocro Mak; Makka Mol; Nawa $\Lambda \mathrm{mb}$, Ht \& Lh; Akel Men; Seho T; Nawa Bd.

Gr. 1'L. - O. J. Archipel, de Moluksehe en Philippijnsche eilanden, op Java tot op eene hoogte van 1800 voeten.

Gmir. - Deze voor de bewoners der opgenoemde eilanden zoo onontberilijke boom dient als volgt: de oude bladeren en het gemoctoo, ecne zivartvezelige stof welke zich tusschen de bladsteelen en den stam bevindt, bezigt men tot het dekken van huizen. Uit deze gemoetoe (ook dook of injock S genaamd) vervaardigt men een vrij goed touw, dat dikwijls op de koopvaardijschepen wordt gelbruikt. De grovere declen dezer doek worden fijngewreven of met kalk vermengel en daar anngebragt, waar men de houten stijlen der huizen tegen de witte mieren wil beveiligen. Uit den strm des booms klopt men cene vrij gocte soort Sago, soms levert eenen boom tot 200 ponden. De jonge bladesen bezigt men dikwijls, even als die van Nipa (Nipa fruticosa 
Thulb.) tot het vervaardigen van sigaren, terwijl de oudere tot het dekken van huizen dienstig zijn. Uit de bladstelen worken schrijfpennen, pijlen en soms visehgereedschap verraardigd. IIet bovenste gedelte der steng, warin de jonge nog nict ontwikkelde bladeren bevat zijn, Palmiet of door de Sumkinezen Dodôl gelıeten, eet men raauw, gekookt en in het zuur gelegd als tocspijze bij de rijst. Uit de bloemsteelen rerkrijgt men door insnijuling en kneuzing een holder sap, dat rersch aangenaam zoet van smaak is, toewak genaamd en veel gedronken wordt, het verwekt echter ligt buikloop. Vooral op de MIoluksche eilanden onderwerpt men dit sip aan eene ligte gisting, vermengt het daarna met bittere plantenstoffen, rooral met eene wortel akkar sesoot (1) genaanid, waarna het do zoogenaamde bittere Sagoweer daarstelt, eenen bedwelnenden drank, welke ook zelfs door Europeanen recl gebruikt, ja misbruikt wordt; matig gebruilst zeer grezond, eenigzins opwekkend en versterkend is, doch misbruilit, even als andere alcoholica, als cen langzaam vergift groote rerwoestingen in het organismus aanrigt. Het versche sap wordt spoedig zuur en bezigt men tot het maken eener vrij goede soort van azijn, nog dient hetzelve tot bereiding cener zwartbruine soort vau suiker, goela djarra genaamd, en ran arak. Voorts eten zoo inlanders als Chinezen de vruchten gekookt en gekonfijt. Zij zouden een scherp, opwekkend en huidprikkelend rocht beratten, clat in de vroegere Moluksche oorlogen dikwijls door de roorvechters werd gebruikt, om moed te bekomen.

102. Вот. Ny. - Carijota furfuracea Bl.

IYL. BEX. - Sarraij S; Sarrawoij S; Sowangkoeng J; Kilomboe J.

Gs. 1יL. - Op Java, Sumatra, Borneo en N. Guinea in bergachtige streken.

Grin. - Even als de vorige levert ook deze boomsagn en cene soort van toewak op, en zouden de ruchten een zeer scherp rocht bevatten. 103 Вот. Nir. - Calamus L. Spec 1.

IVt. BEN. - Hoëh S; H. boeloe S; H. karokrok S; H. korrekrok S; H. krokkot S; Rottan MI.

(1) Rhicophora Maugles $\mathbf{L}$. 
Gr. PL. - Bantam.

GEbri- - Men eet de jonge spruiten afgekenkt bij de rijst en greeft ze soms als wormdrijvend middel aan kinderen, even als die vau andere rottangsoorten.

104. Bот. Ny. - Zalukka edulis Rwdt.

IVL. BE. - Zalak of Zallak of Rottan zalak S. \& MT.

Gri. p'L. - Jara, Bali en alle oostelijk gelegene eilanden, vooral in bergstreken.

Gebr. - Op Jara plant men deze struik veelvuldig om zijne sterlirickende, aangenaam zuu en zamentrekkend smakende viuchten, welke geschild en raauw, gepekeld of gestoofl worden gegeten, zwaar zijn te rerteeren en volgens Hasskarl een aplurodisiacum zouden zijn, welk laatste mij echter niemand heeft berestigd. MIen nuttigt ook raauw en gekookt de spits der stam umboet of hoemoet) en wendt deze na gebrand te zijn bij kiespijn aan. Uit de oude stum maakt men weverskammen, bezigt de oude bladeren soms tot het dekken van huizen en tot het inpakken van arensuiker.

105 Bor. NaI - Daemonorops melanochactes Bl.

IVt. вех. - Hooëh Selan S; H. Sellang S; Seël S: Rottan itum M; Rottan teboe MI; Penjalin J; Uii mette en Uii tehoe Amb.

Gr. PL. - Poeloepinang, de Luzonsche en O. J. eilanden, op Java op lagere bergen en in bossehen op hoogere bergstreken.

Gebrr. - Even als andere rottangsoorten dient ook deze om mede te biuclen en te vlechten, zij is echter minder buigzan, wordt reckil voor grof vlcehtwerk, wandelstokken en werplansen gyelsezigd; de Alfoeren vlichten van dezelve humne eetkorven. Haar umlect unttigt de inlander als toespijze bij rijst en gebruikt hij de oude bladeren tot dekling van woningen.

106 Вот. Nur. - Borassus flabelliformis L.

IrL. BEx. - Lontar MI Siwalen J; Tala Mak; Kepuë-dure Sw; 'Tuï-hu Rtt; Koli 'Tm; 'Tü̈-hun 'I'm.

Gr. PL. - Westelijk Afrika, Java, Madura, Bali, Celebes, MLohkkos en Philiplijneche cilunden, verkiest eenen stenachtigen grond en wordt op Java veel aangekweckt.

GEisi. - Ict harde, zwartachtig gevlukte hout dient tot het 
Huiken van kistjes en voor traliewerk. De top (hocmoct) wordt raauw en gekookt bij de rijst gegeten. De bladeren, na gedroogd te zijn; werden voorheen en ook nu nog door de Indische volkeren gyebeziggl om hunue geschiedunis, legenden enz. op te sehrijven, kumuende men dezelve langen tijd bewaren. Op de beoosten Jiva grelegene eilanden maakt deze boom met de kokospalm de voornamste spijs der inboorlingen nit, daar hij rijkelijk sago bevat, op Celebes vervangt hij zelfs dikwijls de Sagguerus saccharifer Bl. Op Java plant mon liem meer tot bereiding van suiker; deze sniker, goela lontar, goela djawa, ook jagoo-oera of jagara gehaimd, is blecker van klenr on harder dan die der Arenboom, en wordt door kooking verkregen uit het versche sap door insnijding nit de vrouwelijke blocmkolven bekomen, nadat er ecnige gekneuscle zaden der Aleurites moluceana Wld zijn bijgeroegd. MLen kan er ook cene soort van pahnwijn of sagoweer uit bereiden, welke cenen aangenamen smaali bozit. Volgens Rumphins bezigt men de sagoweer of socra, welke men in geringe hoeveelheid uit de bloemkolven der mannelijke boomen bekomt, alleen als greneesmiddel; men clrinkt ze 's morgens nuchteren bij phthisis, dijsenterie, cnz:, en zoude zij dikwijls ook roor Europeamen heilzaam zijn beronden. Op Ceijlon en Coromandel eet men de weeke pit der onrijpe vruchten, doch is een rijkelijk gebruik schadelijk.

De rijpe vrucht wordt ramu genultigd of uit dezelve poenatil bereid, een verdikt suikerhoudend extriet, dat men als toespijze bezigt.

107. Вот. Nur. - Licuala pumila Bl.

IVL. IEE. - Wargoe gedeh S; Wiroe S.

Gr. PL. - In westelijk Java.

GEbr. - Volgens Hassliarl maakt mon uit den stim wanclelstokken, zijnde deze harder \& sterker nog dan rottan.

108. Bot. Nir. - Rhapis javanica 131.

IxL. BEx. - Wargoe $S$; Wiroe $S$.

Gr. PL. - Op de bergen van W. Java.

Geri. - De jonge spruiten of eigenlijker de top der stengr (hoomoet) wordt gekookt bij de rijst gegeten; raanw on grekookit zonde zij een geschikt middel zijn bij chronische diarrhoe. 
109. Bot. Nis - Cocos nucifera I.

IxL. BEx. - Tangkal kalapa S; Pohon njior, Pohon keram-

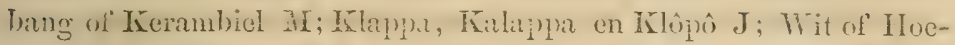
wit krambil, IInewit letjambil en ook Iocwit kelojk $\mathrm{J}$; îjo

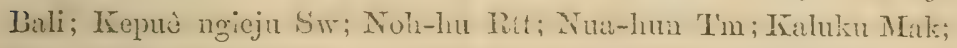
Popo Mon; Niwer MIol; Igo. 'I' Nicoera $\mathrm{Cr}_{1}$; Je- schu Ch.

Gr. PL. - Zij groeit op alle eilandon dezer arehipel, lhet best cohter aan de stranden, verder op alle Zuidzee-eilanden en in West Indie.

Gerr. - Dezen zoo nuttigen on voor de inboorlingen bijna onontbeerlijken boom vermeen ik niet te mogen voorbij gaan, zonder in korte bewoordingen hot gebruik, hetwelk van alle zijne declen gemaakt woxdt, te hebben olygesomd, doch waarvan Rum1)hius, Bhume en andure schrijrers reeds zulke introerige beschrijvingen hebben geleverd, dat ik hen, welke inniger met denzulven bekend willen worden, dan ook naar die schrijvers verwijs. Beginnende met dem wortel zon wordt deze soms in plants van pinanginoten bij de sirihprumfjes gekaauwd, maakt men in brazilie van zijne dume rezelen korfjes en is een afkooksel vas denzelven on de zamentrekliende beginselen een genecsmiddel tegen diarrhoe en koorts. De stam dient soms tot huisbouw, meer echter tot het maken van bruggen, waterleidingen, enz, doch wordt deze spoedig rerrot of dnor witte micren remield; lict onderste gedeelte is zoo hard, dat het gepolijst zijnde op agaat gelijkt. Zijn top (umboet of hoemoet) levert een aangenaam roedsel, en wordt raauw, gekookt of in azijn ingelegd gegeten. Van de jonge bladeren vlecht men korfjes, waarin rijst of ketan gekookt wordt (ketoepat), wardoor dezo lekkerder ran smaak wordt. De oude bladeren dienen mede tot liet maken van manden, tot het beschutten van kleino hutjes, soms tot dekling (atap) van liuizen en voor fakkels; ook schrijft men met scherpe bamboezen brieven op dezelve, ola geheeten; de bladnerven dienen te zaamgebonden roor bezems, terwijl de middelnerf op kleine praauwen soms de plitils ran roerstok rervult; hunue asch berat eene groote huevelheid potasch. De netrormige zelfstandigheid aan de basis der blirderen bezigt men in sommige streken tot het maken van geldzakkon, zelf's ook van cene grove sont 
van kleederen. De bluemschede dient roor fakkels. Het sap, lat bij insnijding uit den bloemsteel vloeit, bevat eene aammerkelijke hocreelheid suiker, is een aangenaam zoete, verfrisschendo drank, welke in Bengalen Toddij en in West Indie Süra genaamd wordt; men bezigt het tot bereiding van arak, van eene soort ran suiker, Jagerij geheeten, en ran azijn. Zelfs de jonge bloosems zouden volgens Rumphius met lontarsuiker gekaauwd en het sap inslikkende bij moeijelijke urienloozing en gonorrhoea heilzaam zijn. Het is echter rooral de vrucht door welker zoo huishoudelijke als geneeskundige anwending dezen boom zoo beroemd is geworden; deze drangt naar haren onderdom verschillende benamingen, de afvallende jonge vruchtjes heeten boengsil, de grootere doch nog onrijpe roedjakh, de halfrijpe bebantjie, de bijna rijpe pemalan en de oude nitgevretene kalongkong. In alle deze toestanden weet de inlander van de geheele noot of ran een gedeelte partij te trekken. De dikwijls nog zeer jonge afvallende vruchtjes, boengsil, gedroogd en met Poelassarie (lign. Alijxiae stellatac) on water fijngewreven zijn een geprezen geneesniddel bij chronische diarrhoe en dijsenterie; uitwendig bezigt men ze bij ecnige huidziekten (korreng besaar), of wel rermengd met aromatica en arak tot het inwrijven van zuchtig opgezwollene ledematen. De grootere doch nog geheel onrijpe vruchten eet men geheel, met de buitenste schil zelfs, als roedjakh, dat is fijngesncten en vermengd met keukenzout en spaansche peper, zijnde dit cen zeer scherpe en ongezonde spijze. Het water der halfrijpe vruchten lerert eenen aangenaam zoeten en rerkoelenden drank, welke matig gedronken onschadelijk is, rooral bij vrouwen dikwijls zacht ontlastingbevorderend werkt en borendien cen goed geneesniiddel daarstelt bij sommige ziekten der piswegen; misbruilst echter heeft hij dikwijls nadeclig op het organismus ingewerkt. De pit der halfrijpe vrucht wordt raanw of mot suiker gegeten, heeft reel van amandelen en dient in de ketken tot het gereedmaken ran onderscheidene spijzen. De rezelige bast der rijpe vuncht (koclit kalapa $\mathbf{M}$, genoffo $T$ ) dient tot Innten, vloermatten, hot inpakkeu van plantenstelken (tjangkok) enz, ook dikwijls tot let maken van touwwerk, dat on zijne groote veerliracht veelal op grooto praauwen ex kust- 
schepen gebruikt wordt. IIaar houtig gedeelte (batokh kalapa $S$, tampoerong $\mathbf{M}$ ) verwerkt men tot waterscheppers, lepels, drinkglazen enz. De pit der rijpe vrucht eindelijk Jevert na geraspt, uitgeparst en met water uitgekookt te zijn de bekende en lekkersmakende klapper-of kokosolie, welke reelvuldig naar Europa overgevoerd wordt om tot zeep te dienen, de inlander even als de boter bij ons te lande gebruilst, terwijl hij ze verder bezigt tot het zachtmaken zijner huid en haren, tot weering en genezing van schurftuitslag en tot het brandon zijisia iamp.

\section{CORMOPHIJ'TA-ACRAMPHIBRIJA.}

\section{CUPRESSINAE C. Rich.}

110. Вот. Nu. - Thuja dolobrata L.

Gr. PL. - Japan; op Java als sieraadplant in eenige tuinen.

\section{GNETACEAE Lindl.}

\section{Bor. Nir. - Gnetum gnemon L.}

INL. BEX. - Tangkil oetan S; Minienjo oetan MI; Koelan oetan Mak; Oetta soï Amb; Gnemon of Gnemo T; op Java noemt men de bast Bago, de bladeren Soö en de vruchten Manienjoh.

Gr. PL. - O. J. Archipel, de Molukko's, N. Guines, de MLitrianen en Philippijnsche eilanden.

Gerr. - De witachtige schors der in het wild groeijende boomen is zeer dum en bijzonder geschikt tot hereiding van vlas, daar zij fijnere en minder ruwe vezelen levert dan het eurow pesche; zij dient tot verraardiging van touw, strengen voor paarden en ander stevig touwwerk, doch rooral voor vischnetton, zullende dit in het zeewater durzamer zijn dan onze hennip, 
waarom Blume in zijne limmplia reeds anthaalt, het van eet lingg helang is men deze zaak naauvkeurig onderzoeke, daar het getal dezer boomen, welke men gemakkelijk met zaad lian voortplanten, in verschillende onzer indische gewesten, vooral in Menado, bijzonder groot is. De jonge bladeren en katjes worden afgekoukt of met klalpermells gestoofd veelvuldig door de inlanders gegeten, zijnde dit ecne spijs wolke zij zoo zeer beminnen, dat zij dezen boom volgens hunphius de koningin der boomen nocmen; zij verkiezen echter de bladeren der zelf gekweckte bonmen boven die der in het wild groeijende, daar deze minder scherpe vezclen bevatten en minder litteling veroorzaken. Even zoo verkiczen zij als spijs stecels de vruchten der aangukweekto boomen, zij eten deze als een geliefkoosd voedsel, nadat zo ronraf gekookt en door verwecking van de aanhangende vezelen gezuiverd of even boven lict vuur geroosterd, of wel gekneusd met klappermelk of olie fijngewreven en gedroogd zijn.

112. Bот. Nu. - Gnetum latifolium BI.

INL. BEY. - Kasunka of Kasunka aroij S; Kasoengka Mt.

Gr. PL. - Op Java vooral in bergachtige streken, Celebes, N. Guinea.

GErr. - Ook nit de schil dezes booms wordt eene soort van vlas bereid, hetwelk dun vezeliger en buigzamer dan het vorige cil zeer geschikt is tot daarstelling ran touwwerk, vooral ronr durrame vischnetten. Om rlas uit dezelve te bereiden worden de ranken op den grond of in den rook eenige dagen gcrlroogrl. waardoor de groene sehil zich gemakkelijk van de onderliggende rezeligo laag aficheilt; deze, vervolgons ran het hout afgezonderd, wordt door lneuzing en rerweeking van do anhangende slijmige declen goscheiden en er rervolgens vlas van gemaitkt. Blume.

\section{PIPERACEAE Rich.}

115. Box. Nar. - Piper longum Dtr. (Chavica Roxburghii Miq).

IxL. BEx. - 'Tjabch aroij S; 'Tjabch djawa of Tjabeh prahoe M. if . T: Iala mandjang MI Ammo eite ette Amb; Malisa lia- 
moel IIt; Mrarisa ammo of Maritsja amme Li; Bitoritsja 'l': Pih-pholh Ch.

Gr. PL. - Bengalen, O. J. eilauden en Molukko's. Op Java vooral aan den Salakh en langs de stranden.

GEBR. - De wortel en het onderst gedeelte der steng worden in stukken gesneden, gyedroogd en in Bongalen onder den naam van Pippula moola als gencesmichdel verkncht; rolgens Rumphius wordt cen drachme ran het poeder des wortels met klipperwater als tegengift bij sommige rergiftigingen gebezigd; drinkt men dezelve met flor: Chamomilla afgetroklen bij gastricismus; kanuwt men de fijnere worteltjes bij tandpijn en zoude het sap der stongols bij waterzucht werkzaam zijn. Hot meest wordt ran dezo plant echter de vrucht geloruikt, zijnle deze de zoogennamde lange peper, welker aanwending zoo huishoudelijk als gुeneeskundig met die der zwarte peper overeenstemt. Bijna alle pharmacologen houden haar voor sterker dan de zwarte, Cullen en Bergius beweren erenwel het tegendeel; zij dient dikwijls ter bereiding der Piperine. Hasskarl geeft aan, dat de vruchtjes gestampt, en met suiker en water tot eenen aangenamen eenigzins priklelenden drank toebereid worden, welke op de bazars bij het glas verkocht wordt; ook worden zij fijn gestampt, vermengd met aluin, plassarie (Alijxia stellata) en banglaai ('Zingiber gramineum), en daarmede de buik ran kraamvrouwen ingewreven; eindelijk wendt men ze nog uitwendig bij beenpijnen ann.

114. Вот. Nrr. - Piper betle L (Chavica betle Miq.)

INL. BEx. - Seureu S; Sirie II; Socro J; Basse Bali; Leko Mak; Ammo, Amme en Ammelaun Amb; Kamoel en Tramelaun $\mathrm{Ht}$; Bido marau $\mathbf{T}$ en Lauhio $\mathrm{Ch}$.

Gr. PL. - Op bijna alle deze eilanden, soms in het wild, meer echter aangekweekt.

GEBr. - Vermongd met kalk, pinangnoot on tabak leveren de bladeren dezer slingerplant de bekende betelpruimtjes, welke op deze eilanden algemeen zon door mannen als rrouwen worden gebruikt, maagprikkelend werken en den adem cenen aangenamen geur mededeclen, voor het oog van Europeanen echter door het roode speeksel en het donker kleuren der tanden een walgelijk gezigt opleverende. Het sap der hladeren werlit bij hen, welke 
aan derzelver gebruik niet gewoon zijn, als een ligt vergift, veroorzakende bij het inslikken duizeligheid, zamentrekking en ontvelling ran mond-en keelholte, tijdelijk veriies van smaak. Endlicher noemt een misbruik van het siriekannwen zeer schadelijk voor con vroeger krachtrol mensel of rolk. De inlander beschouwt de sirie niet alleen als lekkernij, even als de Europeanen de tabakspijp of sigaar, maar kent ook door bijgeloof aan let siriesap in vele ziekten eene buitengewone geneeskrachtige werking toe, bestaande de anwending in niets anders dan in het herhaald besmeren van verschillende ligchaamsleelen met dit roode rocht onder het prevelen van verschillende spreuken.

115. Вот. Nır. - Piper diffusum Vhi.

INL. BEx. - Kasoh, Karok en Karoek S; Bode, Podo-podo en Socroevan J; Sirie dingin en Sirie oetan dingin II; Kralambouw Mak; Ammelau abber mamare en Ammelau tallan mahina Amb.

Gr. PL. - Op Java en omliggende eilanden in schaduwrijke en bergachtige streken.

Gebr. - Ook deze bladeren kunnen in plaats van siriebladen geknauwd worden: hun sap zoude bij dijsurie en gonorrhoea hcilzaam zijn; uitwendig bezigt. men ze met water fijngewïeven als zalf bij hoest en op den buik ingewreren bij koorts en kolijkpijnen. De rruchten, vermengd met adas (Anisum vulgare) on poelassario (Alijxia stellital) en met water fijngewreren, worden ingenomen tegen ingewandswormen en hoest.

\section{CASUARINEAE Mrbl.}

116. Bot. Nir. - Casnarina muricata Rxb. (C. equisetifolia Frst.)

Iru. BEx. - Tjamara laut NI; Tjômôrê J; Krajoe merak Bali; Kajoe angin M. \& Mak; Angi-angin Mak; Aijsamara Amb; Lour Lt; Louewul Lh; Kinllehur IBd; Ureul Cr'; Liluwi 'T'.

Gr. PL. - Afrika, Hindostan, de O.J, Moluksche en Philippijnsche eilanden, N. Holland. Op Java bij Tenger, Lawoe en veel in tuinen.

Genr. - IIet hout, dat rast, harl, sterk, fijn, rood, cenigzins welriekend en duurzaam is, dient veelal voor scheden ran 
wapens, lansstceien, strijukolven, enz, is ook geschilit voor brand-w hout, gevende eene felle hitte en goede kolen leverende. De bast des booms is ligt zamenstrekkend en wordt een afkooksel van dezen als tonicum aangewend. Blanco zegt dat dezelve bij partus zoude werkzaam zijn, de menstruatie bevorderen en het afkooksel nuttig zijn bij haemoptijsis. Rumphins geeft aan dat de inlanders met het afkooksel hunne ledematen inwrijven tegen verlammingen, vooral tegen beri-beri; dat de Makassaren dit drinken bij buikpijn en zij de vruchten met water fijngowreven op het voorhoofd leggen bij hoofdpijn.

\section{MORLAE Findl.}

117. Bor. NM. - Morus indica L.

IYr. BEY. - Bebesahran gedeh S, Bobossaren, Krajoe bobosjaren en Kajoe besaar M; Zong-zaij Ch.

Gr. PL. - Oost Indie, op Java meestal in bebouwde strekeu.

Gebr. - Van dezen boom, van welken Geiger zegt, dat denzelve eenigzins op $\mathbf{M}$ : alba gelijkt, van welken hij door zijne eivormig-langwerpige bladeren verschilt, en dat hij de nu in onbruik geraakte Rad: Lopez leverde, worden de bladeren en viuchten gebruikt. De bladeren dienen tot voedsel voor de zijdewormen en worden ook door de inboorlingen afgekookt als groente gegeten, zullende deze bij vrouwen de zogafscheiding vermeerderen en bij jongo kinderen het rormen van graveel tegengaan; ook de vruchten zijn eetbaar, zuur, doch min smakelijk. Nog vermeldt Rumphius dat do wortel of schors gekookt met adas, plassaric en sandelhout haematurie en gonorrhoe zoude genezen.

118. Вот. Nir. Broussonetia papijrifera Vent.

IYL. BEX. - Diloewang M; Saaij J; Kendong J; Woo Cel; Mala Huom.

Gr. pu. - China, Japan, Java in bebouwde streken en op de Zuidzee-eilanden.

119. - Broussonetia papijrifera Vent, variet. Japonica.

GR. PL. - Japan, op Java in den tuin te Buitenzorg.

GEBr. - De bast des booms, welke zeer taai en hard is, wordt afgeschraapt en gespleten om tot bindtouw te dienon, meer ech- 
ter wordt zij op Jara rerwerkt tot papier of tot grove klechingstuklen, die door klopping uit lawr bereid worden; dit javaansche papier is echter zcer grof en graamrachtig; in Japan schijnt men dit fijner en witter te maken, ten minste wijult Kaempfer zeer uitroerig uit orer ileszelf's bereiding en comt hij rijf soorten van hetzelve op (1). De viuchten zijn eetbaar, sappig, doch smakeloos zoet.

120. Bот. Nir. - Fieus lucescens Bl.

INL. BEN. - Loa S.

Gebr. - Ifet hout is grof, ligt en roodachtig en dient tot het maken vau keukengereedsehappen, als doelangs enz. Het melksap bezigt men tot vogelvangst. De bladeren worken dikwijls gegeten bij rergiftiging met loetjoebong (Datura Sp. div), ook drinkt de inlauder cen afkooksel ran bladeren en vruchten tegen buiklnop. De vruchten zijn eenigzins zoet, niet lekker van smaak en worden raauw als roedjak gegeten.

121. Вот. Nu. - Ficus allutacea BI.

Ixц. DEx. - Kiara lentick S; Iritjiat II; IÍondan J; Awar-awar Bat.

Gr. PL. - Jara, rooral aan den Salakh in rochtige \$osschen.

Gebr. - Het melksap) nit de bladstelen wordt bij doof'heid in de ooren gedruppeld. De schors en bladeren worden met watex grokookt, en gaat de inlunder bij knortsen, rerkoudheid, enz boven den damp ran lict water zitten om in zweet te geraken. De gedroogde bladeren worden als taluk gekorren, met opium rermengd en dan gerookt. De rruchten bezigt men als braakmiddel, men eet daartoe van 10-20 stuks.

122. Bот Nr. - Ficus' benjamina I.

IrL. вEx. - Kiara jajara S; Wariengien MI; Gagawaij?

Gr. pl. - Oost Indie, op Java, Sumatra, Borneo, Celebes enz. reelit in bebourwle strelien, langs wegen en pleinen, op grafplaatsen enz.

(1) Zie Thunberg, flora japonica, pag $72 \& s q q$ 
Grenr. - Deze statige boom wordt door den inlander geplant op alle plaatsen, welke in zekere eerbiedige vereering staan, en dient reele pleinen door zijnen breedgetakten eu koelteverspreidenden kruin tot een waar sieraad; het sap dat zacht ran smaak is en waaruit caoutchouk kan verkregen worden, staat bekend als een werkzaam zacht-oplossend geneesmiddel. De rruchten zijn eetbaar, doch flaauw van smaak en door rogels zeer gezocht.

Boт. Nr. - Ficus elastica Rxb.

INL. BEx. - Kiara karet S; Kollêlet S; Kajoe karet M; Karet MI; Karet tapok M; Penaga Mand.

GR. PL. - Oost Indie; veelvuldig in W. Jara en Sumatra, bemint steenachtige gronden.

Gebr. - Het melksap van dezen fraaijen boom levert de alom bekende caoutchouk, en wordt verder als rogellijm en voor fakkels gebezigd.

124. Вот. Nus. - Ficus politoria Lam.

INL. BEX. - Ampelas lumboet S; Ampelas Ir, J, \& Bali; Dawon gossok MI; Wellat Ht; Itilat en Ila-a-un Lt.

GR. PL. - Op bijna alle O. J. eilanden.

GEbr. - De bladeren, welke zeer ruw op het annvoelen zijn, bezigt men algemeen tot het gladwrijven on politoeren van fijno houtwerken; fijngekneusd wrijft men deze bij hooflpijn aan het roorhooft in; het sap uit den stam wordt tegen buikloop ingenomen en ook door hen, welke aan mocijelijke urienlozing lijden, des morgens nuchteren gedronken.

125. Вот. Nı. - Ficus hispida L. (Covellia hispida Miq).

LrL. BEx. - Bisoroh S; Bunjieng bisoroh S; Moessoe Amb?; Dongdong Mind.

Gr. PL. - Op de moeste dezer eilanden in beschaduwde vochtige streken.

Gebr. - De inlanders tappen het sap uit den stam digt bij den wortel af, bij wijze van toeäk, drinken het bij koorts en diarrhoe on bezigen het ook op wonden. De bladeren worden raauw of ook bij visch gekookt gegeten. Op Bali wordt de vrucht dikwerf genuttigd, doch op Java gecft men steeds ze met dedak gemengil aan cenden om deze meer eijeren te doen leggen. 
126. Bот. Nн. - Ficus japonica Bl.

INL. BEx. - Bunjieng S; Hamoelcêhkeng MI; Ramokêkes MI.

Gr. PI. - Buitenzorg, is derwaarts uit Japan overgezonden door Dr. Siebold onder den naam van F: erecta.

Gebr. - De blideren fijngewreren met adas (Anisum vulgare), poelassarie (Alijxia stellata) en kokosolie worden nitwendig gebezigd bij die ziekte der voeten van den inlander, welke lij sakit blâh noemt.

127. Bот. Nir. - Ficus coronata Rwdt.

IrL. BEY. - Ampelas badak S; Amies mata II; Oeja-oeja-an J.

Gr. PL. - In boschrijke en bergachtige streken van Java.

Gebr. - De bladeren bezigt men tot het polijsten van houtwerken; gedroogd en fijngesneclen worden zij metopium vermengd en gerookt; men geeft ze ook aan kraamvrouwen te eten, en wendt ze fijngekneusd uitwendig op den buik of lendenstreek aan bij kolijkpijnen (sakit proet moelas). Het sap des stams of wel een afkooksel van het jonge loof drinkt men bij kolijkpijnen. De vruchten worden gegeten.

\section{ARTOCARPEAE End!.}

128. Bot. Ny. - Antiaris toxicaria Lesch.

Ivt. BEx. - Pohon Oepas NI; Antsjar J; Ipo of Hijpo Mak.

GR. PL. - In digte bosschen op Java, als bij Japara, Ngungrungan, Passaroeang, Malang, Banjoewangie, verder op Sumatra, Bali, Borneo, Celebes, 'Timor, de Philippijnsche eilanden.

Gebr. - Het melksap van dezen zeer giftigen boom stelt het nit vele handboeken reeds belsende pijlvergift der O. I. eilauden, rooral der Makassaren, daar; het wordt door insnijdingen nit den stam verkregen en gewoonlijk vermengd met de fijngetvrovene wortels van Kaempferia galanga $\mathrm{L}$, van Zingiber casumunar Rxb en van Nampol (eene plant behoorende tot de Nat. Fam. der Aroideae). Anderen roegen hierbij nog eenige aronatica en acria, als de wortel van Alpinia malaccensis Rse, het zaad van Piper nigrum $\mathrm{L}$, on eenige rruchten van Capsicum fru- 
rescens I. Deze massa wordt, innig vermengd en goed fijn rerdeeld, beward in bamboezen kokertjes en datrmede de spitsen der pijlen besmeerd. Rumphins geeft eindelijk nog aan, dat dit sap, nog niet met de opgesomde middelen vermengd, onschadelijk zoude zijn, en als zoodanig zelfs een tegengift tegen den beet van eenige visschen. Vercler somt hij tegen het pijlvergift negen in gebruik zijnde tegengiften op. Zie verder omtrent dezen zoo giftigen boom uitvoeriger.

Rumphius, Amboinsche kruidboek DI II p. 253 \& Sqq.

Blume, Rumphia, Dl I p. 46-59.

Enellicher, Encheirid. botanic. p. 168.

Geiger, Pharmac. Botanik Dl II p. 314.

Pereira, Materies medica DI II p. 267.

V. Hasselt, Vergiftleer DI II en anderen.

129. Вот. NıI. - Artocarpus integrifolia L.

Ixt. Bex. - Nangka S \& M; Poessar J; 'Tat-wel Bali; Rappotsjidoe Mak; Ambi T.

Gr. PL. - Op alle Oost Indische-en Zuidzee-cilanden, op Ja$\mathrm{ra}$ in bergstreken, doch meer aangeplant.

Gebr. - Het sterke, zware, grore en geele hout bezigt men roor huisbouv, meubelen en fijne houtwerken, men gebruikt het ook voor buffelschellen en blokken in de wachthuizen, om dat het een zeer schel geluid gceft. De bladeren dienen even als dic ran Ampelas tot het polijsten van hout, nog jong zijnde worden zij ook door kraamvrouwen als groente gegeten. Het melksap bezigt men tot de vogelvangst. De rijpe rruchten zijn als nageregt door relen bemind, onxijp worden zij ,afgekookt als groente bij de rijst genuttigd; de rijpe zaden eet men bij wijze van kastarjes raauw en geroost, ook maakt men er soms eene soort van brood van, hetwelk zeer voedzaam is.

Rumplius zegt eindelijk omtrent dezen boom nog. "Op MIa"labar en Ceijlon grocit ook uit hetzelve sap, bij en omtrent de "wortelen in de aarde, een tuber of knolle, in het Portugeesch "Ista de Jaca genaamd, zijntle week en geel van binnen, en 't "welk die natie vonr een geprobeerde medicijn houden tegen buik"loop, doch men vindt ze maar bij weinig boomen en worden "nok te koop naar elders nitgevoerd." 
130. Boт. Nir. - Artocarpus caloplijilla Zoll \& Mor.

INL. BEx. - Boeroet S.

Gr. PI. - Java.

131. Вот. Nus - Artocarpus rigida Bl,

INL. Bex. - Boeroet S: Mandalika S; Poessar M.

Gr. pt. - In bergachtige streken bij Buitenzorg. 'Tjiandjor, Krawang.

Grbr. - Volgens IIasskarl worden de klevige sappen met was vermengd en gebruikt tot het verwen van klecljes (batikl kajin). IIet hout wordt als dat ran Nangka (129) gebezigd. De vruchten zijn zuurachtig zoet en aangenaam om te eten.

132. Вот. NM. - Artocarpns incisa L.

Ixt. BFy. - Tiemboel MI; Sockkoen MI; Kloewie MI; Gomo T on Men.

Gr. pt. - Zuid Amerika, de Zuidzeo-eilanden, Molukko's, Oost Indie, op Java reelal in bebouwde streken.

Gerr. - Deze boom is door zijnen smakelijken en reel zetmeel bevattenden rucht roor de bewoners der 'Zuidzce-cilanden hetzelfcle, wat de graanviuchten voor den European, wat de rijst voor den Javaan is; zij wordt door hen dan ook veelvuldig anngekweekt, en zijn er door kultuur vele rerscheidenheden van ontstaan, ran welke de kernlooze de het meest gezochtste is, omdat deze meer vruchtvleesch dan de andere bezit; de eigenlijke in het wild groeijende broodboom heeft groote zaden, welke als kastanjes smakeu. Volgens Meijen zijn drie boomen toereikende om cen' mensch gedurende acht maanden to voeden. Men eet de nog niet geheel rijpe vrucht, welke geroost of gebakken, omtrent als ons witbrood zal smaken; ook wordt door gisting en opvolgend bakken uit haar een roedingsmiddel bereil, niet ongelijk aan het Westphaalsche zwarte brood. Op Jara waar deze boom, door het overgroot antal andere roeclingsmiddelen, bijna overbodig is, worden de vruchten geschild, met onderscheidene kruiclen te zamengekookt en bij de rijst genuttigd; bezigt men zijn melksap roor lijmstokjes bij de vogrelvangst, en worden de oude bladeren na boven het vutur geroost te zijn, met water fijngewreven en daarna uitwendig aangewend tegen vergrooting der milt (sakit koewaija). 
133. Вот. Nur. - Conocephalus suaveolens B1.

IYL. BEx. - Kakegoan aroij S; de mannelijke plant Aroij kakeedjoan S, Kállas J; de rrouwelijke Aroij luksa S en Gestó J.

Gr. PL. - In vochtige kreupelbosschen der Preanger-regentschappen, Banjoemaas, Patjitan, Kedirie en Soerabaija.

Gebr. - De bast of liever de jonge stengels dezer slingerplant bezigt men als touw om te binden.

\section{URTICACEAE Endl.}

131. Bot. Nar. - Urtica baccifera L.

Gr. PL. - Philiplijnsche eilanten, op Java in sommige tuinen.

Geir. - Blanco zegt van deze plant alleen, de vrucht heb ik gegeten, dozelve is wit, doorschijnend en gelijkt eenigzins op eene moerbezie.

13ว. Вот. Nrr. - Urtica ovalifolia Bl.

Irt. BEx. - Poeloes badak S; Poeloes djelatong S; Dawon gatel MI; Dawron seetan ML; Polot, Polat, en Aij polut Amb; Daulassi $\mathrm{T}$; Salattan $\mathrm{Bd}$.

Gr. PL. - De geheele O. I. Archipel.

GEBr. - Hare groote bladeren verwekken op de huid een jenkend, hevig brandend gevool, waarom zij zeer dikwijls als priklielend middel nitwendig bij verlammingen enz. aangewrend worden. Dit bijtend vermogen hangt volgens Endlicher bij de Urticasoorten af van eene eigenaardige stof, welke ontstaat in de onder de opperhuid annwezige haarvormige klieren, en zotude deze stof roornamelijk bi-carbonas ammoniae zijn. Nog wordt op Java de stam met water geklopt en dit in het water geworpen, wantoor als dan de visschen zouden bedwelmd geraken.

136. Вот. NıI, - Urtica ardens $\mathrm{Bl}$.

IVL. BEx. - Poeloes malella S; Poeloes malaba S; Dawon gatel, D. seetan en D. kemadoe M.

Gr. PL。 - Java.

Gebr. - De bladeren in stam bezigt men als de rorige soort, de eerstc zijn echter meer in gebruik; nog wordt het sap, dat door insnijding uit den stam wordt verkregen, bij ougontstekingen in de oogen gedruppeld. 


\section{AN'TIDESMIEAE Sweet.}

137. Вот. Ny. - Antidesma bunias Sprg.

INL. Bex- - Hunie of Hoenic S \& MI; Hoenie djaheh S; Boenie karambou $\mathrm{J}$; Katti koeta of Koeti kotta B:tt; Boeuie karbo Mak.

Gr. PL. - Meestal in vochtige bewoonde plaatsen.

Gebr. - Volgens Endlicher zijn de vruchten ran de meeste Antidesmeae aangenaam zuu, eetbaar, haren smaak nagenoog gelijkende op die der vruchten van Ribes- en Berberissoorten. De jonge saprijke bladeren van A. bunias $L$ zijn zuur bijna als die van zuring, worden met andere groenten gekookt gegeten en zijn geroemd on hare zweetdrijvende eigenschappen tegen sijphilitische aandoeningen. Op Java eten koebeesten gaarne de bladeren, nuttigt de inlander ze raauw of gekookt, mengt hij ze in verschillende zweetdranken, en geeft hij ze, om hareu zamentrekkeuden smaak, met zout en trassie (een stinkend mengsel uit garnalen en kleine visschen bereid) aan vermagerde en door ziekte uitgeputte menschen. De rruchten worden raauw gegeten, of ook met visch gekookt om dezen eenen zuren smaak mede te deelen.

\section{CHENOPODEAE Vent.}

138. Bot. Nir. - Basella cordifolia Lam.

INL. BEY. - Gandoola burrum S.

Gr. PL. - Malabar, op Java veelal in tuinen.

Gевr. - IIet loof dezer slingerplant wordt door rele indische rolkeren en ook op Javi, gokookt bij wijze van spinazie, als groente gegeten. De Jaraan wrijft het met djaroeng boddas (Barleria multiflora IIsskl.) en water fijn, dient het als dan inwendig toe bij buikloop of bezigt het uitwendig tot inwrijving zijner ledematen bij rheumatische en andere beenpijnen. Volgens Rumphius zonde het zacht ontlastingberorderend werken en volgens Blanco de vruchtbaarheid der vrouwen zeer berorderen. De saprijke, roodvleezige bessen bezitten eene roode, weinir rasthoudende kleurstof; $n p$ Jara dienen zij fijn- 
gestampt en na bijroeging van een weinig meel van ketan (Orijzal glutinosa) tot kleuring vau konfituren, gebak enz.; in Japan beclient men zich van dezclve tot het roodverwen van aardewerk (serico) en katoen.

\section{AMIARAN'CACEAE RBr.}

139. Bot. Ny. - Gomphrena globosa L.

INL. BE.. - Radna poetic ML; Boenga knop MI; Rabna bakadja $\mathbf{J}$; Adas-adassan J.

Gr. pL. - Oost Indie, 'Timor, China, Japan, de Societeits- oilanden, Brazilie en in geheel Europa, op Java in tuinen.

Gebi. - De bladeren leveren een smakelijk moeskruid, zijn gezond en behooren tot de openende, oplossende gencesmiddelen; de bloemen dienen tot versiering.

140. Bor. Nur - Aërva sanguinolenta BI.

IVL. BEN. - Katoempang burrum S; Gondang kassé J.

Gr; PL. - Rondom Batavia in tuinen en in het wild, Timor, Amboina en Spaansch Amerika.

GEbr. - Volgens Rumphius mengen de javaansche doekoens dit kruid onder verschillende djamoes, welke zij in-en uitwendig bij haematurie en gonorrhoea aanwenden.

141. Bот. Nyr. - Amarantus tricolor L. (Amarantus melancholicus Moq. var. $\beta$. tricolor Lam.)

IrL. BEx. - Sengang burrum $s$; Scngang meirah S; Bajem meirah M.

Gr. PL. - Perzie, Ceijlon, China, Japan, de Zuilzee-eilanden; Zuid Amerika, op Java meestal in tuinen.

Gerr. - Tegenwoordig is nog hier en daar, doch vooral vroeger was het kruid als oplossend middel officineel, onder den narm van herba Amaranti tricoloris s. Gomphrenae sijmphoniac.

142. Вот. Nur - Amarantus spinosus I.

IxL. זEx. - Sengang tjoetjock S; Bajem doerie MI Bajem oetan M; Bajem monjet MI.

GR. PL. - Tropisch Azie, Afrika en Amerika; op Java veelvuldig in onbebouwde streken en in tuinen.

Gribr. - Ilet kruid wordt op Jamaika en ook in deze gewesten soms als groente gegeten; in de Moluklo's bezigt men den wortel tegen tandpijn. 
143. Bот. Nrr. - Celosia cristata L.

IXL. BEx. - Jaw: Rottok S' Jawer ajam MI; Rara aijam MI; Bajem cjlor loetjing MI Her J; Bangon bangon nabara Mand; Serewoeng Men.

Gr. PL. - Oost Indie, Nepaul, Japan; op Jara in let wild en in tuinen.

Geвr. - Van deze sieraadplant wordt door de inboorlingen het kruid als groente genuttigd en in Azië liare bloemen, welke zamentrekkend zijn, tegen diarroeac, blennorloeae, overvloedige stoudenvloed, bloedbraking en dergelijke ziekten aangewend.

NIJC'TAGINEAE JsS.

144. Bот. Nu. - Mirabilis jalappa I. var. flore coccineo.

145. " " " " L. " " purpureo.

146. " " " " . " " "luteo.

Irx BEx. - Kembang pagi soreh Mi; Kemhang soreh MI; Kémbung poekoel ampat M; Boenga waktoe ketjil hl; Ditron passar soreh MI; Katigret J; Notja en- Kembang nolotja J \& Bali.

GR. PL. - Is waarschijnlijk uit Peru afkomstig, doch nu ook in Mexilio, N. Granada, Martiuique, Mruritis, Cochin- china, 'Timor en Japan; op Java in tuinen veelvuldig.

GEbr. - De wortel dezer plant, welke in Europa slechts eenjarig is, doch in warme Iuchtstreken lange jaren blijft roorlgroeijen, hield men lingen tijul roor den echten Jalappawrortel, welke echter van cene Convolvulacea (Îjomoca jalappa Pursh.) afkomstig is; oud zijnde gelijkt hij zeer op den echten, werkt minder sterk purgecrend dan deze, heeft eenen minder walgelijken smaak en wordt somtijds nog bij hijelrops tocyediend. Do Japannezen maken viln de zarlen een wit blanketsel, dat lumne vrouwen reel bezigen; ook op Jara en Sumatra rorelt dit reel gebruikt, en daartoe de zaden van lumne schil ontclaan en fijngerreven,

\section{LAURINEAE Endl.}

147. Boт. Ny. - Ciunamomum Zeijlanicum Nees. 
1xL. res. - Kiamies S; Kajoe manies Mr; Tíajoe manies djangan M; Keninga J.

Gr. PL. - IIindostan, Ceijlon, China, op Java aangekweckt.

Gebr. - De bast van dezen boom is de beste kaneel van den handel. Gedroogd zijnde, bezight de inlander ze als specerij bij zijne spijzen en bij vele geneesmidtlelen; volgens Hasskarl drinkt hij de bladeren als thee afgetrokken; zijn de bittere vruchten door rogels zeer gezocht en kumnen zij tot het maken vin kaarsen gebruikt worden.

148. Вот. Nu. - Cinnamomum aromaticum Nees.

INI. BEx. - Kajoe manies tjina Mr.

Gri. PL. - Is uit China naar Java overgebragt en aldaar kultuurplant.

Gebr. - Deze boom levert de cortex Cassia lignea van den handel, welker huishoudelijke en geneeskrachtige anweuding dezelfde is als die van kaneel.

149. Вот. Nзг - Persea gratissima Grtn.

IYL. BEN. - Djamboe wolanda Mr; Apolat MI.

Gr. PL. - West Indie, Zuid Amerika, naar Java in tuinen overgebragt.

Gebr. - De vrij groote, groenachtige rrucht, in West Indie onder den naam van Advogado-peer bekend, heeft eenen aangenamen smaak en wordt door menschen, zell's door sommige huisdieren gaarne gegeten; daar het vruchtvlecsch eenigzins olieachtig en zeer week is, smaakt zij gewoonlijk den nieuw aangekomen Europeaan in den beginne niet, wanneer hij dezelve echter een paar malen goed toebereid met MIaderawijn en suiker, of met zout en peper gegeten heeft, verkiest hij haa spoedig boven andere tropische vruchten; waarschijnlijk hangt hare eigenaardige smaak van eene vette olie af; wanneer de keru slechts eenen dar nit de rleezige rruchtmassa genomen wordt, verliest zij rectls hire kiemkracht.

150. Вот. Nуг - Tetranthera multiflora Nees.

INL. BEN. - Poespa S; Hoeroe batoe S; Kipapak S.

Gr. PL. - In bosschen op den Salakh en Gedeh.

Gíbr. - Van vele Tetrantherasoorten is het lout ligt, wordt weinig door insekten angetast en daarom als bouwhout gebezigd. 
Cit de rruchten van eenige kan door drukking een op was gelijkend vet bekomen worden, waarvan de inboorlingen kaarsen vervaardigen. De jaranen bezigen een aftreksel der bladeren en ook soms van de welriekende bast inwendig tegen koortsen; met het sap der fijngekneusde blarleren wrijven zij zich het ligchaam in om te zweeten.

151. Вот. Ny. - 'Tetranthera japonica Spr.

LYL. BEN. - Hoeroe djapan S.

Gr. PL. - Schijnt uit Japan naar herwaarts te zijn overgebragt.

\section{DAPHNOIDEAE Vent.}

152. Bot. Nı. - Dais dubiosa Bl.

KYL. BEN. - Kakapassang S: Godong lameh S; Dawon blibinam $M$; Kampang garang $M$.

GR. P'L. - In bergachtige bosschen van Java en Noesakambangan.

GERR. - Ontrent dezen boom heb ik niets vermeld gevonden, wel echter ran Dais octandia L, waarmede hij veel overeenkomt; van dezen worden de bessen door de Javanen als emetica on purgantia aangewend:

\section{ARISTOLOCHIEAE Endl.}

153. Bот. NM. - Aristolochia indica L.

INL. BEx. - Akkir poeloe ron MI; Tuhe tuttunu of Teboe toettoenoe $\mathrm{Bd}$; Bessa magoemie $\mathrm{T}$; Wallas J.

GR. PL. - Hindostan, de Mroluksche archipel.

Gebr. - De wortel dezer plant, radix Puloronica door Rumphius genoemd, wordt in Indie als rolksmiddel en tegengift geroemd en aan hem nagenoeg dezelfde of gelijke krachten toegekend als aan rad. Serpentariae virginianae. Daar hij zeer bitter is, wordt een aflooksel aangewend tergen buikpijnen en tusschenpoozende koortsen, als diureticum bij waterzucht en graveel, en eindelijk in Hindostan verondersteid tegen jicht en als stondendrijrend middel goede diensten te kumnen bewijzen. 


\section{PLUMBAGINEAE Vent.}

151. Boт. Nu. - Plumbago rosea $L . ~=$ P. coccinea Boiss. IXr. BEx. - Djaroeng burrum S; Hamproe lemah S; Aklkar binassa M; Tjintekka J; Ḱmbaug gennie J; Ajjokkol ketjil Amb; Bama T; Nchodatoe on Nehoctana haue Ht; Kajoe auwaran IB.

Gr. PL. - China, Java en verdere O. J. eilandeu.

GEuk. - Van deze plint, welke in Hindostan geroend wordt. cen tegengift tegen verschillende vergiflingen te zijn, kan de wortel door ziju scherp sap, zeer good de plaats van audure blaartrekkende middelen vervullen, daar hij reeds na 6 á $S$ uren blaren veroorzaalst; bij hooftlijn wordt ze ook veel voor het roorhoofd gebondeu. Omtrent deze huidprikkelende eigunschap vermeldt IIorsficld; "hij is na de kellorwortel (NLoringa pterijgosperma Girtu) de roornaanste dezer klasse, op de huid angewend brengt hij bijna dezelfde uitwerksselen als de Cantharides te weeg; hij schijnt meer ontsteking en pijn te veroorzaken, doch minder uitzweeting rau wei; ik hob gewoonlijk ene sterke rnodheid en ook uitstorting ran bloed zien ontstaan na de aanwending van den verschen wortel. De $\mathrm{P}$. europea is reeds in vele materies medican vermeld; zij barit dezelfile ojwekkende eigenschampen en wordt hoofdzakkelijk plaatselijk aangewead bij tandpijn." De inlanders geven ook cen afkooksel der wortels to drinken aan zieke paardon, om deze vet en glanzend te maken,

155. Вот. NM. - Plumbago auriculata Lam $=$ P. capensi: Thub.

LxL. BEy. - Djaroeng blaauw S; Seriwan M.

Gr. ru. - Kaap de goede hoop, Natal, MLauritius, Oust Indie. Assam, op Java in het wild en in tuinen.

GEsR. - Sieraalplant.

\section{COMPOSITAE Vaill.}

156. Boт. Nм. - Elephantopus scaber L.

IXI. BEX. - Tjangtjang s. Tjangtjeng S.

Gr. Pr. - Oost Indie, Nepanl, Silhet, Luznn, Timor, op Ta. va langs de wegen en in weilanden. 
Gris. - De geheele plant, doch meestal slechts de in stukken gesnedene wortel, wordt afgekookt en gebruikt als versterkend en de minnedriftwekkend middel; om aan het laatste doel te beantwoorden wordt zij rermengd met de fijngewrevene wortel van kawoeng (Sagguerus sacchariferus BI.), djoekoet biliilan (eene Graminea), adas (Anisum vulgare L.) en poelassarie (Alijxia stellata $\mathbf{R} \& \mathrm{~S})$. In koud water afgetrokken, wordt dit dikwijls tegen ehronische buikaandocningen en spruw toegediend. De bladeren worden in stoom gekookt en als groente genuttigd, staan als genezend bedeksel vin huidzweeren bij de inlandsche bevolking in goeden naam en worlen dikwijls aan paarden tocgediend tegen hoest, ontstaan door verkouding of vermoeidheid.

157. Вот. NII - Ageratum conijzoides L.

IrL BEN, - Djoekoet baauw S; Babadottan S.

Gr. rL. - Tropisch Amerika en Afrika, Madera, Mauritius, Oost Indie, de Sandwichs eilanden; op Java in het wild.

GEBR. - Het kruid wordt door sommigen als groente gegeteu; de gedroogde wortels in plaats ran thee afgetrokken en gedronken; met de met water fijngewrevene wortels wordt het lighchaam ingervreven bij vermoeidheid, gevatte koude of koorts.

158. Bor. Ny. - Eupatorium celebicum $\mathrm{Bl} \sqsubseteq$ Vernonia celebica Dc.

Gr. PL - Op Celebes in bosschen.

159. Вот. Nлг - Aster indicus L.

IVL BEX. - Kembang aster M.

GR. PL. - In vele tuinen op Java als sieraadplant.

160. Вот. Nir - Blumea macrophijlla Dc.

IVt. IBEY. - Semboeng lalakki S.

Gr. PL. - Op Java reelvuldig in bergstreken langs beekjes.

GEBr. - De wortel wordt in water geweekt en hiervan alle morgen een kopje gedronken bij buiklijden, of wel zij wordt met adas en poelassarie fijngewreven en in poedervorm hiertegen toegediend, en ook aan kraamvrouwen ingegeven. De bladeren bezigt men als zweetdrijvend middel tegen koorts, en wendt ze uitwendig fijngewreven in den omtrek ran wonden aan. zoo als bij de besnijdenis. 
i61. Bot. Nir. - Blumea balsamifera De $=$ Plucliea balsamifera Less.

IVL BEN. - Semboeng aweweh S; Soemboeng M, J \& Bali; Aijlaun tahina Amb; Madikapo T.

Gr. PL. - Oost Indie, Cochinchina, Luzon, op Javàen elders in klei-en steenachtige gronden.

Gebr. - Van deze plant, omtrent welke al het bij de voorgaande aangegevene ook van toepassing is, merkt Rumphius aan: " men mengt de bladeren met andere kruiden of kookt ze alleen "en gebruilkt ze bij buikpijn door winden of koude reroorzaakt, "men maakt vau dezelve warme stovingen bij beri-beri, en bij "diegenen, welke slap en lang ziek geweest zijn, waarop ecn "wakker zweeten volgt, doch moet ze niet bij koortsige of uit" tecrende lijders gebruiken. Tot het eerste bad bezigt men sem"bong, lagondi (Vitex trifoliata L), wilde guajavos (Psidium " guajara Rddi) en limoenbladeren. Op Bali mengt men de bla"deren met het sap van poele (Alstonia spectabilis $\mathrm{RBr}$ ) en dawon " koentoet (Paecleria foetida L.) en geeft dit bij buikpijn, wor"men. Het afkooksel der bladeren verdroogt de overvloedige "maandstonden." Horsfield heeft van deze plant de volgende beschrijving gegeven: "eene plant van eenen aangenamen balsem") achtigen geur; de smaak is prikkelend; hare opwekkende "hoedanigheden zijn gepaard met eene groote hoeveelheid slijm. "Een warm aftreksel werkt vrij goed als diaphoreticum en wordt "zeer algemeen zoo door Javanen als Chinezen aangowend als " een borstmiddel. Verschillende geneesheeren te Samarang heb" ben mij verzekerd dat het standvastig gebruikt wordt bij borst"pijnen, catarrhus, enz."

Blanco eindelijk schrijft ran de Philippijnsche eilanden dat aldaar de inlanders hetzelve veel, vooral bij ziekten van vrouwen bezigen; in de handen eenigen tijd gehouden zoude het het beven dezer tegengaan.

Tegenwoordig worlt het in hospitalen veelvuldig anngewend als diaphoreticum en expectoraus, of ook als mondspoeling bij salivatic.

162. Bot. Ny. - Pluchea indica Less.

IVL. BEN. - Loentas M; Bloentas en Baloendas M \& S. 
Gr. PYo-Oost Indie, Poeloe pinang, Luzon, Java, Borneo, rimor.

GEur. - Du bladeren dezcr zijn eren als die der voorgaande plazt aromatisch en eenigzins priklelend, zij worken door sommigen afgekookt als groente genuttigel, meer echter als geneesmiddel, zijnde zij in baden en warme stoviagen uitwendig aangetrend ecae goede zenuwprikkel en inwendig toegerliend bij wijze ran thee afgetrokken een geschikt zweetdrijvend middel; reeds Horsfield raadi dezive zeer ter verdere proefneming aan om als surrogaat van andere middlelen bij, tle armere rolksklasse te worden gebezigd.

163. Bот. Ny. - Dahlia variabilis Desf.

GR. PL. - Mexiko, is uit Europa nar Java's tuinen overgebragt.

GEer. - Van alle Dalliasoorten, welke roor lhet eerst in 1786 naar Europa overgevoerd zijn geworden, zijn de knollen en stengels, tubera et caules Dahliae, in gebruik; hobben zij gekookt eenen aromatischen echter niet zeer aangenaam to noemenen smaak, zoo dat menschen ze nict grarne eten en zelfs paarden en rundvee ze niet lusten. De knolvormige uitzettingen der wortelvezelen, welke een stijfselaarlige stof (Dahline) eenigzins op Inuline grelijkende, eene aetherische olie en cene bittere aromatische stof bevatten, worden door de Mexikanen als zweet- en pischijvend middel aangeprezen bij kolijkpijnen, opzettingen, maagbezwaren, enz. In den jongsten tijd heeft Dr. Nauche te Parijs een afkookscl der knollen on stengels met melk rermengril tegen scrophnlenze longtecring amberolcn. Pa:jun raalt de klcurstof der violette blocmbladen als een zeer gevolig herkenuingsmiddel roor zuren en alkalien arn, dat de meeste andere blanuwe plantenkleuren in gevoeligheid zonde overtreffen.

164. Boт. Nx. - Spilanthes psendo-aemella L.

INI. BEx. - Jottan lumboet S; Dawon lada $\mathrm{iI}$; Sinelo goratsji 'i'.

Gr. PL. - Oost Inclie, op Java langs de wegen en in onbebouwde streken.

Gror. - Het kruid wordt fijngewreven mot atals, poelassarie en water en zon in- als nitwendig angewend hij rerschillende 
pijnlijke aaudoeningen, als beeupijnen, stijfheid der ledematen, kies- of tandpijn, enz. Volgens Rumphius geven de Arabische schoolmeesters hetzelve veelal aan hunne leerlingen, oin hen gemaklkelijker de Arabische letters te doen uitspreken, zijnde hetzelve scherp en bijtend op de tong.

165. Вот. Ny. - Zinnia elegans Jeq.

Gr. PL. - Mexiko; uit Europa als sieraadplant naar de tuineu op Java overgebragt.

166. Bот. Ny. - Helianthus annuum L.

IVL. BEx. - Kembang mata harie II (Zonnebloem).

Gr. PL. - Mexiko en Peru, is uit Luropa naar Java overgebragt en wordt daar in tuinen als sicraadplant gekweekt.

GeBr. - Hare groote, zoetc, als hazelnoten smakende zaden worden door kinderen gaarne gegeten, zij kunnen tot eene zeer smakelijke brei of pap gekookt worden; in Amerika worden deze gestampt en er eene soort van brood van gebakken of op andere wijze toebereid genuttigd, ook dienen zij tot voeder von vogels. Uit dezelve perst men eene zachte, zuivere en rette olie, Zonnebloemolie of ol. sem. Helianthi, welke bij spijzen, salade en tot het branden der lamp kan gehruikt worden. De jouge afgeschilde stengels en bloemknoppen kunnen als groente bij wijze van artisjokken gegeten worden.

167. Вот. Nıг. - Bidens L. Spec. 1.

Gr. pt. - Groeit op Java als sieraadplant bijna verwilderd in vele tuinen.

168. Вот. Nur. - Cosmea parviflora Wrlel = Cosmos parviflorus Hmbd. \& Bpl.

Gr. PL. - Mexiko. Als sieraadplant uit Europa naar Java overgebragt.

169. Вот. Nir. - Tagetes patula L.

INL. BEN. - Taai aijam M.

Gr. PL. - Mexiko. Is als sierplant tegenwoordig over bijna alle landen des aardbols verspreid.

170. Вот. Nu. - Tagetes erecta L.

Irt. BEx. \& Gr. Zie voren.

Gerr. - Geiger haalt van deze alleen aan, dat de onaangenaam riekende bloemen, Flores africani s. 'Tagetis, vroeger ofticined waren 
171. Bot. Nur. - Achillea squarrosa Ait.

IXL. BEN. - Tatter goenoeng S.

Gr. PL. - Japan; als sieraadplant op Java in vele tuinen.

172. Вот. Nגז. - Pijrethrum indicum Css.

Irt. rev. - Sarroenic wolanda M; Saronie M; Fiokhotie Ch.

Gr. PL. - China, Japan, Oost Indie, op Jara als sicraalplant.

GEnR. - De bloemen in water afgetroklen worden als ongwater bij pijnlijke ophthalmiëu aangewend (Rumphins).

173. Вот. Nur. - Tithonia tagetiflora Desf.

Gr. PL. - Mexiko. Op Java in tuinen als sieraadplant.

\section{LOBELIACEAE Brtl.}

174. Вот. Nм. - Lobelia cardinalis L.

Gr. PL. - N. Amerika, op Java in tuinen overgebragt.

Gebr. - Aan hare wortel, welke scherp en giftig is, worden wormdrijvende krachten toegekend.

\section{RUBIACEAE JSS.}

175. Bot. NII. - Coffea arabica L.

INL. BEN. - Koppi M \& S.

Gr. PL. - Gelukkig Arabie en Aethiopie, en ran danrals kultuurplant overgebragt naar Oost Indie en midden Amerika.

GErr. - Deze plant levert de bekende kofij en caffeinum. De inlanders bezigen als drank meor het aftreksel der bladeren, dan dat der boonen. (Zie nitvoeriger omtrent deze de rerschillende handboeken orer Materies Medica on Pharmacic).

176. Вот. Nм. - Pavetta macrophijlla Bl.

Ivt. BEx. - Moehoen boddas S; Mahoen S.

Gr. PL. - Op Java in bergachtige bosschen.

Grabr. - Vin eenigge Paretta-soorten zijn de haderen en bast, welke zuiver bitter zijn, met adstringerende en tonische krachten bedecld (Endlicher). Tan alle Pavetta-soorten worden stukkeii der tatken an het cene cinde gebrand, waartoor aan het tegenorergestrlde een sap nitloopt, dat men op ijzer laat vallen en alstan eene zwarte rerf geeft, om de tanden merle te verwen, 
zij wordt door ouderlom niet wit, zoo als die, welke men bij de Chinezen kan koopen (Hasskarl).

177. Вот. Nu. - Ixora incarnata De, flore roseo.

INI. BEx. - Sokka blaanw S; Santen djaroeng S; Sokka meirah Mr.

178. Bот. Ny. - Ixora incarnata Dc., flore albo.

Ixt. BEx. - Sokka horldas S; Santen djaroeng S; Sokka poetie M.

Gr. PL. - Beide op de Moluksche eilanden, op Java aangekweekt.

179. Вот. Nı. - Ixora javanica De.

INL. BEv. - Moehoen kahoeroewang S; Sokka koening Mr.

GR. PL. - Op Java in bergachtige bosschen.

Geisr. - Alle deze Ixora's verstrekken reelal den javaansche tuinen tot sieraad. Van I. coccinea vermeldt Horsfield dat de wortel ook huidprikkelende, blaartrekkende eigenschappen bezit, echter minder krachtig is din die van Plumbaga rosea $I$, dat hij ook bij tandpijn wordt aangewend, omdat dezelve de speekselvloed sterk bevordert.

180. Вот. Ny. - Canthium Rheedii Dc.

INI. IBEx. - Tjoetjoek kaliageh S; Toemboeng kanjoet S.

Gr. PL. - Malabar, op Java in tuinen.

Gebr. - De bladeren en bast ran sommige Canthiumsoorten zijn zuiver bitter en wordt hen eene adstringeerend-tonische kracht torgekcnd (Endlicher). De vruchten van sommige C. soorten worden afyekookt en bij de rijst gegeten, zij zijn aangenaam zuur, daarbij eenigzins wrang (Hasskarl).

181. Вот. Nм. - Paederia tomentosa Bl.

INT. BEx. - Aroij kahitoetan gedeh S; Aroij kahitoctan lumboet S; Kahitoetan S; Dawon koentoet M.

Gr. PL. - Op Java in bergachtige streken.

Grebr. - Van deze en andere Paederiasoorten, doch vooral van die der P. foetida Lam, welke in de MLolukko's vrij algemeen roorkomt, rerspreiten de bladeren, in de hand fijngewreven wordende, ecnen sterken reuk of liever stank, niet ongelijk aan dien door flatus veroorzaakt, ook door invlocd ran de zonnewarmte wordt de dampkring overvuld van haar onaangenaam aroma, waarom de inlander dan ook niet ten onregte aan deze planten 
den naam van dawon koentoet gegeven heft. Niettegenstaando dit echter eet hij dezelve gaame bij zijne rijst, en dient hij de fijngewrevene bladeren of wel het sap der stengels bij buikpija door flatulenti: reroorzaakt met goed gevolg toe, zoo uit als inwendig genomen. Volgens Lindleij bezigt men de bladeren in geneeskrachtige baden en. worden zij in aftreksel inwendig toegediend bij retentio urinae en koortsen. De wrortel bezit braakwekkende eigenschappen.

182. Bот. Ny. - Morinda citrifolia L.

IrL. BEX. - Tjangkoedoe S; Mangkoedoe en Mangkoedoe dawon bezaar MI; Menkoedoe Bd; Baija Mak; op Java heeten de onrijpe vruchten Pentis, de rijpe Patjeé.

Gr. PL. - Malabar, Pegu, O. I. Arehipel, hier dikwijls in tuinen.

GEBr. - De schil der wortels, volgens eenigen ook de bladeren, dient tot roode verfstof; zij wordt tot dit einde afyewasschen, gedroogd, fijngestampt en vermengd met sossabast (Leiocarpus fruticosus B1.) Met kalk fijngewreven wordt zij bij paarden op wonden gelegd, welke ontstaan zijn door het schuren der zadels. De jonge bladen worden raauw en gekookt bij de rijst gegeten; zij zonden ook werkzaam zijn bij diarrhoeae en kolijkpijnen, daartegen uit- en inwendig worden aangewend, en wonden spoedig heelen. De vruchten, van welke Blinco vermeldt, dat zij oud zijnde eenen zoo slechten reuk verpreiden, dat zelfs geen dier ze eten wil, worden zoo rijp als omrijp door de inlanders gegeten, zij zijn zuurachtig. Volgens Rumphius drinkt men deze, door een' doek nitgeperst en met een weinig lkalk gemengd, bij dijsurie, en zouden zij met azijn fijngewreven en gcdronken of wel raauw uit de hand gegeten opzwellingen der milt genezen. Bontius geeft aan, dat zij gebruikt worden bij dijsenterie, cholera, phthisis, pleuritis, haemoptö̈ enz. Eindelijk geven de Javanen nog de vrucht met eenig keukenzout te eten aan aamborstigen en bezigen zij haar tot het reinigen ran hun hoofthaar. (1)

(1) De te rroeg aan de wetenschap ontrallene pharmaceut der $3 \mathrm{kl}$. Van Heijningen heeft in 1851 uit deze plant getrokken eene groene kleurstof; zijn overlijden was oorzaak dat die gewigtige ontdekking tot dus ver geene volledige resultaten heeft opgeleverd. 
183. Bor. Nu. - Morinda bracteata Rxb.

Ixt. BEx. - Nrangkoedoe en Bankoedoe laki laki M; Koedue kras J; Tjangkoedoe kantjil J; 'Tiba Bali; Bengkoedoe Mak; Nenu en Neñoe keri Amb; Komi-komi ' $\boldsymbol{~}$.

Gr. PL. - O. I. Archipel, de Andaman, Moluksche en Philippijnsche eilanden; op Java in bergstreken.

Geur. - Behalve dat het hout voor vogelkooijen veel gebruikt wordt, en aan jouge kinderen de vruchten als wormdrijvend middel toegediend worden, zoude de aanwending dezer plant zoo geneeskrachtig als huishoudelijk dezelfle zijn als die der voorgaande.

184. Boт. Nм. - Manettia cordifolia Mart.

GR. PL. - Brazilie, van daar naar Java overgebragt en in eenige tuinen aanwezig.

Gerr. - De bast des wortels wordt in Brazilie geprezen als een heilzaam middel tegen hijdrops en dijsenterie, zij wordt in poedervorm in giften van eene halve tot anderhalve drachme toegedieud, werkt als een braakmiddel, en zoude de Rad. Ipecacuanhae kummen vervangen.

185. Вот. Ny. - Cascarilla muzonensis Weddel. $\models$ Cinchona muzonensis Goudr.

GR. PL. - Columbia, naar Java overgebragt.

GEBr. - Deze plant zoudle volgens Lindleij eene suort van echte kinabast opleveren, zij is echter nog onvolledig bekend.

186. Вот. Nr. - Gardenia florida L.

INL. BEN. - Katja piering M.

Gr. PL. - Oost Indie, China, Japan, Kaap de goede hoop, op Java in tuinen.

Gebr. - Deze plant is om hare bloemen, welke eenen jasmijnachtigen reuk verspreiden, door de inlanders, Chinezen en Japannezen zeer geacht. Volgens eenigen worden de bessen als eetbaar, door anderen als ontlastingbevorderend, zelfs als wormdrijvend opgegeven. Uit het gecle sap der bessen wordt cene verf:tof bereid, welke in Japan in vele winkels te koop is, en zeer geschikt zoude zijn tot het kleuren van aardewerk; de Chinezen tellen het sap onder hunne verknelende en rexzachtende geneesmiddelen. 
187. Вот. Nıг. - Gardenia radicans Thnb.

Gr. PL. - Japan, op Java in tuinen.

I88. Вот. Nu. - Gardenia grandiflora Lour.

Gr. PL. - Cochinchina, op Java in tuinen,

Gerr. - Volgens van Heijningen leveren de zaaddoozen de in den handel voorkomende chinesche verfstof, Wongski genaamd, welke de Chinezen nict alleen als verfstof maar ook tegen koorts aanwenden (zie natuurkundig tijdsehrift voor N. I. Jaarg. 1. Bladz. 159).

189. Вот. Nмr. - Gardenia Reinwardtiana Bl.

Gr. PL. - Moluksche eilanden, op Java in tuinen.

Int. Bex. en Gebr. - Deze drie planten, alle Katjapiering II geheefen, worden om lunne schoone on welriekende blocmen dikwijls als sieraadplanten in de tuinen gevonden.

190. Вот. Nм. - Mussaenda frondosa L.

IVL. BEN. - Kingkilaban S.

GR. PL. Java, veelal in bebouwde streken.

Gebr. - Het sap van vele Mussaenda-soorten wordt gedronken en ook de oogen daarmede gewasschen, indien ex zich een rood vlies over dezelve heeft getrokken (Hasskarl).

\section{LONICEREAE Endl.}

191. Boт. Nxr. - Lonicera japonica Tnbg $\Rightarrow$ Lonicera chinensis Wats.

Gr. PL. - Nepaul, China, Japan, op Java als sierplant in tuinen.

GEbr. - Zeer vele Lonicerae, van welke sommige om humne schoone en sterkriekende bloemen in tuinen veel aangeplant worden, worden om hunne scherpe, zamentrekkende en bittere krachten als geneesmiddel nanbevolen en werden vroeger in braakwekkende, purgecrende en pisdrijvende mengsels toegediend; humne bloemen werden om de vlugtige olic veclvuldig als zweetdrijvend middel angewend.

JASMINEAE RBr.

192. Boт. NM. - Jasminum sambac I. \& 
193. Вот. Nu. - Jasminum sambac L. flore pleno.

IxL. BEX. - Malatti S. M; Malatti soesoen M; Boenga malatti J; Baloer Mak; Malori en Kopa poetie Amb; Boenga woengan Bd; Saja manoere T; Boenga mandoeroe Men; Saktiloë Ch.

Gr. PL. - Op alle O. I. eilanden, veelal als sierplant in tuinen.

Gribr. - De geurige witte bloemen zjjn door de inclische volkeren bemind, zij worden vooral door de schoone sekse gebruikt tot versicrsel van hun hoofuhaar, op de slaapsteden, enz; nit dezelve worden eene vlugtige olie en water bereid, welke als cosnetica zeer gewild zija. De olie zoude volgens Prosper Alpinus in Egijpte door de vrouwen gebruikt worden, om daarmede verhardingen der techleelen to bestrijken, ten einde dezo week to maken, het water bezigen de Portugezen in plaats van rozenwater bij groote hitte. Een aftreksel der bloemen wordt vooral op de Philiplijneu veel als oogwater bij ligte oogontstekingen der kinderen aangewend. De met adas, poelassarie en water fijngewreven bladeren legt de Javaan zich op het voorhoofil bij hoofilpijn en roode oogen. Bladeren en bloemen met rijstmeel tot een papje gewreven dienen om daarmede kleine kinderen te besmeren, ten einde hen te bekoelen; eindelijk zoucle de wortel met water fijngewreven en gedronken bij koortsen heilzaam zijn.

194. Bот. Nar. - Jasminum scandens Vhl. en

195. Вот. Nм. - Jasminum glabriusculum Bl.

IVL. BEN. - Malatti aroij \& Kamanden aroij S.

Gr. PL. - Java in boschrijke streken, in tuinen dikwijls als sierplanten.

\section{LOGANIACEAE Endl.}

196. Bor. Nu. - Fagraea auriculata Jeq.

IrL. BEx. - Kiterong badak S; Mengando badak S; Gompong M; Pitja piering wolanda M.

Gr PL. - Oost Indie, Sumatra, Singapore, bij Buitenzorg op boomen. 
GEBr. - Om hare bloemen dikwijls als sieraadplant rangeplant.

197. Bот. Nur. - Fagraea morindaefolia Bl.

IVL. BEX. - Tjangkoedoe badak S; Tjangkoedoe oetan MI K:tjanglioedoe M; Baros J.

Gr. PL. - Op Java aan den voet der Salakh en op de Philippijnsche eilanden.

\section{APOCIJNEAE Lindl.}

Bот.NM. - Allamanda cathartica L.

IVI. BEN. - Lameh aroij S.

Gr. PL. - Guijana, op Java in tuinen.

GEBr. - De bladeren van deze Allamandasoort in aftreksol toegediend beschouwt men als een heilzaam ontlastingbevorderend geneesmiddel, in kleine giften vooral ter genezing van het schilderskolijk; in groote giften verwekken zij hevige brakingen en ontlastingen. De inlanclers alhier gaan boven de stoom van het water, waarin deze bladeren ziju afgetrokken, zitten wanneer zij koorts (sakit moeriah) hebben.

199. Вот. Nıг - Ophioxijlon serpentinum L.

INL. BEX. - Poeleh pandak S; Akkar tikoes M.

Gr. PL. - Indisch schiereiland, Pegut, Ceijlon, Java.

GEBr. - De wortel wordt door Telinganesche (Indische) geneeskundigen gebruikt als fubrifugum en alexipharmacum, rooral in chronische gevallen (Lindleij). Hij wordt door Garcias als een middel tegen slangenbeten zeer geroemd en door hem genoemd "primum et laudatissimum remedium." Ook op deze eilanden zoude hij daartegen zoo in- als uitwendig worden gebruilkt. In China wordt hij beschonwd een maagversterkend middel te zijn en ook bij colica, indigestic, enz. toegediend; in gronte giften is hij braakverwekkend. Op Java geeft mon hem teggen lintworm en uitwondig bij schurft. Volgens Rumphius wordt het melksap bij maculae corneae in de oogen gedruppeld, is de steng in stukken gesneden en gekaauwd goed bij benaanwdheil en buikpijn; fijngewreven en met water ingenomen is hij heilzaam tegen koorts en braking, alsmede bij cholera en impetigo. Horsfold 
ook prijst deze plant als tonicum en febrifugum ter verdere proefneming aan. Hij zegt: ik heb reeds proeven genomen met twee andere soorten van dit geslacht, welke haar in bitterheid veel gelijken, de eene genaamd Poelé-an, de tweede Krodoe hras; het is zeer waarschijnlijk dat deze eenigermate in werking en eigenschappen met de eerste soort overeenkomen." Nog is in de Javaansche verartsenijkunde deze plant van aanwending, gevende men de bladeren met gras vermengd aan paarden te eten als een laxans; de bladeren en bloemen fijngestampt met water en een weinig kalk vermengd, worden op wonden van paarden gelegd, welke door drukking der zadels ontstaan zijn.

200. Вот. Nu. - Thevetia neriifolia Jss.

IYL. BEY. - Gindjeh M.

Gr. pu. - Antillen, Nieuw Granada, Peru, op Java, Mauritius enz, in tuinen gekweekt.

GEBR. - Volgens Lindleij bezit deze plant een zeer giftig melksap, van lietwelk Blanco aangeeft, dat het braakverweklsende eigenschappen zou bezitten. Hare bittere en ontlastingbevorderende bast wordt aangewezen als een krachtvol febrifugum; twee grein van deze zouden in kracht gelijk staan met eene gewone dosis Chinine. Het hout heeft eenen zeer onaangenamen geur en worrt in die streken, waar het in het wild groeit, gebezigd tot bedwelming van visschen. Op Java worden de gedroogde en fijngesnedene bladeren door sommige aldaar woonachtige Bengalezen bij wijze van tabak gerookt.

201. Вот. Ny. - Cerbera odollam Hmlt.

LYL. BEN. - Bientaroh gedeh S; Bientara M.

Gr. PL. - Oost Indie, de Philippijnsche eilanden, enz, vooral langs de stranden.

Gerr. - Volgens Lindleij zoude het melksap van Cerberasoorten het giftigste der Apocijnaceac zijn, en ook caoutchouk bevatten. De bladeren en bast bezitten ontlastingberorderende krachten en zouden rolgens Waitz in werking met de Folia Sennae overeenkomen. De vrucht bezit nareotische eigenschappen bijna golijk aan die ran Datura; Horsfield was eens getuige van de werking eener kleine hoevcclheid (een scrupel van het buitenst gedeelte) bij eene jaraansche rrouw, welke deze uit nieuwsgie- 
righeid hal ingeslikt; er ontstond ijling, zij kon de haar omringentle personen en voorwerpen niet meer onderscheiden, doch behield haar spraakvermogen; deze tocstand duurde vijf uren. Uit de zaden persen de Javinen eene olie, welke zij bezigen om te branden; inwendig gebruikt zoude dezelve in geringe hoeveelheid genomen dijsenterie te weeg brengen, in grootere giften echter zoude zij bedwelmende eigenschappen bezitten en als zoodanig reeds vaak den dood hebben veroorzaakt. Nog bezigen de Javanen de vrucht uitwendig bij wijze van kataplasma bij huidziekten, ontvellingen, enz.

202. Вот. Nır. - Cerbera lactaria ImIt.

LyL. BEy. - Bientaroh leutiek S; Bientara M; Manga brava MI Kiajoe soesoe M; Kiajoe gretje M; Bientaroh Bali; Sassoerroe oetan Bali; Lamboeto Mak; Wabbal Amb; Goro en Goro-goro T.

Gr. PL. - Door den geheelen O. I. Archipel.

GErr. - Behalve dat al het bij de voorgaande plant opgesomde ook op deze betrekking heeft, wijdt Rimplius ontrent deze nog in de volgende bewoordingen uit: "de Amboinezen eten de "jonge bladeren, welke zachte stoelgang verwekken; de melk heeft " eene sterke purgecrende kracht. Een weinig der bast met klap"perwater gekneed en door cene doek gewrongen is de gewone "purgatie der Amboinezen, doch hiervan moet nog al veel in"genomen worden. De pitten zouden zeer schadelijk zijn; echter " maakt men uit deze eene soort van lampolie en van de pap "welke overblijft met katoen gemengd eene soort van kaarsen, "IIet melksap zoude goed zijn op de beet of steek van sommige "visschen, alsvan de ikan swangi."

203. Bот. Nм. - IḰpsia arborea B1.

INL. BEY. - Kiloetoeng S.

Gr. PL. - Op Java in bergstreken.

Gebr. - De bladeren en jonge takken worden fijngewreven en zoodanig voor het voorhoofd ingewreven bij hevige hooflpijn.

204. Fr. - Tabernaemontana sphaerocarpa BI.

LvL. BEN. - Hamproe badak S; Moehoen poetie M.

Gr. PL. - Java, wordt veel in tuinen aangetroffeu.

Gerr. - Deze op grafplaatsen dikwijls angeplant wordende en veel melksap bevattende plant wordt voor zecr giftig gehouden. 
205. Bor. Ny. - Tabernacmontana L. spec. fan macrocarpa?).

Irr. BEx. - Kajoe dagdar S; Kala-antong J.

Gr. PL - Java.

Gebr. - Een afkooksol der bast, bladeren enz. wordt bij koorts op de huid ingewreven. In oostelijk Java kneust men de bladeren met kalk fijn en wrijft deze op het voorhoofd bij roode oogeu.

206. Вот. Ny. - Plumeria acutifolia Poir.

Irr. Lז5. - Samohdja S; Kambodja M; Sambodja er F Ímbang gocling tsjoctsjoe Amb; Koelong tsjoetsjoe'I'.

Gr. PL. - In zuidelijk Azie en eilanden algemeen aangekweekt en aldaar als het ware in het wild wassende.

Gerr. - Deze fraaije boom met sterk riekende witte bloemen worlt veel op de inlandsche graven anngeplant; zijn wortel worlt in Malabar roor een doodelijk vergift gehonden; de schors bezigt men op Jara nitwendig bij de ziekte der voetzolen, sakit bliih geheeten; zijn melksap, dat drastische eigensehappen zal bezitten, gebruiken de Jaranen bij kiespijn door caries veroorzaakt; de geurige bloemen worden tusschen de kleederen ggelegit, vooral tot weering van insekten; soms ook worden zij gुekoufijt gegeten.

297. Вот. Nуг - Lochnera vincoides Rchb. flore albo.

Tru. IsEx. - Kembang tembaga boddas $S$; Kambang saharic tjina M.

298. Bor. Nrr. - Lochnera vincoides Rchb, flore rubro.

INL. BEY. - Kembang tembaga blaauw S.

Gr. PL. - De Kiaraibische eilanden, Mexikn, Brazilie, de Kaap de goede hoop, Mauritius, Oost Indie \& Philippijnsche eilanden; op Java in tuinen gekweekt.

GEmr. - Sommige Vinea- of Lochnerasoorten zijn bitter en adstringeerend en worden daarom wel bij diarrhoeae aangewend.

209. Bот. N.r. - Alstonia spectabilis RBr.

IYL. BEN. - Lameh aweweh S; Poelie M. \& J.

Gr. PI. - 'Timor, op Java in tuinen.

GErr. - Iet hout dezes booms wordt veel bij het begraren vim lijken gebezigd, omdat hetzelve onder den grond lang be- 
waard blijft, boven don grond echter wordt het door insekten spoedig verteerd. IIct melksay wordt in het tandrleesch ingewreven bij aanhoudend bloeden van hetzelve (IIasskarl). Het hout van sommige Alstoniasoorten als zeer bitter zijnde, zal dezelfile geneeskrachton als de Gentiaanwortel bezitten. De Javanen kooken van dezen boom de bladeren met water af en dienen dit aan lumne karbouwen bij buikzickten toe. Nog wordt door hen de bast gedroogd, tot poeder gestampt en van dit pocder 10 tot 20 grein, met water overgegoten, ingenomen bij tusschenpoozende koortsen en als zoodanig door hen als zeer heilzaam geroemd; of met dit middel ook door Europesche geneeskundigen reeds proeven zijn genomen is mij niet bekend; wel rermeldt Waitz in zijne praktische waarnemingen als een zuiver bitter en maagversterkend middel een bast ook Pocle genaamd, deze is echter volgens hem afkomstig van Tabernacmontana citrifolia, en niet van eene Alstonia, het schijnt dus een ander middel te zijn; de Javanen toch zijn dikwijls gुewom cenen zolfien naam aan twee, dric en meer gehecl verschillende planten te geven.

210. Вот. Ny. - Nerium oleander L. flore rubro.

IvL. BEv. - Djurei burrum S; 'Tjaptjek meirah M, en

211. Вот. Ni. - Nerium oleander I. flore albo.

INL. BE. - Djurei boddas S; 'Tjaptjek poetie MI.

Gr. PL. - In de landen rondom de Middellandsche zee; wordt op Java om zijne schoone en geurige bloemen dikwijls in tuinen aangetroffen.

GEbr. - Deze plant behoort onder de nareotiseh- scherpe vergiften gerangschikt te worden; verscheidene doodelijk afgeloopene grevallen vindt men van haar opgreteckend, niet alleen van kinderen door let gebruik der bladeren of blocmen veronzatakt, maar ook zelf's van een twatftal soldaten, welke bij M:ulrid vleesch gegeten hadden, dat boven dit hout geronsterd was geworden (Gard. Chronicle 1814). Volgens Dupare bezit hatre gomhars zoer hevig braakrerwekkende en drastisehe cigenchanpen. Bij Nizza gebruikt het landvolk de bast en het hout als rattenvergift; in Provence bezigglen de monniken het laatite wit weering ran scladelijke huisinzekten en wordt in zniclelijk Europa cen afkcoksel van de bluderen angewent bij huidwom Volgens 
Graij hecft de Olcanter de eigenschap om trochel modilcriy water helder te maken even als de Strijchnos potatorum.

212. Boт. Nu. - Strophanthus scandens R. \& S. $=$ S. diehntomus De. $\gamma$ Loureiri.

IVI. BEN. - Kikoejah S.

Gr. PL. - Java aan den voet der Salakh; Cochinchina, in vochtige gronden.

\section{ASCLEPIADEAE Jeq.}

213. Вот. Nur. - Asclepias gigantea RBr.

INt. BEN. - Badocrie S; Wadoerie M; Madoerie en Modorie NI, J. Bali; Sidagorie J; Kore Bi.

Gr. PL. - In Oost-Indië op onbeboutwde steenachtige gronden vrij algemeen.

Grbr. - Van deze aan melksap zeer rijke plant is de wortcl officineel cn onder den naam van Mudarwortel, Rad. Mudaris bekend, van dezen is vooral de bast werkzaam, welke rijk is aan Mudarine, eene eigenaardige extractiefstof. Volgens Duncan bezit het Mudarpoeder in verbinding met opium alle eigenschappen van pulvis Doveri; weinige greinen Mudarine verwokken cene ruime braking en gelooft hij zelfs dat zij zeer goed do Ipecacuanha kan vervangen. In kleine giften $(5$ ì 8 grein ecn paar malen daags) werkt dezelve als een diaphoreticum en expectorans. Volgens Waitz zoude zijne werking met die van rad. Colchici autumnale en rad. Sarsaparillac cenigzins overeenkomen, daar hij vooral de werking van huid en nieren verloogt. In Indië wordt hij zoo door de inboorlingen als door sommige Europesche geneesheeren gegeven tegen arthritis, sijphilis, elephantiasis, de beet van vergiftigde dieren en zulfs togen intermitterende koortsen.

Volgens Rumphius zor hij ook de stuipjes der kinderen tegengaan en Waitz bezigde hem nog in inspuiting bij beginnend carcinoma uteri. Volgens dierproeven van Rieord Madianna kan men de wortelbast en het melksap als emetica beschouwen, welke echter in groote giften noodlottige uitwerkselen knunon opleveren. Naauwkeurige onderzockingen en proefnemingen lsan men 
alsnog nootzalkelijk beschouwen. I Iet hout getbrand wordende levert fijne kolen, welke de Balinezen bij de buskruidbereiding zouden bezigen. De Javanen gebruiken het melksal' uitwendig bij furunculi en bij kies- of tandpijn door caries veroorzalakt. De bladeren wenden zij in afkooksel aan bij sakit blalı; wrijyen zich tegen rheumatische pijnen met dezelve het ligelaam in, wulke alsdin tenzelfien prikkel als fol. Urticae stimulimtis zouden veroorzaken; soms ook geven zij ze te eten aan zieke afficmagerde paaxden. Van den bast der takken vlechten zij touw, de wol der vruchten kan tot vulling van kussens dienen, en eindelijk zou volgens Rumphins het siup der bladeren in de ouren gedrupheld hardhoorendheid genezen. Zie uitroeriger omtrent deze plant:

J. P'ierot, de mudar sive Calotropis gigantea Rlbr. Lugd. Bat. 1839.

I. L. Geiger. Plarmacentische Botanik 1. 666 \& Sqr en andere schrijvers.

21\%. Вот. Nu. - Asclepias curassavica L.

IrL. 13Ex. - Kapas tjiendeh S; Kapassan M.

Gri. pr. - Antillen; tegenwoordig in bijna alle keerkringslanden in het wild groeijende.

Grebr. - Van deze kleine plant met fialiaje goudgecle bloemen wordt de wortel of wilde Ipecacuanha in West-Indie door de negers als een braking- en ontlastingbevorderend middel gebruikt en gezegd zeer werkzaam te zijn bij druiper en witte vloed.

215. Вот Nx. - 'Tijlopliora cissioides Bl.

IYr. BEY. - Aroij putjiet aijam $\mathrm{S}$; Boentalie oijot $\mathrm{S}$.

Gr. PL. - Java aan den voet der Salakl.

GErr. - Irasskarl geeft ain dat de fijngewrevene blitleren bij buikpijn op den buik gelegd of liever nog ingenomen worden. Vin eene andere tot dit geslicht behoorende struik, de mele op op deze eilanden te huis behoorende 'T. asthmatica Wgt. \& Arnd, is opgeteekend, dat deze zich bij dijsenteric als cen heilzaam geneesmiddel zoude betoond hebben; in groote giften werkit zij braakverwekkend, in kleine giften dikwijls herhaald cehter purgeerend.

216. Bor. Na. - IIoija macrophijlla 131. 
IYr. вrx. - Kilamprahan S'; Aroij kikandel badak S; Dawon pittis MI; Dawon kappal J: Pittis pittisan Bali; Walebissi Amb.

Gr. pr. - Java in bergstreken en omliggende eilanden.

GEsr. - IBij pijnen in de ledematen door vermoeidheid, rhenmatismus enz. bezigen de inlanders do fijngewrevene blaten om deze pijnlijke deelen daarmede in te wrijven. Nog zoulen de bladeren in water gekookt en gedronken gonorrhoea genezen en het melksap dienstig zijn tegen de steek van vergiftigde visschen.

217. Bor. Nyr - Marsdenia parviflora Desn.

INL. BEx. - Taroem aroij S.

GrR. PL. - De O. I. Archipel.

Gerr. - Deze plant schijnt even als de Indigo tot verfstof te kunnen angewend worden, ten minste bezigen de Javanen het kruid tot het donkerblanuw of zwart verwen humner kleederen.

218. Bot. Ny. - Pergularia aceedens B1.

Irr. BEx̌. - Rak nassi M. S.

Gr. PI. - Bengalen, O. I. schicreiland, Sumatra, Java, Mradura, vooral langs de stranden, wordt om have kleine doch genrige bloemen veclruldig in tuinen aangetroffen.

\section{GENTIANEAE JSS.}

219. 130т. Nv. - Villarsia indica Vent $=$ V. Simsii Don $\leftleftarrows$ Limnanthemum indicum Griseb.

Irc. 1B.x. - Tiuratteh leutiek S; Taratteh ketjil \& Taratteh sajor MI; 'Tomuljong terljator en 'Tomljong poetie ML. J. Batli; Talipoe Mak.

GR. P'J. - Oost Indie, Java, Bali \&c, bij Batavia in zachtstromende wateren.

GErr. - Van deze plant nuttigen de Chinezen de stengels bij wijzc van artisjokken en eten zij ook de wortels gebraden en gekookt.

IAABIATAE JSS.

220. Boт. Ny. - Ocimum basilicum I.

Ixt. Bt... - Selassio S; Lampas J. en 
2.2. Bot. Nu. - Ocimum basilicum L, var $\beta$ ublongo-lanceolatum Bl.

IXL. BEN. - Selassie burrum S; Lampas hitam J.

Gr. PL. - In warme streken van Azie en Afrika; wordt op Java dikwijls op graven gevonden.

Cesr. - IIet kruid bezit opwekkende, zwecturijvende krachten, komt in werking bijna met melisse on thijm overeen, en wordt vooral bij ligte koortsen, verkoudheid toegrediend; op Java geeft men cen aftreksel van hetzelve aan kraamvrouwen ter bevordering der lochiae. Dikwijls wordt het kruid als specerij gebezigd. De zaden, welke vecl slijm bevatten, worden in water geweekt, en na bijvoeging van een weinig suiker dit vocht op Java langs de wegen te koop aangeboden, of als eene verkoelende drank dikwijls bij feesten gedronken.

222. Bo'r. Nur. - Ocimum brachiatum Bl.

INL. LEN. - Selassie woengoe S.

Gr. PL. - Java, rondom Batavia op drooge gronden.

GEBr. - Zie vorige plant.

223. Вот. Nм. - Coleus bicolor Bnth.

IVI. BEN. - Djawer kottok konneng S; Miana M.

Gr. PL. - Op Java aan den voet der Salakh.

GEbr - De Inlander legt de jonge bladeren ter verkoeling op wonden en zweeren en wendt hen ook tegen herpes uitwendig aan. Over het algemeen zijn de Coleussoorten, welke met die van Ocimum bijna overeenkomen, door de indische volken om hunnen aromatischen geur zeer gezocht. Men gelooft dat het kruid, hetwelk van de Mascarenische eilanden onder der naam van Patchoullij naar Frankrijk gevoerd wordt, ook van eene Colens afkomstig is (Endlicher).

224. Вот. Nu. - Pogonostemon menthoides Bl.

IVt. BEx. - Dilem S \& M.

Gr. pL. - Java, vooral op beschaduwde plaatsen aan den Gedeh.

Grir. - De jonge takjes dezer aromatische plant leggen de inlanders dikwijls tusschen hunne kleederen, om dezc tegen insekten te beveiligen.

225. Boт. Nu, - Mentha piperita $L_{\text {. }}$ 
Gir. PL. - Europa, tegenwoordig in alle wereldleeten veel aam geplant.

Gebr. - Zie Pereira, Materies medica p. 383 en andere wer ken.

226. Вот. Nu. - Salvia officinalis L.

GR. PL. - Uit Europa in de tuinen van Java overgebragt.

Gerr. - Zie Pereira, Mat: medica p. 393 en elders.

227. Bот. Ny. - Salvia coccinea L.

INL. BEY. - Totongoün S.

Gri. Pr. - Midden- en Zuid Amerika, op Java als sierplant in tuinen.

228. Вот. Nм. - Salvia fulgens Cav.

GR. PL. - Midden- Amerika, in tuinen op Java als sicrplant 229. Bот. Ny. - Rosmarinus officinalis L.

Gr. PL. - Zuidelijk Europa, Azie, op Java in eenige tuinen, Gebr. - Zie Pereira, Materies medica p. 393.

230. Bor. Ny. - Leonurus javanicus Bl.

IrI. LE. - Tjitjabean oetan S; Galieboeng boeloe S.

Gri. PL. - Westelijk Java in schaduwrijke bergachtige streken.

231. Bот. Nм. - Leucas linifolia Sprg.

INL. BEN. - Djoekoet seetan S; Dawon seetan M; Dawon heran M; Dawon patjie patjie M; Bati-bati Bali; Goffo haijran 'T.

Gr. PL. - Oost Indic, Madagascar, Bourbon, Boeroe, de Philippijnen.

GEBr. - De wortelen worden tot het roodverwen dex nagels aingrewend, het sap viu het uitgeperste kruid worlt op oude wonden gedroppeld, bijzonder indien er reels wormen zijn op ontstaan, welke alsdau spoedig verdwijnen; voegt men er eenig water bij, zoo wordt dit in de oogen gerlruppeld tegen koortsen (Hisskari). Nog zouden op Bali de bladeren met andere groenten vermengd gegeten worden.

VERBENACEAE JSS.

232. Bor. Nu. - Stachijtarpheta mutabilis Vhl。

IYI, BEY, - Kimeurrict meirah S. 
Gr. PL. - Z. Amerika, Caracas, Trinidad, op Java in tuinen.

GEer. - De bladeren worden met kalk fijngewreren en alsdan op gezwollene wonden en zweeren aangewend.

233. Вот. Nм. - Stachijtarpheta indiea Vhl.

IYI. BEX. - Djaroeng lalakki S; Boetoe kawanes MI.

Gr. PL. - Bengaten, Ceijlon, de Mascarenische cilanden, Pocloc pinang, Java en de Philippijnsche eilanden.

Gebr. - Op Java wordt de wortel tegen gonorrhoca aangewend en de blateren met adis en poelassarie te zamen afigekookt tegen bloedige stoelgang geelronken. Morelijk bezit deze plant, welke zeer veel gelijkt op de S. jamaicensis Vlil. ook de zwectdrijrende eigenschappen, waarom de Zuid Amerikatusche vollieren deze laatste dikwijls bij ziekten aanwenden.

234. Вот. Nur. - Lantana stricta L.

I.Y. BEX. - Djoekoet oeriek ariek S.

GR. PL. - Jamaika; op Java veelal in tuinen.

235. Вот. Nır. - Lantana salicifolia Kîth.

Grr. PL. - Zuid Amerika aan de Orinoco; op Java in tuinen als sierplant.

236. Вот. Ny. - Lantana mixta L.

Irt. BEx. - Garoet badak S; Dawon wedoessan J.

Gr. PL. - Brazilie; op Java in tuinen, langs de wegen in heiningen.

Gebr. - Van vele Lantanasoorten worden in Amerika de bladen in plaats van thee afgetrokken en gedronken, en om humne sterk aromatische eigenschappen tot genecskrachtige baten en stovingen bij rheumatismus aangewend (Endlicher).

237. Вот. Ny. - Vitex pubescens Vhl.

Irt. BEx. - Harras S; Laban MI; Harrassas gedeh S.

Gr. PL. - Oost Indie, Poeloe pinang, Singapore, Sumatra en Java.

Gerr. - Lindleij geeft an dat in Indie een afkooksel der aromatische bladeren het warme bed helpt vormen, dat men an vronwen na laare bevalling laat gebruiken; dat zij fijn gokneusel aan de slaaystreck bij hoofilpijn worden aangewend, en men kussentjes met dezelve oprevuld onder het honfd leyt, on verkoutheid en hoodelijn te verdrijwen. Volgens IItsidarl worden 
wortel en bast in stukken gesneden en afgeknokt bij lendenpijn en zwakte getronken. De schil en bast worden ook gestampt onter bijvoeging van zeer jonge klappernoten, de bast van mangat, de schil der pinangpalnboom, aluin, koperrood en wat kurkuma, dit alles wordt te zamen gestampt en gekookt; het water op de groen te verwene voorwerpen, als garen, kleedjes enz. gegoten, nadat deze reeds te voren blaauw geverwd waren; ecne keer opgieten maakt dezelve ligt groen, twee keeren reeds donkerder, enz. Nog wrijven de inlanders de fijngekneusde bladeren aan de lectematen in tegen rheumatische en andere beenpijnen.

238. Вот. Nu. - Vitex trifolia L.

Irt. 1BE. - Galing galing S'; Lagoendie XI; Tandjong saharic II; Lania MIak; Aijtette toeban, Aijlon tocban en Aijtoeban Amb.

Gr. Pr. - De Sechelles, Oost Indie en eilanden, Nieurv IIolland, China en Japan; op Java in rochtige oorden langs rivieroevers.

GErr. - Omtrent deze àomatische struik lieb ik het rolgende vermeld gevonden. Volgens Rumphius werken de bladeren uitwendig aangewend verwarmend, verdeclend en pijnstillend, bij wijze viln omslagen of pappen op wonden, kneuzingen, zulfs bij beri-beri en verlammingen, bij schurft en andere huidzickten. De blutwen en bloemen in eene kast gelegd verdrijoen kakke?lakken en hunne rook de muskieten. Op Bali bezigt men een aftreksel "der blailen inwendig bij colica flatulenta, amenorrhoca en gestoorde lochiae. Op Java is het vroeger bij beriberi toegediend.

Horsfield zegt. "het is eene prikkclend-aromatische struik, "welke groote werkzamheid bezit. Zij wordt door Rumphius " en Rheede geroemd; de eerste prijst het uitwendig ian bij "zwellingen en zickten der huid; de liatste getuigt dat de bla"deren tot poeder gebragt en ingenomen de tusschenpoozende "koorts genezen. De wortel en een bad of stoving der bloemen "worden uitwendig aangewend bij rheumatismus en plaatsclijke "pijnen in alle ligchaamsdeelen.

y Bontius roemt hare deugden zeer hoog; hij noemt haar 
"Indian I'rivet en verklaart dat zij in deze streken zeker, lijk het genis aan Chamomillae enz. kan vergoeden. Aan hem "is toevertrouwd, zoo heet het, dat een naauwkeuriger onderzoek "met de bladen dezer struik bewerkstelligd heeft bewezen, dat "deze bij alle pijnen zoo bij pas ontstane als bij verouderde " zeer pijnstillend werken. Omslagen van deze bevorderen de maind"stonden, bespoedigen de verlossing en genezen ziekten der baar" moeder. Inwendig genomen bevordert dit geneesmiddel de urien"afscheiding, brengt hulp aan bij pijnen der nieren en pisblaas, "en stilt kolijkpijnen."

Waitz verneent dat deze plant de krampstillende (antihijsterische) kracht niet bezit, welke aan de kamillen eigen is; hij wil haar liever gelijk gesteld hebben met de rad. Levistici en baecae Juniperi, daar zij even als deze beide pistrijvende eigensehappen bezit, en daarbij door hare vlugtige olie weldaclig op het darmkanaal zou werken. Hij diende han derhalve toe bij lijelers met waterzucht, met een gevoclig verzwakt darmkauaal en bij kolijk.

Lindleij bezigt slechts de volgende bewoordingen; "de blateren " zijn een krachtrol oplossend middel en worden door de NIaleijers " aangewend tot verdrijving van zwellingen. De bladeren "worden in aftreksel en afknoksel gegeven, en als pap aunge"wend bij vergrooting der milt."

Volgens genomene proeven houd ik het er roor, dat de bladeren in aftreksel toegerliend als aromatisch zweetdrijvend middel bij katarhale koortsen zeer goede diensten kumnen bewijzen. Door de Javanen worden zij mede als zoodanig aangewend, en ook fijngekneusd nitwendig gubezight bij beenzweeren of zwellingen der ledematen.

239. Bot. Ny. - Tectona grandis L.

IYL. BEN. - Djattie, Jattic en Kajoe jattie S, MI \& J.

Gr. PI. - Oost Indie en op dezen geheelen archipel.

Gers. - Deze boom is de grootste en merkwaardigste van alle Verbenacene; zijn hout is bitter, zeer hard, door dien het rijk is an kiczelaarde, eenigzins gyclijkende op mahonijhout, doch ligter, zeer duurzaam, zeer geschikt voor huisbouw, en vooral de Engelschen kennen aan hetzelve cenen eersten rang on- 
der de scheepsbonwhouten toe, zij noemen het 'Teakthree, 'Teak of 'Teckhout, en zoude in duurzaamheid dit geene der andere Aziatische boomen overtreffen; men verkiest dat, lietwelk van Bombaij uitgevoerd worlt, boven de andere soorten uit l'ogu, Java enz; een sehip uit Bombiaj-teakhout gebouwd zoude honderd en meer jaren kumnen dienen. Bchalve deze deugdzatumleid van het hout geeft Rumphius nog aan, dat het hoe onaangrenaam van smaak ook de kracht heeft on allerhande spijs en drank te verbeteren en cholera te stuiten; dat de zeevaarders (MIalcische) hiervan hrune waterbakken maken, daar zij gelooven dat het hout het water gezond maakt; dat kajoe jattie met kajoe taai (Gumira foctida Hsskl.) het gewone middel der inlanders tegen cholera is. De gom of hars uit den boom verkregen bezigt men volgens Blanco in gorgeldranken tegen keelaandoeningen. De bladeren, welke een bitter zamentrekkend stinkend sap bezitten bezigt men tot rondkleuring van andere houtsoorten, of voegt ze bij andere verfstoffen, om aan lijnwaden eene vastere roode kleur te geven; een afkooksel van deze bezigen de Maleijers in cholera; met suiker ingelegd of gekonfijt plegen zij ze tagen aphthae toe te dienen; hun sap zoude op wouden zuiverend en bloedstelpend werken. De bloemen bezitten een pisdrijvend vermogen.

240. Вот. Nз. - Gmelina asiatica L.

\section{INL. BEX. - Wareng M.}

Gri. PL. - In bijna geheel Oost Indie, op alle deze en de Philippijnsche eilanden; op Java bemint zij vochtige weiden.

Gesr. - De slijmige bladen der Wareng worden bij urethroblennorrhocae aangeprezen; het sap der bladeren en vruchten wordt op Java tegen oorpijnen in de ooren gedruppeld. Horsfield hatt ze aan in zijne rubriek van tonischo middelen, hij zegt zij bij de Portugezen vroeger in hooge achting stonden, dat zij dezelve Rais Madre de Dios noemden; dat de opgaven omtrent hen zeor bijgeloovig en onbenaald zijn en hij deze vermeldt op grond cener mededeeling uit Malakka ontvangen; dat de Javaan dezelve als een giftplant beschouwt.

241. Вот. Nyr. - Clerodendron inerme Grtn.

LYt. nes. - Kembang boegang S; Grmbir laut MI; Birindjene Mak; Waijle en Wale poetie lohaha Amb. 
Gr. ru. - Oost Indische, Moluksche, Philippijnsche en Marianneneilanden; op Java langs strandplaatsen.

Geirr. - Rumphius geeft aan, dat van deze plant de bladen, wortel en zaden in en uitwendig gebruikt worden bij rergiftiging duor visschen; dat de bladeren op versehe wonden worden aangewend en zij somtijds bij de rijst gegreten worden, niettegenstaande humnen onaangenamen smaak. Volgens Blaneo legrt men op te Philippijnsche eilanden de fijngekaauwde blocmen op den navel ran barende vrouwen, indien de vrueht dood is. Fondlicher zegt omtrent het geslacht Clerodendron in het algemeen, dat verscheidene soorten van dit schoone geslacht om hunne geneeskracht tot de toovermidclen der Indische volken behooven; vele worden om de anngename geur der bloemen zeer gezocht. De wortel, welke sterk riekend en aromatisch bitter is, en de blateren, welke bitter en scherp zijn, pleegt men bij serophulense en sijphilitische andoeningen aan te wenden.

Findelijk vermeldt Lindleij dat Clerodendron inerme on sommige anderen soms als geneesmiddel zijn aangewend om hunne gering bittere en halfzamentrekkende eigenschappen, doch dat zij van geen groot belang schijnen te zijn.

242. Вот. Nu. - Clerodendron serratum Sprg.

INL. BEx. - Singoegoe S; Sirie goengoe M \& J.

Gr. PL. - Oost Indie, Nepaul, Assam, Java.

Gris. - De wortel met water afgewreven eet men op Java om eene heldere stem te krijgen; de blateren geeft men alleen, of wel vermengd met mangkoedoe, sereh enz. bij wijze van groente of in aftreksel aan kraamvrouwen ter bevordering der kraamzuivering; het aftreksel wordt ook toegediend tegen koorts of aan jonge kinderen tegen buikpijn en wormen.

243. Вот. Nзг - Clerodendron laevifolium BI.

IXL. BEX. - Kibangbara S; Kibangbara itam S.

Gr. Ps. - Op Java aan den Salakh en Gedeh in weilanden.

24. Bот. Na. Clerodendron calamitosum L.

Ixt. EEx. - Kembang boegang $\mathrm{S}$.

GR. PL. - Oost-Indië, Cochinchina, op Java veclal in tuinen.

215. Вот. Na. Clerodendron paniculatum I.

IYI. BEx. - Kembang boegang S; Poetjoeng oetan NI; Waroe $\operatorname{dlogong} J$. 
Gr. Pr. - Oost-Indie en alle eilanden, Cochin-china; op Java veel in tuinen.

246. Вот. N.r. - Clerodendron squamatum Vhl.

Grr. rL. - Oost-Indië, Japan, op Javr in sommige tuinen.

247. Вот. Nu. - Clerodendron firgrans Vent, rar. pleniflora.

İ̃. BEx. - Baus S; MLalatti wolanda en Takokkak oetan MI; Malatti octan M; Malatti toempock Bat; Wora warie toempoek J.

Gr. PL. - China, op Java veel in tuinen.

248. Вот. Nx. - Clerodendron siphonanthus RBr.

Gr. PL. - Bengalen, Java in het wild en in tuinen.

249. Вот. Nar - Clerodendron L. sp. nov. (flore albo.)

Gri. PL. - Afkomstig uit den Botanischen tuin te Buitenzorg en onder dezen naam toegezonden.

Grbr. - Alle deze soorten worden slechts als sicrplanten in tuinen aangekweekt.

250. Вот. Nu. - Duranta Plumieri Jeq. = D. Fillisia Jeq.

Gr. rL. - West-Indië, St. Domingo, Cuba, Jamaika, Mexiko, Peru, op Java in tuinen als sieraadplant.

251. Вот. N.м. - Callicarpa cana L.

Irt. BEx. - Katoempang S; Kikatoempang S; Kinjorang $\mathbf{S}$; Abo-abo S; Dawon maniran karbo J; Polto-polto Mand.

Gri. Pr. - Bourbon, Calcutta, Poeloe Pinang, Malakka, Java, Timor.

Grisr. - De Inlanders wrijwen het kruid fijn en legrgen dit op wouden om zwelling te voorkomen en de likteekenrorming te bespoedigen.

De Aziatische Callicarpae, zegt Endlicher, munten uit door eene aromatisch-bittere bast, de bladeren worden om hunne pistrijkende werking geprezen; die van C. americana L worden bij hijdrops veel angewend. Volgens Lindleij bezit de bast van C. lanata Vhl. cene eigenaardige aromatische en cenigzins bittere smaak, wordt zij door de Cingalezen gekaauwed, wanneer zij geene betelbladeren kunnen bekomen en rekenen de Matleijers ze onder humne diuretica. 


\section{CORDIACEAE RBr.}

252. Bor. Nir. - Cordia suaveolens B3.

IVL. BEv. - Kendal M. S.

GR. PL. - In bergachtige bosschen van westelijk Java.

Genr. - Het hout is grof, wit en week, wordt door witte mieren ligtelijk aangetast en is derhalve slechts geschilit voor huisbouw. De bast wordt bij gebrek aan gambir (catechu) bij het betelkaauwen gebruikt. De bladeren fijngewreven on met poelassarie gemengd dient men aan kraanvrouwen toe, of ook wel afgetrokken te gcijk met de gedroogde bladeren van krak nassi (Pergularia accedens Bl.) geeft men ze aan koortslijders.

Horsfield geeft van kendal, echter van eene andere soort, de C. mijxa L. op: nde gedroogde vrucht, welke dikwijls naar " Europa overgevoerd wordt, is meestal beschadigl, beschimmeld " cn wormstckig; zij wordt zelden gebruikt; bij maceratie bezit "zij overvloedig slijm en is alsdan dienstig bij buiklijden en ont"stekingachtige aandoeningen der pisbuis; de vrucht bezit verder " een losmakend en ontlastingrerwekkend vermogen; tien a twaalf "drachmon pulpa werken even.als ecne gelijke hoevelheid Cas"sia. De bast is een der hoofdgeneesmiddelen der Jaranen, zij "wordt aangewend bij koortsen en behoort tot de zachte tonica". Vin de wortel dezer plant geeft Lindleij op, zij ontlastingbevorderend werkt.

\section{ASPERIFOLIAE Linn.}

253. Bor. Ny. - Ehretia buxifolia Rxb.

INL. BLw. - Seroet tjina Mr.

Gr. PL. - Oost Indie op woeste en boschrijke plaatsen.

GEBr. - Van deze plant, welker wortel vele Indische volken aanwenden tegen cachexien en verouderde sijphilis, brandt de Javaan het hout on bezigt dit tot zwartverwing zijner tanden, ook gebruikt hij een aftreksel der bluderen zoo nit- als inwendig bij koortsen ter bevordering der huidafseheiding.

254. Вот. Nur. - 'lommefortia tetrandra BI.

INL. BEN. - Ojot sisier S; Kembang sisier M. 
Gr. PL. - Op Java in bergachtig kreupelhout on langs het Zitidzeestrand.

2.5. Bот. Nur. - Tournefortia argentea L.

IvL. Bey. - Tambakkoan S'; 'Tambako laut M; Moral babaloe MI; Moral en Mokal ahua Amb; Nela Lt; Karpoo T.

Gr. PL. - Op Javir en Nocsakambangan langs de stranden, verder op 'Timor, de Molukkos, Marimnen, Nicuw Holland en Maturitius.

GEbr. - limphins geeft anu, dat de bladeren als groente worden genuttigd en men in de Molukko's de wortel inwendig toodient bij galachtig kolijk.

256. Вот. Nu. - Heliotropium peruvianum L. en

257. Вот. Ny. - Heliotropium Voltairianum L.

Gr. PL. - Peru, de Andes, op Java in tuinen.

Grir. - Dezo planten zijn om humne geurige, naar Vanille riekende bloemen, zeer gezocht.

258. Вот. Nu. - Mijosotis arvensis Sibth $\models$ M. intermedia lik.

Gr. PL. - De Muizenoor of Vergect mij niet groeit door gehecl Europa, Siberie, Noord Amerika, aan de Kaap de groede hoop, Java en op de meeste plaatsen des Indischen Archipel.

\section{CONVOLVULACEAE EndI.}

259. Bor. Nu. - Convolvulus batatas $\mathrm{L} \models$ Batatas edulis Chois.

INL. BEx. - Oebie MI; Oebie djawa MI; Oebie kastelia en Oebie batatas M; Kastela Bali.

Gr. PL. Oost Indie, wordt echter in bijna alle tropische gewesten atngeplant.

Gebr. - De Inlanders eten de onderardsche lnolleu, welke ecn vrij gned voedsel zijn on bezigen de bladeren op brandwonden. Volgens Geiger bereiden de Portugezen uit dezelve eene brei (Pepada) en met suiker humne Marmoda, strekt de knol tol roedsel en bezit deze eene vlugtire cenigzins giflige stof, echter geene purgeerende hars. 
260. Bor. Ns. - Ipomoea vitifolia Sw. var $\beta$ angularis.

IXL. BEN. - Aroij kawoijang S.

Gr. PL. - Oost-Indië, Java, Timor.

GEBr. - De vruchten worden soms gegeten, doch zijn nict lekker.

261. Вот. Nr. - Calonijetion speciosum Chois.

IVL. BEX. - Aroij gurrung S??; Terong korrie S.

Gr. PL. - Mridden- en Zuid-Amerika, Oost-Indië, Polijnesic: op Java veelal als sieraadplant in tuinen, voor prieeltjes enz.

262. Bот. Nu. - Quamoclit vulgaris Chois.

IXI. IEx. - Aroij ketilan S'; Boenga tali MI: Tonka langit MI; Birara ef; Bou batati J: Bonga hollanda Amb; Bonga javia Bu.

Gr. r.s. - Gcheel Oost-Indië, vechuldig in tuinen als sicrplant, ook in Brazilie en Manritius.

Gebr. - Rumphius zegt op Bali worden de bladeren fijn gewreven op gezwellen gelegd en zelfs als groente genuttigd.

Volgens Geiger waren vroeger herba en semina Quamoclit in de apotheken als laxantia verkrijgbaar, doch zijn beide thans buiten gebruik geworden. Lindleij vermeldt dat de wortel als niesmiddel in gebruik is.

263 Вот. Ny. - Pharbitis nil Chois.

Gr. pr. - Oreral tusschen de keerkringen, op Jara veelal in heiningen, ook als sierplant.

Gebr. - De wortel en zalen bezitten waarschijnlijk ook drastische eigenschappen.

SOLANACEAE Brtl.

264. Boт. Ny. Nicotiana tabacum L.

IYI. BEx. - Tambako NI, S; Tambako songrom S.

Gr. PL. - Zuid-Amerika, is naar Jara orergebragt en aldatr kultuurplant.

GEbr. - De bladeren rlezer plant, welke onder andere bestanddeclen de zoo giftige Nicotine en tabaksolie bevatter, berigen de Inlanders om to rooken, bij humne betelprumtjes en nitwendigg op brandwonden; hare verdero geneeskrachtige aanwenring, b. v. als eneticum, drasticum, anthehuinticum enz. sehijnt 
lum onbekend te zijn. (Zie uitvoeriger omtrent deze laatste de bestaande handboeken over materies medica en toxicologie.)

265. Bor. Nir. - Datura arborea I.

INL. BEx. - Koctjoeboeng M, S; Kikoetjoeboeng S.

Algemeene benamingen voor alle Datura-soorten zijn Doctra MI. J. Bali \& Mak; Loetroü Amb en Wantchoüe Ch.

Gr. rt. - Pert, Chili, op Java in tuinen.

Grisr. - Volgens Pereira bezit deze plant dezelfic genceskrachtige eigenschappen als de D. stramonium. Wildenow vermeldt, dat wanneer vele dezer boomen in eenen tuin bij elkander staunde to gelijktijdlig vele geopearle bloemen hubben, lumne uitwaseming in stat is om bij zwakke menschen stuiptrekkingen te weeg te brengen.

266. Boт. Nir. - Datura alba Nees.

INL. BEx. - Koetjoeboeng boddas S; K. poetie M; Toejong pongor Mand.

Gr. Pr. - Op zandige gronden in Oost-Indië, Java, Sumatra, enz.

Gism. - Wcgens de bedwelmende eigenschapluen dezer plant, vooral der bladeren en vruchten, wordt van haar door de Indische rolkeren tot een geneeskrachtig en miscladlig doel raak gebruik en misbruik gemaakt. Reeds $\mathrm{A}$. Costa en van Iinschoten kenden deze krachten, darr zij verhalen dat zij in lumnen tijd misbruikt werd door ligte vrouwen tot bedwelming van manspersonen. Tolgens Fir. Pijrard zouden de mannen opl de Maldivische eilanden haar bezigen ter bedwelming van meisjes en vrouwen, om deze tot humen wil te krijgen. Endlicher geeft aan, men gewoon is hare zaden ander de opiumpraeparaten der Oosterlingen te mengen, en zij gerookt wordende eene eigenardige soort van welbehagen te weeg brengen. Hasskarl zegt, dat op Java van alle Daturasoorten van de fijngewrevene bladeren, vrucht en zaad het sap bij lieden welke ijlende zijn wordt in de oogen gerlrupletil. Nare bekomene inlandsche oprgaren worlt het kruid ran deze on de rorige sonrt veelvulligg anngewend hij hoofdpijn, verwondingen enz. als pijnstillend middel; en zoutden dieven zich van hetzelve des nachts bedienen, de rook in de kamers blazende, om de zich in deze bevindende por- 
sonen in conen vasteren slaap te brengen. Ook Furopesche geneeshecren in deze gewesten bezigen deze soort vaak ter vervanging van D. stramonium I. en wel, zoo als Waitz beschrijft,

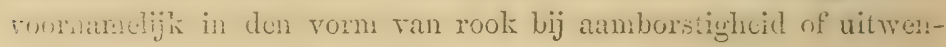
dig in verzachtende en pijnstillende kataplasmata.

267. Вот. Nr. - Datura metel L. $\approx$ D. nigra Rmph.

INT. BE.. - Koetjoeboeng kassian S.

Gr. PL. - Oost-Indië, Zuid-Amerika en Zuidelijk Europa.

ĆEBR. - Het bij de vorige plant opgegevene zoude grootendeels ools op deze toepasselijk zijn; bchalve dit vermeldt $110 \mathrm{~g}$

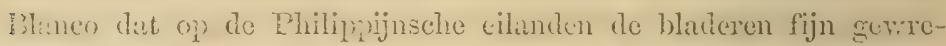
wn en nitwerndig bij seimhiss angewend worlen ch Lincileij rat 16e priesturs in den tempel te Duluh deze zonden gebruilit liebben, om hunne voorspellingen te kummen berrerkstelligen.

268. Вот. Nur - Datura fastuosa $\mathbf{L}$.

IXL. LEY. — Koetjoeluoeng kassian S; K. soesoen S.

Gr. PL. - Oost-Indië, Afrika, aangekweekt in Europa cn Amerika.

Griser. - Ook deze plant is in werking bijna gelijk aan de 1). strun:onium. Ifor fül açit: "de Inclische rolkeren kennen? " an deze grootere krachten toe dan an de D. stramonium; zij " wordt beschonwd als een uiterst goed middel tegen asthma " op de kust van Coromandel en Ceylon; de Javaan bezigt "haiar hufilzakelijk als anhelminticum en nitwendig hij herpeti"sele zikliten; zij wordt in tuinen dikwijls als sierplant aango"kweekt."

Volgens Blanen worten re bladeren nitwendig hij abeesten gebezigd. Pereira rermeldt dat Dr. Christie in 1811 voor het eorst de andacht op dezelve vestigde. De IIr. Skipton gaf cen alkorksel der wortel tegen larampachtige anmborstighed en br. Ariams achruile cone tin!tum bereid op le wijze ran Tra Disi1alis. Tolgens Armolit buit zij dezelfile eigensehappen als de Jeilutoman, onk met betrakking tot de inwerking op de pupil.

269. Вот. Nıг. - Phijsalis angulata Hsskl.

INI. BE.. - 'ljentjenettan S; 'Ijenattan S; Tjiploekan J.

Gr. PL. Java, de Philippijnsche oilanden enz.

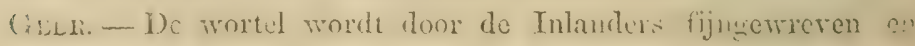


dectrokkon uan zeex kleine kinderen to drinken geroven hij buil. juen, rooral tegen wormen; de rijpe vruchten worklen goegeten. Tan deze lartsten zegt Blanco, zij bij lijjlropsiën, piszickion, ecclzucht on villende zickte worden toegudiend; acht vruchtjes zouden per week gegeven worden.

270. Вот. Nлr. - Capsicum annum L.

Ivц. BEN. - Tjabeh gedeh S; Lombok J.

Gr. pu. - In Azie, Afrika en Amérika tusschen de kecrkringen; op Java wordt hij veel rondom de huizen en in tuinen aangekweekt.

Greir. - De Inlanders bezigen de rijpe en omijpo rruchten fijngestampt bij let toebereiden ran de meeste hunner spijzen: de bladeren wenden zij bij furuneuli en onderbuikszieliten nitwendig ann en het sap drumpelen zij in de oogen vin lijders aan hevige ijlente koortsen. Sommige Amerikanische rolkstammen bezigen hes sap bij lnume pijlirergiften. (Zie omtrent de vurtere genecskrachtige annwending de rerschillente handhoeken over materies medica.)

271 Bот. Nri. - Capsicum sinense Jeq.

IvL. BEN. - 'Tjabeh tjina Mr.

Gr. PL - China, op Java veelvuldig als sierplant in tuinen.

GERR. - De vrucht wordt somwijlen bij spijzon gobruikt.

272 Вот. NM. - Capsicum baccatum L.

Gr. PL. - Indië, Zuid-Amerika, Guinea, op Java veelal als sierplant gezocht.

GEBr. - Oolk de vruchtjes dezer, welke zeer scherp en bijtend van smath zijn, worden soms tot kniding van spijzen gebeziggd.

273. Вот. Nir. - Capsicum oblonge Hort.

Gr. PL. - Wordt op Java veclvuldig in tuinen als sierplant gevonden, en is waarschijnlijk van elders ingevoerd.

274. Bот. Nx. - Capsicum fastigiatum Bl.

IxL. BEN. - Tjabeh rawiet S; Lombok seetan J.

Gr. PL. - Oost-Indië.

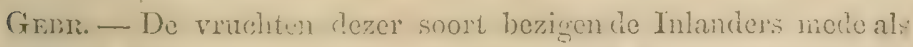
condiment hij hrmne spijzen, zij zijn echer veel scherieri dan eenige andere soort. 
275. Bот. Nu. - Solanum verloascifolium $\mathrm{I}$.

INI. 13Ex. - 'Tatter S, MI \& J Lanting Manul.

Gr. pr. - Zuidelijk Azië en Amerika, Java, 'Y'imor, de I'hilipijinsche cilanden enz.

GEBr. - Van deze plant, welke ook verdoovende eigenschappen zoude bezitten, verbranden volgens Hasskarl de Javaneu de stengels en gebruilien de alsdan uit deze vloeijende sappen tot zwatrurwing humer tanclen en onk tegen kiespijn. Nog eten zij de vruchten, na alvorens ze geroosterd te hebben en geven de bladeren aan hunne honden te eten om deze tot de jagt op groot wild aan te zetten; met zout fijngewreven dienen zij de laatste ook toe bij loofdpijn en aan kraamvrouwen. Ninneer paarden met drocs behebt zijn, stoppen zij dezen in den nous een mengied bestaancle nit dawon tatter, dawoin pepareh (fol. MLmordicae Charantiae L.), lankwas meirale (rad. AIpiniae galangae Sw.), bawang meirah (bulbi Allii ascalonici L), djinten itam en (ijerock tipies (suecus Citri limonelli Hsskl.), laten hen daama gocd warm loopen en baden, waarna uit den neus, dikwijls met vrij gocl gevolg, spoerig veel taai slijm begint te rloeijen.

276. Вот. Nu. - Solanum flavescens Dun.

I.I. Br. - Karoendoeng $\mathbf{S}$.

Gir. PL. - Trinidad, Java.

Grizr. - De vruchten worden soms gekookt bij de rijst gegeten.

277. Bor. N'r. - Solanum pseudo-saponaceum Bl.

IIL. MEN. - Takokkak boddas S; 'Texong tjina MI; Magai M.

Gr. Pr. - Op Tava in onbebouwde oorden.

Gissr. - Nadat de vruchten van zaad ontdann zijn, worden zij met 'enigzmur (tamarinde, azijn) toebercirl en lijj de rijst genuttigd.

278. Вот. Nr. - Solanum macranthum Dum.

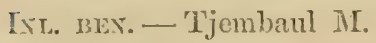

Gr. PI. - Brazilie, op Jara als sierplant in role tuinen.

279. Вот. Nar. - Lijeopersicum eseulentum Mill.

INI. IEx. - Bonclot S; Leuntja komier S; 'Tamatta MI 'Terong blanda $\mathrm{J}$; Belondottan $\mathrm{J}$.

Gr. I'L. - De liefde's-appel behoort in Zuid Amerika to huis, doch workt in alle warme en gematigdo luchtstreken veelvuldig als sieraatplant anngekweekt. 
Gerr. - De vruchten, lichde's-appelen bijgenaamd, lobben dezen naam bekomen door de veronderstelling dat zij genuttigd wordencle de kracht zouden bezitten om teedere gevoelens op to wekken; zij worden op rerschillende wijzen tocbercid als tocspijze genuttigut; ook de bladeren zouden, zoo als liumphius atangedt, in de MLolukkos als groente bij visch gegreten worden. Uitwendig ancewend roumen Irongatarsche geneesheeren deze vrucht als cen voortreffelijk middel tegen anthrax. In den laatsten tijdheeft Bennet haar ook tot inwendig gebruik aanbevolen, on gelooft liij zelf's calomel daarmede te kunnen vervangen. $O_{p}$ de Philippijnsche eilanden bezigt men de bladeren als cene vuilgroene verfistof:

280. Bот. Nur. - Cestrum foetidissimum Jeq.

Gr. PL. - West Indie, op Java in vele tuinen.

Grin. - De meeste Cestrumsoorten zijn bitter en bezitten verzachtende, verdoovende en pischrijrende eigenschappen; zij worten in verschen toestand tot zuivering van wonden en zweren gebezigd. De gekneusde bladen en vruchten wendt men in Brazilie aan tegen leveraandoeningen en catrurhus der blas. Eone soort, C. diurnum $\mathrm{L}$, geeft men in Peru tegen koorts.

\section{SCROPIULARINEAE RBr.}

281. Вот. Nur - Angelonia II \& B. (spec 1.)

Grr. PL. - Zuid Amerika, op Java als sierplant in vele tuinen. 282. Boт. Nx. - Browallia elata $\mathrm{L}=\mathrm{B}$. demissa $\mathrm{L}$.

Gr. PL. - West Indie, Guijana, Columbia, Brazilie, op Jara als sicrphant overgebragt.

233. Вот. Ny. - Torenia oltusa BI.

IXL. BEx. - Djoekoet mata keujup S.

Gr. PL. - Westelijk Java.

28t. Вот. Nur. - Buddleija salicina Lam $\leftleftarrows$ I3. asiatica Lour.

Ir.. BEx.- Kihinissan S; Kimonjenjen S; Kipierict S.

Gr. PL. - O. I. Sehiereiland, Poeloe pinang, Java.

Grisr. - Volgens Hasskarl worden de bladen boven vuur rerwarmd en op den buik gelegd bij likoortsen.

285. Loт. Nir. - Buddloija Lindleijana Fort. 
Gr. Pt. - China en bịliggende silanden; op Jara in sommigg tuinen.

256. Bot. Mar - Diccos ioncifolins Prs $=$ Artanema sesamoides Bnth.

IXI. BE.Y. - Wiedjion allas S.

Gr. PL. - Oost Indie, Ceijlon, de Philippijnen, Java.

287. Bor. Nu. - Russelia juncea Zucc.

Gr. pr. - Dhexilo, nis Jave rechitig alo siexphent in tuinen.

\section{ACANTHACEAE RBr.}

288. Вот. Nu. - 'Thunbergia alata Boijer.

289. " " " " " $\operatorname{var} \beta$ aurantiaca Jeq. en 290. " " " fastruosa Schltu.

IXL. BEX. - Waarschijnlijk Patoek manoek of P. gagak S.

Gro. PL. - Deze schoone slingerplanten vinrt men in onsiclijk Afrika, luet Oost Indiche Sclierciland on op Jara in liet wild en in tuinen.

201. Bor. Ny. - Tucllia brasilineis Iiont (an Di,teracanthuts Schauterianus $\mathrm{N}$ ab E).

Gr. PL. - Uit Zuid Amerika naar Java overgebragt, en onder den esrsten naam ran Bhitenzorer aan rezen tuin trenezunden.

GEBr. - Sieraadplant.

292. Вот. Nir. - Barleria prionitis $\mathcal{L}$.

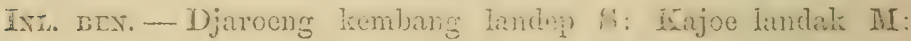
Bonga landap J; Gomo landak J.

Gr. PL. - Oost Indie en alle deze eilanden in het wild en voor heiningen.

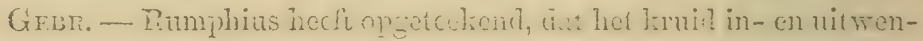

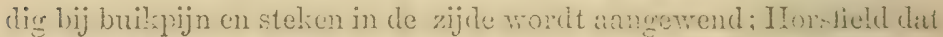

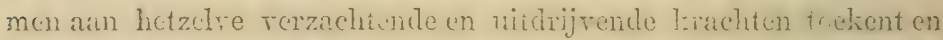
Hasckarl dat de bladeren met cen winig kalk fijngevieven op let voorhoofd ingesmeerd worden bij hoofdpijn, enz.

293. Вот. Nм. - Barleria multiflora Hsskl.

LYL. BEN. - Djaroeng boddas S.

Gr. PI. - Java, in het wild on tot ombeining ran tuinon. 
29!. Вот. Nir. - Barleria eristata L.

IXL. BEX. - Djaroeng woengoe S; Dj. blaảuw $\mathrm{M}$.

Gr. PL. - Oost Indie; op Java veel in heiningen.

GErrr. - De inlanders kooken den wortel met adas en poclassarie en drinken dit afkooksel tegen lendenpijn.

295. Bот Nar. - Crossandra infundibuliformis N. ab L.

IYL. BE.Y. - Djaroeng boentoet oetjing S.

Gr. PL. - Oost-Indie, op Java veelal als sierandplant gezocht. 296. Bот. Nм. - Graptophijllum hortense Nees, var. A album IIsskl.

INL. BEN. - Handullum boddas S; Tommon J; Dawon toclak

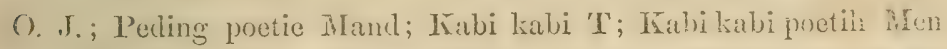
297. Bøт. Nir. - Ginptophijllum hortense Nees, var. 13 viride Hsskl.

IYI. BEN. - Handullum hiedjoe $\mathrm{S}$, en

298. Boт. Nir. - Eraptophijllum hortense Nees, var. C' rubium Hsskl.

IxL. BEx. - Handullum burrum S; Temman J; Demong J; Selantom Mand; Loelajo 'T; Kabi kabi meirah Mn.

Gr. r'. - Oost-Indie en archipel, de Philippijnsche cilanden cinz, op Java veelvuldig in tuinen.

Ciebr. - De bladeren van deze rondom de woningen der Jaranen reelvuldig angekweclit wordende planten worden door lıen gehruikt tot versiering lumner fiestmaaltijelen, tot reinigin: van hun hoofdhaar; fijugewreven smeeren zij ze bij hoofdpijn voor het voorhoofd; blateren en schors wenden zij ils ver. deetend on rijpmakend mildel in pappen bij rerschillende verhardingen, gezwellen aan; met water afgetrokten dienes uij de: bladeren uit- en inwendig aan kraamvrouwen toe, wanneor deze zeer vermoeid zijn. Ook van de Philippijnsche cilinten schrijli

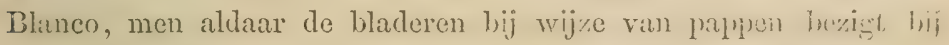
vorharde gezwellen en bij eene huidzielite, Sarna genaamd.

299. Bот. Ny. - Gendarussa adhatoda Std. = Adhatodit vasica $\mathrm{N}$ ab E.

INt. BEX. - Boeboekoean S; 'L'itempéan J.

Gr. PL. - Oost-Indië en eilanden, Cuba, Mrartinique.

GeBr. - Volgens Geiger waren van deze heester vroeger de 
reuklooze bittcre bladeren onder den naam van folia Adhatodice in de apotheken anwwezig. Volgens Lindleij worden de bittere en exnigzins aromatische blocmen, bladen en vruchten der Adhatoda gezegd krampstillende eigenschappen te bezitten.

300. Вот. Nм. - Gendarussa vulgaris Nees.

IvL. BEv. - Handaroessa of Gandaroessa M, J \& Bd; Daussa Bali; Sisangkil Mand; Sosa Amb.

Gr. PL. Oost-Indië; op Java veelal in tuinen.

Gerri. - Van deze struik zouden volgens Rumphius cie rortels, in atkooksel ingenomen, goed zijn bij koortsen en cliolera. Du fijngewrevene blauleren bezigen de Inlanders nitwendig bij hoofdpijn, koorts, lendenpijn en furunkels, tot dit einde wrijven zij ze dikwijls met plassariebladen en water fijn tot eene soort van pap. Een aftreksel der bittere eenigzins aromatische bladen heb ik dikwijls met goed gerolg als zweetdrijwend nidAul bij katariluale koortsen toegediend; dit aftreksol zoude volgens Blaneo ook zeer dienstig zijn bij keelaandoeningen. Volgens IIorsfich zoude men an de Gendarussa bruakrerwekkende cigenschappen toekennen; hij vermeldt niet of men dit aan de wortels, dan wel aan de blacleren doet, van de laatste heb ik deze werking nimmer bespeurd. Windelijk hailt Lindleij nog an men in Indiö de gerouste bluderen uitwendig bazight bij rheumatismus met zwelling der gewrichten.

301. Вот. Ny. - Rhinacanthus communis Nees.

Ixt. Bex. - Kalawara S; Trebeh djapan S; Akkar treba Mr; Dinwon boerong en D. sarong boerong Mr.

Gr. pu.-Oost-Indië, op Java in het wild en tot hoiningen.

Gerr. - De wortel met aziju afgetrokken of wel de blinderen met zout tot een papje fijngervreven worden op Java uitwendig gebezigd bij scabies en herpes circinnatus, en bij deze latatste wannecr de kringen niet al te nitgebreid zijn of wanneer geene algemeene ziektevorm, b. v. sijphilis, ten gronde ligt, dikwijls met zeer goed gevolg; in vele apotheken vindt men dan ook togenwoordig acetum on tinctura Rhinacanthi in voorraad roorhinden. In Europa werd dezo werking roor het cerst in 1820 bokend, en dezelve door Blumenbach anngewend. 
302. T3oт. Nur. - Dicliptera spinosa Hort $\rightleftarrows$ Barleria lupulina Tindl.

INL. BEx. - Tatempéan J.

Gr. pL. - Mrauritius, op Java in tuincu.

303. Bот. Nu. - Dieliptera bivalvis 131. $=$ D. jaraniea Nees. Gr. PI. - Westelijk Java.

Gris. - Beiden worden vaak als sieraadplanten aangekweekt.

\section{BIGNONIACEAE RBr.}

304. Bот. Ny. - Calosanthes indica BI.

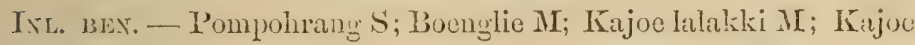
lanang M.

Gr. PL. - Oost Indie, Malabar, Java, Palembang.

Gebr. - Omtrent deze plant vindt ik alleen door Hasskarl p. 103, 758, melding gemaakt, waar hij schrijft: "de schil wordt "gestanpt en met water aangenengel en dit bij die maagzickte ge"dronken (njeurieh hateh of sakit atie), warbij een gevoel ran " hitte in dezelve en geen eetlust voorhanden is. Ook de bladen "worden op gelijke wijze gebruikt. Bladen en blosmen worden "gegeten; de vruchten, nog niet rijp, echter $2-3$ voeten lang "zijnde, worden in stukken gesneden en de zaden daaruit weg. " geworpen en dan afgekookt en gegeten."

Op Java en in het Palembangsche vermengen oude Inlanders, meestal gegoeden of hoofden der bevolking, den wortel met verschillente andere kruiden en nemen dezen in tegen impotentia virilis.

305. Вот. Nu. - Bignonia chelonoides $L=$ Stereospermum chelonoides De.

INL. BZEx. - Kitjaang S.

Gr. PL. - Oost-Indië, Java.

GERr. - De bladen fijjngesneden en vermengd met zout, zemelen en

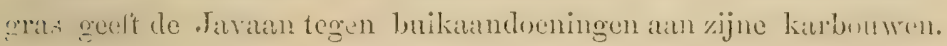

GESNERLACEAF Endl.

306. Bot: Nir. - Gesneria barbata IIrt. Lugd. Gir. pr.. - - Op Java als sierandplant in de tuinen anwezier. 


\section{MIJJRSINFAE RBP.}

307. Вот. Nu. - Mraesa latifolia Dc.

INL. BEX. - Kipüet lumboet S.

Gr. $\mathrm{rI}_{\star}$ - Java.

Grisi. - De bladeren worden raauw gegeten tegen graveel.

308. Вот. Na. - Maesa japonica Hrt. Bog.

GR. r'. - Schijnt uit Japan naar Java te zijn overgebragt en aldaar als sierplant anngekweekt.

\section{SAPOTACEAE Endl.}

309. Bor. Nur. - Achras sapota I $\leftleftarrows$ Sapota achras MIll.

INt. BEv. - Boewa saauw S. M.

Gr. P... - Jamaika, Venezuela, Oost Indie, op Java in tuinen ingevoerd.

Geer. - Van dezen boom, welke om zijne lekkere vruchten,

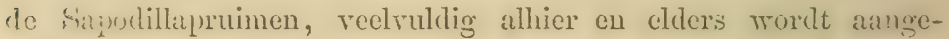
kweelst, bezit de bast rijkelijk een bitter melksap, en wordt forn verschillende schrijvers als koortsweerend middel aangeprezen, en ronmamelijk in Amerika als zoodanig aungewent. Tolgens Lindleij zoude zij ook ecne rette olie beratten, welke tol lutishouldijk gebruils wordt anngewend. De bittere zalen, gratna stpodillae, zullen als openend en pistrijvend middel bij rele aanlueningen der urineaf'schuidende werktuigen heilzatam werlsen; in al te groote giften celiter hevige pijnen veroorzaken en soms gevarilijk worden. De Jaraan schijnt slechts luct schoone hout tot rerraarliging ran fijne meubelon te bezigen en de rruchten als lekkernij te beschouwen.

310. Вот. Nyr. - Mimusops elengi L.

Irt. nis. - Tandjong MI; Iíembaug tandjong MI; op Jitra heeten de vruchten Ketjée.

Gi. rL. - Oost-Indië, in deze gewesten veelruldig als sieraarplant in tuinen gezocht.

Grißr. - Van dezen schoonen boom met klcine, frataije en sterk-

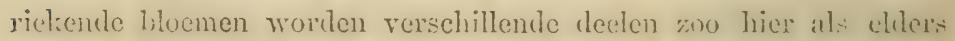

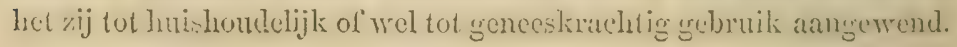


De wortel met azijn fijngewreven is volgens Rumphius goed bij zwelling dess anngezigts; met water gewreven seef hij ol het good is duarmede tegen spruw den mond te gorgelen. De bast. des booms prijst genoende schijver in afkouksel tegen angina en tandpijn ann; rolgens Horsfield is zij een goed tonicum en in eenige declen rim dit ciland gebruikelijk bij koortsen en als eeu algemeen versterkend middel zeer gezocht; en terwijl IIasskarl nog opgecit diut ze fijngetvreven op schurftiga plaatsen aangewend workt, verzckerden mij verschillende inlanders dat zij met de jonge bladeren, met adas en plassarie vermengel, vechuldig tegen siruw (salkit sariawan) gerreven wordt. IIet hout, rlat grof en sterk is en ligtelijk done witte mieren wordt aangetast, is geschilit tot verschillend draaiwerk. De bladeren, welke op het vuur geworpen stcrls knappen, zonden fijngewreven en roor het roorhoofil gessneerel goned zijn bij honfilpijn; met artas en plassarie vormengul ingenomen en ouk als tabak grurockt met goed gevolg bij spruw gegeven worden. De wolriekende blocmen worden anneengeregen in liet hoofthan gedragen; nit deze eene aetherische olie en water gestookt, welk laatste Iimmphius zegt men aan koortlijiters te trinkein gecft. De rijpe rrichten, welke cen korrelig, zoetachtig en matig zamentreklisencl vleesch bezitten worden gregeten, en ook met waiter fijnguwreven aan in barensnood zijnde vrouwen te drinken gegeven. Uit de zaden wordt eene vette olie verkregen, welke door de schilders zecr gezocht is en ook bij de baring zoude toegediend worden.

\section{UMBELLTEERAF JS.}

311. Boт. Nir. - Hijdrocotijle asiatica L.

INI. BEN. - Antannan gedele S; Dawon pegagan Bt; Dawon knekocran II; Dawon kaki koedi M; Sendag (). J; Rabaspa en Penggaga J; Paidoh Bali; Aijlaun rihute en Assotelina laun Amb: Aijlaun kapepoeli Lh; Bissi mattan Bd; ISoloditi manoma en Línoditi massour $\mathrm{T}$.

Cr. PI. - Op rochtige plantsen in bijna de scheele zuilelijle en intertropische aardgordel, doch variecert vecl in grootte en 
sanzien; op deze eilanden vindt men haar bijna overal in grasvolden, langs en in sawa's.

GEBr. - Van deze wanlijke nuttige en op Java veelvuldig [zelmikt wordende plant geeft Endlicher an, dat zij vroeger om luare oplosiende, pishrijrende en wondheelende eigenschappen in de apotheken was opgenomen; dat deze zelfte lof ook anu andere Aziatische en Amerikaansche soorten wordt toegekend.

De meer bejkildulijk over Indische plinten handelende schrijvers geven het volgende aan: "Rumph. Amb. kruidb. DI VI, "men eet de bladeren bij de rijst als groente; nitwendig bezigt "men dezelve reclvuldig op kleine beenzweeren, om deze spoe" dig te doen heelen. MTen geeft het kruid en het sap han kleine "kinderen tegen wormen en buikpijn. Kaauwt men het met "pinang, dan is het een tegengift tegen vergiftigde spijzen. Het " kruid zonde cen heilzaam middel zijn tegen graveel (sakit gir"gissan) en waterzucht, als zijnde zeer pisdrijvend, ook tegen "astlima en kinkhoest."

Hasskarl op pag. 3 zijner aanteekeningen enz. geeft alleen aan, diat de bladeren als toespijze bij de rijst ratuw en gekookt worden genuttigd.

Blanco in zijne Flora de Filippinas 1839, zegt: "dat men het "sap bij ooglijden, wanneer de bulbus oculi rerwond is en ook "bij nubeculae correae aanwendt, men toucheert namelijk de oo" gen met de af'gebrokene bladsteelen; verder dat men or eene "siroop van maakt, welke bij verkoulheid wordt gredronken."

Horsfield bevestigt dat zij is nuttig bevonden tegen grareel cn gemeenlijk tegen druiper wordt aangewend. Inlandsche berigten door mij zoo hier als elders op Java ingewonnen bevestigen, dat de plant veelvuldig als groente wordt genuttigd; dat het kruid bij verkoudlueid, hocst, wordt toegedicnd en als pischrijwendo middel zeer heilzaam is bij gravecl, waterzucht on bij het nicrenlijklen door let misbruik ran djengkol (de vrucht ran Inga bigemina WVld.) vaak opgewekt. Ook rele Europescho geneeshecren in dezc gewresten schrijwen haar tegen wroordig tegen waterzucht voor, en 'en heb ik ze zell's tegen chronische dijsenterie (!) zicn treedienen. Wat de resultaten hieremtrent zijn gewest is mij bij gebrek aan zelfprocven nict volkomen bekend, wensche- 
lijk zal liet cohter zijn dat met deze plant meer naauwkenriger procven genomen worden, te meer, daar ik goloof wij spoedigy door seheikundig onderzoek met liare werladidige bestanddeclen bekend zullen zijin.

\section{ARALIACEAE JSS.}

312. 13от. Ny. - Panax cochleatum De.

IVl. 1BEN. - Mamangkokan S; Dawon mangkok MT; Dawon papela II; Dawon koijn MI; Dawon tapaleman Mand; Aijloloij en Aijlatun niwel Amb; Dawon grisek Bd; Goera bate en Rauparoro 'T.

Gr. PL. - Java, Sumatra, de Moluksche eilanden.

Gisr. - Van dezen fraaijen heester, uit welks afgeliouwonen stam ecne op Opoponax gelijkende gomhars vlocit, bezigt de Inlunder viak de natx sehotcltjes gelijkende blaten als horden bij zijnen maaltijd; hij eet ze als groente afgekookt bij zijne rijsst; de jonge bladen, welke cenen sterken eenigzins naar peterselie zwecmenden reuk bezitten, worden op Jaya in klappcrolie gelegd en deze olie door rrouwen in het hoofdliaar geberiggt. Rumphius en anclere geven aan, dat de bladen en vooral de wortels zwreet- en pisclrijvende eigenschappen bezitten, waarom zij inzonderheid tegen gravecl worden toegediend. Op 'Ternate zoule men de-met klapperolie bestrekene bladen op zwerende borsten leggen.

313. Вот. Nur. - Panax fruticosum I.

IYL. BEx. - Kadongdong laut S, Mr; Kadongdong batoo S, Mr; Dawon papeda papoea MI; Sarile halat Amb; Goera batoe en 'Tampoesong 'T.

GI. PL. - Java, Amboina, 'Termate.

Geris.-Ook van dezen schoonen, tot omheiningen dikwerf gobezigd wordenden hecster worden de zumachtig smakende bladeren raauw en gekookt als groente gegeten; met water fijngekneusd, worden zij uitwendig bij pokken gebruikt, wannecr deze sterke jeukto veroorzaken. Inwendig toegediend zijn de wortel en bladeren sterk diuretiseh, veel krachtiger dan die der voorgaande soort. Fien afkooksel van wortel en bladeren bezi- 
:jen volgens Rumphius de vrouven als stondendrijvend middul. 311. Вот. Nar. - Sciadiphijllum scandens Dc.

Iys. BEX. - Kiradjoen S; Ramok giling S.

GR. PL. - Cheribon.

Grare - Volgens Ifasstarl worden de sappen gedronken bij ziekten van het tandvleesch; men neemt ook stukken van het hout of de taklien, brandt deze op den cencen kant, waardoor de sappen op den anderen Fant nitloopen, warmete alsclan het tandvleesch wordt ingewreren. Nog worden bast, bladeren enz. nitwendig tegen beenpijnen en rheumatismus aangewend.

315. Вот. Nur - Hedera aromatica Dc.

INL. BEN. - KKirendang S; Pagang poejoe S.

Gr. PL. - Java.

Gebr. - Het hout is geschikt voor huisbouw.

316. Bот. Nr. - Hedera nodosa Hsski.

IVL. BE.. - Kilanghit S; Kadoja of Kedojo J.

Gr. PL. - Westelijk Java.

GEbr. - Het hout is zeer goed roor bouwhont; de bladeren worden in het water geworpen om visschen te bedwelmen.

317. Вот. Nir. - Heptapleurum rigidum Hsskl.

Tru. DEN. - Sango bocana s; Djangkorang MI; Toelak tangal $M$.

Gr. PL. - Westelijk Javr.

GEBr. - Het hout is geschikt voor bouwhout.

\section{AMPELIDEAT Tith.}

318. Bot. 'Nur. - Cissus arachnoidea Hsskl.

INL. BEX. - Boengbocroctoe S; Goengoeroetoe S.

Gr. pL. - Oost-Indië, op Java vooral in Bantam en Buitenzorg.

Grer. - Het getal der Cissussonrten, schrijft Endlicher, is ontelbaar; sommige derzelve wendt men om humne verkoelcnde en oplossende eigenschappen in de rollsgenecskunde am, ran andere dienen de jongere bladeren afrekookt tot spijs. Op tara celruilst men ran deze sonrt de blarleren tot reiniging ran het hoofthaar; van de zoete rruchten, - zegt Blume, lare druiren 
overireffen in grootte die des wijnstoks, terwijl zij in overvlood on zoetheid van sap voor deze niet wijken. De inlanders zijn zeer op deze verlekkerd; ook worden zij gebruikt om cenden te voederen en dit gevogelte meer eijeren to doen leggren.

319. Вот. NM. - Cissus quadrangularis L.

Yrt. BEN. - Hariang S; Sala lakoe Mi; Tikal baloeng J; 'Tikal toelang $J$.

Gr. PL. - Zuidelijk Azie van af Arabie tot Cochinchina, Java.

Gerr. - Een afkooksel van de stengels met tamarinde vernengi berigen de Inlanders uitwendig tegen rheumatische pijnen; volgens blauco worlt deze plint ook tegen slimgenbuten nangewend.

320. Bot. Nur. - Cissus repens Lam.

IYL. un. - Aroij hariang , Aroij karoklsot S; Dawon bisol Mr; Sumbung toelang Bali; Wari lottoe lottoe $\Lambda$ mb; Goemi rotto rotto ' $T$.

Gr. pL. - Malabar, Java en verdere eilanden.

GEBR. - De bladeren worden in plaats van zuring bij let bereiden van spijzen gebezigd, ook wrijft men met deze verschillende houtwerken, om de aderen van het hout beter te duen uitkomen en dit meer glans te geven. Volgens liumphius legt men ze op Bali op beenwonden, en worden zij met goed gevolg, na met kurkuma en zout fijngewreven te zijn, op furunculi enz. aangewend.

321. Bот. Nur. - Cissus crenata Vhl.

IrL. IBEx. - Aroij landuk leutiek S; Matta oedang MI.

Gr. PL. - Oost Indie, Java.

Gism. - De zuursmakende blateren bezigen de iulanders dikwijls tot het toebereiden hunnor spijzen, wenden ze als zuiverend en rijpmakend oplegsel voor zwecren en abcessen aan cn wassehen mot hen humne met schurft (kocdik) belıcbte lutusdieren.

322. Boт. Nn. - Vitis vinifera $\mathrm{L}$.

INt. BEx. - Pohon boewah anggor MT.

Gri. r's. - Zuidelijk Azie, Europa, naar Java overgebragt en

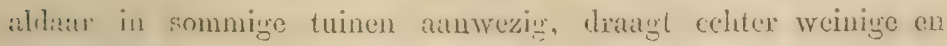
zure rupheliten. 


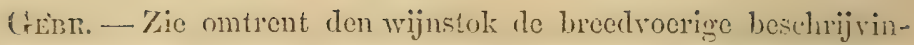
gen in de verschillende handbocken over geneesmiddellecr, enz.

323. Bor. Nu. - Vitis sijlrestris B1.

IYL. BEY. - Aroij sirareb S; Djebis oetan MI; Gangh J; Riany-riang MLand; More More MLak; Kükoeti loeti Bt; Libe latoen Bon.

GR. PL. - Java en omliggende eilanden in bergachtige streken.

Gebr. - Rumphius haalt slechts aan dat de rijpe vruchten gegeten worden. Volgens Hasskarl worden de sappen bij hittc de. ligcham gutronken en hiertegen ook de fijngewrerene bladen op de heete deelen of over het geheele ligchaam ingesmeerd; ook bij hoodilpijn zouden zij zeer dienstig zijn. In MImelheling berigt men de zure bladen mede als gुeueesmirlitel, men hectt mij cchter niet bepaald kumnen opgeven wartegen.

324. Bot. Nrr. - Leea rubra 131.

IxL. BEx. - Gingiang burrum S; Girang J; Mamadi Meu.

Gr. pt. - Op Java en elders op vochtige, moerassige plaatsen.

Grer. - De bladen en jonge takken van deze en andere Jecasoorten worden met asch fijngewreven en het sap dezer alsdan op verouderde en stinkende wonden gelegd, waarna deze spoedig een zuiver anzien verkrijgen. De rruehten worken bij wijze van roedjak toegediend tegen dijsenterie en frambocsiac.

325. Вот. Nr. - Leca sambucina Wld.

Ixt. BEx. - Selangkar S; Gingiang S; Kibncaija '́; Kajoc aijer parampocan Ni; Kalawassan J; Aijukka Amb; Kollo tala 'I.

Gr. PL. - Mrauritius, Oost Indie, op Java en eilanden op beschaduwde plaatsen.

Gerr. - Bij Rumphius leest men: "de blacten dezer worden " als groente gegeten; het sap verkoelt de verhitte oogen on de "Bladeren trekken den brand uit bij knortsen. Ifet geraspte hout "met gember tot eene pay gemaakt slart men om rerlinule leule" maten. In de MIolukko's bezigt men het hout en cle bladen op "wonden, ook als bloedstelpend middel."

Hasskarl, gehed orerecukomstigg de done mij ingewomene hejigten schrijft op 1). 108, 799, dat het salp hetwelk, wannecr ecn 
stuk hout aan het eene eincie gebrand wordt, uit den stam loopt, tegen dooflieid in de ooren wordt gedrupueld; dat men met de fijngewrerene jonge stengen het ligchaan insmeert bij cene zielste, welke den naam draagt van door den duirel veroorzaklt te zijn (sakit badie, sakit seetan). Als anulet plaats men stuklken van het hout in de bosschen om duivels te rerjagen on op de wegen, welke naar de kampongs leiden, on velerlei ziekten uit deze te weren.

326. Bor. Nis. - Leea robusta Rxb.

LY̌. IBEx. - Soelangkar S.

Gr. PL. - Java, vooral op den Megamendoeng.

GEbr. - De wortel fijngewreven en vermengd met adas (Anisum vulgare $L$ ), poclassarie (Alijxia stellata $R \& S$ ) en water drinken de inlanders tegen dijscnterie (sakit boewang aijer dara).

\section{CORNWAE Dc.}

327. Вот. Ny. - Aucuba japonica 'Thnb.

Gr. PL. - Japan; nare Java in tuinen overgebragt en als sieraadplant aangekweekt.

\section{LORAN'THACEAE Lind!}

328. Вот. Nrr. - Loranthus L. sp. plur.

INL. BE. - Mengando S; Taai bosrong M.

Gr. PL. - Parasietisch op vele boomen, vooral op Ficus-, Citrus-, Melia- en Mangiferasoorten.

Grar. - Bij Endlicher lecst men, dat dezo planten uit bijgoloof recels door de Druiden vereerd, dit ook dioner de Javanon worden gedaan, omdat zij bij roorkeur op de schaduwrijke takken hunner geliefle boomen, de Fïus benjaninit en Ir. religinsa leren. Volgens IIasskarl worlen de fijngurrerene bladen op eene sorrt ran schurft aangewend, welker blaayjes met ctter geruld zijn, (korreng iesienja bodtas, sakit kruies of sakit bangsar). De inlanders bezigen ze ook uitwendig, in de laatste stadia der kinderpokken, on ecne te diepe likteckenvoming te voorkomen. 


\section{CRASSULACEAE DC.}

329. Boт. Ny. - Kalanchoë laciniata De.

I.: T. 13Ex. - Boenticries S; Trjakkar hobck M: Patok bebek M; Aijhulia letjil \& Aijhuila mahina Amb; Alabobo en Krabi mangou 'T.

Gr. PL. - Mlauritius, Java, de MIolukko's.

Gezr. - De bladeren dezer plant worden door vele Indische volkeren, ook op Jiva oin humne verknelende en wondheelende cigenschappen aangeprezen; zij worden tot dit einde fijngewreven cir op de lijilende deelen gelegd, en zullen vooral bij hoofipijn cene zecr gocte werking batoonen. Volgens Rumphizus wordt het sap tegen koorts gedronken.

330. Bот. Nus - Brijophijllum calijcinum Slsb.

INL. BEx. - Boentieries konneng S; Patok bebek en 'Tjotjor bebek $\mathrm{J}$; Dingin-dingin Mand.

Gri. PL. - Mlauritius, Java, de Mrolukko's.

Gebr. - Al het bij de voorgaande plant vermeldde is ook op deze toepasselijk; roorts geeft Endlicher op, iets wat rele inlanders mij bevestigen, dit de blateren 's morogens vroog zuur. 's middags smakeloos en 's aronds bitter plegen te zijn. De bladeren worden ook in olio gelegd, daar deze olie de haargroei zeer zoude bevorderen. IIet sap wordt uitwendig aangewend bij hoofupijn en roode oogen.

\section{MLENISPERMACEAE De.}

331. Bot. Ny. - Anamirta cocculns Wgt \& Arnd. = QpdeutF

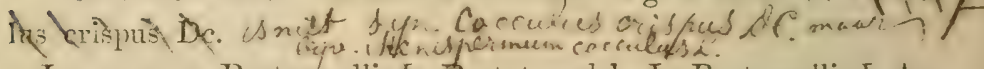

Irt. IBEx. - Poctratralli .f; Poetat waleh J; Bretowalli J; Antowalli en Androwalli Bali;

Gr. PL. - Malabar, Ceylon, Java, de Molukkos.

GeBr. - Over deze plant, waarvan de werking der zaden, don de in dezelve bevatte giftstoffen Pikrotoxine, Menispermine en Paramenispermine, in de verschillende handboeken over vergiftleer recds uitrocrig beschreven is, en omtrent welker geneeskrachtige anwending mon de in den laststen tijel in deze ge-

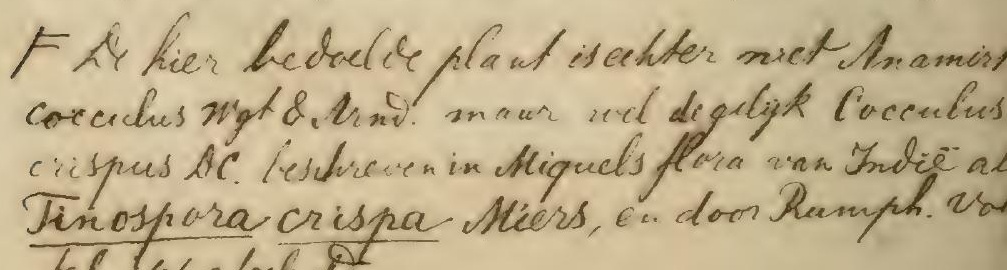


Werien genomene procven breedvoerig in den 3den en taien farrgang ran het Geneeskundig tijdschnit van Nederland,ch-hitliz lezen kan, wil ik slechts kurt zijn en mij hoofdzakelijk bepalen, bij datgene, wat vroegere schrijvers omtrent hare verschillende deelen hebben opgeteekend. Wat de geschiveluis; betreft, zoo leest men bij Geiger dat de kokkelkorrels reeds toor de Arabieren bekend waren, en roornamelijk dowr Aricunna en Serapion rermeld werden; dat zij in de Duitsche apotheken reeds vroeg ingeroerd werden onder den nam ran Bitcene cotulae elephantinae en ook ouder dien van Gullae orientales werden verkocht; dat Condronehus in 1581 eene verhandeling selireef over de wijze hoe men met dezelve visschen vangt; dat zij vroeger in den rorm ran kataplasma tegen jicht en podagra werden geroemd.

Rumphius geeft aan, dat de Balinezcin deze plant gobruiken togen koorts en geclzucht, ook nitwendig fijngewreven bij wijze van pleister tegen xug- en lendenpijn, terwijl de vrouwen haar tegen buikpijn innemen; liij noemt ze Funis fullens. I Iorsfield rangschilt haar onder de tonische gencesmiddelen. Blanco geeft van de Philippijnsche eilanden op: "De vrouwen bezigen de vmeh"ten bij dijsmenorrhoea; deze zijn ook een abortivum. MIen " doet de zaden in de darmen van een dier en werpt deze in het " water nm den kaaiman te vergiftigen, ook vermengt men de zaden " met andere kiniden on daarmede visschen te vinngen. Derien" en vierdendaagsehe koortsen verdwijnen, wanneer men een wa"terachtig of wijnachtig aftrelsel ran het hout drinkt, let zwoet " wordt daarloor geel gekleurd."

Omtrent de namwending in den jongsten tijd eindelijk reeft Geiger op: "als gencesmidelel worden de kokkelkorrels inwendig " niet gebezigd. Men strooit het poeder ol, het hoofil tot donding " van ongedierte; zij maken een hestanddecl uit ran het I'ulvis en "Unguentum pediculorum. Werpt men deze knorels in het wates "zoo worden de risschen daarloor bedwelmol, zoo dat men ze go"makkelijk vangen kan; zulke vergiftigde viśschen kumaca ech"ter ligtelijk nadeelig worden. Nog strafbaarder ir do antwen"ding der korrels bij het bereiden ran bier (Portor), om dit "bedwelmenter te maken, lutgeon roomanelijk in Enclant 
"geschiedon zal. De olie der kernen bezigt men in Indië tot "kaarsen, ook dient daar de wortel der struik als geneesmiddel, "even als de bittere stengels onder den nam van Putrawalli, " tot bestrijding van tusschenpoozende koorts."

IIet is hooflzakelijk de aanwending tegen laatstgenoemde ziekte, waarover uitvoerig de genomene proeven in het Geneeslsundig tijdschrift vermeld werden, en waaromtrent de resultaten zijn, dat de stengels dezer plant even als zoo vele andere bittere middclen wel bij ligte koortsanvallen goede diensten kumnen bewijzen, echter nimmer de kina of chinine zullen kumnen vervangen, noch toegediund worden bij die koortsen, welker onmiddelijke conpeering eene levens-aanwijzing is.

332. Вот. Ni. - Stephania rotunda Lour.

IXL. BEX. - Aroij gurrung boddas S.

Gr. PL. - Tangerang bij Batavia.

Gebr. - De ranken worden door de inlanders zonder eenige toebereiding om de lendenen gebonden bij lendenpijn.

MIJRISTICACEAE RBr.

333. Вот. Ny. - Mijristica fragrans Houtt.

Irt. Bey. - Pala M; Gozora 'T; Lauhau Ch.

Gr. PL. - Mtolukko's, Java, Sumatra, Bengalen, Bourbon, West Indie.

Gesr. - De inlander bezigt de muskaatnoot on de foelie tot kruiding zijner spijzen, en mengt ze ook dikwijls in zijne genessmidhlen, rooral bij die tegen onderbuiksziekten. Rumphin: vermeldt vele voorbcelden, waardoor hij van de noot en van de uitwaseming des hooms de bedwelmende en dronkenmakende kiacht wil bewijzen.

\section{ANONACEAE Dun.}

334. Вот. Hyr. - Uvaria littoralis Bl.

INL. BEN. - Kitjantoeng aroij S.

Gr. PL. - Westelijk Java.

GEBr. - De zocte vruchten worden gegeten; het sterke hout wordt voor vogelkooijen gebezigd.

335. Boт. Nir. - Uvaria odornta Lam.

INL. kEX. - Kananga ML, J; Kimanga wangi M; Kananga prit 
J; 'T'sampé .J; Sondat Bali; Kópabbar en IIopponabbal Aml): Kappawarita Lt; Saija kananga 'I.

Gr. PL. - Zuidelijk-Azië; op Java veelvuldig in tuinen.

GÉBr. - Van dezen on zijne geurige bloemen veelvuldig angephant wordenden boom, bezigt men het hout soms roor stijlen van huizen, welke echter spoedig rergan; de bast wordt met water fijngewreven en bij wijze van pap op de zijcle golengl bij knortslijiler's met vergrooting der milt (sakit koswaija); de bloemen wrorden door Inlandsche vrouwen veel in het haar gedragen en bij fuesten gebezigd; uit deze wordt eene vlugtige olie vurkregen, welke met Michelia champacea en andere aromatica benerens kurkumawortel tot eene zalf bereid wordt, waarmede men het ligchaam van aan koorts lijdenden inwrijft, en ouk vooral gobuzigd wordt om bij koude en regenachtige dagen de huid to verwarmen. De met koenjit [Curcuma longa L] en cljahej [Žingiber officinale $\mathrm{L}]$ te zamenfijngewrevene zaadkorrels zag Blume met goed gevolg uitwendig aanwenden tegen intermittecrenle koortsen, en wel bij een kind op de maagstreek, nadat mon to vergecfs langen tijd inwendig geneesmiddelen had toegediond.

336. Вот. Ni. - Artabotrijs intermedia Hsskl.

IVL. BEY. - Kananga aroij S; Kallak S; Kananga tjina MI.

Gr. PL. - Wordt op Java om hare gुeurige bloemen zeer bemind en in bijna alle tuinen geronden.

337. Bот. Nм. - Artabotrijs suaveolens Bl.

INL. BEx. - Aroij kiladja lalakki S; Kananga oetan MI; Tali karbau M; Doeri karbau MI Warimetten Amb.

Gr. PL. - O. I. archipel.

GEbr. - Van deze plant, welke veel tot omheining van tuinen wordt aangeplint, worden de rankende takken zamengevlnchten tot touw om koebeesten rast te houden, soms ook wordt van dezclve touw voor vischfuiken gevlochten. De blademenen afgetrokken eenen aromatischen drank, welke vonral togen cholera, laauw en veel gedronken, door Blume werd anngewend. De bloemen zijn om hunne geur gezocht.

338. Bot. Ny. - Anona muricata L.

IYL. BE.y. - Nangka wolanda M; Nangka sabrang M. 
Gr. PL. - Zuid Amerika, de Caraibische eilanden, op Java overgebragt.

GEmR - Do amgenann zumsmakende verfrisschende rruchten worden op Jivit als nageregt zeer gezocht, zij zijn tamelijk gezond, zacht laxeerend, on limmen matig gebruikt met vrucht als resolvens worden aangewend. Van dezelve zegt Endlicher: "hare vruchten munten zoowel door schoone vorm, als door "aangenamen smaak en lekkeren geur nit, van daar dat zij voor"al door Luropesnen roor lakkenij worden gehouden, terwijl " zij terens rijkclijk gonuttigd niet zoo als de andere tropische "vruchten voor de gezondheid schadclijk zijn, maar zolfs in ziek"ten der sijjsverteoringstoestel, zoo als in diarrhoe en dijsente"rie, waarbij greene ontstekingswrsschijnselen meer annwezig zijn, "eurler huilzaam zijn." Ontrent dit laatste merkt reeds Blceker aan, dat als dit van de boewa nonna (Anona reticulatd L) waur kan zijn, het van deze rrucht, de Zuurzak, stellig onwaar is. 339. Вот. Nм. - Anona asiatica L.

LYL EEx. - Sirikaija M. J' Mranüa papnea Amb; Boewa ati 'T. Gr. PL. - Ceijlon, op Java in vele tuinen.

Gresr. - De aangename, zoete vruchten dezer zijn mede op Java zeer gezocht en gezonder dan die der vorige plant.

340. Bor. Nar. - Anona reticulata L.

INL. Bey. - Boewa nonna MI; Nona Mi; Manoä M.

Gr. PL. - West Indie, op Java en verdere eilanden veel in tuinen.

GEer. - Van dezen op de Autillen to huis behoorenden, thans door relicel Limerika en ook over dezen archipel bijna algemeen rerspreidden boom wrijft de inlander de bast met water fijn en wendt deze uitwendig bij wijze van pap op de miltstreck aan bij lijilers met koorts en rergrooting der milt (salkit koewaija). De sterk riekende bladeren worden tot liet rijpmaken ran abeessen gel)ezigd en als wormdrijrend milhlel anngeprezen. De rruchten bezitten een geurig, zost, zecr fijn rruchtvleesch en zijn als lekkernij cloor velen gezocht; zij zijn zeer grezoud cn worden hoor rele schrijwers geteld onder de tegen diarrhoe en dijsenterie zecr heilzame geneesmidtelen, in Amerika worden zij daartoe voor 
de rolkomene rijpheid gednogd. Volgens Blaneo kunnon zij met water b:j wijze van thee afgetrokken als dagelijksolhe drank gुebruikt worden. Uit de zaden bereidt men een sterk zamentrekkend extrakt.

\section{MAGNOLIACEAE DC.}

341. Bот. Nı. - Talauma mutabilis Bl.

Ixt. bex. - Tjampakka leuwung S; Kirapat S; Toontjoeng M. S.

Gr. PL. - Westelijk Java.

Grbr. - Het hout bezigt men soms voor spinnewielen; de bloemen worden tusschen kleederen gelegd en in het hiar gedragen.

342. Вот. Nar. - Talauma pumila Bl.

INL. BEX. - 'Tjampakka gondok S; 'Tjoentjong S.

Gr. PL. - Westelijk Java.

GEBr. - De bloemen zijn door vrouwen zeer gezocht.

343. Bот. Nis. - Magnolia obovata Thnb.

IYL. BEN. ?

Gr. PL. - Japan, op Java als sieraadplant in eenige tuinen.

344. Boт. Nu. - Michelia Blumei Std.

INL. BEN. - Tjampakka burum S; Tjampakka Mi Kembang kantil J; Champé J; Bonga eijolja Mak; Koppatum en Kioppi poekkoeri Amb; Kubane Lh.

Gr. PL. - Op vele dezer eilanden in het wild en in tuinen.

Gremr. - Deze boom wordt om zijne geele, geurige doch spoedig verwelkende bloemen bijna overal in den Míaleischen archipel aangeplant; van zijn fijn en wit spint maakt men hrissraad en buffeljukken; het zwarte hout is zeer geschilit voor fraaije scheden van wapenen, geweerladen en de grootere stakken voor meubelen. De inboorlingen van beider sekse versieren met te bloemen hun hoofthaar na het bad en op feestdagen, strooijen de bloembladen tnsschen humne kleederen en op hunne legersteden of mengen ze in liunne zalven. Bijna alle deelen dezes booms zijn bitter, aromatisch of eenigzins scherp van smaak, warrdoor zij de ingewanden prikkelen, door vooral den bloetsomloop in het 
pontader- en banmocderlijk stelsel te rermeerderen. De wortellast in pocderroim met water toegediend, roept de maandstonden te roorschijn on drijlt bij lang en rijkelijk gebruik bij zwangeren de vrucht ait. Men prijst de bast aan ter bevordering der kraamzuivering; de nog niet geopende knoppen met klapperwater afgekookt worden tegen gonorrhoea gedronken; de bladeren met rad. Kaempfuriae rotundae fijngewreven bezigt men tegen arthritis, of wel afzonderlijk tegen graveel. Ook uitwendig worden zij als goneesmidlel angewend in badein tegen rheumatische en arthritische pijnen, als gorgelfhank bij angina cn tegen slechtrickenden adem. Een nit de bloemen gedestillcerd water geeft men in Malabar tegen flaauwie. De zaden eincleljjk, welke cene zeer scherpe siof bevatten, worden met gember en galangawortel tot pocder geturagt on lij kinderen, wellie aan tusschenponzende lioortsen lijden, in de magstreek ingewreren; zij zouden zoodoende goede dienston bewijzen. Tan het uit de zaden geperste sap merken Rheede en Rumphius nog aan, dat het tegen windzucht op den buik wordt ingewreven. Op Java, doch vooral te Batavia schijnt omtrent de geneeskrachten ran dezen boom den inlanders niets bekend te zijn.

345. Вот. Nur. - Michelia L. Sp. 1.

INL. BEx. - Tjampakka MI.

Gr. PL. - In tuinen als sierplant.

\section{DILLENIACEAE Dc.}

346. Вот. Nм. - Delima intermedia B1.

IXI. BEx. - Kiassahan lalakki S.

Gr. PL. - Westelijk Java.

Grвг. - De cenigzins rankende stengels worden als touw gehezigd, doch zijn niet zeer sterk; het sap uit deze wordt bij oogzwakte in de oogen gedruppeld.

PAPAVERACEAE JSS.

347. Вот. Ny. - Argemone mexicana L.

IXI. BEX广. - Iempoeng S; Toedjoc J. 
Gr. ru. - Mexiko, tegchwoordig op Java bijna verwilderd.

Gerr. - Van de West-Indische klephoul hebben rerseheidene inlanders mij rerzekerd, dat soms de bladeren door hen als groente worden genuttigd en zij fijngewreven deze nitwendig tegen parotitis bezigen. In West-Indie geeft men een aftreksel ram dezclve als zweetdrijvend middel; terwijl volgens Ilaneo zij op de Philippijnsehe cilanden met maderawijn afgetrokken bij maculas corneae in de oogen worden gedruppeld. De zaden bezigt men als braak-en purgeermiddel. Dr Grainger heeft dit op de volgende wijze aangewend; waar mon geene Ipecacuanha bij de hand heeft, zegt hij, kan men zich volkomen op het volgende braakmidlel verlaten; men wrijve twee drachmen van het zand der Argemone fijn en meng het met cene halve pint kookend water, liat het koud worden, giet het door cenen doek en maak het met suiker zoet, om hetzelve lieriloor aangenamer ran smaak te maken; deze hoevechleid is genoegzaam voor ecnen rolwassenen neger. Het geclachtige sap uit de versche plant, hetwelk aan de lucht blootgesteld tot eene op guttegom aclijkende massa opdroogt, wordt rolgens Wildenow roor cen roortreffelijk wondheelend middel in West-Indië gehoudcn; Geiger en Endlicher geven op het tegen hijdrops wordt toegediend.

Volgens Lindleij beschouwen de Indische geneeskundigen het sap als werkzaam bij oogziekten on wenden zij het op sijphilitische zweeren aan; de Javanen bezigen het uitwendig bij veroulderde huidziekten.

\section{CAPPARIDEAE Vent.}

348. Вот. Ny. - Crataeva magna Dc.

IvL. BEY. - Randoe allas J. S.

Gr. PL. - Cochinchina, Java.

Gesr. - De bast met water fijngestampt wordt als huidprikkelend en roodmakend middel uitwendig bij herige koortsin atangewend.

349. I30т. Nx. - Cleome Blumeana Sehlt. = Gijnandropsis affinis $\mathrm{BI}$.

Ivr. BEx. - Sasawi leuwung S; Entjeng-entjengan J.

Gr. PL. - Op Java in het wild en als sierplant in vele tuinen. 


\section{NIJMPHAEACEAE Slsb.}

350. Bor. Nur. - Nymphaea stellata De.

IvL Bex. - Taratteh leutick S; 'Taratteh ketjil en 'T. wiroe M.

Gr. PL. - In stilstaande wateren en langs meeroevers van 'Tropisch Azie, Malabar, Java en andere eilanden.

\section{NELUMBONEAE Brtl.}

351. Вот. Nyr. - Nelumbium speciosum Wld.

INL. Bex. - Tiaratteh gedeh s; 'Tarattio M \& Bali; 'Tonjo Mak; Lien Ch.

Gr. PL. - In zachtvlietende en stilstaande wateren van Tropisch Azie, Java, Sumatra en verdere eilanden.

Gebr. - Deze plant, de Lotus der Egijptische en Indische mijthen, werd van de vroegste tijden af door de Egijptenaren en Indische volkeren hoog vereerd, zij bezigden haar om de beeldtenissen humner goden te bekroonen, enz; de vruchten werden door hen gegeten, doch door hunne priesters en door de am hen gelijk gestelde Pijthagoristen het als verboden beschouwd, zich met deze te voeden. Nog tegenwoordig vinden bijua alle deelen der plant hare huishoudelijke of geneeskrachtige anwending. De oude, taaije vezelige wortels lereren volgens Blume, na afgekookt te zijn, ecnen laffen eenigzins bedwelmenden drank, welke pisdrijvende e'genschappen bozit; de jonge wortels daarentegen, welke ongelijk meer zetmeel bezitten, zijn zoo gekookt als gebraden als cene als Artisjokken smakende groente te gobruiken, en voornamelijk goed voor zoodanime zieken, welke aan langdmige, uitputtende diarrhoeae hebben geleden. Ook de jonge stengels en bladeren kan men als groente nuttigen. De oudere bladeren dieneu op Java veelvuldig tot het impakken van goederen De zachtzamentrekkende, naar Anijs riekende bloemen worden gebruikt bij wijze van Flores Rosarum. Het lijmige melkachtige sap der blocmbladen en bloemstelen zegt men nuttig te zijn bij krampachtige aandoeningen, tegen braking en diarrhoc. De raauwe en gekookte zaden behooren tegenwoordig tot de spijzen der Indische volken en Chinezen, ook op Java verkoopt men 
ze als zoolanig; omrijp en 'ranuw gegeten lebben zij den smaak vam hazelnoten, rijp zijnde en gekookt of in asch gebraden komen zij meer met kastanjes overeen.

De onrijpe zaden met suiker tot eene brei gekookt zijn als eene voedzame spijs voor kinderen aan te bevelen, welke aan chronische diarrhoe en atrophie lijden, bij wolke laatste zij echter roorzigtig moeten worden toegediend, vooral wanneer er neiging tot stoelverstopping mogt anuwezig zijn; ook bij volwassenen zou dit zacht zamentrekkende voedsel aan te raden zijn. Volgens Bleeker prijzen de Chinesche geneesheeren te Batavia een uit de oulere zaden met suiker bereid moes als een bij dijsenterie hoilzaam zamentrekkend middel aan. De van kiemwit onthloolte zaden waren vroeger onder den naam van Egijptische boonen bekend en ook in de geneeskunde in gebrtik.

\section{TURNERACEAE DC.}

352. Вот. жи. - Turnera ulmifolia L.

Gr. PL. - Jamaika, midden Amerika, op Java in vele tuinen. GEBr.-Deze plant, in tropisch Amerika algemeen verspreid, wordt onder de aromatisch tonische en expectoreerende geneesmiddelen gerekend.

353. Boт. Nun - Tumera sericea H. B. \& Kth.

INL. BEN. - Roempoet toewan Schil MI.

Gr. PL. - Zuid Amorika, op Java veelvuldig in tuinen en te Batavia bijna in het wild groeijende.

\section{BIXACEAE LndI.}

354. Bот. Nлг - Bixa orellana L.

IXL. BEx.-- Galiengum is; Gloege of Gloego MI K Kasoemba kling J; Taloekka Amb; Ramboeta 'T.

Grr. Pt. - Tropisch Amerika, wordt op de Caraibische en Indische cilanden veclvuldig angekweekt, dient op Java meestal tot omleiningen en is van daar naar de Moluksche eilanden overgebragt.

Cress. - Van dezen in 'Tropisch-Amerika te huis behoorenden 
boom, welle door kultuur orer bijna alle warme gowosten des andlols is overgebragt, gebruilst men rerschillente declen. Men geloolt dat de wortels de gestoorde toestand iler sijjsrerteringsorganen zouten verbeteren en versterkende eigenschappen bezitten. Uit den wast des booms kan men touwen en strikken verraardigen, welke zeer duurzaam zijn. Vian het hout bedienen zich de Indianen tot het maken van vumr, daar dit spoedig gewreven wordende weldra ontvlamt. De aromatisch bittere zaden zeght Martius, dat hart- en maagsterkende, zamentrekkende en koortswerende eigenschappen bezitten. IImnne roodachtige versehe pulpa rerspreid eenen violenreuk en heeft eenen bitteren scherpen smaak; nit hetzelve bereiden de bewoners dier streken ecn verkoelend afkooksel, dat volgens hun zeggen koortswerend is en een tegengift, vooral tegen de Maniocea of Tatropha manihot; zij bezigen het terens tegen haemorrhagiae, diarrhoe en ook tegen lithiasis. Uit de gekneusle en langen tijd in water geweekte zaden wordt door drukking en goelurige afspocling met water cene roodkleurende stof verkregen (zamengesteld uit twee kleurstoffen, eene geele en eene roode), van eenen eigenardigen onaangenamen reuk en zcer zamentrekkenden smaak, welke onter den naam van Orleans, 'Terra orellana/Uruen, Roucort, Arnotto) in den vorm van koeken of bollen in den handel is, door schilders en verwers veel gebruilkt wordt, dikwijls in plaats ran saffraan wordt gebezigd on rroeger ook in de apotheken tot het kleuren van zalven en pleisters, zoo als ran het Emplastrum diachijlon comp: werd tocgelaten. Volgens 1Lac Gulloch is de Orleans het beste en onschadelijkste mididel om boter en kats te klenren en wordt als zoodanig in Engeland en op hot vaste land van Enropa in kassmakerijen gebeziggl. In Sipaanseh Amerika mengt men haar in de chocolade, welke daardoor cene schoone kleur bekomt en aangenamer ran smaak zoute worden. De inboorlingen van Amerika beschilderen zieh met deze stof op eene jammerlijke wijze, zij zoeken in de roolachtige kleur cen afzigtelijk rersiersel, als ook ecne beschutting tegen de beot rim muggen. Volgens Geiger werd de Orleans rroeger in poederrorm inwentig gegeren, zij zoute afvoerend werken, en in Amerika nog als hartversterkend mildel gebezigd worden. Volgens Blan- 
co moet zij een bloedstelpend en maagsterkend middel zijn, terwijl Blume hare gunstige werking bij hardnekkige diarrhoe aanhaalt.

355. Вот. Nur. - Phoberos rhinanthera Endl.

INL. LEx. - Roekem MI, S; Roekem kembang MI; Kíijoe popoan MI.

Gri. rL. - In vochtige oorden rondom Batavia, bij Patjitan, enz.

GEbr. - Volgens IIasskarl worden de jonge takjes boven het vuur gehouden, alsdan gestampt en het water na koud greworden te zijn tot oogwater gebruikt; het hout is zwaar, sterk en rood, cehter van geringen omvang en dient vooral tot rijststampers. De vruchten zijn lekker om te eten, na ze eerst in de handen gewreven te hebben, om ze zoct en malsch te maken.

356. Вот. Ny. - Flacourtia cataphracta Rxb.

IXL. BEX. - Roekem manis M, S; Koepa landak S; Lobi lobi manies Mi Apésoong Mand.

Gr. PL. - Oost-Indië; op Java in het wild en in tuinen.

Gebr. - IIasskarl meldt omtrent deze plant hetzelfle als van de voorgaande. Volgens Lindleij worden de jonge schenten en bladeren, welke den smaak echter niet de bitterheid van rhabarber bezitten, voor zamentrekkend en maagsterkend gehouden en in de Cirkars (eene landstreek in Bengalen) tegen diarrhne en algemeene zwakte voorgeschreven; in Bahar wordt een koud aftreksel van deze tegen heeschheid gebruikt.

\section{PANGIACEAE BI.}

357. Вот. Nır. - Pangium edule Rwdt.

INL. bex. - Pangi MI, Mak. \& Bali; Pitjoeng J; Klowak J; Bobbij T; Sawan T; Anij Amb; Hami Br.

Gr. PL. - Ceylon, Java en omliggende eilanden.

Grinr. - Daar niet alle door mij geraadpleegde schrijvers volmaakt omtrent het gebruik, enz. van deze plant overeenkomen zoo wil ik elk dezcr atzonderlijk nagaan. Rumphius zegt: "liet "sap der bladeren in rottende zweeren of wonden geworpen "doodt de wormen, welke ditar in zijn; ook indien men rottend 
"vleesch vol wormen in deze bladeren wikkelt, zouden de wor. "men er afvallen en het vleesch weder ecne roode kleur aannc"men. Kippen deze pitten etende zouden sterven. De Balinezon " cten dezelve niet, dan na ze eenige weken in water geweekt en eerst " aan kippen gegeven te hebben, on te beproeven of zij nog gif"tig zijn. De bladeren met zout en limoensap afgewreven wor"den bij schnrft (sakit kadel), enz. op de huid gesmeerl. Ińne"beesten onvoorzigtig van de bladeren etende, gebeurt het soms "dat zij sterven." Horsfield geeft aan, dat de olie tot het bakken van pastij en visch wordt gebezigd, en dat de zaden, welke zeldzaam gebruikt worden, bij hen die aan het gebruik datrvan niet gewoon zijn, stoelgangberorderend werken. Verder dat alle deelen des booms, welke Rumphius Pangium noemt, vooral de bast, de bladeren en de rruchtschillen, gezegd worden krachtig wormdrijvende eigenschappen te bezitten. De zaden, welke Kloewak heeten, zijn voor de Javanen cen levensmiddel.

Blume rerhaalt dat de bast, bladen, vrucht en zaad scherpe narcotische eigenschappen bezitten, dat door deze de hersenzenuwen sterk aangedaan worden, angst, hoofdpijn, dnizeligheid, slaapzucht, walging en zelfs vlagen van krankzinnigheid worden veroorzaakt; dat het gebruik dezer den mensehen en dieren schadelijk, ja doodelijk, kan zijn. Dat hunne scherpe en narcotische eigenschappen waarschijnlijk gelegen zijn in eenig op Menispermine gelijkend alkaloid, rerbonden met ecne lijmige bittere extraktiefstof; hare wijze van roorkomen in deze, zoo wel als in eenige Menispermeae, zal ecn chemisch onterzoek moten beslissen.

Endlicher bemerkt slechts dat de Ceijlonezen de rutchten hij wijze van cocculuskorrels bezigen tot het bulwelmen ran risschen.

Bij IIasskarl in zijne aanteckeningen $1.101, N^{\circ} 719$ leest men: "de schil en bladeren worden gestampt en dienen tot het bedwel"men van visschen. De rruchten worden geschild, dan afyekonkt " en met eenen stcen geslagen tot dat de harde bot breekt; de "vleczige pitten worden er nitgenomen, in een hak 2-3 digen "geweekt, waarop zij kummen worken gegeten. Tet men ze zmi- 
"der deze toebereiding, dan wordt men bedwelmd en de dood " zal kunnen volgen. De pitten worden over het vuur geroost "en bij de rijst gegeten; om er olic van te maken moet men "het vleesch of in de zon of over vuur droogen, in korten tijd "fijn stampen, boven stoom kooken en in eenen zak ran de schil " van djaloepang (Grewiae sp. div.) persen, waarop er ecne roode "lampolie uitloopt, die niet gegeten kan worden en zelfs bij het " branden eenen sterken walm geeft."

Eindeiijk geeft Lindleij op, dat de weeking in koud water aan de pitten de schadelijke giftige eigenschappen ontneemt; dat de bast in het water geworpen de visch bedwelmt; dat het sap der blaten als wormdootend gebezigd worlt en ook bij huidziekten; dat koebeesten ze eten en waarschijnlijk op het voetspoor ran Horsfield, dat de olie der zaden bij het braden wordt gebruikt.

Over het algemeen neemt de inlander, welke de zaden gaarne cet, uit rrees vin bedwelmd (mabokh) te geraken de roorzorg, nimmer deze zoo pas van den boom geplukt te eten, doch ze eerst langen tijd in water te laten weken of onder de asch te leggen. Pas opengemaakt of van hume ivoorharde schaal ontdaan verspreiden de kernen eenen sterken eijanaardigen reuk, dit gevoegd bij de vlugtigheid en oplosbaarheid van de vermoedde giftstof in water, doen mij gelooten, zij waarschijnlijk een cijambevattend bestanddeel in zich sluiten. Ook de olie bezigt men op Java nimmer tot, braden,

\section{PASSIFTOREAE JSS.}

358 Bot. Nir. - Passiflora coeruleo-racemosa Sab.

Gr. rL. - Europa; op Java als sieraadplant in vele tuinen.

359. Bor. Nur. - Passiflora pubescens Kth.

Gr. PL. - Caracasan; op Java als sieraadplant aangekweekt.

\section{PAPAIJACEAE BI.}

360. Вот. Nu. - Carica papaija $\mathrm{L}$.

IYL. BEY. - Papaija AI; Gedang S; Kattes J. 
GR. PL. - Oost Indie, wordt op Java veelal rondon de woningen aangeplant.

Gerr. - Van den Papaijaboom, welke op bijna elk erf geronden worlt, in zeer korten tijd tot eene aanzienlijke hoogte oprroeit en door zijnen schoonen bladkroon op den neestal eenvoudirgen, zeldzaam getakten stam zeer veel op dien der palmboomen gelijkt, wordt de wortel, welke eenen onaangenamen naar Raphlianus putrescens zweemenden reuk bezit, door de inlanders afgekookt en toegediend bij urethroblennorrhoeae, gravecl en andere ongemakken bij het wateren; tot dit zelfile doel zoude ook liet sap uit den stam en de bladeren gebeziggd kunnen worden. De een zeer ligt en week hout bevattende stam, de bladeren en de onrijpe vruchten bezitten overvloedig en bitter doch niet scherp sap, hetwelk na herhaalde scheikundige onderzoekingen gebleken is rijk te zijn aan fibrine. In de maag gebragt verwekt dit sap eenen ontstekingachtigen toestand des darmkanaals; met honig of suiker rermengd en toegediend, doodt het de ingewandswormen; uitwendig gebezigd zoude het rerschillende huidzickten (impetigo) genezen. Tolgens Irott is dit sap vooral in Vollijnie en de Ukraine als anthelminthicum zeer gezocht, vorral tegen ascarides (1) inwendig zoude het van $1-12$ ons, en daarma een laxans, worden gegeven. Volgens Blaneo wordt dat der vruchten op de Philippijnsche cilanden als cosmeticum bij zomersproeten aangerrend. De uitwasoming ran het net water verdunde sap en van de plant zelve werkt wonderbaar krachtig op de dierlijke vezel, welker kracht zij zoodanig verzwakt, dat raauw en versch vleesch, of wel dat van zeer oude dieren genomen, zeer spoedig week (malsch) wordt; gedurcnde eenige minuten in met weinige drupluls van dit sap bedecld water gedompeld, of wel gedurende cenen nacht in een papaijablad gewikkeld of aan den stam opgehangen gaat dit,

(1) Len theelepeltje vol van lict door insujjding in de schil van de nog nict volkoinen rijpe vrucht verkregen melksap opgelost in ecu ons lkokend water wordt op vele plaatsen in den O. I. Archipel als wormmidtel, bij kinderen tusschen de 4 en 8 jaren, gegeven in de giften van alle dric nur cen theelepeltje.

Op liet ciland Mauritius cu nar men zegt in de West-Iulic, wordt van dat middel nagenoeg op voorschreven wijzo on docl, gebruik gemanlt. 
ten zij het spoedig gegeten worde, vervolgens in verrothing over. Deze bijzonderheid, zegt Endlicher, is door vele en geloofwaardige getuigen bevestigd. De bladeren, welke de Negers in Zutd Amerika in stede van zeep tot het wasschen van linnen bezigen, geeft men op Tava dikwijls aan paarden, welke ze gaarne eten on daardoor voor verstoppingen zouten bewaard worden; met de pit van kokosnoten te zamen uitgeperst vordt de olie dezer laatste groenachtig en sterk gुemaakt. De mannelijko bloemen weekt men in heet water, droogt deze darma in de zon, legt ze in azijn in en worden zoodoende als toespijze (atjar) genuttigd. De vruchten nog onrijp zijnde worlen gekookt als groente, of wel gekonfijt en als zuur ingelegel gegeten. Rijp zijncle zijn zij zoet, eenigzins geurig, bezitten cenen eigenaardigen smaak, worden door velen gaarne raauw genuttigd en bezitten verkoclende, zacht laxecrende eigenschappen. De zaden hobben eenen cigenaardigen scherpen naar sterkers gelijkenden smaak on zijı wormdoodend.

\section{CUCURBITACEAE $J_{S S}$.}

361. Bот. Nx. - Brijonopsis scabrella BI.

INL. BEN. - Aroij bóbontangan S.

Gri. Pr. - Oost Indie, Westelijk Java,

Geßr. - De kleine, ronde, roode vruchtjes worden raauw bij de rijst gegeten en gelijken in smaak zeer op kinmkommors (IIasskarl).

362. Вот. Nм. - Citrullus edulis Speh̀, $\beta$ Jacé Ser.

IxL. Bex. - Batteka MI; Semangka J, Bali \& Mak; Sikoü Cli.

Grr. Pr. - Afrika, Oost en WVest Indic, Japan, op Java veelaI in tuinen.

Gebr. - De vruchten, welke cen fraai rood, zoetzuurachtig, cenigzins aromatisch en zoex sappig vleesch bezitten, zijn zeor verkoelend en worden vooral door de inlanders on ook door vele Europeanen met graagte gegeten, dech zijn vonral vorr de lizatsto nadeclig, daar zij dikwijls int windzucht, diarrhoea en cholera rects annleiding gegeven hebben; den gezonden inlander hinderen zij minder, daar deze gewoonlijk ecnen overmaat van spe- 
corijen nutligt. Volgens Rumphins zoute de vrucht ecn goed tegengift zijn bij vergiftigde wonden, zelfs bij pijlvergift, door het vleeseh op de wond te leggen, en zoude het ook diegene helpou, welke te reel opiata gebruikt hebben. Bij Geiger feest men dat zij als diaetetisch middel bij ontstekingsziekten vermrlend wordt. De zaden waren vroeger officineel, behoorden tot de zoogenaamde vier verkoelende zaden en werden soms in cmulsievorm voorgeschreven; hun voorheerschend bestandideel is cene vette olie.

363. Вот. Nir. - MIomordica Charantia L.

IrL. Bes. - Aroij pepareh S; Parijah S; Papareh MI; Pareh aijam MI. J; Paparihan Amb; Koukoüe Ch.

Grs. pL. - Indie; wordt op Java in het wild en in tuinen gevonden.

Gesr. - De bladeren met olie overroten zijn in tropisch Azie om hunne wondheelende kracht in gebruik; met de ranken gedroogd bezigt men ze in de Molukko's in plaats ran IIop bij de bereiding van het zoogenaamde suikerbier; in stoom gekookt ect men ze bij de rijst; fijngewreven smeert men met hen den buik van jonge kinderen in, opdat deze geene wormen zullen krijgen. Ook de bittersmakende vruchten worden in stoom of in water afgekookt of wel met zout ingelegd rijp en onrijp gegeten, zij zullen zeer gezond zijn; hun sap geeft men als blockzuirerend en de zogafscheiding bevorderend middel aan kraamrrouwen te driuken; ook giet men een weinig hiervan in den mond ran pasgeborene kinderen, on deze van alle aanhangend slijm te licruijelen; met olijfolie overgoten, wordt deze olie onder den naan ran Oleum $\lambda$ Iomordicae tegen ontvellingen, brandwonden enz. aangewend. Iorsfield geef aan, men aan deze plant veel werkzaamheid tocschrijft bij gonorrhoea, verstoppingen, graved en andere zickten.

36t. Bot. Nur. - Momordica bicolor Bl.

IVL. İE. - Aroij pípassan S; Aroij pepareh gengeh S.

Gr. PL. - Westelijk Java, de Molukko's.

GiEsr. - De wortel net adlis en poelassaric vermengd geeft men inwendigg bij buikziekien; de blateren worden in stoom go-

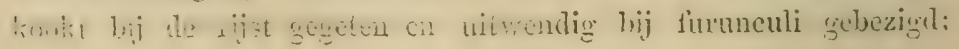


onk de afgekonkte vruchton, welke zoet zijn on o, Lummes (Luffi acutungula Ser) gelijken, wordon gegeten.

365. Вот. NхI. - 'Trichosanthes L. (spec 1.)

LYL. Lex. - Laboe parrang M; Waloe MI.

Girr. PL. - Java.

GEBr. - De vruchten worden afgekookt gegeten.

\section{CACTEAE De.}

366. Вот. Nır. - Cereus niger SIm Dk.

Gir. PI. - 'Thopisch Amerika; naar Java als sieradplant overgebragt.

367. Bot. Nyr. - Cereus multangularis Slm Dk.

Gr. pL.-Amerika; op Java als sierplant in sommige tuinen.

368. Вот. Nı. - Phijllocactus Jenkinsonii IIrt. Grou (Slbr).

Gr. pL. - Op Java in eenige trinen als sieradplant.

369. Вот. Nм. - Opuntia polijantha Haw.

IrI. BEN. - Tjeulie badak tjoetjoek S; Docrie entong J.

Gr. Pr. - Zuid Amerika; op Java in tuinen.

GEEr. - Deze stekelige Nopalplant wordt tot heiningen aangewend en dienen de stekels te gelijk voor spelden, om de hoodjes met de moedereochenille op nieuwe planten vast te steken (Lisskarl).

370. Вот. Nir. - Opuntia monacantha Wld.

IVL. BEN. - 'Tjeulio badak tjoetjoek S; Nopal J.

Gr. pL. en Gebr. - Zic de vorigo plant.

371. Boт. Ny. - Opuntia coccinellifera Mill.

IvL. BEN. - Tjeulie badak tjeribon S; Nopal J.

Gr. PL. - Tropisch Amerika; op Java als kultumplant.

GEBR. - De vruchten hebben cen fraai rood echter smakeloos sul) en worden tot stilling van den dorst genguten (IIitsskand). Zie verder omtrent de cochenille en cochenilleteclt de bestiande liandboeken.

372. Boт. Nus, - l'ereskia grandiflora Ml1. Gr. PL. - Zuid Amerikal; op Java als sieraadplant gezocht. 


\section{PORTULACACFAE JSS.}

373. Вот. Nis. - Portulaca oleracea $\mathrm{L}$.

IXI. Bex. - Gellang S; Kellang S; Ramok gollang S; Krokot J :

Gr. PL. - Europa, Amerika, Japan, in Indie zeer algemeen.

GEbr. - Het ziltige, zuurachtige kruil eet men bij wijze van salade, moesgroente, in soepen, enz., dikwijls ook in plaats van zuring, welke spijs door geneesheeren dikwijls bij scorbutus en andere ziekten om hare verkoelende en bedarende eigenschappen wordt roorgeschreven. Het wordt ook in azijnmakcrijen gebezigd. Het sap zoude volgens Blanco dienstig zijn bij verduisteringen van het hoornvlies en ook bij bloedspliwing, doch is dit twijfelachtig. De zaden behoorden vroeger tot de semina quatuor frigida minora en werden met wijn toegediend als emmenagogum.

374. Bот. Nur. - Pharnaceum strictum Endl.

INL. BEY. - Djoekoet tridi.

Gr. PL. - Azie, op Java in velden en tuinen.

\section{CARIJOPHIJLLEAE Fnzl.}

375. Bот. Nur. - Dianthus chinensis $\mathrm{L}$.

Gr. PL. - China, op Java in tuinen.

376. Вот. Nu. - Dianthus versicolor Fisch.

Gr. pL. - Zuidelijk Frankrijk, op Java als sicraadplant in tuinen.

GEbr. - De bloemen van Dianthussoorten bezitten eenen aangenamen geur. Eene siroop, gelei en gedestillecrel water is soms in de apotheken voorhanden (Endlicher).

\section{PHIJ'TOLACCACEAE RBr.}

377. Bот. Nu. - Rivina purpurascens Schrd.

INL. BEN. - Ranteh peutjang S (??).

Gr. pL. - Brazilie, op Java als sieraadplant om hare schoone roode bessen aangekweekt. 


\section{MALVACEAE JSS.}

378. Boт. Nir. - Hibiscus surattensis $\mathrm{L}$.

INI. BEN. - Gammat oetan S; Dawon tsjoe tsjoe ramboct II; Salamgaro $\mathrm{T}$.

Gr. ru. - Oost-Indië, np Java tegen andere hecsters opklimmonde.

Geirn. - Recis Rumphins geeft op dat de bladeren bij visch worden gekookt, om deze eenen aangenamen zuxen smaak mede te deelen; de 'Ternatanen berigen den wortel op eenige harde gezwellen aan de ledematen. De bladeren worden ook fijngewreven uitwendig bij hevige hooflpijn anngewend. Volgens Fndlicher wordt deze plant nevens vele andere als een de Althaea vervangend middel aangeprezen.

379. Вот. Ny. - Hibiscus rosa sinensis L, A flore rubro simplici.

Irl. Bey. - Kembang sapatoc burrum S; Doeriban S; Bocnga raija meirah $\mathrm{M}$; Wari $J$.

380. Вот. Nr. - Hibisens rosa sinensis L, B flore rubro pleno.

Irt. BEN. - Kembang sapatoo burrum soesoen S; Djinka ML: Kembang waribang Bali; Boenga raija Men; Oebo oebo roriha ' 1 '. 381. Bot. Na. - Hibiscus rosa sinensis L, C flore carneo simplici.

IrL. EEx. - Kémbang sapatoe boddas S; Doeriban boddas S; Boenga raija poetih Mi; Wari wari poetih Bali; Oebo ocbo dado ' $\mathrm{T}$.

De plant zelve, niet elle varieteit afzonderlijk, zou boven dien nog de volgende namen dragen, als Fiocla sapatoc Bat; Boengar raija M; Bonga bissoe Mak; Innporaij en Mimila Amb; Oubo oebo ' $\mathrm{T}$ ' en Kajoe wanoe wanoe $\mathrm{Bd}$.

Gr. p'L. - Oost-Indië, op Java en elder's veelvuldig om humne schoone bloemen aangekweekt.

Gebr. - De wortel der witte soort worlt afgekookt met vurucht gedronken tegen koortsen en kolijk. De bladeren zijn om hunne slijmige en verzachtende cigenschappen in gebruik on wascht de inlander met deze zijn loofthiar. Ontrent de knoppen leest 
men bij Blume: "Volgons Rhade zoulen de afgelsookte knop"pen de vrouwen onvruchtbar maken en volgens Rumphins " zoude cen Bandanees zich van dezelve bediend hebben om " eene vrucht af te drijven. Volgens den laatsten bevorderen "rooral de nog ongeopende bloemen met azijn ingenomen do "marnlstonden, eene werking die toeh bezwarlijk alleen uit de "atstringeerende eigenschapuen dezer bloem kan ontstaan." De blemen, rooral de roode, zijn loor Inlanders en Chinczen zeer bonind. Zij gebruiken ze bij alle lumne feosten, omilat rood Inume IFleur der blijdschap is; zij bezigen ze tot het zwartmaken ran hunne schoenen en verwen ook hunne wenkbraauwen met dozclve; om himne slijmige adstringeerende eigenschappen kumen zij bij rele ontstekingaclitige aandocningen ran lucht- eu piswegen in aftreksel toergediend worten en worden door Europesche genechlnceren alhicr dikwijls verortend; tijngekneusd worden zij donr de Inlanders op wonden, zweeren on gezwellen gelegd, welke laatste zij vaak verdeelen, wameer de ontsteking niet te hevig is.

382. Вот. Ny. - Hibiscus sijriacus L,

Ixt. BEx. - Kembang sapatoo boelaautw M, S; Malgi M?

Gr. pt. - Sijrie, Kramiolen, Japan, op Java als sierplant clikwijls aangeplant.

383. Bor. Nar. - Hibiscus renustus BI. $\Longrightarrow$ Abelmosehus venustus $\mathrm{R}$ Ill.

IXI. BEY. - Kóaknasang S; Waroe landak MI. S; Waroe lot MI.

Gr. PL. - Deze plant wordt door de Inlanders hoog geschat om hare verzachtende en verweelsende eigenschappen. De blitderen en wortels zonden rijk aan slijun zijn, en inwendig bij koortsen, huidzieliten, doorloop, druiper cnz. in aflooksel worden angewend; als omslagen dienen zij om de etterafscheiding van ziveeren te bevorderen. Blume.

384. Boт. Nu. - Abelmoschus pseudo-abelmosçhus WVll.

IVt. BEx. - Kawohroh S; Wawaran J; Ragocloh J; Gandapoera MI, J \& Bail.

Gr. PL. - Op Java in het wild en in tuinen, Bali, Timor.

GEbr. - De bladeren dienen tot reiniging van het hooflhaar en Rumphius vermeldt, zij ook met den wortel on za- 
den in vele zalven of smeersels gemengd worden. De zaden of Bisamkorrels, in West-Indie Gumbo musqué genanmd, verspreiden eenen muskusaardigen reuk, waarom zij door de schoone sekse zeer geacht zijn, zij strooijen ze om hunnen geur en om deze voor insekten te beveiligen tusschen hunne kleeneren, of berooken die er mede; fijngewreven en onder bloem van rijstmeel (bedakh) gemengd, bedienen sommige zich van dezclve als smeersel ter rerzachting der huid bij uitslagziekten, zoo als bij roode hond, waartegen dit middel zich zeer werkzaam betoont, loordien het de ziekelijk verhoogde prikkelbaarherd der huid vermindert. Zij zijn in den handel nog steeds in hoogen prijs, daar zij zeer goed in parfumerien in plaats van Amber en Muskus kumnen gebruikt worden. Zoo als Vesling aanmerkt, mengen de Arabieren ze in humne koffij. Inwendig gyebruikt zullen zij versterlende en maagprikkelende eigenschappen bezitten; volgens Blan:o zijn zij clienstig bij dijsurie en andere zickten der urienafscheidende werktuigen; terwijl zij tot poeder gebragt on met rum overgoten in de WestIncliën voor een krachtig middel tegen slangenbeten worden gehouten.

\section{Bot Nys - Paritium tiliaceum Hil.}

IYL. BEY — Waroe laut M; Kajoe waroe MI; Kondong waroe J; Haroe Amb; Pappetole Lh; Varook Bi; Varoe ranoe Bu.

Gr. PL - Oost-Indie langs strandplaatsen; op Java veelal langs de wegen en rondom tuinen.

Gerr. - Van deze plant, van welke alle deelen door hun overvloedig slijm verzìchtend werken en zeer goed de plaats onzer Althaen en Malvat kumen vervangen, wexken volgens liumphius de wortels afgukookt en gedronken zesr verkoelend bij koorsen; uit de bast en jonge takken kumen grof en fijn touwwerk rervaardigd worden, dat zecr dumzam is, tot strikisen, vischnetten cnz. verwerkt wordt, en waarvan men op de West Indische eilanden de zweepen vervaardigt, waarmede de slaven gegieeseld worden. In de Lampongs maakt mon uit de schor's ecne zeer grove soort van kleedjes. IIct hout, dit bijzonder sterk is, dient voor huisbouw, stijlen, buffelkarren, zalels, rijstunolens: kistjes enz; an hetzelve kent Blanco con brativerwekkid ver- 
mngen toc. Het say uit de verschillende deelen der plant bezigt men als oogwaschwater voor kleine kinderen. De bladeren wor-den afgeknokt gedronken bij moeijelijke urienloozing en wendt men de blocmen mot azijn afgetrokken op de Philippijnen uitwendig tegen oorpijn aan.

386. Вот. Nu. - Gossijpium indicum Lam.

IVL. BEN. - Kapas lumboet S; Kapas hoema S; Kapas meirah M; Aha Ht; Ahamahoe Lt; Karamboe Bd; Kapa 'T.

GR. PL. - Oost-Indie, op Java en elders als kultuurplant.

GEBr. - Ook deze plant, welker vruchten de bekende boomwol leveren, bezit door een overvloedig slijm zeer verzachtende cigenschappen en kumnen de bladeren en bloemen zeer goed de slijmige middelen onzer apotheken vervangen. Volgens Endlicher zoude een sterk atknoksel der blaten echter braking verwekken. De zaden, welke fijngewreven mot water eene slijmachtige emulsie geven, dient men tegen hosst aun kinderen toe; de uit deze bereidde olie zou voor lampolie zeer geschikt zijn.

387. Bот. Ny. - Gossijpium vitifolium Lam.

IVL. Bex. - Krapas gedeh \$; Kipas besaar Mr Kapas angries J; Kapas taun J; Sajor gebe Mol; Kapa 'Tnb.

Gr. PL. - Oost-Indie, op Java als kultumplant.

GEBR - Van deze in geneeskrachtige eigenschappen met de beide vorige geheel overeenkomende plant nuttigen de inlanders de bladeren als groente en drinken deze met water fijngewreven hij diarrhoe. In Brazilie worden de jonge bladeren en zaden gebruikt bij dijscinterie, on zij bij homicrania in azijn gedoopt op het hoofd gelegd.

388. Bor. Nir. - Sida atropurpurea B1.

IVI. BEN. - Sidagorie M, S.

Gr. PL. - Westelijk Java in het wild en in tuinen.

Gesr. - Ook deze plant zal slijmige, verzachtende cigenschappen bezitten on als de vorige kunnen toegediend worden.

389. Вот. Nжr. - Sida retusa L.

IrL. BEx. - Sidagorie S, MT; 'Thé oetan M.

Gr. PL. - Mauritius, Oost Indie, Java en Molukkos.

Gerr. - Bij Rumphius reeds lecst mon, dit kruid heeft eene rexzachtende reirwedente kiracht; de wortel met gember gekaauwd 
- wordt bij wijze van pleister gelegrl op harle gezwellen; aldus toebereid gencest hij ook buikpijn en berigt men hem op wonden, vooral kogelwonden. De gekneusde wortel wordt in deń mond gehouden tegen tandpijn. Volgens Hasskarl bezigt men de bladeren als was om er garen mede te bestrijken. De slịmige wortels werken emollieerend.

390. Boт. Nrr. - Abutilon striatum Hk.

IVL. BEN. - Poeloetan laut Mr.

GR. PL. - Op Java als sieraadplant in vele tuinen.

\section{STERCULIACEAE Vnt}

391. Вот. Nur - Adansonia digitata L.

BEx.-- De bekende Boabab- of apenbroodboom,

Gr. PL. - Uit Senegambie naar Javà overgeplant.

Gebr. - Deze boom is een der grootste boomen van den aardbodem; dikwijls vindt men stammen van 30 roet niddellijn, doch zijne dikte is niet geëvenredigd aan zijne hongte, daar hij zijne digt beschaduwde takken verre naar alle zijden nitspreidt, zoodat zich cene menigte menschen ouder denzelven voor de zonlitte kunnen verschuilen. Alle zijne deelen zijn rijk aan slijm en verzachtend. Het hout is week en zacht. De gedroogde en tot poeder gestampte bladen, Lalo genaamd, zijn cen gelietkoosd middel der Afrikanen, welke deze onder hume spijzen mengen, ten einde de te sterke huiduitwaseming, waaraan zij in die streken onderhevig zijn, te verminderen; onk door Europeanen zijn zij dienstig bevonden bij vele gevallen van diarrhoe, koorts en andere ziekten. De rrucht, het het meest in gebruik zijnde deel des booms, is ecne tienhokkige zaaddoos van de grootte cener meloen, welke gevuld is met een week meelig merg, waarin de zaden bevat zijn. Dit mery heeft eenen aangenamen zuurachtigen smatk on wordt dikwijls raauw of in suiker ingelegd gegeten. MIet water en suiker gemengrl is het eenen heilzamen drank voor teringlijlers, ook bij tijphlicuse koortsen en andere. IIet gedlongrle met water gemengrde merg (volgens anderen de sehil der vruchten) wordt in Egijpte bij dijsenterie toegediend. De roornaminte bestandleclen zijn eene op gummi S'enegal ge- 
lijkonde gom, cone suikerhoudende stof, zetmeel en cen zuur, waarschijnlijk appelzutu.

392. Вот. Nr. - Gossampinus alba Hmlt.

IVL. bex. - Randoe M, S; Kapok MI; Ahamahoc Amb; Kraijlocpa T; Kawo-kawo Mak.

Gr. PL. - Oost Indie, op Java, Sumatra, Borneo en elders reelvuldig in tuinen of rondom de huizen.

Gebri. - Het zeer ligte en wecke hout van dezen boom is tot niets geschilit; ten zij om er iusckten op te bewaren. Ds zeer slijmigre bluderen dienen bij wijze van zeep tot reiniging van het hoofdhair, in aftreksel worden zij bij hoest, gonorrhoea cnz, toegुediend. De onrijpe vruchten worden raauw bij wijze van roeljak gegeten; rijp zijnde leveren zij de kajok, eene grovere soort ran boomwol, welke meestal gebruikt wordt tot opvulling ran kussens en matrassen, waarbij men vooral moet zorgen dat ze van do zaden outdaan worde, dewijl de muizen deze gaarne eten. 1) schil der vruchten wordt fijugewreven en bij eene moeijelijke verlossing de kranmvrouw op den buik gesmeerd. Uit de zaden perst men ecne olie, welke voor lampolie geschikt is.

393. Вот. Nar. - Durio zibethinus L.

IxL. Bev. - Kadoe S; Doeren J; Doerian J; Doerein Mol.

Gr. PL. - Oost Indie, op Java, Sumatia en Borneo veelvuldig in het wild en aangekweekt.

GE;r. - Ilet hout word gebeziggl voor huisbouw, plinken enz, doch spoedig door insekten verteerd. Het merg der zeer gedoornde vruchton, dat zeer week, wit- of geelachtig is en eenen zeer sterken onaangenamen stinkenden gear rerspreidt, wordt door hen, welke ten laatste aan dezen gewoon zijn geworden, met graagto gegeten en voor eene der lekkerste vruchten ran dezen archipel gehouden; het is moeijelijk te verteeren, vele personen gevoeten na hetzelve dikwjils een lastig en hevig oprispen, zoude het dikwijls huiduitslagen veroorzaken, zeer sterk opwekkend op de geslachtspheer inwerken en de urienafscheiding bevorderen. Vooral de inlanders eten gaarne dit merg, zij zergen het roor hen even voedzaam als vleeselspijzen zoude ziju. Ook de pitten worden geroost bij wijze ran kistanjes gegeten, doch verwekken een scherp fevoel in de ked. 1) schil der 
rruchten wordt tot kolen gebrand en deze als tondel gebruil: liare asch zouden de Chinezen beziggen tot het bereiden der kasoembaverw (Orleans) en andere klemstoffen. Uitwendig luezigen de inlander's deze schil bij een huiduitsheg, knokne-rawit gyenaamd; fijngewreven en daamede den buik ingesmeerd, gerfth zij zelfs na eene obstructio van 6 ì 7 dagen eene gemalkiclijle ontlasting.

394 Boт. Ny. - Sterculia nobilis Smth.

IVL. BEY. - Hantap passoeng S.

Gr. PL. - Oost Indie, op Java in bergachtige bosschen.

Gobr. - Terwijl Hasskarl aangeeft, dat het hout van alle Sterculiasoorten niet sterk is, spoedig door insekten. wordt angutast en daarom zelden tot bonwhout gebezigd, verzekeren mij vele inlauders dat deze boom een selioon bouwhout afgeeft. I) zaden worlen geroosterd bij wijze van kastanjes gegeten en zullen bijna als deze, doch eenigzins wrang, smaken; uit dezelve trekt men ook cene vette olie. De fijngewrevene vruchten worden nitwendig bij schurft anngewend.

395. Вот. Nм. - Sterculia colorata Rxb.

IxL. BEx. - Hantap hoelang S; Hamerang S.

Gr. pL. - Oost Indie, op Java in bergstreken.

Gesr. - Zie omtrent de zaden en het hout de voorgaande soort. 1)e fijngewrerene bast bezigt do inlander nitwendigg bij hecte koortsen.

\section{BU'TINERIACEAE RBr.}

396. Bот. Nуז - Theobroma caca I.

IY̌. IEY. - Tjoklat; Koppi wolanda M; Ka-kau Mr.

Gr. rL. - Zuid-Amerika; op Java en verdere eilanden dikwijls in tuinen gekweekt.

GEBr. - De Inlander schijnt van de kakaoboonen geen bijzonder gebruik te maken; omtrent het nut der liakaoboter, chocolade enz. zie de bestaande handboeken.

397. Вот. Nu. - Guazuma tomentosa IKth.

IYL. DEx. - Djatti wolanda ML; Kaijoe goorda M.

Gr. PL. - Zuid Amerika; op Java veelvuldig langs de wegen aangeplant. 
Gebr. - Het hout is zeer geschikt voor planken in paardenstallen. 1)e bast des booms zal een roortreffelijk middel zijn tegen lierpes en lepra, en als zoodanig in Amerika veel aangewend worken. De blateren worden door geiten gaarne gegeten. 398. Boт. Nur. - Krleinhovia hospita L.

INx. BEx. -- Tjangkolloh s; Kattimaha J Kietimo J; Katta mala Bali; Kauwas Mak; Kinar Lt; Kenal Ht; Ngaro 'T.

Gr. PL. - Westelijk Java, Sumatra, Borneo, de Moluksche eilanden.

GEsr. - IIet sterke fraaije hout van dezen boom, dat zwart en wit gevlekt is, is door den inlander zeer gezocht, daar hij het bezigt voor de scheden zijner wapenen, vooral voor krisscheden; een stuk voor eene krisschede, dat mooi gevlekt is, betaalt hij dikwijls met 50 à 70 gulden zilver. De bast kan tot touw verwerkt worden. De bladeren, welke veelal tot reiniging van het hoofthaar gebruikt worden, worden fijngewreven ook nitwendig aangewend bij eene ziekelijke zwelling der ballen, welke de Inlander sakit kalingsir, peler toeroen, noemt. Het sap der bladeren wordt in de oogen gedruppeld bij beginnende blindheid: Volgens Blanco kan meu de jonge loten en bladeren eten, en zouden deze cen voortreffelijk middel zijn bij sarna (vermoedelijk huidwaterzucht?), wanneer men deze lijders met cen aflsooksel derzelve wascht.

399. Вот. Nı. - Visenia umbellata BI.

IrL. BEN. - Bientienoe M, S; Bintinoe boddas $\mathrm{S}$.

Gir. PL. - Oost-Indie, Java, Sumatra en Borneo in bergstreken.

GEen. - Van dezen boom, welke door zijnen bijzonder spoedigen groei en schaduwrijke takken uitmunt, worlt het weeke hout soms tot het bouwen van hutjes in de rijotvelden gehruikt. De ran de buitenschil bevrijdle bast wordt tot touw gedraaid en gebezigd om buffels mede vast te binden, doch is niet zeer sterk; men doet de bast ook aan paarden bij wijze van haam (kalong) om don hals en stopt hen ecn weinig afgeschuapt spint in den nets, wamnecr zij an verkoudheid of ligte droes lijilen. 400. Bot. Na - Pterospermum suberifolium Wld.

IYL. BEY, - IIariekockoen S; Bajoer MI. 
Gr. PL. - Op Java in boschrijke streken.

Gebr. - Deze boom levert een goed en sterk bouwhout, ook zeer geschikt voor boomen van rijtuigen.

401. Вот. Nir. - Pterospermum diversifolium Bl.

INL. BEN. - Tjerlang S; Kitjerelang S; Walan MI. S;

Gr. PL - Westelijk Java.

GEisr. - Deze levert een grof doch veel gebruilst wordend bouwhout.

\section{TILTACEAE Jss.}

402. Вот. N3 - Berrija ammonilla Rxb.

IVL. BEN - Kisampang S; 'Toekoel takal MI.

Gr. PL. - Ceijlon, is naar Java overgebragt.

Gebr. - Het ligte lout, Trincomalec-hout, bezigt men op Java als bouwhout; op Ceijlon worden uit hetzelve eene soort van praauwen, MLassoola-boats genoemd, vervaardigd.

\section{TERNSTROEMIACEAE De.}

403. Bот. Nu. - Dicalijx odoratissimus Bl.

IVL LEN. - Kisarjawan S.

GR. PL. - In boschrijke bergstreken van Java.

Grers. - De bast wordt gestampt en in het tandvleesch ingewreven, ook het poeder ingenomen bij scheurbuik, spruw, sakit serjatwan, waarbij vooreerst eene klene schurft versehijnt, die grooter wordt en alle zachte deelen om den mond en zelfs de neus wegvreet; men gebruikt dezelve ook tegelijk inct de schil van tjangkoedoe (Morinda citrifolia) om er garen in te donpen en daardoor donkerrood te verwen. Het hout is sterk, wordt door witte mieren niot angetast en dient voor bouwhout; de blarlen worden raanw bij de rijst gegeten, ook worden zij lijngewreven en door kraamvrouwen op den buik gesmeerd; tevens worden de gestampte bladen bij de voornoemde ziekte van den neus op de ontvelde deelen gelegd. Hasskarl.

404. Bor. Nu, - Thea sinensis Sms.

IYI. BEN. - Thé M. Ch. 
Griv PI. - China, op Java als kultuuplant.

Gimk. - Ilet gebruik der Thee en Theine is genoeg bekend en in verschillende handbocken beschreven.

\section{CLUSIACEAE Lindl.}

405. Boт. Nu. - Garcinia mangostana L.

IXL BEY. - Mingostan Mr; Mangies MI; Mango ML.

Gr yL - Mrolukkos. Op Java en elders op bewoonde plaatsen.

Gibr - Van dezen boom, welke door zijne geurige, anngenaam smakende vruchten uitmunt, die Bontius reeds de guliten appelen van IIssperio genoemd heeft, eet de Inlander de bast met trassi tot cene sooxt van sambal bereid tegen hevigge buikloop. De stam levert cen sterk, zwaar en zeer goed bouwhout, dat ook voor lansen, rijststampers, enz is te gebruiken, doch zich mocijelijk laat splijten. Do vruchten zijn uiet alleen aangenaam van smaak en onschadelijk, man kunnen zelfs bij vele ontstekingsziekten toegediend worden. De met looistof en roode kleurstof rijk bedeelde vruchtschillen worden echter als geneesmidtel het mecst gebruikt; recls Rumphius meldt het gebruik van cen aftreksel dezer tegen dijsenterio, terwijl nog hoden de inlanilers en vele europesche genecshecren haar toedienen bij chronische diarrhoe en dijscnterie en als gorgeldrank bij spruw en zweren van mond en keelholte. Waitz gebruikte ze verder nog uitwendig bij prolapsus ani, bij putriede verzweringen, koud vuux, bij angina tonsillaris en inwendig bij rerouderde gonorrhocae.

Omtrent de Garciniae in het algemeen meldt Blume het volfुende: "de batsten der tot dit geslacht behoorende bomen berat" ten cen slijmharsachtig sap, meestal geel van kleur, hetwelk

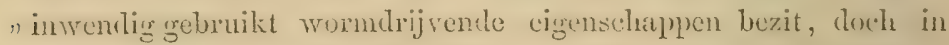
") ved geringure mate dan le Cintegom, wellie onk van Gareiniat-

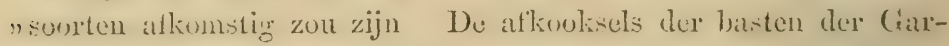
"ciniae, en rooral de schillen lumner vuchten, zijn daar") bij zamentrekkend en men heeft ze bij chronische diarrhoc

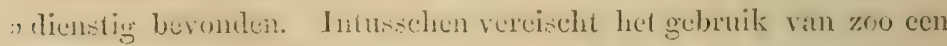

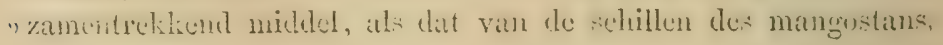


1) lij diarrhoe de grootste omzightigheicl, daar mij gevallen bekend "zijn, dat na het gebruik van dezelve de doorloopen wel is watr "ophichden, doch ook tevens den grond gelegd werd tot onge" neeslijke verhardingen in het klicrstelsel des onderbuiks. MIcer "is het uitwendig gebruik dezer schillen aanteprijzen, bij vb: tot "mondspoelingen bij verslapping der slijmvliezen, aphthae, bo"venmatige kwijling door kwik on tot wasselingen. IBijzonder "zijn in de huishoudkunde deze schillen dienstig tot het looijen "van leder en om zwart te verwen, daar zij in vorband met an") dere verfstoffen eene zeer duurzame kleur aan de stoffen geven, "zoodat de chinezen ze daartoe bijzonder bezigen, zoo zelfs dit " doze schillen der Mangostan in vroegere jaren naar China werdeu " uitgevoerd, hetgeen zelfs tegenwoordig nog soms plaats vindt. Dit "overigens het waterachtige vleesch, dat de zaadliorrels onzer " MLangostans omgeeft, door den fijnsten en rerfrisschendsten smaak, " zoo veel ik weet, alle onze andere Indische vruchten overtreft, " is te bekend om er hier veel van te zeggen."

406. Вот. Nм. - Stalagmites dulcis Murr.

INI. REY. - Gledok pantok S; Gertok pantok S; Mangong S; Moondoe M S; Moendoe manies MI; Moendoe allas M.

Gr. PL. - Westelijk Java in bergstreken.

Gesr. - De zure omrijpe en de rijpe vruchten, welle zumrzoctachtig zijn, worden gekookt en raauw gegeten.

407. Вот. Nar. - Calophijllum sulatri Brm.

Irc. IBE. - Seurisatie S; Sereti besaar S; Soelatric II; Bintangor laut M; Hataul lau mocri Amb.

Gr. PL. - Op Java in tuinen en langs de wegen.

GEBr. - Wortel en bladeren afgekookt, worden grebezigd tot inwrijving der onderste ledematen bij pijn, vermocidheid cn\%. Het hout in dienstig voor masten van praauwen en daksparren. De zunachtige vruchten worden door de inlanders gegeten; lij ecne ruim gebruik veroorzalken zij echter ligtulijk levige buikpijnen en diarrhoe. Uit het versehe zaad wordt door persing en kooking cene olie bereid, welke vectal tot lampolie dient, toch ouk gebruikt wordt tot genczing van verschillende huidzickten, lot berordering der hatrecroed en tot inwrijving van stijve ledemateri. 


\section{AURAN'TIACEAE Corr.}

4.08 Bor. Nyr. - 'Triphasia sarmentosa Bl.

IVt. BEY. - Kaliageh S.

Gr. PL. - Westelijk Java.

409. Bоr. Nu. - 'Triphasia aurantiola Lour.

Ixt. BE. - Kiengkit MI, S; Djeroek kingkit MI; Ijeroek tjina $\mathrm{MI}$.

Gr. PL. - Indie, Cochinchina, China; wordt op Java in vele tuinen aangeplant.

Gebr. - De inlander mengt de bladeren in versehillende zijner djamoes tegen buikzickten (proet dingin). De kleine, oranjeroode, angenaam riekende en smakende vruchtjes, waarom de boom in tuinen zeer gezocht is, worden door inlander's en Chinezen tot ecne aangename konfituur met suiker gekookt.

410. Bor. Nyr. - Murraija exotica $\mathrm{L}$.

INL. BEX. - Kamoening MI; Kamoening japan M.

Gr. PL. - Oost Indie, is op Java om zijne geurige, witte bloemen in vele tuinen en langs sommige wegen aangeplant.

Gerr. - Het zeer fijne, geele en sterke hont wordt voor handvatsels en scheden van wapens, wandelstokken en ander fijn werk gebezigd; de bladeren worden in rerschillende djimues gemengd, welke de inlander, bij wijze van poeder, tegen vermoeidheid, builspijn, enz. inneemt.

411. Вот. Nir. - Cookia punctata Sonner.

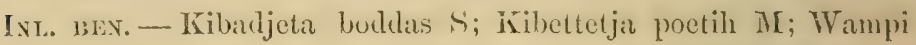
Ch.

Gr. pL. - China, de Moluksche eilanden; op Java vooral in steenachtige bergstreken.

GeBr. - De schors en bladeren gebruikt de inlander uitwendig bij seabies. De anggenaam atrmatische riekende bladeren worden als aromatisch mangmiddel dror geneoskundigen armgewend (Geiper). De rruchten worden in China, op de I'luiliprijnen en ook op deze eilanden dikwijls als lekkernij gegeten, doch zullen bedwelmende (dia bekin mahokh) eigensehaphen bezitten.

412. Вот. Nu. - Aegle marmelos Rxb.

Ivı. Bx. - Tangkocloe M; Madja J; Bila Mak. 
Gr. PL. - Oost Indie.

Gesr. - Bij Rumphius leest men omtrent dezen bnom, van welks vruchten tegenwoordig in Bengalen zoo geneeskrachtig als huishondelijk een ruim gebruik gemaakt wordt tegen diarthe en chronische dijsenteric, en aldaar gedroogl, in aftreksel, als siroop, sorbet, marmelade, conserf en extrakt toebereid, worden gegeven on als zeer werkzaam aangeprezen (1), dat de jonge bladeren bij de rijst worden gegeten; dat men de bladeren met rijst en kurkuma fijngewreven op het lijf smeert om huidjenkte te doen verdwijnen Uit liet pulpa der vincht zoude vroeger cene soort van Opium adulterinum gestookt zijn. Bontius heeft de slijm der vruchten zien gebruiken bij spruw en de gebradene "vrucht bij dijsenterie en cholera.

Volgens Rheede veronderstelt men op de kust van Mralabar dat cen afkooksel van wortel en bast een uitmuntend middel is bij hijpochondrie, melancholie on harthezwaren; worden de bladeren in aftrekselrom gebezigd bij asthmatische bezwaren en do eenigzins nog onrijpe vrucht bij diarrhos en dijsenterie; dit alles somt ook Lindleij op.

Greiger deelt medo dat de wortel en bast gegeven worden bij gestoorde spijsvertering en andere ziekten des darmkanaals, dat de bladeren en bloemen toegediend worden bij aamborstigheid en andere krampachtige aandoeningen.

Door verschillende Javanen, hen ondervragende ontrent het gebruik dezes booms in den tegenwoordigen tijd op Java, werd mij grezegd, dat de bladeren worden toogediend bij wormziekte en ook gebezigd op wonden, welke hume parrden door het drukken der zadels soms bokomen De vruchten worden als lekkernij gegeten.

413. Вот. Nir - Citrus amara Hsski

1.NL BEN. - Djeroek limoh gedeh S; Djeroek post M.

(1) Zic hieromtrent de mededeelingen van Dr. Hugh Cleghoin en Alexandre Grant in the Indian annals of Medical science, No III, Octbr, $1854 \mathrm{cn}$ de vertaling van deze in het Genecskundig tijdschrift voor Nederl. Indie, filc Jaarg. Afl. 1-4, pag. $550 \mathrm{cn}$ volgende. 
Gr. PL - Op Java in het wild en in tuinen.

Gebr. - Iret sap der goudgeele, kleine, ronde, met een geelgrocnachtig bitterzuur vlcesch bedeelde vruchten wordt soms bij wijze van citroensap aangewend.

414. Вот. Nar. - Citrus limonellus Hsskl.

IYL. BEX. - Djeroek honjch gedeh S; Dj. niepies of tiepies M. S; Dj. liemoh MI Djolıe Bali; Lemo kapas 1Lak; Aussi pipis Amb; Oesse krawo $\mathbf{B d}$; Lemo java $\mathbf{T}$.

Gr. PL. - Door dezen geheelen archipel in het wild en in rele tuinen.

GEir. - De kleine, ronde, aangenaan zure vruchtjes worden dikwijls in het zout en in het zuur ingelegd bij vleeschspijzen geunttigd; hun sap dient om aan vole spijzen eenen aangenamen smak mede te deelen, wordt als citroensap met suikerwater gedronken en ook aan rele zieken gegeren; verder wordt het gebruikt tot het schoonmaken ran ijzerwerk, als krissen, lansspitsen enz. Rumphius roemt nog het citroensap met water en eenige koperdeelen bezwangerd als cen goed oogwater.

415. Bот. Nrr. - Citrus decumana L.

IrL. BEN. - Djerock matjan MI; Dj. bali MT; Jamboä MI; Lemon kassomba M; Lemon kaloekoe MIak.

Gr. PL. - Oost-Indië, Zuid-Amerika, Japan; op deze eilanden meestal in tuinen.

GeBr. - De groote vruchten van dezen boom, de bekende pompelmoezen of Adamsappelen, zijn om hun geurig, aangenaamsmakend en zeer gezond, saprijk, wit of roocl rruchtrleesch zeer gezocht, bij rele ziekten aan te bevelen, als berorderende zij de galafscheiding on diumontlisting en roor pas aangekomene Europeanen zeer heilziam. De dikke, sponsachtige, reel aetherische olie berattende schil wordt met suiker gekoolit soms als koufituur gegeten.

416. Bот. Nr. - Citrus sarcodactijlis Sbld.

IVL. BEN. - Djeroek tangan M.

Gr. PL. - Op Jara in sommige tuinen, is remoedelijk uit China en Japan overgebragt.

GEsr. - De vruchten, wellie veel op ecne lialfgesloteno mist, warran de vinger: mot dikke, lange en scherpe nagels 
roorzien ziju, gelijken, bezigen de Chinezen dikwijls als ofturhande roor hunne beelden; zij zijn het dan ook rooral welke dezen boom roortplanten; de vruchten, welke eeno dikke schil en weinig zuurachtig rleesch bezitten, worden als konfituur genuttigd.

Het gebruik der uit alle deze soorten te rerkrijgene Citroenolie vindt men in vele handboeken beschreven.

\section{MELIACEAE JSS.}

417. Boт. Nxr. - Melia Azedarach L.

IYL. BEx. - Kakera kikera MI; 'Tjakra-tjikri MI; 'Tikoessan Mr; Mimboo M.

Gr. PL. - Sijrie, Zuidelijk Azie, Ceijlon, Java \&c.

Grbr. - Aan alle deelen dezer plant, wolke zeer bitter zijn, schrijft men uitmuntende wormdrijvende krachten toe, in groote giften zonden zij duizeligheid, walging, braking, doorloop, zelfs den dood kunnen veroorzaken. Vooral aan liet pulpa, dat de zaden ongeeft, schrijven vele sehrijvers deze laatste werking toe, doch Turpin, welke het meermalen aan honden heeft gegeven, zonder dat deze er eenige hindernis ran ondervonden, en in Carolina de zaden ongestraft door kinderen zag inslikken, ontkent dit ten stelligste. Uit den bast zou men volgens Heine eene soort van $\mathrm{Ca}-$ techu kumnen verkrijgen; aan de bladeren en bloemen kenneu rele eene bedarende eigenschap toe, terwijl de olie door persing en kooking uit de zaden verkregen, op verschillende platatson als lampolie gebezigd wordt; van deze zaden maakt men op de Philippijnsche eilanden rozenkransen.

Ontrent de Taraansehe Meliasoorten selnijrente, rermeldt Blume het navolgende: "zoo b. v. zijn de basten onzer Meliae bij "ile inlandsche berolking onder den naam MTindi of Kalicra-kiliera "(Alelia Azedarach) en Imbo (Mr. Azadirachta) bekend, niet slechts "nitmuntende wormdrijvende middelen, maar komen onk, wegons "Hitume in eenen loogen graad tonische eigenschappen, in menig. "opzigt met onzen kinabast orereen. Derzelrer gुebruik is bijzon"der anngewezeis bij rerzwaklicurle doortonjen zonder neiging " tot ontsteking, b. v. bij het bord (cholera morbus) en ook bij "dien geesel, welke men te regt don naam van cholera geeft en 
adie in de laatste tijden onze bezittingen zoo schrikkelijk heevi " geteisterd.

" IIier verdient lict gebruik van cen zwak afkooksel van den "wortelbast als een behoedmiddel tegen deze ziekte, wanneer "men zich volstrckt van behoodmiddelen bedienen wil, mis"schien den voorrang boven alle andere en men kan zich "zelfs van ruime giften van dit afkooksel eene uitmuntende " werking beloren, zoodra te krampachtige toevallen slechts eeni"germate zijn nit den weg geruimd.

"Ook de viuchten dezer planten toonen wormadrijvende eigen"schappen, en zelfs de bladeren der kakera-kikera tusschen boe"ken gelegd beveiligen deze tegen mot en andere schadelijke " insekten. Versch geknensd worden zij uitwendig tegen het hoofi" zeer (tinea) met een gewenscht gevolg gebruikt."

Ik wil hier nog bijvoegen dat vau deze plant, als mede van de Azadizachta indica Jss, nit welke lantste Piddington een alcaloid, Azadirine genaamd, wil bekomen hebben en hetwelk hij als surrogaat der zwavelzure chinine voorslaat, door mij dikwijls goede uitwerking gezien is bij de op rele moerassige plaatsen in deze gewesten heerschende tusschenpoozende koortsen, vooral bij die welke den inlander aantastten on niet zeer intensief verliepen. Er werd als dan gebruik gemaakt van een aftreksel der bladen en van den bast der jongere takken, zijnde deze verre weg bitterder dan die der oudere takken of van den stam. Om deze echter met kina of chinine geijk te stellen en toetedienen in gevallen, waarbij levensgुevaarlijke verschijnselen zich roordoeir, zoo als bij pernicieuse koortsen, zoude ik niet clurven, maar hatar veeleer met de Menispermum coceulus en andere in deze gewesten als febrifuga geroemde midtelen brengen tot de onafzienbire rei der togen tusschenpoozende koortsen als werkzaam roorgestelde bittertonische middelen. Een naauwkeurig chemisch onilerzoek vim bast en bladeren zoude, geloof ik, spoedig eenige rpheldering in dezen kunnen geven.

418 Вот. Nu. - Melia excelsa BI.

Irt. niex. - Mindi S; Miendrie J.

GI. PL. - Poeloe pinang, op Java in het wild en in tuinen.

fisbr. - llet ligte, grove, witte on nict dwor witte mieren atan- 
getast wordende hout bezigt de inlander als bouwhout en rooral ter vervardiging zijner kleine praauwtjes of kano's; zij gebruiken verder den bast als koortsweerend middel on de jonge bladeren tegen scabies.

419. Bor. Nıг. - Melia L. (spec. Sumatr:)

IXL. BEN. - Kindog (??)

Gr. PL. - Sumatra's Westkust.

Gesr. - Ilet hout zal zeer sterk en voor bouwhout geschikt zijn.

420. Вот. Nн. - Aglaija odorata Lour.

IxL. Brex. - 'Tjoelany MI; Kamoening tjina MI; Patjar tjina J: 'Tsjioelang Ch.

GR. PL. - Oost Indie; op Java in de meeste tuinen.

Gebr. - Om de altijd groene en glinsterende bladeren, doch rooral om de kleine welriekende bloemen, welke de schoone sekse gaane tot versiersel in hun hooldtnoisel bezigen, wordt deze heester veelvuldig aangekweekt.

421. Вот. Nu. - Lansium domesticum Jeq. A Duku Hssk.

TYL. BEY. - Doekoe M. S.

Gr. PL. - Op Java en elders veelvuldig in tuinen.

Geвr. - Het hout is sterk en geschikt voor huisbouw, wordt echter weinig gebruikt. De de grootte en gedaante ran gecle pruimen hebbende vruchten ziju goed rijp zijndo aangena:m zuurzoetachtig van smaak, als nageregt zeer bemind en gezond. De schil, welke op liet vuur geworpen eenen eenigzins welrickenden geur verspreill, bezit een wit, kleverig, aan do lucht blootgesteld zwartwordend melksap; gedrongd en fijngestampt zijnde, wrijft dê inlander zich met haar het ligchaam bij het baden in, om daardoor esne zachte huid te bekomen. Aan de groene, imig bittere zadeu worden wormurijvende eigenschappen toegekend, en aan kinderen twee of drie, met water fijngewreven, ingegeveu.

422. Bот. Ny. - Sandoricum indicum Cav.

INL. BEx. - Kitjapie S; Sendoel S; Sontol J.

Gr. rL. - Oost Indie, de P'hilippijnsche en Moluksche eilanden; op Java in vele tuinen.

GEBr. - Volgens Rumphins wordt de aromatische wortel met. 
azijn eu water fijngewreren inwendig bij kolijkpijnen anngewend; hij zil inwendig toegediend een krampstillend maagmiddel zijn, terwijl Blume aan hem gelijke hoodanigheden als aan den wortel van Meliasoorten toekent; hij wordt op Java bij witten rloed toegediend in verbinding met den zeer bitteren en $\mathrm{za}$ mentrekkenden wortelbast van Xijlocarpus oboratus. Volgens Endlicher kent men aan de Amerikaansche soorten eenen muskusreuk en purgeerende en braakwekkende eigenschappen toc.

De stam levert een fraai bouw - en meubelhout. De vruchten worden raauw, gedroogd en soms gekonfijt gegeten.

\section{CEDRELACEAE JSS.}

\section{3 Вот. Nм. - Cedrela febrifuga Bl.}

IVI. BEN. - Soeren M. J. \& Bali; La-oelit en La-oerit Lt; Oelasse Ht; Unas en Onos Br; Fijtale Huam; Lossal U1.

GR. PL. - Oost-Indie, Java in bergstreken.

Gerr. - Van dezen op Java te huis behoorenden boom wordt het weeke en ligte hout veelal tot het maken van praauwen aungewend, tot huisbouw zal hetzelve, omdat het bij liet droogen krom trekt, niet gesehikt zijn, doch reel gebruikt worden tot vervaardiging van kistjes, doozen, bakken en ander huisraad.

Geneeskundig ran groot belang is de bast, welke in Indie reeds setert langen tijd in gebruik is en nu sedert eenige jaren ook in Europa ofticineel is geworden onder den nam van cortex Cedrelae, China ran Giava, China china uit Oost-1ndië; zijn looklbestanddeel celijnt looistof te zijn, een alcaloide is in denzelren nog niet gevonden, wel verondersteld (Cedreline). Reeds Rumphins vemelit dat ech afkooksel ran den bast on de blateren met djaringoe (Acorus terrestris limphr.) gechronken werd bij lioorts en bij vererooting der milt. IIorsfield, Blume, Berton en Waitz vermelden mede zijne koortswecrende krachten, doch hebben zelve den bast meer tegen chronisch gewordene diarthoe en dijsenterie met goed gevolg toegediend. Tegenwoordig wordt hij nog door eenige geneosheeren tegen lioortsen on cliarthoo varordend, hij schijint ecliter cerder tonisch-adstringeerend to werken en niet met chinabast of chinine gelijk te stellen te zijn, ten 
minste is zijn gebruik niet algemeen geworden. Men schrijft hem roor in afkooksel met cortex Alijxiae en cort. Sintok, in tiuktuur en in extraktrorm, an welke laatste Waitz eenige gelijkenis op eatechu toekent. 'Terwijl Horsfich en IIasskarl opgeven dat de Javaan ran den bast geen geneeskundig gubruik maakt, zoo schijnt zijne toediening in Westelijk Jiva ja bijna onbekend te zijn, nit Midden- en Oost-Java verzekerden mij echter vele inlanders, dat de bast vermengd met Djahej pait (an Zingiber cassumumar Rxb?) in attkooksel wordt toegediend bij koortsen en diarrhoe. (1)

424. Bot. Nir. - Swietenia mahagoni L.

Gr. PL. - Zuid-Amerika op steenachtige gronden, is naar Java overgebragt.

Gebr. - Van dezen aanzienlijken boom is het geurige, digto en fraai bruinroode hout onder den naam van Mahagoniehout beroemd, wordt door schrijnwerkers veel verwerkt en is van hooge waarde. De bittere en zamentrekkende bast wordt als surrogaat der kina door vele Engelsche en Amerikaansehe geneesheeren bij tusschenpoozende koortsen on andere ziekten in poeder, aftreksel en extraktvorm toegediend.

\section{SAPINDACEAE JSS.}

425. Boт. Nur. - Schmiedelia racemosa L.

INL BEx. - Kibëok S; Lamboetang M; Klinting biroe M; Tjoekilang: $\mathrm{J}$.

GR. PL. - Oost-Indie, in Oostelijk-Java vooral op lage gronden en in eenige tuinen.

GEBr. - Het liout gebruikt mon voor wandelstokken, warvoor de slangen zeer bevreesd zouden zijn en op de vlugt gaan. D2

(1). Zic nitvoeriger omtrent het gebruik van dezen bast: Blume, bijdragen tot de Florn van Java. p. 199 \& sqq; Waitz, praktische waarnemingen over eenige Javaansche geneesmiddelen p. 27-32. 
bladeren worden tijngestampt, gekookt on met indigowater vermengd, om zwart te verwen; de rruchten worden gegeten, doch zijn niet lekker.

426. Bот. Nı. - Vitenia edulis Std.

INL. BE. - Kilalaijoe S; Kitjileijouw S; Lalego M; Klajoe en Katti-lajoe J; Toebi-sira Mand.

GR. PL. - Java en elders in lagere bergstrekeir.

Gebr. - Ilet hout van dezen boom, ofschoon van geringen omvang, is sterk en zeer taai, zeer goschikt voor rijststampers en stelen van verschillende werktuigen. De jonge bladeren worden als groente gegeten; met de met water fijngewrevene bladeren besmeert de inlander zich het ligchaam, volgens Hasskarl bij eene ziekte, waarvan zij zeggen dat de duivel hen zoul hebben aangetast (orang kenah scetan, sakit badi); ook bij eene soort van herpes circinnatus (sakit kadas) en in Mandheling bij rheumatismus en nachtelijke beenpijnen; de vruchten worden rijp en onrijp, raaûv en gekookt door hen gegeten.

427. Bor. Nu. - Cupania Lessertiana Cmbscl. = Mischocarpus sundaicus Bl.

IvL. BEY. - Kihooëh S; Kihooi S; Waliklar J.

Gr. PL. - Java, Noesakambangan, Sumatra.

GEBr. - Het zeer taaije hout wordt gebezigd voor handvatsels en verschillende gereedschappen, en is minder geschilst om vuur te vatten (Blume).

428. Boт. Nir. - Nephelium Iappaceum L.

INL. LEN. - Ramboctan bocloe M. S; R. atjeh M; R. goenong J.

GR. PL. - Oost-Indië; op Java veelal in tuinen.

Gebr. - Het hout, dat grof, rood en zwaar is, dient soms als bouwhout, doch wordt cloor insekten lirgtelijk anngetast. De aangename zuurachtige vruchten der gekweekte soorten vindt men als nageregt op vele tafels, worden gatrne gegeten en zijn zeer gezond. De in het wild groeijende echter bezitten bijna geen spoor van sappig vruchtvleseh. Uit de zaden wordt ecne soort ran lampolie bereid.

429. Вот. Ni. - Nephelium litchi Don.

INI. BEN, - Litchi Cll. 
GR. PL. - China en Indie; op Java in tuinen overgeplant.

GEBR.-Ook de vruchten dezer bezitten eenen aangenaam zuurzoetachtigen smaak, zijn zeer gezond en bij sommige ontstekingachtige aandoeningen of verstoorde galafseheiding heilzaam; zij zijn vooral door de Chinezen zeer bemind. De gedrongde vruchten worden uit China naar Java veelvuldig overgevoerd onder den naam van Litchi of Lingkeng, en vooral door vrouwen gaarne gegeten; te Palembang schrijft men aan deze stondendrijvende krachten toe. Het hout is geschilst voor bouwhout.

430. Bот. Nir. - Nephelium Noronhianum Cmbsd.

IrL. Lex. - Kihooëh S; Kiramboctan oetan M; Seggel \& Eggel M; Tjeroggol monjet Mr.

GR. PL. - In bosschen van westelijk Java.

Gebr. - De stam levert een sterk bouwhout en wordt veel gebruikt roor molens, buffelkarren, ploegen, rijststampers enz.; vool brandhout is het minder geschikt, omdat het niet vlug wil branden. De vruchtjes worden door kinderen en apen gegeten.

\section{RHAMNEAE RBr.}

431. Bот. Nir. - Ziziphus jujuba Lam.

INu. IBEN. - Bidara I; Balis bukkol Mak.

Gr. PL. - Indie, Cochinchina, China, Japan; op Java meestal in tuinen en langs de wegen.

Geer. - Van dezen boom zal de stam een sterk bouwhout leveren, dat ook veel voor handvatsels van gereedschappen gebruikt wordt. Rumphius noemt den wortel zeer bitter, bijna gelijk aan slangenhout; de wortelbast wordt gedronken bij moeijelijke urienlozing; de schors des booms bezigt men op Bali tegen diarrhoc. Volgens Horsfield bezit deze laatste zeer tonische eigenschappen, wordt hij aangeprezen bij maagzwakte en ziekten der ingewauden, doch is hij minder werkzaam dan de Poelé. Eudlicher geeft op liij door vele indische volken in plaats van Quassia wordt aangewend. Op de takken dezes booms zal zich dikwijls lak (gummi lacea) bevinden (Geiger).

De bladeren bezigt men op Java bij het afwasschen van lijken 
en fijngekneusd uitwendig bij hooflpijn. De vruchten zijn meelig, zoctachtig van smaak, in Europa in sommige apothelicn onder den naam van Jujubae voorhunden, en worden door den inlander gegeten. Gedroogd worden zij als inwikkelend, verzachtend, ligt oplossend middel bij borstkatarrhen anngeprezen, doch steeds in verbinding met andere zelfstandigheden aangewend; zij zijn een bestanddeel der Augsburger borstthee. Rumphius zegt dat de Amboinezen de half rijpe vruchten bij borstaaudoeningen bezigen, doch weerspreekt derzelver nut.

\section{EUPHORBIACEAE Bitl.}

432 Вот. Nм. - Euphorbia nerüfolia L.

IvL. BEx. - Soesoerra S; Soedoc-soedoe MI. J; Sosuchoe O. J; Blarlong Bali; Oebat dingin Amb; Aijluaa Ht; Karamban-dinar $\mathbf{B d}$; Sjuggi lida ' $\mathrm{T}$.

Gr. PL. - Op Jara en elders, meestal langs strandplaatsen.

Gebr. - Van deze Cactusaardige struilk, welke de inlander veelal als omheining of bij het maken van rersterkingen aanplant, wordt op Java slechts, zoo verre mij beliend is, het melksap uitwendig bij furunculi en sommigs huidziekten aangewend; meerdere deelen van haar zijn echter zon op deze eilanden als vooral op den vasten wal van Indie in gebruik. Zoo zoude do wortel den beet ran vergiftige slingen heelen. De wortelbast, gekookt met rijstwater en arak, bezigt men volgens van Rheede bij waterzucht en is een zecr doelmatig geneesmiddel. Uit het hout zouden soms krisheften gesneden worden. De bladeren behooren, daar zij den stoelgang zeer bevorderen, tot de hijdragoga; op Hitoe zoulde men deze daartoe in rijstpap mengen; op Bali echter ze als groente bij visehspijzen nuttigen; verwarmd en op den buik gelegd zullen zij de urienafscheiding rermeerderen; gekorkt en bij wijze vain omslagen grebruikt pijnntillend werke!s. IIet uit de boven een zacht ruur verwarmde bladeren geperste sap wordt soms in plaats rim azijn gebruikt. Het melksap der plint, that in de keel branding rerwekt en in de oogen grakende hevige ontsteking doet ontstaan, werkt ontlastingherorderend en wordt door de Hindoes tegen tusschenponzende koorten en onderbuilisverstop- 
pingen, als ook tot het branden ran wratten en kwaadardige zweeren aangewend. Volgens IIorsfield kan het bij wijze van gom gedroogd gemakkelijker toegediend worden; hij diende het als dinreticum, tweemaal daags vijf grein, net vertrouwen en goed gevolg bij eenen lijder aan hijdrops toe. Nog vermeldt Rumphius dat men op 'Timor een weinig melksap aan kinderen geeft, welke aan wormen lijden. Bontius gebruikte een extrakt der bladeren tegen hijdrops, paralijsis, enz.

433. Boт. Nı. - Euphorbia antiquorum L.

INL. BEx. - Soesoerra S; Dawon soerroe J; Soedoe J.

Gr. PL. - Afrika, op Java bij bouwlanden on langs de stranden.

Gerr. - Deze plant levert tegenwoordig met de E. canariensis de bekende Euphorbium of resina Euphorbia, eene zeer scherpe ligt brandbare stof, wellie, wanneer men zich bij het tot poeder stooten dezer niet in acht neemt, spoedig ontsteking ran het slijnvlies ran neus en oogleden doet ontstaan, en hooflzakelijk zamengesteld is nit scherpe hars, was, mijricine, plantenlijm, caoutchouk en eenige zouten. In Indie bezigt men het vermengd met de uit de zaden van Sesamum orientale geperstte olic uitwrendig bij rheumatische aandoeningen, inwendig tegen hevige constipatio alvi. De Arabieren maken met meel van hetzelve hunne sterk drastische, pisdrijvende pillen, terwijl zij de gekookte takken aan humne kameelen te eten gegeven. Op Java is deze werking der gomhars den inlander niet bekend, doch vermengt men deze met het sap van temoe lawak (de wortel eener zingiberacea) en wrijft dit in bij scabies, waarloor de mijt zoude sterven.

434. Вот. Nu. - Euphorbia tirucalli L.

INL. BEN. - Tikal baloeng S; Patta toelang J; Pohon hidop J; Kajoe tangan J.

GR. PL. - Java in bebouwde moerassige gronden, ook veel in omheiningen.

Gebr. - Ooli deze plant berat ece zeer seherp melksap. Hare wortel prijst van Rheede in afkooksel gegeren aan bij darmpijnen, als den stoclgang zeer bevorderende. Het jonge loof wordt ap Java in water geweekt, fijngewreven en dit water gechronken 
om cone rijkelijke stoelgang te verkrijgen. Volgens Rumpliuts zoude de buitenste fijne bast na fijngewreven te zijn bij cene bsenbreuk on liet gebrokene lid worden aangewend. Het melksap, waarvin mien op de Philippijnsche eilanden gelooft, dat het gebrokene beeneinden weder zou doen zamenkleven, gebruikt de inlander uitwendig bij seabies, herpes en andere chronische huidziekten als causticum; in Indie zal het ook als blaartrekkend middel aangewend worden.

435. Bот. Nur. - Euphorbia thijmifolia Wld.

IxL. BEx. - Mamaniran M; Nanangkaän S; Patikan J.

Gr. PL. - Op Java in weilanden en langs de wegen; Japan.

Gebr. - Een afkooksel van het kruid dezer plant, welke cenigzins aromatisch en zacht zamentrekkend is, geeft men in Indie gewoonlijk aan kleine kinderen bij diarrhoe en om ingewandswormen te verdrijren. Op Java wordt de geheele plant fijngewreven met adas, plassaric en water en inwendig toegediend bij hevige diarrhoe, dijsenterie en ander buiklijden. Het sap der stengel wordt bij vlekken op het hoornvlies in de oogen gedruppeld. Volgens Hasskarl legt men de fijngervrevene plant ook als bedeksel op wonden.

436. Вот. Nr. - Euphorbia canaliculata Hrt. Bog.

Gr. PL. - Onbekend; is eene sierplant.

437. Вот. Nar. - Euphorbia splendens Bot. Mag.

Gr. PL. - Amerika.

GEbr. - Is eene sieraadplant, den Javaan onbekend.

438. Вот. Nм. - Pachijstemon triloðum Bl.

INt. BEN. - Marra en Marra burrum S.

Gr. PL. - Java in bergstreken.

Gerr. - Het hout der oude boomen dient roor bouwhout on huishoudelijke gereedschappen; met het melksap der jonge plinten lijmt men boeken.

439. Bот. Ny. - Homalanthus Leschenaultianum A. Jss.

INt. EEV. - Karumbi S.

GR. PL. - Op Java in kleihoudende bergstreken.

Gebr. - De bast wordt gestampt, en of in water geweekt, of beter afrekookt en het water afgegoten, en darmede kleedjes gàreu, enz. zwart geverwd. De bladeren worden over het vuur 
gedroogyd zonder ze te verbranden, dan fijngewreven en in het voeder van beesten gedaan, welke door ecne soort van kleine wormpjes (karmi) aange tast zijn (IIasskarl). Met atas en poelassarie vermengd en fijngewreven bezigt men ze uitwendig bij hoofelpijn.

\section{Bот. Nir. - Acalijpha densiflora BI.}

IvL. BE.. - Tali andjieng S; Boentuet koetjing Mr. S; Ningsi lumboet $\mathrm{S}$; Ejkor koetjing $\mathrm{MI}$; Lunga tambang $J$; Kocpossa IIt; Lofitti 'T.

Gr. PL. - Op Java en elders veelvuldig in tuinen.

GerR. - Vele Acalijphasoorten prijat men als oplossend, pisen zweetdrijvend en ontlastingberorderend aan. Van deze soort in het bijzonder heeft Rumphius opgeteckend, : de wortel en bla" deren lioudt men voor een specifiek middel tegen bloedspuwen. "Uitwendig wrijft men de bladeren in bij cene luidziekte, de "witte melaatschheid, noman poetie genaamd. De bladen wor"den ook grebruikt tegen spruw der kinderen. Anderen bezigen " daartoe den wortel."

441. Вот. Ny. - Cnesmone javanica Bl.

INI. EEN. - Poeloes aroij S.

GR. PL. - Java in bergachtige streken.

442. Вот. Nлг - Claoxijlon indicum Endl.

IYL. BEX. - Taliengkoep S. MI; Bleketoepoek J.

Gr. PL. - Westclijk Java in bergstreken.

GEer. - IIet hout brandende verspreidt dit eene rook, welke de ademhaling zeer bemoeijelijkt; het jonge loof wordt afgekookt en als groente bij de rijst genuttigd; bast, bladeren enz. fijugewreven worden bij aamborstigheid op de horst ingewreven.

443. Boт. Nu. - Claoxijlon minus Endl.

INI. BEx. - Seroet of Sieroet S.

Gr. PL. - Westelijk Java in bergstreken.

444. Bor. Nir. - Elateriosperma tapos B1.

INL. BEN. - Tapos S.

Gr. PL. - In bosehrijke bergstreken vau Westelijk Java.

GEBr. - Het hout is wel wit en fraai, maar wordt niet gebezigd, daar het niet sterk is en spoedig dnor de witte mieren wordt verteerd. De vauchten leveren eene olic, die bij snijzen 
kan worden aangewend en ook als lanpolie dient. Hasskarl. 445. Вот. Nu. - Aleurites moluccana Wld.

IXL. BEx. - Moentjang S. J; Kamierie M; Boewa kras MF; Sapiri Mak; Ampiri Bg; Kalleli Bm; Siboe en Siboet Br; IJaro-mahoe Amb.

Gr. PL. - Op alle deze eilanden in bewoonde plaatsen.

GEsr. - De als noten of amandelen smakende zaden worden, zoo door Europeanen als inlanders, onder verschillende spijzen gemengd als specerij benuttigd. Fijngestampt en met katoen of den bolster wan kokosnoten vermengd of gekneed en in bamboezen gedaan leveren zij eene soort van fakkels. Gedroogd, fijngestampt, daarna in stoom gekookt en uitgeperst verkrijgt men van haar ecne gromachtige rette olie, welke versch zijnde tot het bereiden riun spijzen kan gebruikt worden, niet lekker, evenwel onschadelijk zal zijn, doch meestal slechts tot lampolie dient, gebrand wordende cenen stinkenden walm verspreid en voor onze lampen niet geschikt is.

446. Bот. Ny. - Jatropha multifida L.

INL. BEN. - Djarak tjina M.

Gr. PL. - Is uit Amerika naar Java overgebragt en wordt aldaar in vele tuinen gevonden.

Gebr. - De hazelnootgroote, bleekbruine zaden, Nuces purgantes, Avellana purgatrix, Been magnum, worden als die wan Curcas purgans IIdk $(\$ \$ 7)$ angewend. Onder den naam van Oleum Pinlıen of Braakolie bragt men roor eenige jaren nit Brazilie eene in giften van 1 ì 2 droppels hevig purgerende olie, welke waarsehijnlijk nit deze zaden verkregen worlt, die rolgens Soubeiran volstrekt dezelffe bestanddeelen als die der Curcas purgans bezitten. Ook de blateren worden als purgeermiddel aangewend, zij zullen een tergengift tegen dat des Manschincllenbooms (Hippomane manzinella L) zijn。 - Geiger.

Ook deze jlant laat zich in stekken ligt vontplanten, en wordt datarnn reel in heiningen angetroffen. De dikke knollen worden na eerst in asch gebraden te zijn gegeten. Hasskarl.

447. Boт. Na. - Cureas purgans MIdk.

INL. BEY. - Djarak kosta M; Djarak pagger M.

Gr. Pt. - Cuba, Nicuw-Crentala; op davi in bebouwde plaat- 
sen en vooral in heiningen aaugeplant.

Gebr. - Van dezen, door steklen ligt voortteplantenen, giftigen heester beschouwt men de bladeren als roorhakend en verharde gezwellen verdeelend; zij zullen ook geschikt zijn tot heeling der door de paardeuvlieg veroorzaakte wonden aan de oogen der paarden en tot bedwelming van visschen. De plant is rijkelijk bedeeld met een zeer scherp melksap, hetwelk men veronderstelt dat eene reinigende en wondheclende kracht bezit, en het linnen zwart verwt; op Java wrijft men daarmede de tanden in, om deze zivart te maken. De zaden, welke zoo in nitwondig amzien als in innerlijk maaksel reel met die van Ricinus overeenkomen, waren vroeger onder den nam van Braaknoten, Nuces catharticae, americanae seu barbadenses, Semina ricini majoris s. ficus infernalis in de apothelien aanwezig; zij zijn reukeloos, hebben aanvankelijk eenen olieachtigen smaak, waarna een aanhoudend brauden in de keelholte rolgt, werken sterk drastisch purgeerend en braakwekkend, zijn zeer gevaarlijk en zelfs doodelijk. De Jaraan is voor deze zeer bevreesd, sommige echter eten cen half of een geheel zaadje om eene rijkelijke stoclgang te verkrijgen; meer genomen ontstaat volgens hen hevige braking, stoelgang en duizeligheid. Blanco geeft aan, dat wanneer zij te hevig werken men de handen moet in koud water houden of liever eerst de embrijo's uit dezelve nemen; ook ran Humboldt geeft dit laatste aan. Een zuur, acidum Jatrophicum, hebben Caventou en Pelletier nit de zaden verkregen, waardoor waarschijnlijk hunne hevige werking veroorzaakt wordt.

Uit deze zaden wordt eene olie geperst, welke vroeger onder den naam van helsche olie, oleum infernale s. cicinum in den hanclel was, en in kleine giften hevig purgeert. Soubeiran vond haar helder, kleur- en reukeloos, in den beginne van cenen zachten, later echter scherpen smaak; zij schijnt in kouden alcohol in het geheel niet, in warmen slechts weinigoplosbaar to zijn, waardoor zij zich ran ricinus- en crotonolic zoude onderscheiden. Op Java bezigt men har als lampolie en ook om garens en kleedjes mede rood te verwen waartoe zij vermengd wordt met moentjang (sem. Alcuritis moluceanae), tjabeh (fruct. Capsici fructesc.), djahej (rad. Zingiberis), lankwas (rad. Galan- 
gae) en andere. IIet vernis, dat de Chinezen bezigen om hanno kasten, gewcren (boxes) mede te bedekken, wordt verkregen door kooking dezer olie met ijzeroxijde.

De ecrste berigten omtrent deze zaden en olio heeft men volgens Greiger te danken aan den Spaanschen abt Monardes; men diende ze vroeger bij anasarca en andere soorten van waterzncht zoo in- als uitwendig toe; ook bij ilens, chronische jicht, enz. werden zij zeer geroemd. 'Tegen wormen liet men ze op den buik inwrijven.

448. Bот. Nı. - Manihot utilissima Pohl.

INt. Bes. - Oebie dangdur MI; Oebie kajoe MI; Oebie djindral $\mathrm{Mr}$; Oebie wolanda $\mathrm{MI}$; Hoei danghtur $\mathrm{S}$; 'Tjamporang $\mathrm{S}$; Ketella randoe $J$; Ketella kajoe $J$; Ketella pohon $J$; Boedin $J$; Oebie prantjis Mand.

Gr. PL. - West Indie, Zuid Amerika; op deze eilanden meestal tot omheiningen of in tuinen aangeplant. Zij laat zich ligt door stekken voortplanten, waarbij de inlander het bijgoloof koestert, dat de wortel giftig zoude worden, wanneer de stekken bij het planten verkeerd in den grond worden gestoken.

Gebr. - Deze achtroet hooge heester is door kultuur tegenwoordig niet alleen door geheel Midden en Zuid Amerika verspreid, man ook naar Azie en Afrika overgebragt. Zijne knolvormige wortel, welke soms meer dan dertig ponden weegt, bevat cene groote hoeveelheid giftig melksap, dat gedronken wordende maagpijn, oprisping, walging en braking doet ontstaan, terwijl Piso zegt, dat door hetzelve de oogen spoedig donkergeel gekleurd worden, langdurige duizeligheid en hooftpijn ontstazm en cindelijk koude der ledematen, angst en zolís den dood volgen. Niettegenstaande dit wordt in Amerika toch dil giftige silp, watarvan eene halve drachme tocreikende zorr zijn om een' mensch te dooden, met peper gekonkt als specerij bij vleeschspijzen gewuttigd, daar door kooking de giftige stof vervliegt en het overblijwende aldus onschadelijk en roedzaam wordt. Door gisting wordt uit liet versche sap des wortels eenen dronkenmakenden drank verkregen. Uit dezen wortel worden twee snorten ran zetmeel bekomen, welke den Zuid-Amerikanschen volkeren 
tot spijs dienon en zij op rerschillende wijze tocbereiten, er brood van bakken enz. Om deze te bekomen worden de wortels gocd fijn geraspt, lhet melksap er uitgeprest, diarna het mrelige orerblijsel met water goud uitgewasschen en op steenen of ijzeren phiten verhit; op deze wijze wordt de giftstof en afgerrisclien en door de hitte verrlugtigd. Ifet orurblijtsel vormt de belionde Cassare, Manico of Mandiocea en wordt, wanneer men rau

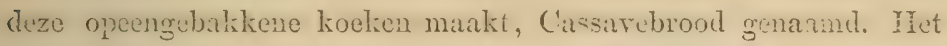
water, watumede de gestampte wortel herhaaldelijk afgewasechen is, lant, wanneer men het in rust laat, een fijner zetmeel nelerplofiu, diat 'Tiplocea heet. Deze beide zetmeelsonrten lumnon in roedzamheid met bijna allo andere wedijveren en worden dikwijls nar Europa nitgeroerd. De rersch afgeschraante wortel legt men in Amerika nog op onzuivere zwerende opperrlakten.

Op Jara nuttigt de inlander de jonge bladeren afgulsontst als groente. De wortels worden roor exne aangenamespij; gehomita cn raauw, gekookt of in asch gebrieten gergeten, echter mijle men de diarin zich berindente rezelen niet mede te eten, diar door deze braking en buikpijn zoude ontstann. De fijngesnedeno blizderen vermengd met eeu weinig ran de rrucht der Arenpran on zcmeleu geeft men aan parden, welke aim ingewandswormen lijden, witurdoor zij meerdere onthasting krijgen en de wormen gedood of uitgedreven worden.

419. Вот. Nur. - Gelonium glomerulatum Bl.

INL. Bex. - Penawar bëas S; Ganglot J; Kïnauk S; Djanglot J;

Gr. PL. - In lagere bosschen van Java en Noesakambangan.

Grur. - Tau dezen bijna immer blueijenden en rruchtelragenden heester wordt het hout roor lansstelen gebezigd.

450. Вот. Nır. - Ricinus communis $\mathbf{L}$.

INL. BEv. - Djarak kaliki S; Djarak selassar S.

Gri. rL. - Zuidelijk Azie, Afrikia en Amerika, Japan, op Java reelvuldig gekweekt.

Gebri. - Uit de zaden worklt door kooling en persingr de bekende licinus- of Castorolie bereid, welle den inlauder soms 
als prirgecrmidul, meestal echter slechts als ecne stinkende lampolie bezight, tot welk einde liij de zaden met die ran kapok (Gossampinus alba IIam.) rermengt en te gelijk uitperst. Ifet sap, door warmte nit de bladstelen en bladeren gedreven, druppelt hij in de onren bij hooflpijn en bij doofheid door verkouding veroorzaakt. De bladeren met aluin tot ecine pap bereid worden nitwendig op chronische zweren aangewend; met melk gekookt bevorderen zij, volgens Blanco, de etterafscheiding bij verschillende gezwollen beter dan elk ander kataplasma. Als ontlastingbevorderend en wormdrijrend middel worden soms de zaden gegeten, echter slechts weinige en met omzigtigheid. De olie gomengd met kalk on kapok wordt als stopverw tot het kalefateren van praauven en schepen gebezigd.

451. Вот. Ny. - Codiaeum variegatum Rmph, A latifolium aureum.

IrL. nex. - Kadomaas S; Kajoepoering maas gedeh S; Kajoe maas besaar $M$, en

452. Вот. Nu. - Codineum variegatum Rmph, B angustifoleum rubrum.

Ive. rex. - Kajoepoering burrum lentiek S; Handaroessa burrum S; Kadomaas S; Kajoe maas ketjil Mr; Dawon tamman J.

Voorts worden nog roor alle varieteiten dezer plant de narolgrende namen olgegeven, als: Sosal Ht; Aijtette obte on Aijtette olite IIuah; Gandiroessa koening Bd. en Kodiho of Dahingora T.

Gr. PL. - Op Java en elders veelvuldig in tuinen,

Gisan. - De wortel en bast dezer plant zijn scherp en reroorzaken bij het katauwen cen geroel van branding in de mondliolte.

Volgens Rumphitts gecft men cen aftreksel vau den wortel der roode raricteit aan klcino kinderen tegen maaglijnen. De jonge takjes geoft mon mot zout en water aan vermagerde buffels, om deze spoedig vet te maken. Bladeren en takken bezigt men als sierand bij vele fuesten; fijngekneusd worden zij nitwendig tegen londenpijn angewend en dic der laatste soort soms als groente genuttigd.

453. Вот. Nx. - Baliospermum axillare $\mathrm{Bl}$,

IvL. BEN. - Oedoe lada S; Pantjahan S.

Gr. $\mathrm{PL}_{\text {L }}-J_{\text {ava in }}$ bergstreken. 
454. Bor. Nu. - Croton tiglium IImlt.

IrL. efy. - Timalakkian S; Pantjahar M; Tjeraken J; Adal adal J.

Gr. PL. - West-Indie, Oost-Indie, op Java in vele tuinen.

Gebr. - De drastische werking ran de zaden en de olie dezes booms algemeen bekend zijnde, zoo zal ik alhier slechts vermelden, dat de geschilde wortel op Amboina aangewend wordt togen waterzucht. De bast en het hout, allier niet in gebruik, bezitten cenen scherpen brandenden smaak en drastische eigenschappen. Wanneer het hout, de bladeren of de zaden worden fijngestampt en in cenen vijver geworpen, sterven de visschen daardoor. Om ruimen stoclgang te rerkrijgen roostert de inlander een zardje boven het vtur en ect dit goheel of gedeeltelijk. De olie op den buik ingewreven zoude soms darmontlasting verwekken; door hare scherpte rocpt zij cchter dikwijls groote puisten te voorschijn.

455 Bот. Nм. - Bridelia stipularis B1.

IYL. BEx. - Kanjelıeh lumboet S; Kandrie S; Fätockoe gelang NI; Amadijeh MIand.

Gr. PL. - Batavia en elders in vochtige tuinen.

Gebr. - Van dezen boom dient het hout veclal voor huisbouw; de bladeren met water fijngewreven worden aan kraamvrouwen tocgediend en bij hoofdpijn roor het roorhoofd gesmeerd; op de Philippijnsche cilanden worden de gedroogde bladeren door eenige Indianen in plaats van tabak gerookt.

Omtrent de Brideliasoorten in het algeneen vind ik rermeld dat de bast van alle Aziatische soorten adstringeerend is.

Op Java worden de jonge spitsen der takken van deze van de schil bovrijd en in water gedoopt, en dan op die plaatsen van het oog gedrukt, welke eene witte kleur hebben, waardoor het zien nagenoeg belet rordt (maculae corneae), doch moet dit middel reeds in lict begin dor zitkte worden aangewend, anders verdwijnen de vlekken niet meer. Iasskarl.

456. Bor. Ny. - Sauropus rhamnoides B1.

IVL. BEN. - Katoek S; Babing J.

GIs. IL. - Westelijk Java in vruchtbare gronden.

Gebr. - Bladeren en vruchten worden raauw en afgekookt als 
groente bij de rijst gegeten; de bladen fijngerreren met patock bêbek on water worden nitwendigy gebezigd tegen furunculi, hooflpijn, koorts, enz.

457. Boт. NıI. - Phijllanthus nuriri $\mathrm{L}_{\text {s. }}$

Ist. bex. - Mamaniran S. Mr; Nangkilïn S; Katocmba lemang S; Dawon tjinta MI; Aijlaun mahaij Amb; Datwon ketjil IBd; Goffo miskien ' $\mathrm{T}$; IJgo-ijgo ' $\mathrm{T}$.

Gr. pL. Door geheel Indie op rochtige woeste of bubourite gronden; Japan.

GEBr. - De wortel, bladeren en jonge loten worden in Indic als afvocrend, pistrijvend en wondheelend anngeprezen; de bladeren wellse bitter zijn als een goed maagrersterkend middel. Volgens Rumphius wordt de wortel met pinang gekianwid bij tand-, buik- en Iendenpijn en geeft men het kruid afgewreven met water aan kinderen tegen vallende ziekte en stuipen.

Volgens de eenparige getnigenis van rele inlanders bewijst een afkooksel der geheele plant of alleen, of met den wortel van Carica papaija L. rermengd, goede diensten bij gonorrhoeae, pijnlijke urienlozing, graveel enz.; bij ecrstgenoemde aandoening maken ook vele Europeaneu hiervan gebruik. Om deszelfs rruchtaflrijvende kracht gebruiken inlaudsche vrouwen het raak tot een onzedelijk doel.

458. Вот. Nu. - Melanthes rhamnoides BI.

IrI. bEx. - Tjetjerennean S; 'Tjitjerannan S; Boeroeng randa S; 'T'jontjong beloet J.

Gr. PL. - Javia in kreupelbosschen. 459. Bот. Nir. - Cicca disticha L.

IVI. BEN. - Tjermeh M.

Gr. PL. - Oost-Indie, op Java veelvuldig in tuinen.

Gerr. - De wortel bezit hevige brakwekkende en purgeerende eigenschappen, misschien wel to hevig om er in de geneeskunde gebruik ran te maken, daar vele inlanders mij rerzekeren, dat honden ea kippen rerwond wordende met eene pijltje, dat met het melksap des wortels berochtigd is, dadelijk dood nedervallen. Ook Masskarl geeft åan, dat de steek met eene pen daarran reeds doodelijk zal zijn. Volgens Rumphitus geeft men cen stukje van den wortel met mostaardzand en water fijnge- 
wreven aan aamborstigen te drinken. De inlanders bezigen alhier ecn aftreksel ran dezen tegen sakit bocboelan. Een afkooksel der blateren, welke zweeturijvende eigenschappen bezitten, zal tegen sijphilis angewend worden. Do angenaam zunrzoete en saprijke ruchelen worden raauw, gekookt, onder andere groenten gemengd, in het zout ingelegd of gekonfijt gegeten. De zaden hezitten purgeerende eigenschappen.

460. Bot. Nir. - Anisonema dubia B1.

INL. Bex. - Wawoeloetan S.

- Gr. PL. - Bij Tangerang in krempelhout.

Gerr. - De bladeren en stengels fijn gestampt en afgelioolit bezigt men tot het zwartverwen van katoenen stoffen.

461. Bот. Nir. - Bradleja rubra Std.

IrL. BEx. - Kimoeka S; Marehmeh mienjak S.

Gr. PL. - In kreupelbosschen ran Bantam, Buitenzorg en do Preangerregentschappen.

Gebr. - Het hout is roor huisbouw gesehilkt; uit den bast der oudere boomen rervardigt men tour roor vischnetten, terwijl de bladeren bij de rijst gegeten worden.

462. Bот. Nur. - Pierardia racemosa Bl.

IVL. BEX, - Menting S, M; Kapoendong J.

Gr. PL. - Java, veelal in tuinen.

Gerr. - Het hout dat fijn, week, sterk en fraai is, bezigt men roor liuisbouw en meubelen. De schil wordt eren als die van Alcurites moluceana Wld. gebruikt om garens rood te verwen: De zuturzoete vruchten, welke goed rijp zijnde aangenaam van smaak zijn, worden gaarne gegeten en zijn gezond.

463. Вот. Nıг - Hura crepitans L.

Gr. pL. - Zuid-Amerika op eenen vochtigen grond, van daar in de laatste jaren nar Java overgebragt en in sommige tainen gekweekt, waar zij welig opgroeit:

Gebri. - ITet scherpe melksap des zandkokerbooms, dat in do oogen gebragt ligtelijk ontsteking veroorzaakt, heeft men in den laatsten tijd bevonden een goed middel tegen lepra te zijn. Volgens den Officier van gezondheid Schorrenberg te Suriname moet het melksap ingezameld worden, wanneer de bast het saprijkst is, en geduxende de toediening van dit middel suiker volstrekt 
vermeden worden. De bast wordt versch of op een zandbad uitgedroogd voorgeschreven, ook het melksap kan in rerschen of uitgedampten toestand worden toegediend. In den beginne diende men een braḱkmiddel toe, met tusschenpoozing ran drie a vier dagen, bereid uit anderlalve ons verschen of zes drachmen gedrooglen bast met aclit ons water tot op de helft rerkookt. Twee dagen na het laatste braakmiddel gaf men den lijiclers 's morgens en 'savonds eene pil bevattendo één grein gedroogd melksap, waarna naar omstandigheden dagelijks of om den anderen dag werd opreklommen, totlat zij 16 grein daags gebruikten, welke laatste gift zelden werd verdragen, doch meestal ontsteking ran maag en darmkanaal, enz. veroorzaakte. Was deze toestand weder hersteld, dan werd het braakmiddel weder herhaald en de behandeling op nieuw ingesteld. Van rijf tot vijf dagen gaf men laauwe baden en reinigde de huid met groene zeep. Ofschoon de Heer Schorrenberg bij getrek aan ruimte in het hospitaal zijne proeren spoedig moest staken, zag hij echter bij allen, die aan lepra leden, na een tijdelijk gebruik reeds merkbare Deterschap. Ook bij het Groot Militair Hospitaal alhier werden in 1852-1853 proeven met dit middel genomen tegen hardnekkige psoriasis, en, ofschoon deze onvolledig waren, toch beterschap waargenomen. Volgens Prof. MIulder, welke in 1818 den bast en het melksap scheikundig onderzocht, schijnen in den eersten roornamelijk lonizux en eene eigenaardige hars, in het laatste slechts de hars alleen het bepaaldelijk werkzaam Jestanddeel te zijn. (Zie nitvoeriger hieromtrent de mededeelingen van den Heer Wassink in het Gencesk. 'Tijdschrift roor Nederl: Indie, 40 Jaarg, aflev. 1-4, bladz. 539 \& volgg.)

De zaaddloozen, welke soms roor zandkokers gebruikt worden, springen rijp zijnde met een groot gedruisch open. De platte, raal gecle, op kraanoogen gclijkende en als amanitelen smakende zaden werken sierk purgecrend, in Amerika dient men er 1 à 2 als zoodanig den slaven toc; doch is hun gebruik niet van gevaar ontbloot. 


\section{ANACARDIACEAE Lindl.}

461. Вот. Nr. - Rhus suecedaneus L.

IVI BEY. - Pohon tjap MI; Fasi-no-ki Japan.

Gr. PL - China en Japan, van daar naa Java overgebragt.

Gebr. - Even als uit de Rhus vernix L. vloeit nit dezen boom eene hars, welke met cimnaber en andere kleurstoffen vermengd de Japansche sumak daarstelt en als remis bewaard wordt; volgens Thunberg levert hij echter zoo weinig, dat thet niet der moeite wardig is ze te rerzamelen. De olie uit do gekneusde, na de kooking nog warm gemaakte en onder ecne pers gedrukte zaden dient tot de bereiding van krarsen, on verkrijgt de dikte van talk.

465. Вот. Nм. - Mangifera indica L. (variet. 2).

Irr. BEx. - Manga MI; Batjang Mr; Limoes MI.

Gr. PL. - Oost Indie, thans ook in tropisch Amerika ingcroerd; op Java en elders meestal in tuinen.

Gebr. - Van dezen boom wordt de bast, hooflzakelijk die ran den wortel, welke bitter en aromatisch is, tegen diarrhoe, leucorrhaeae, enz. aangewend, of wel slechts zijn bitter, scherp en aromatisch sap daartoe gebezigd. Volgens Blanco dient een afkooksel des wortels als verfstof. Het grove niet zeer sterke hout wordt als bouwhout gebezigd, doch door witte mieren en andere insekten ligt aangetast. Klecteren, welke in indigo ecrst zijn blaauw geverwd, doopt de Jaraan claama in een afkooksel van den mangabast, om deze ecne groene kleur to doen verkrijgen. Aan de scherpe bittere hars, welke van zelve uit den stam vloeit, kent men cene antisijphilitische kracht toe; alhicr gebruikt men ze slechts als lijm. De jonge bladeren wendt men aan bij hoest en aamborstigheid, de oude zullen tot zuivering der tanden dienen en ook gebruikt worden om thee te vervalschen en zwart te kleuren. Het vleeseh dex steenvruchten, in het algemeen Mangapruimen geheeten, en waarvan door kultuur ecne menigte varieteiten zijn verkregen, bezit eenen aangenamen zocten smaak, waardoor zij op de tafels ran Europeanen en inlanders zeer gewild zijn; bovenmatig geluruikt verweklen zij ligtclijk vermeerderde ontlasting en worden vele door furun- 
culi of andere huiduitslagen geplaagd. Aan zijne bittere zaden kent men cene wormdrijvende kracht tos; met Blaauwhoutvermengd zullen zij eene goede inkt leveren.

466. Вот. Nu. - Mangifera foetida Lour.

IXI. BEX. - Remang S. MI; Ambatjang M.

Gr. PL. - Cochin-china, de Molukkos, op Java in tuinen.

Gebr. - Ook de steenvruchten van dezen boom worden gegeten, zijn echter minter angenaam dan die der rorige soori en bezitton een wit stinkend vleesch.

467. Вот. Nม. - Anacardium occidentale $L$.

Ivt. rex. - Djanboe monjet MI; Mranga monjet MI; Djamboe meldeh MI; Djamboe kratjoe Mi; Djamboe soor Matk; Boura frangi Amb.

Gr. pr. - De Caraibische eilanden, MIuxilso, Zuid- Amerika; op deze eilanden veelal in tuinen.

Gesr:- Van dezen in Wost Indie te huis behoorenden boom bezit de wortel ontlastingherorderende eigenschappen, terwijl de zamentrekkende bast tegen spruw aangewend workt. Uit zijnen stam vlocit eene gomachtige zelfstandigheid, welke zich dikwijls tot eenen vuistgrooten kogel aanzamelt, en in Europa onder den naam van Gomme d'Acajou in den handel gobragt worilt; deze worlt eren als de Aribische gom angewend, terwijl bocken met dezelve bestreken zijnde niet door witte mieron worden aangetast. De bladeren zullen rolgens Endlicher hoofdpijn rerweklien, doch worden op Jiva als groente gुegeter. De saprijke vruchtdrager (oneigenlijk doox velen rrucht genaumd) bezit cene rooke kleur, en aangenaam zoctzuurachtiog, soms eenigzins wrang rleesch, dat als ooft wordt gegeten of liever het sap er uitgezogen, wijl zij gekaauwd wordende door han zuur de tanden stonip maken. Duor de Nrgers wordt deze rruchldrager als een middel tegen maghbzwaren aangewend. IIet sap dient dikwijls als limonade; door gisting hekomt men uit hetzelve eene soort van wijn en azijn; terwijl de Engelsehen het gebruiken tot bureiling ran punch. De noten, wrelke rroeger en nog soms in eenige apotheken onder den naam ran West Indische Oliphantshizen, Anacardia Occidentalia, rerkrijģnar ziju, waren in vroggere tijktu in Eurnja tegun peest- en verstands- 
zTrakte, als ook tegen rerschillende borst- en onderbuilkaandocningen in gebruik, gelden thans nog in Zuid Amerika als cen werkzanm middel tegen chronisehe diarrhoe en worden bij wijze ran amulet om den hals getragen als behoedmidlel tegen chronische ongmatstelingen en roule rlekken in het aangezigt.

Even als de Oost Indische, bevatten ook deze noten tusschen humne twee schalen con zwart zeer bijtend sap, dat op de huid angethagt spoedig ontsteking verwekt en afsehilfering der opperhuid veroorzaakt. De hars, welke uit de noten verkregen kin worden, zal hut sterkste der hlaartrukkende middelen en horen Spaansche vlicgen te verkiezen zijn, wameer men ecne langrhrige afleiling beoogt, de prikkoling der piswerktuigen wil rermijden en van het later gebruik eene prikkelende zalf verschoond blijven; ook kim deze hars zeer goed tot daarstelling van gewaste taf" (tafietas epispastique) dienen. In Amerilia bedient mien zich van het scherpe sap, dat tusschen de schalen bevat is, als bijtmirldei tot remictiging ran wratten, likdoorns en zomerspoeten; ook bestrijken de Indiansehe rrouwen er zich het aangezigt mede, om de huid weg te bijten, waardoor zij ene nieuwe teederdere omerluil twryg bekomen en er alzoo jeughigur zullen uitzicn. Het zwarte sap, als ook het melksap des booms benuttigt men nog tot het beschilderen van lijnwaden en deolt dit aan deze eene onoplosbare zwarte kleur mede. De binnenste schaal der noot omvat eene goedsmakende kern, welke raauw en toebereid gegeten, on als amandelen uit een geneeskundig opzigt kunnen gebruil:t worlen; rolwens Blecker schijnen zij opwckkend op den genitaalspheer te werken. Alvorens ze gebruikt worden moet men ze in water goed afwasschen, om hen van do aanhangende scherpe stof der schalen te bevrijden.

In deze gerresten is de inlander bekend met het gebruik der gom als lijmstre, de geneeskiachtige anwentiug van den bast, de cetbarrheid ran blaten, ruthehthiger's en kemen, alsmete met het blaartrelskend rermogen van lict rocht, dat tussehen de schalen. bevat is.

468. Вот. Nu. - Schinus terebinthifolius Radd.

IYI. BEX. - 'Tangoelong ketjil MI (?)

Gr. PL. - Brazilie, Bourbon, naar Java overgebragt. 
Gerr. - Deze boom, welke eene menigte Jars door de spleten der opperhuid nitzweet, en steeds al zijne takken als met kristallen bedekt heeft, zal echte terpentijn opleveren.

469. Вот. мМ. - Bouea oppositifolia Msn.

Iru: BEx. - Goenarjah S; 'Tjantekkeh S; Gandaria M, J. Gri. PL. - Pegu; op Java veclal in tuinen.

Geisr. - Het fraaije, tamelijk sterke en taaije hout wordt soms voor huisbouw gebezigd, doch dient meer tot vervaardiging ran scheden van wapens, akkel- en timmermansgereedschappen. De jonge bladen en de in het zout ingelegde ourijpe vruchten eet men bij de rijst, de rijpe als lekkernij.

\section{BURSERACEAE Kth.}

470. Вот. мM. - Canarium commune L.

Ivt. LEN. - Kitoewah S; Kanarie MI; IJal Amb; Nanari Bd; Niha 'T.

Gr. Pt. - Oost Indie, de Molukko's; op Java meestal in bebouwde plaatsen en in het wild op den Salakh

Gebri. - Uit den stam dezes booms vloeit eene hars, waaromtrent de meeste schrijvers verschillende opgaren mededcelen. Volgens Wildenow is zij talkaardig, riekt zoo sterk dat zij hoofdpijn veroorzaakt en wordt gebezigd om er filkkels van te maken, welke bij het branden echter zeer stinken. MIerat en Lens gelooven dat zij de Resina Guinea novae, eene soort ran Elemihars, zoude zijn. Volgens Lindleij bezit zij dezelfile eigenschappen als de Copaivabalsem, terwijl Blanco vermeent men deze hars als berookingsmiddel bij phthisici kan bezigen. Het grove en sterke hout wordt veel bij den huisbouw gebezigd, echter door witte mieren anngetast, en daarom meer tot het maken van doelangs (schenkbladen), roeispanen en braudhout aangewend. De zaden worden op deze eilanden viij algemeen bij wijze van amandelen gebezigd, bezitten eenen zoeteren smaak dan deze en veroorzaken door lhun groot gehalte aan vette olie, wamneer zij niet goed rijp zijn, ligtelijk diarrhoe. Volgens Waitz zijn zij aan to bevelen bij ontstekingachtige ziekten van spijs- en urienwegen en bij vergiftigingen door scherpe plantenstoffen. IIet een 
weinig sago rermengr, bereidt men er rolgens Rumpluius het Amboinesche brood van, baggểa on mangêa genaamd, welk brood echter zeer hard en moeijelijk vertecrbaar is. De olie uit de rijpe en in den rook gedrongde zaden verkregen kian versch zijude tot het bereiden van spijzzen, de oude slechts om te branden gebruikt worden.

\section{SIMARUBACEAE Rich.}

471. Вот. Ny. - Quassia amara L.

Gr. PL. - Suriname; op Java ingevoerd.

Gerr. - Zie omtrent dezen boom en het lignum quassiao de verschillende handboeken over materies medica.

472. Вот. Nu. - Samadera indica Grtn.

IYL. BEN. - Gatep pait MI.

Gri. Pr. - Madanasear, Oost Indie, in tuinen rondom Batavia.

Gribr. - Van dezen boom bezitten bijna alle deelen een zuiver bitter, bijna gelijk aan dat der Quassia en Simaruba, hoofilzakelijk echter is dit in den lrast, welke onder den naam ran Cortex Niepa in den handel komt, en in de vruehten voorheerschende.

Duor de bitterstof worden beide deze declen ten hongste gewigtig bij zwakte van het dammkanaal, ziekelijke slijmafzondering van hetzelve, verminderde galafseheiding, in het algeneen bij vele naziekten welke met zwwakheid van maag en ingewanden verbonden zijn. Van Rheede prees een afkooksel harer vruchten aan tegen $\Lambda$ ziatisehe cholera, terwijl Blume met roorded van hetzelve heeft gebruikt gemaakt bij remittecrende en intermittecrende koortsen. Ook de wortel eu de bladeren zullen als koortswecrend middel kumen anngewend worden. De bast daarenboven, welke scherp, ligt bijtend van smaak is en het speeksol roodkleurt, levert verbonden met die van Morinda umbellata het duurzame rood der Oost Indische halsclocken (foulards de l'Inde).

XANTHOXIJLEAE Rich.

4.73. Вот. พм. - Brucen sumatrana Rxb. 


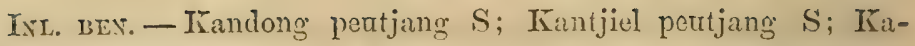
doija S; Loessa radja MI; Kittilang J. Waarschijnlijk zijn de roor twee Brucensoorten door Irorsfield aangegerene namen: Krimonjenjen $S$, Trawalot $J$, Típait $S$ en Pati lalar $J$ ook op deze soort ran toepassing.

Gr. PL. - Sumatra, Java, de Molukkos, China en Cochinchina.

Gerr. - Even als de vorige plant munt deze door een zuiver bitter uit, dat in wortel, bast, bladeren en vruchten bevat is, haar met Simaruba, Quassia en Absijnth gelijk stellen doet en ook eren a!s deze bij atonischen toestand ran maag on darmkanaal, remitteerende en intermitteerende koortsen aanwenden. Borendien prijst IIorsfield een afkooksel ran den bast met die der Cedrela fubrifuga verbonden aan, als zcer heilzaam zijnde in de laatste stadia ran dijsenterie; ook als wormdrijrend middel zoude deze bast kumnen toegediend worden.

\section{DIOSMEAE JSS.}

474. Вот. Nм. - Evodia glabra Bl.

IVL. BEY. - Kisampang $\mathbf{S}$.

Gr. PL. - In hooge bosschen van Buitenzorg en Tjanjor.

Gebr. - IIet fraai witte hout gebruilst de inlander als bouwhont, de bast en bladeren uitwendig tegen schurft van paarden en andere huisdieren. Volgens Blume kan men zich ran een afkookscul ran alle Jaransche Erodiasoorten bedienen als een zuirerend en opwekkend wondmiddel.

\section{RU'TACEAE Brtl.}

475. Bот. Ny. - Ruta graveolens L.

IVL. BEN. - Ingoe MI.

Gr. pL. - Europa, Japan; naar Tava in tuinen orerogebrangt.

Gebr. - Wordt hoofdzalselijk bij klcine kinderen en door kraamvrouwen alhier gebruikt. 
OXALIDEAE De.

476. Вот. Nur - Oxalis repens Thnb.

INr. iskx. - Djoekoct tjuliengtjieng $S$; Datrou assan ketjil II.

Gr. pt. - Iraap de gocde lionp, Madagascar, Ceijlon, op Java in moerassige plaatsen en slooten.

477. Bот. Nу. - Averrhon bilimbi L.

IYL, BEx. - Bliembieng benssie S; Blimbieng Mr; Blimbing bocloe en I31: boelat II; Baijnan tijade Mak; Tagoerela Amb; Tagorera Bd.

Gr. PL. - Oost Indische cilanden, op Java op bebouwde plaatsen.

Gesr. - De fijngewrevene bladeren zal men op Bali bezigen om zich bij hevige loortsen het ligehaam in te wrijven of wel laartegen eon aftreksel gedronken worden; ook bezigt men die ran deze en de volgende soort tot rijpmaking van langdurige zwellingen. De rruchten, welke anngenaam doch scherp zuur ziju, worden onrijp en rijp zijnde gegeten, meestal echter bij andere spijzen gemengd, dan wel in azijn of in suiker ingelegd. Fene conserf of marmelade van deze in plaats van tamarinde gedronken is zeer nuttig beronden bij scorbutus en zoogenaande status biliosus. Het sap der vruchten, waarin veel zuringzuur aanwezig is, kan ook in de huishouding gebezigd worten om linnengoed van roest- en inktvlekken te bevrijden.

478. Вот. хצ. - Averrhoa carambola L.

IYL. BEY. - 'Tjaliengtjieng S; Bliembieng manies MI.

Gr. PL. - Als de vorige soort.

Gebr. - Volgens Rumphius wordt de schors dezes booms met adas on poclassario fijngewreven op den buik gesmeerd om stoelgang te verwekken en roode hond te verdrijven. De saprijke, minder zure en verkoelende vruchten worden meer dan die der vorige soort raauw gegeten, echter ook even als deze toebercid cn an hen dezelfde geneeskracht toegeschreven. Borendion zou het sap rroeger tegen maculae corncae zijn aangeweud on nog gebezigd worden tot het polijsten van ijzer. 


\section{BALSAIIINEAE Rich.}

479. Bот. Nur. - Impatiens balsamina Is.

IYr. BEx. - Patjar J. \& Bali ; Patjar aijer, P. tjina of P. koekoe Mi Lakka ketjil, Lakka ambon, Alhalla ambon en Inne aijer Amb; MLardeni T.

Gr. P'L. - Oost Indie, Japau, op Jara in tuinen nagenoeg ver'vilderd.

Gern. - Ilet kruid dezer als sierplant veelruldig in tuinen gekweckt wordende plant wordt als bedeksel op ligte verwondingen, haar sap met aluin vermengd door de Javanen en Japannezen tot roodkleuring der nagels gebezigd.

\section{COMBRETACEAE JSS.}

\section{Bor. Nrr. - Terminalia catappa I.}

IrL. BEX. - Katappang MI; Katappang laut MI; Telijo Bd; Noessoe 'T.

Gr. PL. - Oost Indie, de Moluksche en Caraibische eilanden; op Java in tuinen.

Gebr. - De zaden, welke aangenamer ran smaak zijn dan die der Kïmaric, worden gedijk hazelnoten en amandelen gegeten. Iet hout van den stam is ecn sterk bouwhout, terwijl de schors en bladeren relbezigd zullen worden tot zwart rerwen, vooral on de tanden te kleuren en inkt te maken.

481. Вот. Nrr. - Quisqualis pubescens Brm.

Irz. I.Ex. - Woetlanie of Oedanie MI, S; Ketjeklok $J$; Tjekok J; 'Tjikau J; Soe-tjoen Ch.

Gr. PL. - Cochin-china, Java, de Molukko's, op Java vooral in kreupelbossehen en langs rivieroevers.

Gern. - Van deze plant worden de zaden rijp on onrijp zijnde onter de wormdrijvende midtelen gerekent en zoo asm rolwassenen als roornanncijk aan kinderen toegediend. Datar zij bij deze lautsten echter ligtelijk braking; herige hik, duizclighuid enz. veronzaken, moet men met hunne toediening zeer vourzigtig zijn, to meer daar kinderen deze wegens humnen naar noten of amandelon gelijkenden smaak gan'ue eten; vin twee tot 
vijf zaden zijn gुenoegzaam. De inlander wrijft er ecn of twee van met aklar dijaroeng, lintjoer en water fijn en geeft dit aan kleine kinteren te drinken, waarop deze de wormen dood zullen ontlasten. Volwassenen kumnen van de rijpe vruchtjes er vele eten. De bladeren, welke cenen onaangenamen geur on cenen sterkersaardigen smaak bezitten, worden soms als groente gegeten, soms ook als wormdrijvend middel toegediend.

\section{OENOTHEREAE Fndl.}

482. Вот. Nyr - Jussiaea fluvialis Bl.

IrL. bEx. - Selalassor MI Randa katilan MI; Kembang tombagaän aijer MI.

Gr. PL. - Java langs beekjes in bergachtige streken.

Gebr. - In tropisch Azic en Amerika worden de ecnigzins zamentrekkende Jussiaeasoorten voor omslagen en pappen gebezigd (Endlicher). Van deze soort zoude men de bladeren met dedak gemengd op Java aan varkens te eten geven.

\section{LIJTHRARIEAE JSS.}

483. Вот. Nar. - Lawsonia alba Lam.

INL. Isex. - Patjar tjina en Patjar koekoe MI; Dawon lakka II; Patjar petok J; Inci Mand; Tingi lakka IBd; Tsjinkahoe Ch.

Gr. PL. - West en Zuid Azie, Noord Afrika; op Jara en omringende eilanden veelvuldig in tuinen.

Gebri. - De wortel dezer plant, welke de Oost Indisehe Alliamna, de Radix Aleanna rera volgens de meeste schrijver's is, is donkerbruinrood en smaakt zacht zamentrekkend; zijne roornaamste bestandeclen zijn roode kleurstof en galnotewzum; hij is in Europa nox in sommige apotheken verkrijobaar en dient tot geelverwen. Volgens Blanco bezigt men hem in Turkijo als cosmeticum. Het hout tot houtskool grebrand wendt men op Java bij spruw, enz. aan. De bladeren maken in rele Oostersche landen een sewightig haudelsartikel uit, daar rolgens de gewoonte dier volken men met deze de nagels, de haren, ja 
zell's paardenstarten on lexter (marokijuleder) rood verwt. (ook alhier is deze gewoonte om de nagels rood te verwen zeer in zwang, en vermengt men tot dat einde de bladeren met zivarte mieren, tjabeh (spansehe peper), bawang poetih (uijen), enz., wrijft dit alles tot een papje te zamen fijn, on bindt dit op de te klourene nagels.

In vroegere jaren van uit Griekenland en later ook vin deze gewesten wordt gemeld, dat de bladeron en bloemen, ligt zamentrekkend zijnde, heilzaam zijn bij spruw en andere andoeningen der mondholte, en zij uitwendig bij verschillende zweren, rooral onijehia, en huidzickten worden aangewend. Bij de oulere Romoinsehe geneeskundigen komt te plant reeds onder den na:m vau Lignstrum roor, terwijl de oude Gricken laar Cijpros nocmden. De geurige bloemen, welke om hummen reuk de inlander's veelal tusschen humne kleederen leggen, zullen in Egijpte tegen hooflpijn, bij wijze ran rlierbloemen in een zalje genaatil, aangewend worden. De rlugtige olie uit deze laatste rerkrijgbaar zal dienstig zijn bij verstijfde en verlamde ledematen.

484. Вот. Nir. - Lagerstroemia indica L.

IvL. BEx. - 'Thé oetan M.

Gr. PL. - Japan, China, Cochin-china, op Java om zijne schoone blocmen in vele tuinen aangeplant.

\section{MELASTOMACEAE RBr.}

485. Boт. Nir. - MLelastoma polijanthum B1.

LYL. BEY. - Harendong goenoeng S; Bitoerong itam MI; Widaduri MI; Tjonkodo kir J; Dockdouk en Kadockdouk Dilli; Nim en Aijnahu Amb; Kramandijn Mak; Geroro mavalla ' $\mathrm{I}$.

Gr. PL. - Oost-Indic; op Java, Sumatra, Borneo enz. mecstal als kreupelhont in hoogere streken.

Gebr. - Volgens Rumphius dient men het sap des wortels toe aan lijilers mot epilepsie of andere zenuwtoevallen; rolgens IIasskarl wordt dezen afge.schrapt, in water gureekt en dit water aan linderen to drinken gegeven tegen ingewamklswormen; of wel men laat zijnen bast 2 à 3 dagen in water weken, wrijf die dan fijn en bindt dit als pap den linderen 
op den buik. De zamentrekkende bladeren kunnen bij diarthoc, dysenterie on blemnorrhocae anngewend worden De zoetsmakende bessen, welke bij het kaauwen de lippen en het specksel ziwart kleuren, hebben aan dit geslacht den naam gereven en zijn ectbaur.

\section{MIJR'TACEAE RBr.}

488. Bor. Nu. Sijnearpia Vertholenii 'Teijsm. \& Bnndk.

IVL. BEx. - Kajoe bessie MI.

Gr. PL. - Molukko's; op Java in eenige tuinen overgebragt.

GEbr. - Deze boom, welke door Rumphius verkeerdelijk al: Metrosideros vera zoude beschreven zijn, levert het zoo bekeude IJzerhout.

489. Вот. Nir. - Eucalijptus robusta Sm.

Gr. PL. - Nieuw Holland.

Gebr. - Deze, welligt een der hoogste boomen van Nienw-Holland, daar hij soms eene hoogte van meer dan 160 voeten bereikt, bezit in den stam vele holten, watarloor zijne jaarringen, doorweven met eene roode of schoon vermillinenkleurige gom, zigtbaar worden. Alle zijne deelen zijn zeer geurig.

490. Вот. Nrr. - Psidium guajava Radd. A pomiferum Radd.

Irr. BEx. - Djamboe biedjie MI; Dj. kloetoek M; Dj. batoe J; Dj. kocneng J \& Bali; Guajava T.

Gr. PL. - Oost- en West-Indie, de Molukko's, op Java in kreupelbosschen en veelvuldig in tuinen.

Grebi. - De bladeren en wortel van dezen boom waren vroeger onder den naam van Folia et Radix Guajavae in Europa officinecl, zij zijn eenigzins geurig en even als de bast zamentrekkend. Eon afkooksel van den wortel, beter nog van den wortclbast, diende Waitz met good gevolg toe bij dijsenterie, wanneer reeds alle verschijnselen van ontsteking verdwench waren door vroegere toediening van kwikmiddelen enz; ook nu nog wordt het door velen tegren chronische dijsenteric aanbevolen, zoo ook een aftreksel der bladeren, wellic als thee, Jamboethee genatumd, bij diarrho on dijsenterie in alle stadia kumnen gredronken worden; ook de inlanders bezigen ze gaarne tergen deze ziekten.

Het wecke, cuhter sterke hout dient voor rijjststampers, scheden 
van wapens, enz. De aangenaam smakende, aromatische en vleezige vruchten kunnen zonder nadeel in groote hoeveelheid genuttigd worden, zij ziju ecliter door de menigte zaadjes den nieuwaangekomenen dikwijls lastig en willen bij hen wel eens ligte diarrhoe veroorzaken.

491. Boт. Ny. - Rhodomijrtus tomentosa De.

IVL. BEx. - Harendong sabrang M:

Gr. PL. - Ilindostan, Cochin-china, China; op Java als sierplant in eenige tuinen.

492. Bот. Nir. - Sijzijgium jambolanum De.

IXI. BEx. - Jamblang S; Doeat S; Djoeat Mi Oebar Mand; Roppa-rappo Mak; Doewé Bm.

Gri. PL. - Oost Indic; op Java en Sumatra in tninen vrij algemeen.

Gesr. - Het hout is een goed en sterk bouwhout; de bast, welke gebrukt wordt om het touw van vischnetten fraai wit te wasschen en sterk te maken, kan ook in afkooksel bij diarrhoe dienstigg zijn. De bladeren worden raauw gegeten en op de Philippijnsche eilanden gedroogd bij gebrek aan tabak gerookt of onder deze gemengul. De blaauwe, zuurachtig zoete, adstringerende, olijfvormige vruchten worden raauw en gepekeld gaarne door den inlander genuttigd.

493. Bот. NıI. - Carijophijllum aromaticum L.

IrL. BEx. - Tjengkeh M; Boenga lawan en Boegoelawan MI; Boehoelawan Amb; Boalawa T; Gomode Td; Tin-sjong Ch.

Gr. PL. - Molukko's, Sumatra, op Java in eenige tuinen; tegenwoordig ook orergebragt naar de Mascarenische en Antillische eilanden en den vasten wal van Zuid Amerika.

Gebr. - Volgens Rumphius wordt de nagel gebruikt als amulet tegen rijandige kogels, als minnedrank vermengil met kajoe rappat en matjaïn, en als een de vlecschlijke lusten opwekkend middel door Chinezen. IIet huishoudelijk en geneeskundig gebruik der nagelen en vooral der nagelolie is te bekend om er hier meer over aan te halen.

494. Вот. Ny. - Eugenia Michelii Lam.

IVL. BEY. - Kijangkar S.

Gr. PL. - Brazilie, Demerarij; op Java in tuineu. 
Gebr. - De vruchten van deze eu andere Eugeniasoorten behooren in Amerika tot de geliefkooscle ooftsoorten.

495. Bот. Nu. - Jambosa vulgaris De.

INL. BEx. - Djamboc aijer mawar, Dj: aijer en Dj. mawar Mr.

Gr. PL - Oost Indie, op Java in het wild en in tuinen, thans in bijna alle keerkringslanden aangekweekt.

Gerr. - De zamentrekkende bast dezes booms on de scherp aromatische zadeu worden tegen diarrhoe en dijsentcrie aangewend. De vruchten, welke eenen aangenamen rozengeur en lekkeren smaak bezitten, worden niet slechts als ecn geliefd ooft raauw en ingelegd gegeten, maar zijn ook benevens de in suiker ingemaaktc bloesems als een verkoelend en bedarend geneesmiddel in gebruik en als ziekenspijze gezocht. De versche zaden zijn ook als homöopathisch genees- en behoedniddel bij epidemische katarrhon werkzaam bevonden.

496. Bот. Nax. - Cerocarpus aquaëus Hsskl $=$ Jambosa aquaëa Rmph.

IXL. BEx. - Djamboe aijer M: Djamboe goelampok anom $J$; Tamboe djene Mal; Jamboe oewer Bali; Gora jadi 'T; Roettoen tsjapeo en Roettoe maun Amb; Oewer Bd.

GR. PL. - Molukko's, op Java in tuinen zeer algemeen.

Grebr. - De schors des booms met water afgewreven zou als mondspoeling heilzaam zijn tegen spruw der kinderen. De fraaije, als het ware uit was gevormde vruchten hebben een aangenaam zuurachtig, saprijk vleesch en worden vcelvuldig raauw of met wiju en suiker gestoofd gegeten; men rindt ze rerscheidene bij elkander aan eene fijne bamboes geregen te koop.

497. Bот. Nir. - Barringtonia speciosa L.

IrL. BEx. - Songgom lalakki S; Poetoen M; Kajoe boeton M; Tocton J; Kalappa lospa J; Lali J; Talisseij Mak; Huttum Amb; Modjo T; Tsjing-khi Cl.

(xr. pL: - Stille Oceaan en Moluksche cilanden, China, Sumatra, op Jara langs de stranden.

Gerr. - Uit de takken van dezen fraaijen boom bekomt men is West Indie door insnijding een weinig sap, dat MIomin of Toddijwijn genoemd en als pisdrijvend middel gebruikt wordt; ook de bast wordt als geneesmiddel aangervend. De bladeren 
kunnen bij wijze van borden dienstig zijn. Uit de schoone blocmen bereidt men eene likeur, welke onder den naam van Eau de Crcole bekend is. Het vleesch der vruchten smaskt aangenaam zoet, bijna als abrikozen en wordt als ooft gegeten, zcelieclen bezigen ze vaak om hunneu dorst te lesschen, terwijl zij, volgens van Humboldt en Bonpland, door kinderen zeer bemind zijn, deze krijgen er cchter na het eten eene geele kleur van, welke na verloop van 2.1 à 48 uren zonder gebruik vau eenig geneesmiddel weder verdwijnt. De zaden fijngekneusd en in het water geworpen bedwelmen de zich daarin bevindende visschen; gebrand en tot pocder gemalen of wel gekaauwd met de pinangnoot, kruilnagelen en banglaai (Zingiber gramineum) worden zij bij diarrhoe en colica nangewend. Uit deze wrijven de Chinezen een slijmig vocht, warmede zij hume regenschermen (pajongs) bestrijken, om deze waterdigt te maken; ook perst men er eene olie nit, welke slechts tot branden gesehikt is. Volgens Blanco zoude de vrucht een rattenvergift zijn.

498. Вот. Nм. - Gustavia valida Dc.

IvI. BEx. - Poetat S; Poetat goenong S.

GR. PL. - Java, Noesakambangan, Sumatra in bosschen.

Gerr. - Bij gebrek aan andere geneesmiddelen bezigen de inlanders de bast en bladeren tegen diarrhoe.

\section{GRANA'TEAE Don.}

499 Boт. Nw. -- Punica granatum L.

IxI. BEx. - Delima M; Salioe en Tsja-lioe Ch.

Gr. pr. - Zuidelijk Europa en Azie, Japan, Afrika; op deze eilanden meestal in tuinen.

GEbr.--- Vermeenende dat het gebruik en aanwending ran den wortelbast en de vruchtschil als wormdrijvend middel genneg bekend is, zoo wil ik hier slechts anuhalen, diut het vruchtmoes aanigenaam zuurzoet van smaak en zeer gezond is; dat de blocmen om lunne schnone kleur zecr gezocht en affgetrokken met water geschikt zouden zijn voor hen, welke aan scorbutus, aphthate of andere aandocningen der moudholte lijelen; dat de vruchtschillen en zaden tonisch en adstringerend werken, en bij leucorrhoe, diarrhoe 
en dijsenterie aangewend worden; dat men ze op Jara drongt, fijnstampt en met den azijn uit den arenboom rerkregen vermengt om eene fraaije schrijfinkt te bekomen; verder dat men de onrijpe vruchten ect en daarbij klapperwater drinkt om de tanden fraai zwart te verwen.

\section{ROSACEAE JsS.}

500. Вот. Nur. - Rosa damascena Mrll.

Is .. Bex. - Kembang aijer mawar S, M; Boenga kembang Mand; Boenga roos Men.

Gr. PL. - Sijrie, op Java en elders als sierplant zeer gezocht. 501. Bот. Ny - Rosa ranunculiformis Hrt. Std

1YL BEN. - Als de vorige plant.

Gr. PL - Europa, alhier als sieraadplant in vele tuinen.

502. Bot Ny - Rubus rosaefolius Sm.

IVL. BEY - Bomberettian S

GR PL. - China, Mauritius, naar Java overgebragt

GEbr - De gekneusde bladeren worden met water bij chronische dijsenterie gedronken, de zuurzoetachtige vruchten worden gegeten .

503 Вот. Nu. - Fragaria indica Andrs.

Gr. PL. - Nepaul, op Java in zeer hooge bergstreken.

GEsR. - De vruchten dezer plant gelijken reel op onze aardbezien, doch zijn kleiner en nagenoeg smakeloos.

504. Вот. Nıг — Spiraca Lindleijaza Sieb.

Gr. PL. - Als sieraadplant in eenige tuinen.

\section{AMHJGDALEAE JSS.}

505. Вот. N.r. - Prunus laurocerasus L.

Gr. pr. - Trebisonde, van daar naar Europa; op Java in cenige tuinen.

GEbr. - Het gebruik der bladeren, actherische olie en water is uitvoerig in verschillende handboeken over materies medica beschreven.

506. Bot. Ny. - Prtwas jaranica Tsmn. \& Bundk. 
Gr. PL. - Westelijk Java.

\section{PAPILIONACEAE Endl.}

507. Bот. N3. - Crotallaria L. spec 1.

IYL. BEx. - Kakatjangan S; Geger soreh MI.

Gr. PL. - Op Java in het wild en in tuinen.

508. Вот. Nir. - Indigofera tinctoria L.

INL. BE: - Taroem MI; 'Titroem kajoe MI; Tom J, Bali \& 'T: Nila Ps; 'Tenarrom Bd; Entoe Mien; 'Tscheen Ch.

Gr. PL. - Oost en West Indie, Afrika, Japan, Java, Sumatra en Bali in tuinen.

Gern. - De inlanders beschouwen de wortels der Indigoplant als werkzaam tegen lsoorts, terwijl zij de bladeren inwendig bij tusschenpoozende koorisen en uitwendig tegen parotitis, phijsconia lienis et hepatis en andere zwellingen anwenden; tegen dit laatste bezigen zij ook de rerfstof. Volgens Blanco zijn vrouwen wulke indigo bereiden ecrder onderherig aan longlijden, dan de mannen. Lindleij geeft aan dat een aftreksel der wortels als waschmiddel gebruikt de wormen doodt; dat het sap der jonge takken met honig vermengd aangeprezen is bij spruw van kleine kinderen; dat indigo in poederrorm op wonden of zweren gestrooid deze zuivert; dat de West Indische ziekte, IJaws genaamd, genezen wordt door omslagen met eene oplossing van indigo. Over het gebruik der indigo in Europa is genoeg geschreven.

509. Вот. Nur. - Sesbania cochinchinensis De.

Gr. PL. - Cochinclina; bij Baudong op rochtige plaatsen.

IVL. BEN. - Tjatjandie S.

Gr. PL. - De bladeren en onrijpe ruchten worden gekookt bij de rijst gegeten.

510. Bот. Nu. - Agati grandiflora Dsv.

Ixt. BEx. - Toeri burrum S' Toeri meirah NI; Sambal J; Kadja toewa Mak; Kallar Bd, en

511. Bот. Nu. - Agati grandiflora Dsv. B flore albo.

INL. BEN. - Toeri boddas S; Toeri poetih M; Sambal J.

Gr. PL. - Oost Indie; op Jara en Sumatra meestal bij de huizen der inlanders. 
Gerr. - De schors van dezen boom, welke zeer bitter is, zouile bij dijsenterie en spruw heilzaam zijn, in groote giften echter een braakverwekkend vermogen bezitten. Men vervaardigt uit dezen verder touw voor vischnetten; gedroogd, fijngestampt en met rijstmeel gemengd bezigen vrouwen hem als blanketsel (bedak), terwijl hij uitwendig bij cene soort van schurft (njerieh bolongan) wordt aangewend. De bladeren worden gegeten en onk op gekneusde plaatsen gelegd, vooral echter zijn de bloemen en jonge peulen eene geliefkoosle groente der inlanders. De gom, welke uit den stam kan verk regen worden, dient bij het iubinden van boeken.

512. Вот. Nuf. - Arachis hijpogaea L.

IvL. BEN. - Katjang soeoek S; Katjang tana S. MI Katjang tjina M; Katjang jappon M; Thou-thau Ch.

GR. PL. - Zuid Amerika, van daar naar Afrika, Azie en Zuidelijk Europa; op Java in tuinen.

GEBR. - De zaden dezer plant worden raauw, gekookt en geroosterd gaarne gegeten, zij zijn zoet eenigzins olieachtig ran smaak; door uitpersing kan men uit deze eene groote hoeveelheid eener aangename, zachte, vette olie bekomen, welke echter hoofdzakelijk als lampolie benuttigd wordt. Zie ontrent de eigenaardige groeiwijze en vruchtrorming het Natuurk: Tijdschrift van N. Indie, Deel VIII, Af. $1 \& 2.1855$, enz.

513. Boт. Nir. - Lourea vespertilionis Dsv.

IYL. BEN. - Djoekoet walet S; Koepoe-koepoe-an Mr.

Gerr. - Cochinchina; op Java in het stijle gebergte van Bezoekie op rotsen, doch meestal in tuinen om de sicrlijke vorm harer bladeren.

514. Bot. Nir. - Uraria crinita De.

IrL. BEY. - Memeongan S; Boentoet seroh S; Boentoel koetjing $M$.

Grr. PL. - Oost Indie; op Java in Bantam on Batavia in kreupelbosschen.

Gerr. - De fijngekneusde bladeren dezer plant bezigt de inlander bij wijze van omslagen uitwendig tegen opgezetheid van den buik of liever der lever (sakit toemboean).

515. Вот. Nu. - Desmorlium triquetrum Dc. 
INL. REY. - Kitjongtjorang $\mathbf{S}$; Kitjingorang $\mathbf{S}$.

Gr. PL. - Oost Indie; op Java in kreupelhout, op vlakten langs strandplaatsen en in vele tuinen.

Gebr. - De blateren met adas en poelassarie vermengd en met water afgewreven drinkt de inlander bij katarrhale aandoeningen on koorts, terwijl hij ze uitwentig bezigt op herpetische en sijphilitische huiduits!agen.

516. Вот. Nu. - Clitoria ternatea L.

INL. BEN. - Kembang tellang Mr; Boenga biroe Mi; Boenga nassi MF: Boenga kalente MI; Saja kotele en Bakijma kotele ' $\mathrm{T}$.

Gr. PL. - Arabie, Oost Indie, de Molukkos, Cuba, Mauritins; op Java in het wild en in vele tuinen om zijne schoone witte en blaauwe blocmen als slingerplant voor prieeltjes gezocht.

GErR. - De wortel zoude braakwekkende eigenschappen bezitten. De bladeren worden door geiten en schapen gaarne gegeten. De bladeren en blaauwe bloemen worden in water eenigen tijd gelegrl, totdat dit eene blaanwe klenr anneemt en dit als oogwater gebezigd bij ligte oogontstokingen rooral van kinderen; of wel zij worden daartoe in de hand fijngewreven, met water vermengd en het sap in de aogen gedruppeld. Ook de bloemen worden gegeten en dikwijls geluruikt om daarmede rijst en gebak te kleuren.

517. Вот. Nмr. - Mucuna velutina Hsskl. A fructu albo.

INt. LEx. - Kwas boddas S.

518. Вот. Nлг. - Mucuna velutina Hsskl. B fructı virido.

INL. BEN. - Kwas hiedjoe S, en

519. Вот. Nu. - Mucuna velutina Hsskl. C fructu nigro.

INL. BEx. - Kwas hiedung S.

Crr. PL. - Op Jara in het wild en veelal bij de woningen der inlanders.

Gebr. - De rijpe en onrijpe rruchten worden afigekookt en bij de rijst gegeten, zijn aangenaam van smaak on zonder echige onaangename geur. Hasskarl.

520. Boт. Nr. - Mucuna pruriens De.

Txt. Brx. - Katjang mëong S; Raraweha S; Kákara gatel Mr: Dawon gatel aijer MI Maiho $\Lambda$ mb; Mä̈ho abbal $\Lambda$ mb; Manguba 13d. 
Gr. Pr.. - Caraibische ciianden, Oost-Indië, Malabar, Molukko's, Westelijk Java in vlakten.

Gerr. - Van deze, vooral in West-Indië veel roorkomende, slingerplant, welker vruchten dikwijls misbruikt worden om iemand eenen pots te stoven, geeft Percira de volgende nitvoerige beschrijving: "een afkooksel des wortels of der peulen zegt men " is pisdrijvend en werd vroeger bij waterzucht geberigd. De ha"r'en verwekken op de huid aangebragt een ondragelijk jenken, " en bij eenige lieden pijn, roodheid, zwelling en zelfs een huid" uitslag. Deze uitwerkselen, die door wrijven toenemen, doch "door aanwending van olie verminderen, zijn toeteschrijven aan "de mechanische prikkeling der haren. De haren zijn om hun"ne wormdrijvende eigenschappen vermaard geweest; hume wer"king wordt verondersteld mechanisch te zijn, dat is, zij worden " verondersteld de ingewandswormen te doorsteken en te kwellen " en ze op die wijze te noodzaken zich los te laten. 'Tot onder"steuning dier verklaring verhaalt de $\mathrm{Ir}$. Chamberlaine, dat hij " eenige der haren wier" in een kalebas die met zeer groote Ascari"des lumbricoides was gevuld, en dat na korten tijd de dieren "hegonnen door een te kruipen, waaruit blijkt dat zij zeer wer"den gekweld; ze met een vergrootglas onderzoekende ontdekte "men, dat de haren in humne ligehamen staken. De reden war"om zij op liet slijmrlies des darmkanaals gewoonlijk niet wer"ken, is toegeschreven aan de slijm die dat vlies beschut. In " cen geval rolgde diarrhoe op het gebruik eener zeer groote do"sis van het electuarium, en in een ander enteritis, nadat die be"reiling eens was genomen, doch het is zeker dat deze veroor" zaakt werden door de werking der haren. Mucuna pruriens is "hoolizakelijk vermaard geweest bij Ascarides lumbricoides en "Ascarides vermiculares, zij was niet even dienstig bij 'Taenia n solitım.

"De wijze van toediening was in siroop of honig als electna"ritm, opgevolgd door jalappe of sennebladen."

Volgens Lindleij worlt een sterk afkooksel der wortels van deze plant met honig zoet gemaakt door de inlandsche praktici toegediend bij gevallen van cholera asiatica.

De bladeren worten op Java gebezigd om er handgrepen ran 
wapens mede te wrijven, ten einde deze zwart te maken. Gualtier roemt de aanwending van de haren der peulen tegen breedeen lintwormen.

521. Вот. Nн. - Mucuna nigricans Std. Nom.

IvL. BEx. - Goengsieng gedeh S; Parran ketjil MI; Parran mette M; Mahoa panteij Amb.

Gr. PL. - Malabar, Cochin-china, Java in bosschen.

GErr. - Rumphius meldt dat hij niet weet dat deze vruchten gebruikt worden; volgens hem houdt Clusius ze voor eetbaar, doch niemand der inlanders wil ze eten.

522. Вот. Ny. — Erijthrina spathacea Dc.

Lru. Bex. - Dedap wangie MI; Dedap sungiet M; Dedap bong J.

GR. PL. - Ròdom Batavia, zeldzaam aangekweekt.

523. Bor. Nar. - Erijthrina secundiflora Hsskl. A inermis Hsskl.

INL. BEN. - Dedap mienjak M.

524. В0т. Nu. - Erijthrina secundiflora Hsskl. B aculeatil Hsskl.

Ist. BEN. - Dedap tjoetjock $\mathrm{S}$; Dedap tis $J$; D: doerie en $\mathrm{D}$ : tjangkrieng II; Tjangkring docire $J$; Dedap malaijoe Mand; Walantakka Men.

Gr. PL. - Beide op Java en elders veelvuldig aangeplant.

525. Вот. Ny. - Erijthrina fusca Lour.

Irs. Bex. - Dedap MI; Tjankring MI. J; 'Tjanging Bali; Dedep serep J; Gelala aijer M; Kanne Mak.

Gr. PL. - Op vele Oost Indische en Moluksche eilanden langs de stranden, aan rivieroevers, enz.

Grвr. - Alle deze Erijthrinasoorten (522 tot 525) worden op deze eilanden veelvuldig angeplant, zij dienen tot omheiningen van tuinen, om dat zij het snoeijen goed verdragen, tot stutten voor verschillende slingerplanten, als sirih, peper, enz. en eindelijk daar zij spoedig en hoog opgroeijon en eenen ;ligten schaduw verspreiden tot beschaduwing van nieuwe plantsocnen, als van koffijtuinen, muskaatnoottuinen enz. Uit hun week en ligt scheurend hout zaagt men planken tot beschutting van huizen; met water afgewreven wordende zoude het toegediend worden tegen haematurie en andere andoeningen der pisafscheidende werktuigen. 
Volgens Rumphius wordt ook de wortel in-en vitwendig toegediend tegen beri-beri. De sterkriekende bladeren ran 522 worden fijn gewreven en bij hooflpijn van kleine kinderen dezen op het voorhoofd gelegd. Wanneer kleine kinderen aan koortsen lijden baadt of wischt de inlander hen dikwijls met de bladeren van 523 en 524, of wel druppelt hen het sap der bladeren in de oogen; dit laatste wordt ook bij kraamvrouwen gedaan. Met de bladeren van verschillende soorten van dit geslacht wordt eene pap gemaakt, welke den kinderen op den buik gesmeerd wordt tegen ingewandswormen. Die van 525 geeft men an paarden te eten, welke droezig zijn. Eindelijk worden de jonge bladeren als groente gegeten en de takken aan de deurstijlen der stallen gebonden, bij wijze van amulet, tegen groote sterfte van paarden en rundvee.

526. Bот. Ny. - Wisteria floribunda Nutt.

Gr. PL. - Japan, op Java in vele tuinen.

Gebr. - Deze sieraadplant wordt vooral op Japan en ook alhier dikwijls rondom de woningen aangetroffen.

527. Вот. Ny. - Phaseolus caracalla L.

IVL. BE. - Katjang monjet Ḿ.

Gr. PL. - Oost-Indië, bij Batavia op drooge plaatsen en langs de wegen.

Gebr. - Hare vruchten worden rijp en omrijp zijnde gegeten. 528. Вот. Ni⿱ - Dolichos L. spec. 1.

Irr. Bex., Gr. PL. en GeBr. - Onbekend. 529. Bот. Nu. - Abrus praecatorius L.

Ivt. BEx. - Aroij saga S; Sogo-tocntong J; Kondori ketjil MI; Aijlaroe pidjar Amb; Aijlaloen IIt; Kajoe lale Bd; Ide-ide malakko T; 'Tjontsjo Ch.

Gr. pL. - Oost-Indie, van daar naar Afrika en Amerika orergebragt; op Java in kleiachtige gronden en in tuinen.

Gebr. - De wortel van deze slingerplant wordt in vele warme landen in plaats der zoethoutwortel gebezigd. De bladeren worden in aftreksel bij verschillende verkoudheidziekten der kinderen, vooral bij hoest, toegediend; in de handen fijngewreven wrijft men bij tand- en kiespijn daarmede de lijdende deelen; terwijl volgens Rumphirs men bij spruw eenen gorgeldrank ge- 
braikt, bestaande uit een afkooksel van sagabladen en zoethoutwortel. De fraaije scharlakenroode, met eene zwarte vlek roorziene zaadjes bezigt men men veelal tot halssnoeren en rozenkranzen; zij worden in sommige landen bij wijze van linzen gegycten, doch zijn een slecht voedsel, daar zij niet zelden hevige buikpijnen, benaauwde ademhaling, stuipen en zelfs den dood reroorzaken; fijngestampt bezigt men ze bij het solderen vau goud; terwijl eindelijk Blaneo opgeeft, dat zij met water en wijn afgetrokken toegediend worden bij epilepsie en hartziekten.

530. Вот. Nu. - Abrus melanospermus Hsskl.

Isc. BEv. - Aroij sikottok S; Aroij sihaijam S; Aroij tali-aijoenan $S$.

GR. PL. - Java.

GFiBr. - De ranken worden zonder toebereïling als touw bij waterwerken aangewend; aan de lueht blootgesteld breckt het spoedig, terwijl het vochtig gehouden lang goed blijft (IIasskarl).

531. Вот. Nж. - Pterocarpus indicus IVld.

IVL. BE. - Angsana M; Lingoo en Lingoa Mi Kajoe sono J; Sono kling J; Pattene Mak; 'Tsjendana Bgr; Narra Bi; Sana en Na Tm; Nala Amb.

Gr. PL. - Oost Indic en eilanden, Molukkos. Op Java vooral in het oostelijk gedeelte veelvuldig.

Gebr. - Zoo nit een huishondelijk als nit een geneeskundig oogpunt hecft deze boom groote wiarde. Z/ijn stam levert een zeer fraui geaderd en stexk hout, dat door inlanders on Europeanen hoog geschat en vooral gebezigd wordt tot vervaardiging van scheden voor krissen en andere wapens, hoofdzakelijk echter voor fijnere meubelen. IIet sap, dat door insnijding van den bast gewonnen wordt, gelijkt, gredroogd zijnde, op kino, is zeer zamentrekkend, en komt in den handel onder den natam van Oost Indische kinogom voor. Dit sap wordt vooral aangewend tot het polijsten en donkerrood kleuren riun menbelen, is inwendig toegediend heilzaam bij chronische diarrhoe en dijsenterie en wordt in het tandvleeseh van kinderen ingewreven, wannecr dit eene witachtige kleur (sakit baroessoe) aanneemt. De bast wordt tot touwwerk roor vischnetten bereid, terwijl een afkooksel inwendig gegeren wordt tegen chronische diarrhoe en 
bij wijze ran mondspoeling tegen spruw. Rumphits haait nog aan, dat de Maleijers en Makasseren de blocmen zeer beminnen en op de bazars verkoopen, terwijl men in de Molukko's soms het hout als renkwerk bezigt.

532. Вот. Ny. - Milletia sericea Wght.

IrL. BEN. - Toewa gatel S, M.

Gro. PL. - Java.

Grum. - De bast, ook de geheele stam, wordt fijngestanipt met water gelilopt en in het water geworpen tot bedwelming van visschen; zelfs kleine kaaimans worden tijdelijk door dit gift bedwelmd. Eene kleine hoeveelheid van den bast of de bladeren wordt gedroogd, tot poeder gewreven en aan kleine kinderen tegen ingewandswormen toegediend.

533. Вот. Nı. - Dalbergia purpurea Rwdt.

Irt. BE. - 'Toewa djenoh S.

Gri. pr. - Batavia, Sumatra, Lampongs in kreupelhout.

Gesr. - De rankende stam bezigt men even als die der voorgaande als vischvergift.

534. Вот. Nı. - Dalbergia angustifolia Hsskl.

IVL. BEN. - 'Toewa lalur S.

GR. PL. - Zuidelijk Bantam in boschrijk gebergte.

Gebr. - Dric à vier bladeren worden met adas, poelassarie en witer fijngewreven en dit zoo nit- als inwendig gegeven tegen vermoeidheid, rheumatische en andere beenpijnen.

535. Bот. Na. - Geoffroija surinamensis Murr $\approx$ Andira retusa Kth.

Gr. PL. - Suriname; naar Java overgebragt.

Grar. - Deze boom levert de als braak- en purgeermiddel bekende cortex Geoffroijae fuscus.

536. Вот. Nu. - Caesalpinia sappan L.

IYt. bex. - Kajoe sappan MI; Setjang S, J; 'Tjang Bali; Sapa Mak; Soepan Bi; Lolan Amb; Soenia 'I'; Roro 'I'd.

Gr. rL. - Over de geheele O. I. Archipel, veelvuldig in vlakten.

Gebr. - Het hont van den stam on wortel van dezen op Java veelal tot omhcining van tuinen aangeplintten en stekeligen heester is bekoud onder den naim van sappanhout, Oost-Indisch verf- 
hout, valsch sandelhout, lignum sappan; rolgens Wildenow is het het Brazilienhout, lignum Braziliense Dit hout, dat bijzonder hard is, bezigt men voor nagels in praauwen, voor lijsten van kasten en voor stoelen; veclvuldiger echter wordt er eene verfstof nit bereid en is het daarom een handelsartikel. Inwendig wordt het in afkooksel soms als bloedstelpend middel toegediend, terwijl een koud aftreksel vaak als oogwater tegen katarrhale oogontstekingen ran kinderen wordt aangewend.

537. Bor. Ny. - Poinciania pulcherrima L, A flore coccineo.

INL. BEN. - Patrakombala burrum S, en

538. Bot. Nar - Poinciania pnlcherrima L, 13 flore flavo.

Iri. REx. - Patrakombala konneng $S$. Voorts dragen deze beide varieteiten nog de volgende namen als: Setjang tjina MI; Í́mbang koepoe koepoe MI; Bonga merak MI; Bonga tsjana MI; Trang doenia MI; Kembang dwang J; Kembang potroinengolo J; Ḱoka en Ḱoeban hadji Amb; Saija tsjina $T$.

Gr. PL. - Oost-Indie, ran daar naar de West-Indische eilanden orergebragt; op Java vindt men beide veclal als sieraadplanten in tuinen.

Gebr. - Van den wortel, welke op Jara ook als roode of roodgecle verfstof wordt aangewend, betwijfelt Rumphins de vergiftige eigenschappen, welke men op Ceilon er aan toekent, terwijl hij anngecft dat inlandsche doekoens hem in aftreksel te drinken geven aan kinderen lijclende aan stuipen, rallende ziekte, enz.

Volgens Lindleij kent men hem tonische en aan de bladeren ontlastingberorderende cigenschappen toe. Omtrent de om hunne schoone kicuren bij inlandsche fecsten zeer gezochtte blocmen zegt Geiger: "de blocmen zijn officincel, zij hebben " cenen aangenamen geur on eenen zecr bitteren, eenigzins aro"matischen smaak; op de Antillen worden zij als krachtig koorts"middel aangewend, ook zullen zij tegen chronische borstan"doeningen en vergiftigingen nuttig zijn. Volgens Ricord Madi" anna bevatten deze blosmen: looizuu met ecn weinig extraktief"stof en slijm, weeke benzoëzuturhoudende hars, roode kleux- 
"stof, gom, looistof, plantenvezels, enz."

Ook Blanco haalt aan, dat zij als febrifugum worden toegediend in wvarm water met suiker.

539. Вот. Nн. - Tamarindus indica $\mathrm{L}$.

Irz. 13ex. - Assam djawa MI; Sunda assam J; 'Tschamba Mak; Tamalakki Bd.

Gr. pL. - Oost Indie, Arabie, Egijpte, Senegambia; op Java zeer algemeen, vooral langs de wegen en in tuinen.

GEBr. - Het sterke, grof geaderde, door insekten niet aangetast wordende hout is geschikt roor bouwhout, doch wordt, omdat let zeldzanm in groote hoeveelheid verkrijgbaar is, meestal op dit eiland slechts roor fijnere meubelen gebezigd; op 'Timor en Bima gebruikt men het tot den scheepsbouw. De blacleren bezigt men soms om aan andere groenten eenen aangenamen zuren smaak mede to deelen. Het angenaam zuursmakende vruchtmoes dient tot ditzelfle einde, doch wordt ook met suikerwater bij wijze vau limonade gedronken en gekonfijt gegeten. Het bezit zacht laxeerende en zweetdrijvende eigenschappen en is vooral bij gestoorde galafscheiding zeer heilzaam. Arabieren, in groote woestijnen reizende, nemen veelal daarvan mede om hunnen dorst te lesschen en mengen het soms met sandelhout en cerlerhout. Volgens Rumphius bezigen de Maleijers nog de oude zwarte tamarinde met komijn gemengd bij wijze van een' zetpil, om spoedig ontlasting te beroxderen. Eindelijk dient het pulpa ook tot reiniging van zilverwerk en tot het wasschen der handen.

540. Bот. N... - Cassia fistula L.

IXL. BEx. - Kajoe radja MF; Tanggoelie S \& J; Bongoe alis $J$; Kajoe doelang Bali; Oette manoe en Pappe pauna Amb.

Gr. PL. - Indie, Egijpte, in Zuid Amerika vermoedelijk ingevoerd; in deze gewesten vooral in de Lampongs, Bezockie en Bali.

Gerr. - Het geelachtige, knoestige en moeijelijk te splijtene hout is zeer duurzaam en dient soms roor stijlen van huizen, ook tot scheden van wapens. De bast des booms kaauwen sommigen met sirih en kalk bij gebrek aan pinangnoten. De bladeren en vruchten fijngewreren smeert de inlander op den buik van kleine kinderen, om de ontlasting te berorderen. Het zoctachtige vruchtmoes werkt laxeerend en is heilzaam bij vele ontstekings- 
ziekten. Eene pit der lange vrncht fijngemalen en mot suiker en water ingenomen helpt volgens IIasskarl tot spoedige ontlisting bij verstoppingen.

5џ1. Вот. Nur. - Cassia alata L.

INL. вEx. - Kateppeng badak S; Kateppeng bener S ; Ǩ̉imanilla S; Dawon koepan MI Dawon koerap MI; Galingang Mand; Matta tekkel Men; Kant-schoa Ch.

Gr. PL. - Oost Indie, Java in kretpelbosschen vooral met vochtigen bodem, Sumatra, de Molukkos, Australie, Amerika.

GEbr. - De wortel, bast, doch vooral de onaangenaam riekende en bittersmakende bladeren, folia Cassiae herpeticac, worden met water, azijn of wel citroensap fijngewreven en uitwendig bij scabieuse en herpetische uitslagziekten, doch vooral bij herpes circinnatus (koerap) aangewend, wanneer de aangetaste plaatsen niet te groot zijn, dikwijls met even goed gevolg als die van Rhinacanthus communis $\mathrm{N}$ ai $\mathrm{E}$. Zij kunnen ook ter vervanging van sennebladen in aftreksel als purgeermiddel worden toegediend in giften vin een half tot een onc op acht ons water; eindelijk zouden zij ook pisdrijvende eigenschappen bezitten. De vruchten worden rijp en onrijp raauw genuttigd.

542. Вот. Ny. - Cassia sulphtrea Dc.

IYL. BEx. - Kateppeng S. MI; Trembaloe J.

Gr. PL. - Mauritius, Oost-Indie.

Gerr. - Het hout dient voor krisscheden.

543. Bot. Nar. - Cassia marginata Rxb.

IrL. BEx. - Boengboengtellang S.

GR. PL. - Java.

Grbr. - IIet zaad gestampten met bijroeging van enigg water op den buik ingewreven bevorlert bij verstuppingen (sikit modjem) spoedige stoelontlasting. Hasskarl.

544. Boт. Nyr. - Cịnometra cauliflora L,

IXI. BE.Y. - Namnam MI, S; Poekic andjing MI; Lammoct Amb. Gr. PL. - Oost Indie, de Molukko's, op Java in tuinen.

GEBr. - De anigenamismakende zumzoete vruchten wrorden raauw en op verschillende wijzen tocbereid als lekkernij gegeten.

5.15. Bor. Ny. - Bauhinia tomentosa L.

IXI. BEX. - Tali kandjolı S; Koepoe koepoe bener S. MI. 
Gr. PL. - Op Java in lagere bergstreken, Ceijlon.

GEBR. - Het hout, dat sterk, vast, wit en fijn is, dient voor handgrepen en scheden van wapens, indien men stukken kan bekomen welke lang genoeg zijn; voor handgrepen heeft het de goede eigenschap, dat deze zeer vast aan de wapens blijven zitten; de bladeren gebruiken, volgens Blanco, de arme Indianon bij gebrek aan azijn, terwijl Lindleij nog opgeeft dat de gedroogde knoppen en bloemen door de indische practici bij sommige dijsenterische aandoeningen aangewend worden.

546. Boт. Nм. - Casparea castrata Hsskl.

INL. BEN. - Kandajakan S.

Gr. pL. - Buitenzorg, de Philippijnen.

GeBr. - Ontrent deze plant melut slechts Blines dat de bladeren zuur zijn.

517. Bот. Nu. - Saraca arborescens Brm $\models$ Jonesia asocca Rxb.

IVL. BEN. - Kembang dêdesh M; Kitakko S.

Gr. PL. - Bengalen, Sumatra, Java, Moluksche eilanden, op Java vooral bij Malang en veelal in tuinen.

GEBr. - Deze boom wordt vooral om zijnen schoonen kroon van donkergroene bladeren en zijne fraaije oranjekleurige bloemen aangeplant.

548. Вот. Nur. - Jonesia declinata Z \& M.

Gr. PL. - Preanger regentschappen.

549. Вот. Nм. - Dialium Indum I.

INt. BEN. - Ranjie S; Koerandjie, Karandje en Karandjang $\mathrm{J}$.

Gr. PL. - Op Java in lagere streken.

Gebr. - Het sterke hout bezigt men voor molens; de bladeren gestampt en eenige dagen in water gerveekt dienen tot schoonmaken van roestig ijzer; het moes der vruchten (Tamarindplum) is alleraangenaamst zuur on wordt gaarne gegeten.

550. Вот. Nu. - Haematoxijlon campêchianum L.

Gr. Pr. - Campêche (Mexilko), naar de West Indische eilanden, Bengalen en Java overgeplant.

GEen. - Levert het als verfstof en geneesmiddel bekende lignum Campechianum. 


\section{MIORINGEAE RBr.}

551. Bот. Ny. - Moringa pterijgosperma Grtn.

INI. LeN. - Kellor M, J; Kelo 'T; Oegekolo 'T.

Gri. PI. - Mratabar, Ceijlon, Java, de Mroluksche eilanden, Afrika, Egijpte. Op Java reelal in tuinen als omheining of tot stutten voor slingerplanten.

Gebr. - De dikke knollige wortel dezer Moringa bezit zoo uit- als inwendig eene groote gelijkenis met den Mierikswortel en wordt ook eren als dezen gebezigd. Wanneer hij met water of azijn fijngeweren wordt en op ecnig ligchaamsdeel gelegrl, rerwekt hij na eenigen tijd roodheil, na langer verwijl zelfs blaren; het is daarom, dat deze en door den inlander en door Europeanen vaak in plaats ran mostaardpappen of spaansche vliegpleisters wordt angewend en vooral bij kinderen goede diensten bewijst. Ook de bast en de bloomen zullen door eerstgenoemden a!s zoodanig gebezigd worden. IIet kaauwen van een weinig van den wortel zou volgens Rumphius het bord tegengaan, terwijl hij in groote giften gebruikt stranguric on abortus zal veroorzaken. Do bladeren en jonge vruchten, welke in veel minderen graad scherp zijn, worden afgekvokt als groente (sajor assam) door velen gegeten; eerstgemelde prijst IIorsfield als een mild diureticum bij slijmyloeijingen (ler pishuis aan, torwijl Rumphius vermellt zij met kalk fijngewruren tegen herpes aangewend worden. De rijpe nootaardige zaden zijn in Europa nog in eenigo apotheken roorhanden onder den naam van Bohen-noten, Nux behen, Glans unguentaria, Balanus mijristica; vroeger werden deze als braak-en purgeermidlel gebruikt. Uit dezelve perst men eene rette, rouk-en smakelnoze olie, welke als Behen olie, Oleum Behenis, naar Europa gebragt wordt en ingenomen, even als elke andere rette olie, ontlastinghevorderend werkt; meer echter, daar zij niet ligt ransig wordt, uitwendig tot inwrijvingen en zalven wordt gebruikt; ook giet men deze op welriekende bloemen, van welke zij de rcuk annneenst, en wrijft dan daarmede het hoofthaar in of bereidt met dezelve Jasmijn- en andere vlugtige olien. Linnacus leidt van dezen bnom liet Lignum nephriticum af, dat door IIernandez en Monardes het eerst in Europa als heilzaam tegen 
niersteenen werd bekend gemaakt; door de meeste schrijvers wordt echter verondersteld dit hout van eeneu anderen boom afliomstig is.

\section{MIMIOSEAE RBr.}

552. Bот. Ny. - Adenanthera pavonina L.

INL. LEx. - Saga kajoe II; Saga pohon II; Kondorin II; TJai S \& J; Aijlaloe Amb; Tsjong-fi-di Ch.

Gr. PL. - Oost-Indie, de Molukko's, Java in vlakten.

GELr. - IIet roode en sterke hout dient den Javaan tot bouwhout, in Bengalen wordt het Rukta chundun of rooul sandelhout genoemd en fijn geschaafd als donkerroode rerfstof henuttigd. De van hunne roode schil ontdane zaden kunnen afgekookt bij wijze van erwten gegeten worden en zullen aangenaam van smakk zijn. De fraaije zaden dienen verder tot het kleinste gewigt der goudhandelaars, aaneengeregen worden zij als halssnoereu door vrouwen en kinderen gedragen, en tot meel gestampt bij het soldeeren van gouden voorwerpen gebruikt.

553. Bot. Nr. - Mimosa pudica L.

IऽL. BEx. - Djoekoet kamaloean S. MI Djoekoet bohrang S; Aroij reba bangon $\mathrm{S}$.

Gr. PL. - Dit sierlijke en zeer gevoelige plantje groeit op Java veclvuldig langs de wegen, in weilanden on aan rivieroevers.

554. Bor. Nys. - Acacia arabica Wld.

Gr. PL. - Senegal, Egijpte, Arabie, Hindostan. Is vau E. gijpte naar Java overgebragt en komt goed voort.

Gebr. - Deze boom levert de bekende Arabische gom.

555. Вот. Ny. - Acacia Farnesiana Wld.

Ixt. BEx. - Nagassarie S; Tjakra tjikri Bat; Sario-sit J; Djepoen $\mathrm{J}$.

Gr. PL. - West-Indie, Zuidelijk Europa, Noord Afrika, 'Timor, Java op drooge vlakten en in tuinen.

GEnr. - De bladeron, bast on wortel worden, rermengl met bawang meirah, fijugewreren of gekookt ingenomen door de Inlanders wanneer zij neiging tot braken geroclen, doch niet kun- 
nen braken. De kogelrormige, zecr getrige, oranjegeele blocmhoofujes zijn door hen zcer bemind; in Etropa zijn deze onder den oncigenaardigen nam van Antilleucrssia, Fleurs de cassie sîches, in don liandel en worden in aftreksel bij gestoorde spijsverteexing, zenuwachtig maaglijden, cnz. tocgecliend, mecr echter om limnen getr in paifumerion en in likeuren gemengt. De jonge peulen, welke eenen knoflookachtigen reuk en scherpen smakk bezittu, beratten ouder lumne buitenste schil cene groote loeveclheil eener klererige lijmachtige stof, welke de inlander bij cograndtoeningen in het ong drunpelt. Naar cene analijse van Ricord Iradiamna bevatten deze hulzen zetmeel, looistof, galnotenzurr on cxtriktiefstof, slijm, sarcacolla, bladgroen en in alcohol oplosbare olie, cerin, houtrezels, enz.. Het pulpa der vrucht is rolgens Blanco zeer goed bij eene soort van wonden in de ooghoeken, welke veelvuldig op de Philippijnsche eilanden worden waargenomen.

556. Вот. Nı. - Acacia leucocephala Lk.

IVI. BEY. - Kamalantienga S; Peteh tjina MI.

Gr. PL. - Tropisch Amerika, op Java in trinen.

Gebr. - De jonge vruchten of liever zaden worden als groento bij de rijst genuttigd.

557. Вот. Nu. - Inga leucoxijlon Hrt. Bog.

INL. BEx̌ - Kitokkeh S; Kimerak S; Kiwangkal S.

Gr. PL. - Bij Batavia in bebouwde plaatsen, enz.

Gebr. - Deze loom lerert cen schoon, iuwendig zwart en sterk bouwhout; zijne schil en bast fijngestampt bezigt men bij het baden als zeep.

558. Bot Nu. - Inga purpurascens IIrt. Bog. $=$ Albizzia stipulata. Bntl.

IYL. BEx. - Djundjieng S.

Gr. PL. - Buitenzorg, enz.

Gebr.- Ilet hont is sterk, ligt en fraai en gelijkt veel opdat ran Soeren ,Cedrela febrifuga), het wordt door de witte mieren niet angetast en roor kano's, bouwhout, planken enz. gebezigd. De bast worlt gestampt en even als die van Kihiang (Leucaena odoratissima IIsskl.) tot het bedwelmen ran visschen en het wasschen des ligchaams gebruikt. Hasskarl. 


\title{
ATPHABETISCE REGISTER
}

\author{
DER GEBRUIKELIJKSTE
}

\section{- INLANDSCIIE PLANTENNAMEN。}

-

A.

Akkar poeloe ron 153 (1).

" tjamakka 48.

" treba 301.

". wangie 28 .

Allang allang 26.

Amies mata 127.

Ampelas 124.

Andong hiedjoe 42.

" meirah 43.

Androwalli 331.

Angrek 57-60.

Angsana 431.

Antannan gedeh 311 .

Antsjar 128.

Apokat 149.

Araroet 77.

Aren 101.

Aroij hariang 320.

" kakeedjoan 133.

" Jetilan 262.
Aroij kikandel badak 216.

") luksa 133.

" papassang 364.

" saga 529.

" sirareb 323.

Assam djawa 539.

Awi $=$ bamboe $21-24$.

B.

Babadottan 157.

Babawangan trisna 53.

Badoerie 213.

Bajem doerie 142.

" meirah 141.

Bajoer 400.

Bakoeng 49-51.

Bamboe ampel 23.

" atter 21.

" djawa 21.

$"$ doerie 22.

" gading 24:

(1) De cijfers wijzen op het rolgnummer der plant, niet op de bladzijden 
Bamboe koening 24.

$$
\text { " tjina } 20 .
$$

Banglaai 64.

Bangle 63.

Baus 247.

Bebesahran 117.

Bidara 431.

Bientaroh 201,2.

Bintienoe 399.

Bira 81.

Bisoroh 125 .

Bliembieng 477,8.

Bobossaren 117.

Bode 115.

Boeboekoean 299.

Boenga knop 139.

Boengboeroetoe 318 .

Boenglie 304.

Boentieries 329,330.

Boentoet koetjing 514 .

Boewa nona 340.

$$
\text { " saauw } 309 .
$$

Boeroet 130, 131 .

Bondot 279.

Bonga landap 292.

Brambang oetan 52.

Bretowalli 331.

D.

Dawon boerong 301.

$\begin{array}{ll}\text { " } & \text { gatel } 135,136 . \\ & \text { kaki koeda } 311 . \\ & \text { kamadoe } 136 . \\ & \text { koentoct } 181 . \\ \text { " } & \text { lada 164. } \\ \text { " } & \text { loeloëan karbo } 18 .\end{array}$

Dawon mangkok 312.

" maniran karbo 251.

" patjie patjie 230.

" pittis 216.

" seetan 135, 136.

"wedoessan 236.

Dedap 522-525.

Delima 499.

Dilem 224.

Diloervang 118.

Djagong 16.

Djahej 62.

Djalie 17.

Djambej 100.

Djamblang 36.

Djamboe biedjie 490 .

" aijer 495,496 .

" aijer mawar 495 .

" kloetoek 490 .

" monjet 467 .

" wolanila 149.

Djarak 446,447,450.

Djariengòe 93.

Djaroeng blaauw 155 .

" boddas 293.

" boentoet oetjing 295 .

" burirum 154 .

" lalakki 232.

" kembang landep 292.

" woengoe 294.

Djattie 239.

" wolanda 397.

Djeroek 413-416.

Djoekoet gehwor 33 .

" kamaloean 553.

$"$ seetan 230 .

Djurei 210, 211. 
Djundjieng 558.

Doeat 492.

Doedoeitan 2.

Doekoe 421.

Doeren 393.

F.

Ella 71.

Etjeeng 31 .

\section{G.}

Galieboeng boeloe 229.

Galiengum 354.

Gambir laut $2 \pm 1$.

Gammat oetan 378.

Gandaria 469.

Gandaroessa 300.

Gandasohlie 74.

Gandoola burrum 138.

Granglot 449.

Gatep pait 472 .

Geger. soreh 507.

Gellang 373.

Gindjeh 200.

Gingiang 325.

" burrtrm 324 .

Girang 324.

Glaga 26.

Gloego 354.

Goengsing gedeh 521.

Gomoetoe 101.

Gompong 196.

H.

Hamproe badak 204.
Hamproe lemah $15 t$.

Handullum boddas 296.

1) burrtim 298.

" hiedjoe' 297.

Hanjexlieh 17.

Hangassan gedeh 73.

Hanjehreh 17.

Hanjoewang burrum 43.

$" \quad$ hicdjoe 42 .

Hantap 391, 39วั.

Harendong goenong 485.

Hariang 319.

Harras 237:

Hatta gedeh 12.

Hoëh 103.

" karokrok 103.

" selang 105:

Hoei gadong 45.

$"$ lielien 44.

Hoenie 137.

Hoeroe batoe 150 .

I.

Ielat 30,31 .

Ingoe 475 .

Ipo 128.

J.

Jamblang 492.

Jawer ajam 143.

" kottok 143:

Jottan Irmboet 164.

K.

Kadjar kadjar 85: 
Kadojo 316 .

Kadongdong batoe 313. " laut 313 .

Kahitoetan 181:

Kajoe angien 116.

" bessie 488 .

" dagdar 205.

" lalakki 305 :

"maas 451, 452.

$"$ manies 147,148 .

" poering 451, 452.

" sono 531.

Kakapassang 152, 383.

Kala antong 205.

Kalappa 109.

Kramanden aroij 194, 195.

Kamierie 445.

Kramoening 410.

Kananga 335.

" oetan 337.

" tjina 336 .

Kanarie 470.

Kandong peutjang 473 .

Kandrie 455.

Kanjehreh 455 .

Kapas besaar 387.

" lumboet 386.

" meirah 386.

n taun 387.

" tjiendeh 214.

Kapoelaga 70.

Kapoendong 462.

IKapok 392.

Karet 123.

Karoendoeng 276.

Karok 115 .

Trartambie 439.
Ǩasoengka 112.

Kassoh 27.

Katappang 480 .

Kateppeng 541, 542 .

Katigret 144-146.

Katilan 73 .

Katjang mëong 520 .

" monjet 527 .

" tana 512.

Katjapiering 186-189.

Katoek 456.

Katoempang 251.

$$
\text { " burrum } 140 .
$$

Kattilaijoe 426.

Kawoeng 101.

Kawohroh 384.

Kellor 551.

Kemang 466.

Kembang aijer mawar 500, 501.

" boegang 241-243.

" dêdesh $5 \pm 7$.

" mata harie 166 .

" pagi soreh 144-146.

" poekoel ampat 144-I46.

" sapatoe 379-382.

" sedep malam 37 .

" sisier 254 .

" tellang 516 .

" tembaga 207, 208.

Kendal 252.

Kíetimo 398 .

Kiamis 147.

Kiara 121-123.

Kibadjeta poetih 411 .

Kibangbara 243.

Kihooëh 427-430.

Irijanglkar 494. 
Kikoejah 212.

Kilkoetjoeboeng 265 .

Kilalaijoe 426 .

Kilanghit 316.

Kiloetoeng 203.

Kimalakkian 454.

Kimerak 557 .

Kimoeka 461.

Kimonjenjen 284.

Kingkilaban 190 .

Kingkit 409.

Kintjoer 68 .

Kiradjoen 314.

Kirendang 315.

Kisampang 402, 474.

Kisarjawan 403.

Kiterong badak 196.

Kitjaang 305 .

Kitjapie 422.

Kitjiat 121.

Kitjongtjorang 515 .

Kitokkeh 557.

Kladie 83.

Kloewat 357.

Kloewie 132.

Koening 65.

" besaar 65 .

" poetih 67 .

Koenjiet 19.

Koenjit 65 .

Koentja 68.

Kioentjic 69.

Koepoe-koepoean 513.

Koerandjie 549 .

Koetjoeboeng 265-268.
Koetjoeboeng soesoen 268.

Kondan 121.

Konneng boddas 67 .

" parrie 67.

" tamman 66 .

Koppi 175.

Koppi wolanda 396.

Koppol 70.

Krokot 373.

Kwas $517-519$.

I.

Laban 237.

Ladja 75 .

Lagoendie 238.

Lamboetang 425.

Lameh aroij 198.

" aweweh 209.

Lampas 220, 221.

Lampoejang pahit 63 .

" wangie 64.

Lampoeng 347.

Lankwas 75 .

Laus 75 .

Leuntja komier 279.

Lida boeaija 40 .

Litchi 429.

Loa 120.

Loeloean sapie 47.

Locmboei 35.

Loentas 162.

Lolloh 89, 90.

Lombok 270.

$$
\text { " seetan } 274 \text {. }
$$

Lontar 106.

" boddas 266 .

kassian 267, 268. Loros setoe 28. 
II.

Madja 412.

Malatti 192-195. " oetan 217.

Mamangkokan 312.

Mamaniran 435, 457.

Mandalika 131.

Manga 465.

Mangies 405 .

Mangostan 405.

MIanienjo oetan 111.

Marra 438.

Memeöngan 514.

Mengando 328.

Menting 462.

Miana 223.

Mindi 418.

Moehoen boddas 176 .

" kahoeroewang 178 .

Moendoe 406.

Moentjang 445.

IV.

Nagassarie 555.

Namnam 544.

Nampoe 88.

Nanangkaïn 435,457 .

Nanas 56.

"sabrang 54 .

" wolanda 54 .

Nangka 129.

" wolanda 338.

Nila 508.

Nopal 370, 371 . o.

Oar 35.

Oebie 259.

" djawa 259.

" djindral 448:

" gadoeng 45.

" kajoe 448 .

" lilien 44.

" tangan 44.

Oedoe lada 453.

Oeja-oeja-an 127.

\section{P.}

Paddie djatra 19.

Pakoe 4-6.

" haadjie 14, 15.

" katakka 3.

" kidang 10.

" lëar 7,8 .

" minjangan 1 .

" tijang boddas 11 .

" tijang gedeh 10.

Pala 333.

Pandan 95-98.

Pangais monjet 12.

Pangi 357.

Pantjahan 453, 454.

Papaija 360.

Papareh 363.

Parahoeloe 71, 72.

Patjar 479.

" aijer' 479 .

" koekoe 479, 483 .

" tjina $420,479,483$.

Patjing 76.

Patoek gagak 32 . 
Patock manoek 288-290.

Patok bêbek 329, 330.

Patrakombala 537, 538.

Patta toelang 434.

Pengawar djambi 9.

Penjalin 105.

Peteh tjina 556.

Pinang 100.

Pisang 80 .

" oetan 81 .

Pitjoeng 357.

Poekie andjing 544.

Poeleh pandak 199.

Poelie 209.

Poeloes badak 135.

" malêla 136.

" aroij 441.

Poessar 131.

Poetat 498.

Poetoen 497.

Poetrawalli 331.

Pohon oepas 128.

" tjap 464.

Pompohrang 304.

Posponidro 78, 79.

R.

Rak nassi 218.

Ramboetan 428.

Ramokêkes 126.

Randoe 392.

$" \quad$ allas 348 .

Raneh 13.

Ranjie 549.

Raraweha 520.

Roekem 355, 356 .
Rottan 103.

" itam 105.

S.

Saaij 118.

Sabbeh burrum 78 .

" konneng 79 .

Saģa kajoe 552.

Sajor klappa 15.

Sampie 92.

Sambodja 206.

Sango boeana 317.

Santen 177, 178.

Sarraij 102.

Saroenie 172.

Sauchun badak 18.

" liulus 48 .

Selassie $220-223$.

Selangkar 325, 326.

Sernangka 362.

Semboeng aweweh 161.

" lalakki 160 .

Sendag 311.

Sengang burrum 141.

" tjoetjoek 142 .

Senteh woclong 88.

Sentoel 422.

Sereh 29.

Seroet 443.

" tjina 253.

Setjang 536.

" tjina 537,538 .

Sidagorie $388,389$.

Singoegoe 242.

Sirie 114.

Sirikaija 339. 
Siwalen 106.

Soedoe 432, 433.

Soekkoen 132.

Soelatrie 407.

Soemboeng 160, 161 .

Soentie 64.

Soeren 423.

Soesoerra 432, 433.

Sogo toentong 529.

Sokka $177-179$.

Songgom lalakki 497.

Sowangkoeng 102.

\section{T.}

'Taai aijam 169, 170.

" boerong 328 .

Takka laut 46 .

Tali andjieng 440.

" kandjoh 545 .

'Taliengkoep 442.

'Tallus 83.

Tambakkoan 255.

Tambako 264.

Tandjong 310.

Tanggoelie 540.

Tangkil oetan 111.

Tangkolloh 398.

Tangoelong ketjil 468.

Tapoes 444.

Taratteh 350, 351.

Taratteh ketjil 219.

Taroem 508.

$$
\text { " aroij } 2 \text { I7. }
$$

Tasbeh 78, 79.

Tatempëan 292, 302.

Tatter 275.
'Tatter goenoeng 17 !.

'Teboe 25.

Temoe koentjie 69.

Temoe tis 67 .

Terong korrie 261.

" tjina 277.

Thé 401.

" oetan 484 .

'Tiemboel 132.

Tikal baloeng 319, 434.

Tiroe boddas 86 .

'Tjabeh djawa 113.

" gedeh 270.

" prahoe 113.

" rawiet 274.

" tjina 271.

'Tjakra tjikri 417.

Tjaloemampang 89.

Tjamara 116.

Tjampakka 341-345.

'Tjangkoedoe 182, 183, 197.

'Tjangkring 524, 525.

Tjangkoeang 94 .

Tjaricang 87, 88.

'Tjantjang 156 .

Tjatjandie 509.

Tjekok 481.

Tjelegor 32.

Tjembaul 278.

Tjengkeh 493.

'Tjentjenettan 269 .

'Tjerlang' 401.

'Tjermeh 459 .

'Ijetjerennean 458 .

Tjeulio badak $369-371$.

'Tjikoer 68.

'Tjiploekan 269. 
Tjoelang 420.

Tjoewawoet 19.

Tjoklat 396.

'Toedjoe 347.

Toemboeng kanjoet 180.

Toeri 510, 511.

Toewa 532-534.

'Tom 508.

'Tommo 67.

'Tommon 296-298.

Totongoän 227.

'Trebeh djapan 301.

Trembaloe 542.

Tsjakkar bebek 329 .
Wareng 210.

Wargoe 107, 108.

Wariengien 122.

Varoe 385.

" landak 383.

" laut 385.

Wawoeloctan 460.

Wiedjien allas 286.

Wiroe 107, 108.

TVoedanie 481 .

Zs.

\section{W.}

Wadorie 213. 

I 


